Roles and regulation of the RETINOBLASTOMA-RELATED protein in Arabidopsis thaliana

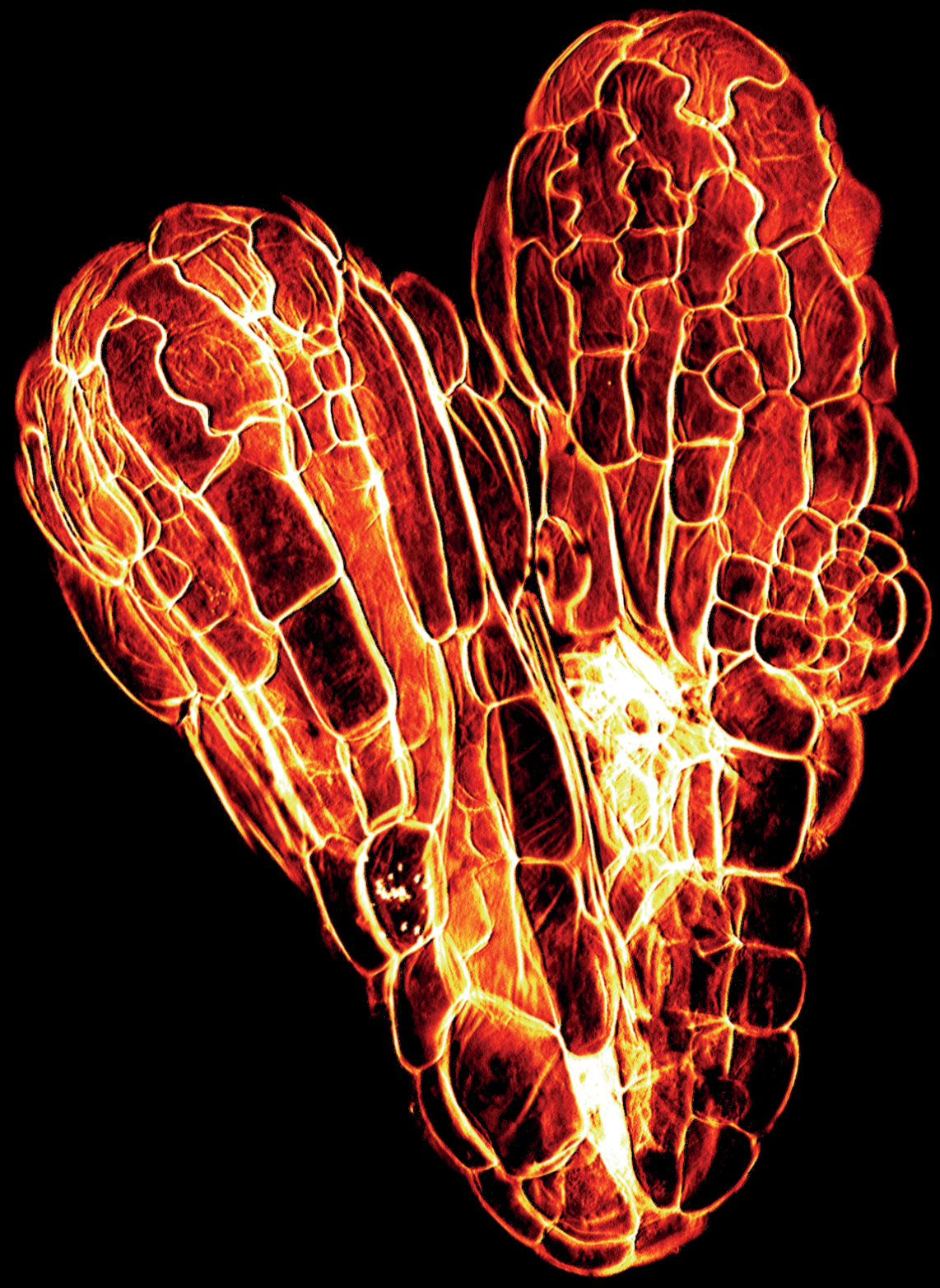

Jorge Zamora Zaragoza 


\section{Propositions}

1. The general assumption that the RETINOBLASTOMA-RELATED protein interactions are disrupted by phosphorylation is incorrect.

(this thesis)

2. Protein crystal structures render insufficient evidence to conclude about the posttranslational regulation of protein-protein interactions.

(this thesis)

3. Companies breeding for elevated sugar content in fruits take advantage of drug addiction in 'consumers' and contribute to an obesity pandemic .

4. The term 'Natural selection' implies the misconception that human activity is unnatural.

5. The prevalent misconception of Social Darwinism claiming 'The survival of the fittest' as Darwin's thesis reflects the apathy of biologists towards social sciences.

6. 'The Green Revolution' evidences the hazard of approaching food security from science and technology only.

7. Non-judgmental discrimination and privilege renunciation are pre-requisites to equality as a human right.

8. European monarchies and US Confederate symbols render an hypocritical attitude towards human equality.

Propositions belonging to the thesis, entitled

"Roles and regulation of the RETINOBLASTOMA-RELATED protein in Arabidopsis thaliana".

Jorge Zamora Zaragoza

Wageningen, 19 November 2021 

Roles and regulation of the RETINOBLASTOMA-RELATED protein in Arabidopsis thaliana

Jorge Zamora Zaragoza 


\section{Thesis committee}

\section{Promotor}

Prof. Dr. Ir Ben Scheres

Professor of Plant Developmental Biology

Wageningen University \& Research

\section{Co-Promotor}

Dr. Ir. Renze Heidstra

Associate professor of Plant Developmental Biology

Wageningen University \& Research

\section{Other members}

Prof. Dr. CS Testerink, Wageningen University \& Research

Prof. Dr. L de Veylder, VIB-UGent Center for Plant Systems Biology

Prof. Dr. D Weijers, Wageningen University \& Research

Dr S Diaz Trivino, Wageningen University \& Research

This research was conducted under the auspices of the Graduate School Experimental Plant Sciences 


\title{
Roles and regulation of the RETINOBLASTOMA-RELATED protein in Arabidopsis thaliana
}

\author{
Jorge Zamora Zaragoza
}

Thesis

submitted in fulfilment of the requirements for the degree of doctor

at Wageningen University

by the authority of the Rector Magnificus,

Prof. Dr A.P.J. Mol,

in the presence of the

Thesis Committee appointed by the Academic Board

to be defended in public

on Friday 19 November 2021

at 1:30 p.m. in the Aula. 
Jorge Zamora Zaragoza

Roles and regulation of the RETINOBLASTOMA-RELATED protein in Arabidopsis thaliana 162 pages.

PhD thesis, Wageningen University, Wageningen, the Netherlands (2021)

With references, with summary in English

ISBN: 978-94-6395-940-7

DOI: https://doi.org/10.18174/551711 
"We have come to this world to accept it, not merely to know it. We may become powerful by knowledge, but we attain fullness by sympathy. The highest education is that which does not merely give us information but makes our life in harmony with all existence". 



\section{Table of contents}

Chapter 1 General introduction.

Chapter 2 A phosphorylation code regulates the multi-functional protein

35

RETINOBLASTOMA- RELATED1 in Arabidopsis thaliana.

Chapter 3 Binding properties of RETINOBLASTOMA-RELATED protein interactors

69 reveal a central role in stress responsive pathways.

Chapter 4 The dual role of the RETINOBLASTOMA-RELATED protein in the DNA damage response is spatio-temporally coordinated by the interaction with LXCXE-containing proteins.

Chapter 5 General discussion.

Apendix Tuning Division and Differentiation in Stomata: How to Silence a MUTE. 147

Summary

Samenvatting

Acknowledgements

About the author

Education Statement 


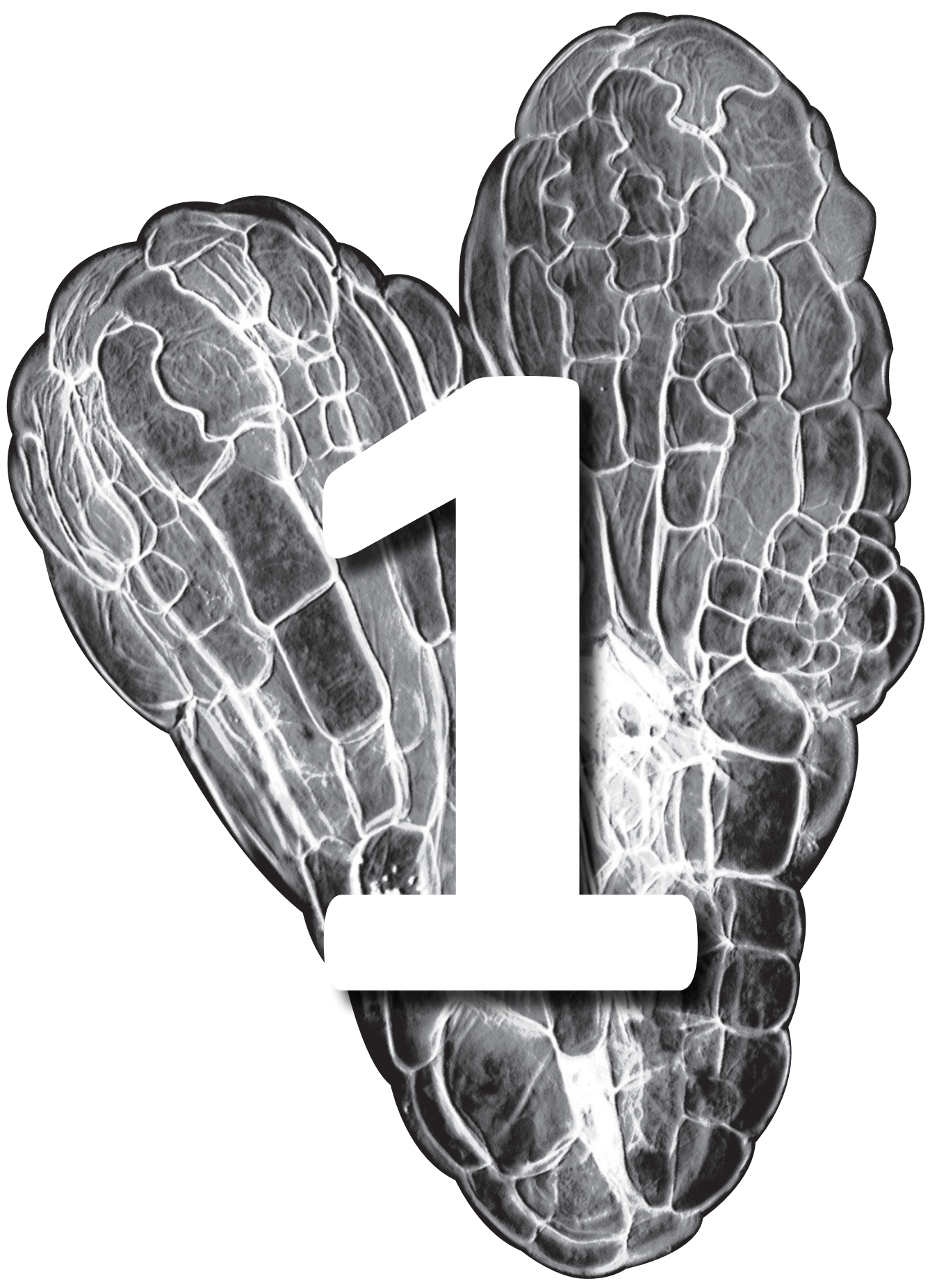




\section{Chapter 1}

General Introduction 
Chapter 1 


\section{General Introduction.}

Throughout evolution, biological organisms gained complexity. As the components of biological organisms establish networks of interactions (Alm and Arkin, 2003), this evolutionary process incorporated new and more complex regulatory modules in preexisting biomolecular networks. Although several types of molecular interactions account for distinct features of life, the increased complexity of multicellular organisms is strongly related to transcriptional regulatory networks (TRN)(Babu et al., 2004; Huang, 2006).

In TRNs, genes or proteins (represented as network nodes) are connected by regulatory interactions (represented by edges), mediating the integrated response of the cell to a particular context (Blais and Dynlacht, 2005). Highly connected nodes are called hubs and they tend to be essential for survival or reproduction of the organism (He and Zhang, 2006; Jeong et al., 2001; Smith et al., 2004). The effect of mutations in hubs are also pleiotropic because they percolate in larger segments of the network, having a higher probability to be involved in essential regulatory interactions (He and Zhang, 2006; Jeong et al., 2001). Local hub connections in the dynamic global TRN, coordinate discrete sub-networks or modules that control specific cellular processes (Babu et al., 2004).

For example, in the unicellular fungi Saccharomyces cerevisiae, environmental inputs trigger short regulatory cascades, whereas intricate processes such as the cell cycle progress through more complex and multiple stages (Luscombe et al., 2004). In a multicellular context, different proliferation rates, cell death and cell fate acquisition require extra layers of regulation to achieve stable patterns, which reflect the stability of the underlying TRNs and their connections (Huang, 2006; Salazar-Ciudad et al., 2003).

This thesis aims to shed light on the molecular mechanisms governing the plant RETINOBLASTOMA-RELATED1 (RBR) protein activity. RBR proteins, present in the vast majority of eukaryotes, are highly pleiotropic and null rbr mutants are lethal (Desvoyes et al., 2014; Hallmann, 2009). While RBR action can be viewed from the unicellular or the single cell perspective (Desvoyes et al., 2014), the protein has acquired context-dependent specific functions in multicellular contexts (Desvoyes and Gutierrez, 2020; Harashima and Sugimoto, 2016). The increasing list of interactions and their roles in both developmental processes and rapid environmental responses, position RBR proteins as hubs in TRN that coordinate cell cycle regulation, stress response and development in a context-dependent manner (Blais and Dynlacht, 2005).

pRB, the first tumor-suppressor gene: the biased attention that spread like cancer.

Statistical analysis of retinoblastoma (retinal cancer) cases led Alfred G. Knudson to the formulation of the two-hit hypothesis in 1971: two mutational events must occur for a 
person to develop eye cancer, either by two independent somatic mutations, or by the loss of heterozygosity in inherited forms (Knudson, 1971). Over a decade later, several studies mapped and highlighted the relevant bi-allelic gene dysfunction underlying Knudson's hypothesis, which is, besides few exceptions, the general rule for cancer types triggered by mutations in tumor suppressor genes (Cavenee et al., 1983; Dryja et al., 1984; Godbout et al., 1983; Murphree and Benedict, 1984).

Due to its clinical importance, research on the RETINOBLASTOMA susceptibility gene (RB) -and its encoded protein, pRb- blasted after 1986 when its cDNA was cloned (Friend et al., 1986), becoming a prototype for tumor suppressor genes and cancer research. Its prominent anti-tumorigenesis role pointed towards its function in cell cycle regulation. For decades, RB research has focused on elucidating the mechanisms controlling $\mathrm{G} 1$ to $\mathrm{S}$ phase transition, but overlooked other important functions (Classon and Harlow, 2002). When research extended beyond mammalian systems and the cancer viewpoint, it became clear that the RB-regulated G1/S phase transition was conserved in almost all eukaryotes, but at the same time, other particular functions attracted the attention of researchers (Cross et al., 2011; Gutzat et al., 2012).

50 years after Knudson's two-hit hypothesis, and 35 years after the molecular work on RB started, we know that RB-RELATED (RBR) proteins in most eukaryotes act as landing platforms where many chromatin modifiers and transcription factors (TF) meet to regulate genetic programs, cell processes and, ultimately, phenotypes at the organismal level (Dick and Rubin, 2013). Thus, RBR multiple functions are context-dependent because its activity reflects on specific protein-protein interactions (PPI) and how they are regulated.

\section{Function and regulation of RBR during cell cycle.}

Life relies on cell division, a cyclic unidirectional process to duplicate and partition the genetic information into two daughter cells. In eukaryotes, the sequential action of diverse protein complexes ensures 1 ) the proper internal and environmental context to fully replicate the genetic material, 2) the accurate and thorough replication of DNA, and 3 ) the equitable distribution of duplicated DNA packed in chromosomes. Surveillance molecular machineries, known as 'checkpoints', control irreversible phase transitions by phosphorylation-dependent signaling transduction and proteolysis (De Lichtenberg et al., 2007). Checkpoints are often driven by active Cyclin-Dependent Kinases (CDK).

CDK activity regulated by phosphorylation (both activating and inhibitory), and proteinprotein interactions (PPI). CDK-inhibitors (CKI) include p16/INK4 and the CIP/KIP family in animals, and the KIP-related protein (KRP) and SIAMESE (SIM)/SIM-RELATED (SMR) families in plants (Besson et al., 2008; Wang et al., 2020). Conversely, CYCLIN (CYC) proteins are obligate interacting activators of most CDKs. Although the CYC family is large, CYCA, B, D and 
E subfamilies comprise the main cell cycle regulators; all but CYCE are conserved in plants (La et al., 2006; Wang et al., 2004).

At the $\mathrm{G} 1$ to $\mathrm{S}$ phase transition, RBR binds to and represses the E2F-DP heterodimeric TF, which in turn activates the S-phase genetic program. This mechanism prevents the start of DNA replication until conditions are favorable to complete such an energy-demanding process. Sufficient nutrient availability and proliferating signals are integrated into the expression of CYCDs. Active CYCD-CDK complexes phosphorylate RBR in multiple serine and threonine residues, inducing structural changes to release E2F-DP, and allowing it to promote the transition to S-phase (Gutierrez et al., 2002).

This simplified mechanism exemplifies the mode of action of RBR proteins. Thus, RB activity is understood as the ability (and affinity) to interact with transcriptional regulators, being CDK-dependent phosphorylation the main regulation mechanism of RBR activity. How many and which interactions, when and where they happen, further determine the multiple functions and essentiality of RBR proteins (Dyson, 2016).

\section{The RB protein structure.}

RBR-family members are defined by the presence of the "pocket" protein domain, comprised by the A-pocket and B-pocket sub-domains, which resemble cyclin folds and are assembled into a single structural unit that engages in multiple PPI (Fig. 1A). For instance, the interface between $\mathrm{A}$ - and $\mathrm{B}$-pockets interacts with the transactivation domain of $\mathrm{E} 2 \mathrm{~F}$, while the B-pocket contains the 'LXCXE binding cleft' (Fig. 1B), a structural groove where the LXCXE motif (being $X$ any amino acid), conserved in many viral and cellular proteins, docks in (Burke et al., 2012; Gutzat et al., 2012). Few PPIs have been mapped to the N-domain and the $\mathrm{C}$-terminal region, both linked to the pocket domain by unstructured regions containing several phosphorylation sites (Desvoyes and Gutierrez, 2020; Dick and Rubin, 2013). Other phosphorylation sites are located to the linker between A- and B-pockets. Structural studies of $\mathrm{pRb}$ showed that specific phosphorylated sites promote intramolecular interactions between the pocket domain and the $\mathrm{N}$ - or $\mathrm{C}$ - regions, interfering with the binding to other proteins such as E2F (Burke et al., 2012, 2014).

Sequence similarity predicts a conserved structure for plant RBR proteins. Arabidopsis thaliana RBR protein is 1013 aminoacid residues long and contains 16 putative phosphorylation sites spread throughout its sequence (Fig. 1 A; Desvoyes and Gutierrez, 2020; Gutzat et al., 2012). 

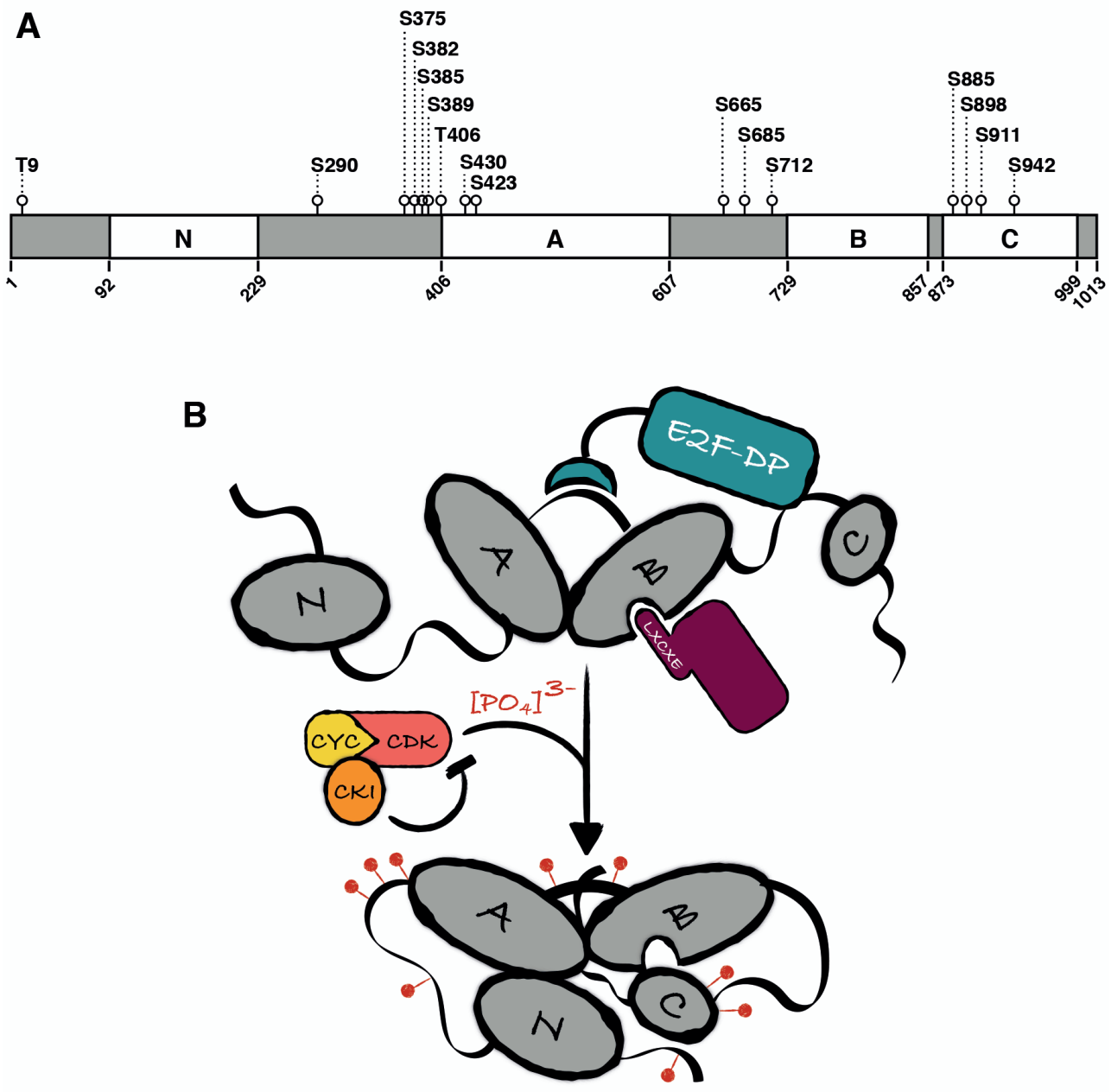

Figure 1: The structure and binding properties of RBR are regulated by phosphorylation.

A) Organization of the amino-terminal (N), A-pocket, B-pocket and C terminal domains (white boxes), inter-domain linker regions (gray boxes), and putative CDK-phosphorylation sites (lollipops) in the Arabidopsis RBR protein. The amino acid position of the phospho-sites and the domain limits are indicated. B) Depiction of the un-phosphorylated RBR protein(domains in gray) interacting with E2FDP transcription factors through the A-B pocket inter-domain region and the trans activating domain of E2F, and with an LXCXE motif-containing protein through the LXCXE-binding cleft in the B-pocket subdomain. CYCLIN-DEPENDENT KINASES (CDK) activated by CYCLIN (CYC) proteins and inhibited by CDK INHIBITORS (CKI) phosphorylate RBR to promote intra-molecular interactions that inhibit its ability to bind other proteins (Adapted from Rubin, 2013). 


\section{Box 1. Plant cell proliferation occurs in meristems.}

In plants, a cell maintains its relative position to neighboring cells throughout its life span, and cell divisions are spatially coordinated to maintain tissue integrity. Positional information plays a key role in balancing cell proliferation and differentiation throughout the plant life cycle because, unlike animals, organogenesis occurs post-embryonically at every developmental stage, either for a single season as in annual weeds, or over thousands of years in long-lived trees (Heyman et al., 2014).

Plant growth relies on the activity of small groups of stem cells located within proliferating structures called meristems, where all cells within an organ are born. To sustain meristematic activity, stem cells self-renew through an asymmetric cell division that generates a new stem cell and a sister cell that keeps dividing and transiting through the meristem (transit amplifying cell, TAC) until it reaches a position where differentiating signals are stronger than mitogenic ones (Bennett and Scheres, 2010). The best understood meristems at the molecular level are the shoot apical meristem (SAM), and the root meristem of the model plant Arabidopsis thaliana.

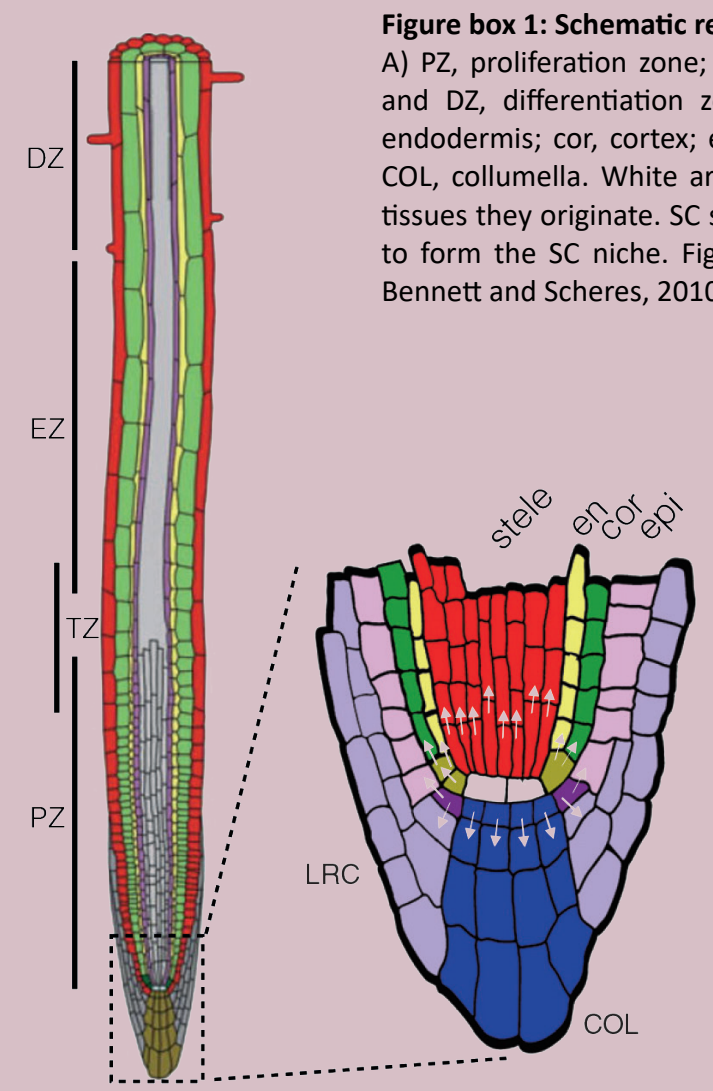

\section{Arabidopsis primary root meristem}

The Arabidopsis root is a cylindrical organ with different tissues concentrically arranged in a radial pattern. From the inside outwards, the vascular tissues phloem and xylem are surrounded by the pericycle (altogether known as the stele), the ground tissue comprised by an endodermis and a cortical cell layers, and finally the epidermis (Dolan et al, 1993). The root meristem, located at the tip, 
is protected by the root cap, which contains the lateral root cap (LRC) covering the epidermal layer, and the columella at the center and most distal part of the meristem (Bennett and Scheres, 2010). Between the columella and the TACs lies the stem cell niche (SCN), containing all stem cells organized around an organizing center named quiescent center (QC) due to its low mitotic activity, and that maintains the stemness of stem cells. From their position, we distinguish the vascular stem cells, columella stem cells (CSC); LRC and epidermis develop from a single stem cell as well as cortex and endodermis do in young roots (Dolan et al., 1993).

The root tip is divided in zones in the proximal-distal axis: above the columella there is the meristematic zone, where the TACs actively proliferate (proliferation zone), pushing the neighbor cells up to the transition zone. In the elongation zone, above the meristem, cells retain cell cycle activity but do not divide anymore, increasing their ploidy through this non-mitotic cell cycle named endocycle or endoreplication. The most proximal section, distinguishable by the presence of root hairs, is the differentiation zone, where cells fully acquire their functional fate (Bennett and Scheres, 2010).

\section{RBR in plants.}

10 years after cloning of human $R B$ was published, two independent studies reported the cDNA isolation of a maize RB-related protein encoding gene, ZmRBR1 (Grafi et al., 1996; Xie et al., 1996). Follow-up research led to the description of the E2F-DP/RBR/CYCD-CDK conserved pathway in G1/S transition (Berckmans and De Veylder, 2009; Boniotti and Gutierrez, 2001). Nevertheless, the notable expansion of the plant CYCD family indicates that their functions could have diversified in the plant lineage (Buendía-Monreal et al., 2011; Wang et al., 2004). Accordingly, accumulated evidence over more than two decades in higher plants revealed a plethora of processes where CYCDs, CDKs, CKIs, E2Fs and RBR are involved.

\section{RBR in root meristem development}

As expected from its role in cell cycle control, RBR downregulation leads to an increased number of cells in the meristem, and the opposite effect is observed upon RBR overexpression. Nevertheless, the effect of RBR on meristem size also relates to its ability to induce cell differentiation in the transition zone (Perilli et al., 2013), similar to the differentiation-promoting activity of $\mathrm{pRb}$ in animals (Lipinski and Jacks, 1999). RBRdependent differentiation is mediated by the cytokinin pathway and the AUXIN RESPONSE FACTOR 19 (Perilli et al., 2013). Interestingly, cytokinin and auxin signaling pathways control the differentiation vs proliferation rate to maintain meristem growth in balance (Benková and Hejátko, 2009).

Meristem maintenance also depends on stem cell activity, and RBR modulates the balance 
between stem cell division and differentiation (Wildwater et al., 2005). RBR likely regulates all stem cell types and the QC, but two cases are best described. In the columella lineage, RBR restricts the rate of division in the CSC, while in the CSC daughter cells, it promotes differentiation (Bennett et al., 2014; Wachsman et al., 2011; Wildwater et al., 2005). In the ground tissue, RBR restricts supernumerary ACD of the cortex and endodermis inititial daughter cell (CEID) to generate only a single layer of each cell type (Cruz-Ramírez et al., 2012; Weimer et al., 2012). ACD of the CEID is promoted by an auxin gradient and the SCARECROWSHORTROOT (SCR-SHR) heterodimeric TF. An LXCXE motif in SCR mediates RBR repression, which is released upon CYCD6;1-promoted phosphorylation of RBR pocket domain. CYCD6;1 in turn is activated by SCR-SHR, forming a feedforward loop that resets after mitotic division through proteolysis of the network components (Cruz-Ramírez et al., 2012).

The LXCXE-mediated RBR-SCR interaction also regulates $Q C$ division. While the $Q C$ replenishes damaged SC by dividing asymmetrically (Heyman et al., 2014), quiescence is maintained by RBR-SCR-SHR and has a protective function that helps the meristem to cope with DNA damage (Cruz-Ramírez et al., 2013). CYCD1;1 and CYCD3;3 are the only CYCDs known to be expressed in the $Q C$, triggering $Q C$ division during early development (Bennett et al., 2014), but whether they exert the same function in response to DNA damage awaits demonstration.

The protective functions of RBR extends beyond the QC cells. Both in plants and animals, depletion of RBR results in genomic instability and spontaneous cell death (Biedermann et al., 2017; Cruz-Ramírez et al., 2013; Horvath et al., 2017; Johnson et al., 2017; Vélez-Cruz and Johnson, 2017; Wachsman et al., 2011; Wildwater et al., 2005). On the other hand, root tips with reduced levels of RBR have a higher regenerative potential than wild-type roots upon tissue damage (Zhou et al., 2019), but are hypersensitive to genotoxic stress (Biedermann et al., 2017; Horvath et al., 2017), indicating that RBR stress-related functions are different according to the nature of the stimuli and the downstream activation of stressresponsive programs.

\section{RBR in reproductive and early development}

Reproductive development of angiosperms starts when the germline generates haploid cells via meiosis. Subsequently, the male and female reproductive structures develop into mature pollen (male gametophyte or microgametophyte) and the embryo sac (female gametophyte or megagametphyte), respectively (Berger and Twell, 2011). The female gametophyte remains arrested until double fertilization, after which it resumes cell division and differentiation to produce seeds containing the embryo and a nourishing tissue called endosperm, covered by a protective seed coat (Guo and Zheng, 2013). Every stage of this sequential processes depend on the finely-coordinated balance of cell division and differentiation, and as such, RBR has prominent roles (Dante et al., 2014): 
- Inactivation of RBR leads to supernumerary embryo sacs due to ectopic mitotic division in the germline; RBR-controlled mitosis-to-meiosis transition relies on direct repression of the stem cell maintenance gene WUSCHEL (Zhao et al., 2017b).

- A truncated RBR protein lacking the B-pocket and C-terminal regions fails to form double strand break-dependent foci during meiosis, leading to reduced recruitment of meiotic proteins to foci, reduced chiasmata and synapsis formation, and fertility defects (Chen et al., 2011), underlining roles in chromatin structure of RBR.

- The low transmission rates of the rbr-1 null allele revealed both male and female gametophytic defects. In emasculated flowers, $r b r-1$ megagametophytes fail to arrest division, developing aberrant seed-like structures with supernumerary cells and nuclei in the position where embryo and endosperm would respectively form. In fertilized pistils, rbr-1 megagametophytes develop aberrant embryos and aborted seeds (Ebel et al., 2004).

\section{RBR in other vegetative processes.}

Seedling establishment: A mature seed germinates upon hydration to resume growth and development. The initial phase relies on the stored nutrients, but eventually the seedling switches to an autotrophic program to sustain growth on environmental energy sources. RBR activity blocks the embryonic program, promoting a switch to autotrophic growth (Gutzat et al., 2011), but arrests cell division if the external energy source is depleted (Hirano et al., 2008), pointing to an integrator role of the energy status into the seedling growth.

Stomata development: Stomata are epidermal valves formed by pairs of specialized cells referred to as guard cells that regulate water and gas exchange. Sequential activity of three bHLH TFs in the stomata lineage, namely SPHEECHLESS, MUTE and FAMA, concatenates complex TRNs that promote subsequent ACDs and differentiation steps culminating in the single symmetric division of the guard cell, and irreversible differentiation (Pillitteri and Dong, 2013; Simmons and Bergmann, 2016). MUTE-dependent and independent expression of CYCDs promote the last division, likely by phosphorylating RBR which, besides blocking ectopic divisions, impedes guard cell fate reversion (Borghi et al., 2010; Han et al., 2018; Matos et al., 2014; Weimer et al., 2018). For a detailed overview of this process, see appendix 1 .

Growth and defense: Exhaustive phenotyping of a strong inducible RBR-down-regulation line throughout vegetative development revealed that RBR is needed for SAM stem cell maintenance, vascular development, stem elongation, and lateral organ development, including leaves, branches and flowers. Interestingly, transcriptome analysis of the same line revealed that changes in stress-responsive programs upon RBR interference were even quicker than those in cell cycle and E2F-target genes (Borghi et al., 2010). As the G1/S checkpoint surveys adequate environmental conditions for cell proliferation, (Gendreau et 
al., 2012; Gutierrez et al., 2002) RBR seems to promote a transcriptional switch between cell cycle and stress-related pathways. Accordingly, RBR and E2FA regulate defense genes and promote programmed cell death (PCD) to stop infection upon biotrophic attack (Wang et al., 2014).

\section{RBR in DNA damage}

DNA damage is a serious threat to any organism, as it compromises survival and genetic information transmission. It can occur through internal processes (DNA metabolism, or metabolic production of reactive oxigen species, ROS), or by exposure to damaging agents (like heavy metals or ionizing radiation)(Choudhury et al., 2017; Kim et al., 2019). In eukaryotes, DNA damage triggers a conserved signaling cascade to arrest cell cycle and activate the DNA repair mechanisms, or promote PCD to avoid propagating mutations, altogether known as DNA damage response (DDR) (Ciccia and Elledge, 2010; Nisa et al., 2019).

Recognition of DNA breaks activates the ATAXIA TELANGIECTASIA MUTATED (ATM) and ATAXIA TELANGIECTASIA AND RAD3-RELATED (ATR) kinases. ATM/ATR initiate a phosphorylation cascade that marks the damaged site with the phosphorylated histone variant $\mathrm{y}-\mathrm{H} 2 \mathrm{AX}$ and recruits other proteins including repair proteins and other kinases to amplify the DDR (Ciccia and Elledge, 2010). Within minutes, "repair foci" become visible to the microscope when such proteins are tagged with a fluorophore due to their dynamic accumulation at the lesion sites (Firsanov et al., 2011; Kuo and Yang, 2008; Lowndes and Toh, 2005; Nakamura et al., 2010). In this way, it was determined that $p R b$ and RBR localize to repair foci (Biedermann et al., 2017; Horvath et al., 2017; Vélez-Cruz et al., 2016), pointing to their functions beyond transcriptional regulation, although transcriptional repression of repair genes is also mediated by RBR (Biedermann et al., 2017; Bouyer et al., 2018).

The main DNA repair mechanisms are non-homologous end joining (NHEJ) and homologous recombination. The former is mutation-prone because no DNA template is available to ensure the correct sequence, whereas the later relies on the availability of a homologous sequence, usually provided by the sister chromatid. In animals, pRb is involved in both repair pathways (Cook et al., 2015; Vélez-Cruz et al., 2016). Although the association with a particular repair mechanism has not been explored in detail for plant RBR, it co-localizes and interacts with BRCA1, and mediates foci recruitment of RAD51, canonical recombinases of the HR pathway (Biedermann et al., 2017; Horvath et al., 2017; Thompson and Schild, 2001). RBR foci also overlap with E2FA and FBL17 foci (Gentric et al., 2020; Horvath et al., 2017), the latter is a F-box protein that regulates cell proliferation and endoreplication by promoting CKIs degradation (Noir et al., 2015). These findings open new questions about the intricate dynamic processes at the chromatin triggered by the constant DNA damage in proliferating cells. 
Besides pRb, the TF p53 is arguably the most important in maintaining genome integrity in animals (Lane, 1992; Williams and Schumacher, 2016). Similarly to pRb, p53 functions extend beyond transcriptional regulation, as it binds to HR proteins RAD51 and RAD54 to modulate their activity on nuclear foci (Linke et al., 2003). p53 has no homologs in plants, but the SUPRESSOR OF GAMMA RADIATION1 (SOG1), a plant specific TF member of the NAC family, is regarded as a p53 functional homolog, although not all p53 functions have been associated with SOG1 (Bourbousse et al., 2018; Mahapatra and Roy, 2020; Ogita et al., 2018; Yoshiyama et al., 2009).

Upon DNA damage, ATM/ATR phosphorylate the C-termini of SOG1 to activate it (Yoshiyama et al., 2013). Phosphorylated SOG1 promotes DNA repair, cell cycle arrest and PCD transcriptional programs binding directly to the promoters of effector genes, or other transcription factors that amplify the response (Bourbousse et al., 2018; Ogita et al., 2018; Ryu et al., 2019; Takahashi et al., 2019; Yoshiyama et al., 2009, 2017). Interestingly, RBR and FBL17 roles during DDR are independent of SOG1 (Gentric et al., 2020; Horvath et al., 2017).

\section{RBR in the DREAM complex.}

RBR proteins mediate cell decisions by interacting not only with TFs, but also with chromatin modifiers, sometimes simultaneously, with the DREAM complex as the most prominent case (Fischer and Müller, 2017; Johnston et al., 2008; Kuwabara and Gruissem, 2014; Matos et al., 2014). Named after its constituents 모, $\underline{R} B$-like proteins $\mathrm{p} 107$ and p130, E2F, and Multivulva-B complex (Muv-B, formed by Lin54, Lin52, Lin37, Lin9 and Rbbp4 proteins), the DREAM complex is cell cycle regulator best described in animals.

Exit from $\mathrm{G} 1$ to a quiescent state known as $\mathrm{G0}$, can be promoted by both intrinsic programs or stress signaling, and depends on DREAM-imposed transcriptional repression of cell cycle genes (Fischer and Müller, 2017). Here, E2F and Lin54 bind to gene promoters in a sequencespecific manner, and Rbbp4 recruits histone deacetylases and chromatin modifiers to repress transcription (Litovchick et al., 2007; Mages et al., 2017; Schmit et al., 2009). Replacement of the E2F-DP/p107/p130 proteins by B-Myb proteins converts the repressor activity of the DREAM complex to an activator MMB (B-Myb-MuvB) complex; DREAM and MMB complexes regulate $\mathrm{S} / \mathrm{G} 2 / \mathrm{M}$ genes, while G1/S genes depend on DREAM and E2F-DP-pRb (Fischer and Müller, 2017; Sadasivam and DeCaprio, 2013).

A slightly divergent DREAM complex was recently reported in Arabidopsis, with RBR as the only pocket protein, E2FB and E2FC as activator and repressor activities on G1/S promoters, and MYB3R proteins regulating G2/M promoters in a sequence-specific manner (Ito et al., 1998, 2001; Kobayashi et al., 2015). Members of the MuvB complex were also found and the list of possible constituents was recently expanded, offering new insights into diversification of alternative assemblies (Ning et al., 2020). 
Similar to RBR, the Arabidopsis DREAM complex members play distinct roles beyond cell cycle repression. For example, they coordinate DNA methylation and chromatin structure in quiescent and dividing cells, contributing to transposable elements silencing (Ning et al., 2020). The Lin54 homologs TSO1 and SOL1/SOL2, play opposite roles in coupling and stabilizing cell division and cell fate transitions during stomata development (Simmons et al., 2019), whereas TSO1 and MYB3R1 form a regulatory module to coordinate meristematic proliferation and differentiation which, if disrupted, leads to severe developmental defects in flower formation and plant sterility (Wang et al., 2018). Moreover, repressor MYB3Rs are downstream effectors of the DDR (Bourbousse et al., 2018; Chen et al., 2017). As RBR participates in all these functions, it is possible that the hub properties of RBR are linked to the dynamic nature of the DREAM complex. Besides the RBR-E2F interaction, the molecular determinants of the DREAM complex assembly are largely unexplored. In Chapter 3, we provide new insights in this matter.

\section{Functional links to RBR phosphorylation.}

RBR activity is regulated by phosphorylation, and the main kinases for RBR are CDKA and CDKBs in complex with CYCAs, CYCBs, or CYCDs (Inzé and De Veylder, 2006; Willems et al., 2020). As such, CDKs, CYCs and CKIs coordinate cell division and differentiation alongside RBR (Gutierrez, 2005; Sablowski and Carnier Dornelas, 2014). While CDKs are broadly expressed, CYCs and CKIs are highly regulated, conveying context-dependence to RBRphosphorylation (Cao et al., 2018; Collins et al., 2012; Godínez-Palma et al., 2017; Jun et al., 2013; Peres et al., 2007; Vanneste et al., 2011; Wen et al., 2013; Yi et al., 2014). For example, almost all CYCDs are expressed throughout maize seed germination, but their associated kinase activity exhibit dynamic patterns that cannot be inferred from their mRNA or protein accumulation (Godínez-palma et al., 2013; Gutiérrez et al., 2005; Lara-Núñez et al., 2008; Vázquez-Ramos and Lara-Nuñez, 2008).

While only 3 CydDs exist in humans, plant genomes encode seven CYCD sub-groups, each containing one or more members (Buendía-Monreal et al., 2011; Wang et al., 2004). Their expression patterns and studied functions indicate that they participate in seed development and germination (Collins et al., 2012; Godínez-palma et al., 2013; Masubelele et al., 2005; Vázquez-Ramos and Lara-Nuñez, 2008) lateral root formation (Nieuwland et al., 2009; Sanz et al., 2011), stem cell division in embryos and roots (Cruz-Ramírez et al., 2012; Forzani et al., 2014), vascular growth (Collins et al., 2015; Zhao et al., 2017a), and stomatal development (Han et al., 2018; Weimer et al., 2018). Similarly, CYCAs expression is developmentally controlled, and they regulate plant growth at several stages besides acting during S/G2/M phases, endocycle and meiosis (Boudolf et al., 2009; Bulankova et al., 2013; Magnard et al., 2001; Vanneste et al., 2011; Wang and Yang, 2014). CYCBs regulate G2/M (Ito et al., 1998, 2001) and, together with CDKBs, promote RBR nuclear foci accumulation alongside other roles during DDR (Biedermann et al., 2017; Weimer et al., 2016). 
Another indication that RBR functions are influenced by phosphorylation is the wide range of RBR-mediated processes affected by CKIs (Gutierrez, 2005). By controlling cell division rates, endocyle entry, and cell size, CKIs contribute to vegetative growth and development under- and above ground (Jun et al., 2013; Sanz et al., 2011; Serrano-Mislata et al., 2017; Sizani et al., 2019; Wen et al., 2013). Reproductive success and gametophyte development are affected by changes in KRP expression associated with de-regulation of the RBR networks (Jun et al., 2013; Sizani et al., 2019; Zhao et al., 2012, 2017b). Furthermore, CKIs regulate biotic stress responses, organ regeneration, and a SOG1-dependent G2/M checkpoint in DDR (Bourbousse et al., 2018; Cheng et al., 2015; Coelho et al., 2017; Ogita et al., 2018; Wang et al., 2014; Yi et al., 2014).

Arabidopsis encodes 5 A/B-type CDKs, 31 A-,B-, and D-type CYCs, and 20 CKIs differentially expressed genes but only one RBR gene (Menges et al., 2005; Vandepoele et al., 2002; Wang et al., 2004; Yi et al., 2014). The huge combinatorial potential of specific kinase complexes is overwhelming to study. Although RBR is not the only protein phosphorylated by CDKA/B, the overlapping functions and the putative 16 CDK-substrates within its structure, suggest that RBR integrates part of the CDK-dependent signaling. The increasing list of RBR-interacting transcriptional regulators, and the suppression of $c d k a$ mutants by $r b r$ supports this idea (Nowack et al., 2012).

In conclusion, the initially proposed simple mechanism of progressive CDK-CYCDs-mediated phosphorylation of Rb proteins to release E2F TFs and activate S-phase genes has shifted to a complex picture, where RBR proteins remain central but phosphorylation is no longer an on/off switch, but a fine-tuning mechanism to modulate RBR-context dependent activity. A pRb 'phosphorylation code' has been hypothesized in mammals (Munro et al., 2012; Rubin, 2013), and contradictory evidence for differential pRb phosphotylation states suggests that deciphering it will not be an easy task (Gubern et al., 2016; Sanidas et al., 2019). The need to understand differential phosphorylation and protein-interaction activity of RBR within the physiological context is also emerging in plant research (Desvoyes and Gutierrez, 2020; Harashima and Sugimoto, 2016).

\section{Outline of the thesis.}

In Chapter 2, we describe a systematic experimental approach to tackle the question of the functional relevance of RBR phosphorylation. The current knowledge of RBR functions derive mostly from knock-out alleles, or transcriptional up- and down regulation of the gene. To overcome gamethophytic lethality of knock-out alleles, we combined a down-regulation system that allows complementation analysis of transgenic RBR, with phosphorylation variants harboring either loss- and gain of function point mutations of RBR phospho-sites. The results indicate that RBR sub-functions can be partially disentangled by combinatorial phosphorylation, and provide new insights on specific RBR-phosphorylation roles in the 
Arabidopsis primary root meristem. Interestingly, phosphorylation-mediated functions of RBR depend for a significant part on the integrity of the LXCXE motif-binding cleft.

In Chapter 3, we set out to discover new RBR protein interactors. We used ten different versions of RBR, including eight highly substituted phosphorylation variants, and an RBR allele that disrupts LXCXE-mediated interactions, as baits in the $\mathrm{Y} 2 \mathrm{H}$ screening of the Arabidopsis TFs library (Pruneda-Paz et al., 2014). Previously known and unknown nuclear proteins showed differential binding properties to the baits. Our results indicate that not all RBR interactions are regulated by phosphorylation. Interestingly, those interactions that were not affected by the phosphorylation state of RBR, are somehow related to general stress responses, as it is the case of NAC044; thus, we speculate that, upon stressful conditions, RBR must be able to interact with such proteins regardless the cell cycle phase. Moreover, our results offer an insight into the plant DREAM complex assembly through the LXCXE motif-mediated binding with a MuvB component.

In Chapter 4, we show that the structural and transcriptional roles of RBR during DDR depend on the same molecular determinant: the B-pocket subdomain interaction with proteins containing the LXCXE motif. The biochemical constraint of having to bind different proteins through the same docking site, imposes a spatio-temporal series of events to coordinate DNA damage repair with NAC044-mediated cell cycle arrest, and subsequent resumption of cell division.

In Chapter 5 I discuss our experimental findings in the context of the available literature, and provide a bigger picture of the molecular mechanisms underlying RBR functions looking through the lens of evolution. On the basis of an ancient phosphorylation-regulated RBRcentric network that successfully couples cell size control, cell cycle, and DDR, I elaborate on the central position RBR as an integrator hub for developmental and environmental signals into cell decisions.

Appendix. Although the experimental work in this thesis does not contemplate stomata development investigation, I include an appendix with our preview highlighting and reflecting published insights on the RBR position within the TRN that regulates the final guard cell division (Zamora-Zaragoza and Scheres, 2018). 


\section{References}

Alm, E., and Arkin, A.P. (2003). Biological networks. Curr. Opin. Struct. Biol. 13, 193-202.

Babu, M.M., Luscombe, N.M., Aravind, L., Gerstein, M., and Teichmann, S.A. (2004). Structure and evolution of transcriptional regulatory networks. Curr. Opin. Struct. Biol. 14, 283-291.

Benková, E., and Hejátko, J. (2009). Hormone interactions at the root apical meristem. Plant Mol. Biol. 69, 383-396.

Bennett, T., and Scheres, B. (2010). Root development-two meristems for the price of one? In Current Topics in Developmental Biology, pp. 67-102.

Bennett, T., van den Toorn, A., Willemsen, V., and Scheres, B. (2014). Precise control of plant stem cell activity through parallel regulatory inputs. Dev. 141, 4055-4064.

Berckmans, B., and De Veylder, L. (2009). Transcriptional control of the cell cycle. Curr. Opin. Plant Biol. 12, 599-605.

Berger, F., and Twell, D. (2011). Germline Specification and Function in Plants. Annu. Rev. Plant Biol. $62,461-484$.

Besson, A., Dowdy, S.F., and Roberts, J.M. (2008). CDK Inhibitors: Cell Cycle Regulators and Beyond. Dev. Cell 14, 159-169.

Biedermann, S., Harashima, H., Chen, P., Heese, M., Bouyer, D., Sofroni, K., and Schnittger, A. (2017). The retinoblastoma homolog RBR1 mediates localization of the repair protein RAD51 to DNA lesions in Arabidopsis. EMBO J. 36, 1279-1297.

Blais, A., and Dynlacht, B.D. (2005). Constructing transcriptional regulatory networks. Genes Dev. 19, 1499-1511.

Boniotti, M.B., and Gutierrez, C. (2001). A cell-cycle-regulated kinase activity phosphorylates plant retinoblastoma protein and contains, in Arabidopsis, a CDKA/cyclin D complex. Plant J. 28, 341350.

Borghi, L., Gutzat, R., Fütterer, J., Laizet, Y., Hennig, L., and Gruissem, W. (2010). Arabidopsis RETINOBLASTOMA-RELATED Is Required for Stem Cell Maintenance, Cell Differentiation, and Lateral Organ Production. Plant Cell 22, 1792-1811.

Boudolf, V., Lammens, T., Boruc, J., van Leene, J., van den Daele, H., Maes, S., van Isterdael, G., Russinova, E., Kondorosi, E., Witters, E., et al. (2009). CDKB1;1 forms a functional complex with CYCA2;3 to suppress endocycle onset. Plant Physiol. 150, 1482-1493.

Bourbousse, C., Vegesna, N., and Law, J.A. (2018). SOG1 activator and MYB3R repressors regulate a complex DNA damage network in Arabidopsis. Proc. Natl. Acad. Sci. U. S. A. 115, E12453E12462.

Bouyer, D., Heese, M., Chen, P., Harashima, H., Roudier, F., Gruttner, C., and Schnittger, A. (2018). Genome-wide identification of RETINOBLASTOMA RELATED 1 binding sites in Arabidopsis reveals novel DNA damage regulators. PLoS Genet. 14, 1-35.

Buendía-Monreal, M., Rentería-Canett, I., Guerrero-Andrade, O., Bravo-Alberto, C.E., MartínezCastilla, L.P., García, E., and Vázquez-Ramos, J.M. (2011). The family of maize D-type cyclins: Genomic organization, phylogeny and expression patterns. Physiol. Plant. 143, 297-308. 
Bulankova, P., Akimcheva, S., Fellner, N., and Riha, K. (2013). Identification of Arabidopsis Meiotic Cyclins Reveals Functional Diversification among Plant Cyclin Genes. PLoS Genet. 9, e1003508.

Burke, J.R., Hura, G.L., and Rubin, S.M. (2012). Structures of inactive retinoblastoma protein reveal multiple mechanisms for cell cycle control. Genes Dev. 26, 1156-1166.

Burke, J.R., Liban, T.J., Restrepo, T., Lee, H.W., and Rubin, S.M. (2014). Multiple mechanisms for E2F binding inhibition by phosphorylation of the retinoblastoma protein C-terminal domain. J. Mol. Biol. 426, 245-255.

Cao, L., Wang, S., Venglat, P., Zhao, L., Cheng, Y., Ye, S., Qin, Y., Datla, R., Zhou, Y., and Wang, H. (2018). Arabidopsis ICK/KRP cyclin-dependent kinase inhibitors function to ensure the formation of one megaspore mother cell and one functional megaspore per ovule. PLoS Genet. 14, 1-30.

Cavenee, W.K., Dryja, T.P., Phillips, R.A., Benedict, W.F., Godbout, R., Gallie, B.L., Murphree, A.L., Strong, L.C., and White, R.L. (1983). Expression of recessive alleles by chromosomal mechanisms in retinoblastoma. Nature 305, 779-784.

Chen, P., Takatsuka, H., Takahashi, N., Kurata, R., Fukao, Y., Kobayashi, K., Ito, M., and Umeda, M. (2017). Arabidopsis R1R2R3-Myb proteins are essential for inhibiting cell division in response to DNA damage. Nat. Commun. 8, 1-12.

Chen, Z., Higgins, J.D., Hui, J.T.L., Li, J., Franklin, F.C.H., and Berger, F. (2011). Retinoblastoma protein is essential for early meiotic events in Arabidopsis. EMBO J. 30, 744-755.

Cheng, Y., Liu, H., Cao, L., Wang, S., Li, Y., Zhang, Y., Jiang, W., Zhou, Y., and Wang, H. (2015). Downregulation of multiple CDK inhibitor ICK/KRP genes promotes cell proliferation, callus induction and plant regeneration in arabidopsis. Front. Plant Sci. 6, 1-12.

Choudhury, F.K., Rivero, R.M., Blumwald, E., and Mittler, R. (2017). Reactive oxygen species, abiotic stress and stress combination. Plant J. 90, 856-867.

Ciccia, A., and Elledge, S.J. (2010). The DNA Damage Response: Making It Safe to Play with Knives. Mol. Cell 40, 179-204.

Classon, M., and Harlow, E. (2002). The retinoblastoma tumour suppressor in development and cancer. Nat. Rev. Cancer 2, 910-917.

Coelho, R.R., Vieira, P., Antonino de Souza Júnior, J.D., Martin-Jimenez, C., De Veylder, L., Cazareth, J., Engler, G., Grossi-de-Sa, M.F., and de Almeida Engler, J. (2017). Exploiting cell cycle inhibitor genes of the KRP family to control root-knot nematode induced feeding sites in plants. Plant Cell Environ. 40, 1174-1188.

Collins, C., Dewitte, W., and Murray, J.A.H. (2012). D-type cyclins control cell division and developmental rate during Arabidopsis seed development. J. Exp. Bot. 63, 3571-3586.

Collins, C., Maruthi, M.N., and Jahn, C.E. (2015). CYCD3 D-type cyclins regulate cambial cell proliferation and secondary growth in Arabidopsis. J. Exp. Bot. 66, 4595-4606.

Cook, R., Zoumpoulidou, G., Luczynski, M.T., Rieger, S., Moquet, J., Spanswick, V.J., Hartley, J.A., Rothkamm, K., Huang, P.H., and Mittnacht, S. (2015). Direct involvement of retinoblastoma family proteins in DNA repair by non-homologous end-joining. Cell Rep. 10, 2007-2019.

Cross, F.R., Buchler, N.E., and Skotheim, J.M. (2011). Evolution of networks and sequences in eukaryotic cell cycle control. Philos. Trans. R. Soc. B Biol. Sci. 366, 3532-3544. 
Cruz-Ramírez, A., Díaz-Triviño, S., Blilou, I., Grieneisen, V.A., Sozzani, R., Zamioudis, C., Miskolczi, P., Nieuwland, J., Benjamins, R., Dhonukshe, P., et al. (2012). A Bistable Circuit Involving SCARECROW- RETINOBLASTOMA Integrates Cues to Inform Asymmetric Stem Cell Division. Cell 150, 1002-1015.

Cruz-Ramírez, A., Diaz-trivino, S., Wachsman, G., Du, Y., Arteaga-Vazquez, M., Zhang, H., Benjamins, R., Blilou, I., Neef, A.B., Chandler, V., et al. (2013). A SCARECROW-RETINOBLASTOMA Protein Network Controls Protective Quiescence in the Arabidopsis Root Stem Cell Organizer. PLoS Biol. 11, e1001724.

Dante, R.A., Larkins, B.A., and Sabelli, P.A. (2014). Cell cycle control and seed development. Front. Plant Sci. 5, 1-14.

Desvoyes, B., and Gutierrez, C. (2020). Roles of plant retinoblastoma protein: cell cycle and beyond. EMBO J. 39, 1-18.

Desvoyes, B., De Mendoza, A., Ruiz-Trillo, I., and Gutierrez, C. (2014). Novel roles of plant RETINOBLASTOMA-RELATED (RBR) protein in cell proliferation and asymmetric cell division. J. Exp. Bot. 65, 2657-2666.

Dick, F.A., and Rubin, S.M. (2013). Molecular mechanisms underlying RB protein function. Nat. Rev. Mol. Cell Biol. 14, 297-306.

Dolan, L., Janmaat, K., Willemsen, V., Linstead, P., Poethig, S., Roberts, K., and Scheres, B. (1993). Cellular organisation of the Arabidopsis thaliana root. Development 119, 71-84.

Dryja, T.P., Cavenee, W., White, R., Rapaport, J.M., Petersen, R., Albert, D.M., and Bruns, G.A.P. (1984). Homozygosity of chromosome 13 in retinoblastoma. N. Engl. J. Med. 310, 550-553.

Dyson, N.J. (2016). RB1: A prototype tumor suppressor and an enigma. Genes Dev. 30, 1492-1502.

Ebel, C., Mariconti, L., and Gruissem, W. (2004). Plant retinoblastoma homologues control nuclear proliferation in the female gametophyte. Nature 429, 776-780.

Firsanov, D. V, Solovjeva, L. V, and Svetlova, M.P. (2011). H2AX phosphorylation at the sites of DNA double-strand breaks in cultivated mammalian cells and tissues. Clin. Epigenetics 2, 283-297.

Fischer, M., and Müller, G.A. (2017). Cell cycle transcription control: DREAM/MuvB and RB-E2F complexes. Crit. Rev. Biochem. Mol. Biol. 52, 638-662.

Forzani, C., Aichinger, E., Sornay, E., Willemsen, V., Laux, T., Dewitte, W., and Murray, J.A.H. (2014). WOX5 suppresses CYCLIN D activity to establish quiescence at the Center of the root stem cell niche. Curr. Biol. 24, 1939-1944.

Friend, S.H., Bernards, R., Rogelij, S., Weinberg, R.A., Rapaport, J.M., Albert, D.M., and Dryja, T.P. (1986). A human DNA segment with properties of the gene that predisposes to retinoblastoma and osteosarcoma. Nature 323, 643-646.

Gendreau, E., Cayla, T., and Corbineau, F. (2012). S phase of the cell cycle: a key phase for the regulation of thermodormancy in barely grain. J. Exp. Bot. 63, 5535-5543.

Gentric, N., Masoud, K., Journot, R.P., Cognat, V., Chabouté, M.E., Noir, S., and Genschik, P. (2020). The f-box-like protein FBL17 is a regulator of DNA-damage response and colocalizes with RETINOBLASTOMA RELATED1 at DNA lesion sites. Plant Physiol. 183, 1295-1305.

Godbout, R., Dryja, T.P., Squire, J., Gallie, B.L., and Phillips, R.A. (1983). Somatic inactivation of genes 
on chromosome 13 is a common event in retinoblastoma. Nature 304, 451-453.

Godínez-palma, S.K., García, E., Sánchez, M. de la P., Rosas, F., and Vázquez-Ramos, J.M. (2013). Complexes of D-type cyclins with CDKs during maize germination. J. Exp. Bot. 64, 5661-5671.

Godínez-Palma, S.K.S.K., Rosas-Bringas, F.R., Rosas-Bringas, O.G.O.G., García-Ramírez, E., ZamoraZaragoza, J., and Vázquez-Ramos, J.M.J.M. (2017). Two maize Kip-related proteins differentially interact with, inhibit and are phosphorylated by cyclin D-cyclin-dependent kinase complexes. J. Exp. Bot. 68, 1585-1597.

Grafi, G., Burnett, R.J., Helentjaris, T.I.M., Larkins, B.A., DeCaprio, J.A., Sellers, W.R., and Kaelin Jr, W.G. (1996). A maize cDNA encoding a member of the retinoblastoma protein family: Involvement in endoreduplication. Proc. Natl. Acad. Sci. 93, 8962-8967.

Gubern, A., Joaquin, M., Marquès, M., Maseres, P., Garcia-Garcia, J., Amat, R., González-Nuñez, D., Oliva, B., Real, F.X., de Nadal, E., et al. (2016). The N-Terminal Phosphorylation of RB by p38 Bypasses Its Inactivation by CDKs and Prevents Proliferation in Cancer Cells. Mol. Cell 64, 25-36.

Guo, A., and Zheng, C.X. (2013). Female gametophyte development. J. Plant Biol. 56, 345-356.

Gutierrez, C. (2005). Coupling cell proliferation and development in plants. Nat. Cell Biol. 7, 535-541.

Gutierrez, C., Ramirez-Parra, E., Castellano, M.M., and Pozo, J.C. del (2002). G1 to S transition: more than a cell cycle engine switch. Curr. Opin. Plant Biol. 5, 480-486.

Gutiérrez, R., Quiroz-figueroa, F., and Vázquez-ramos, J.M. (2005). Maize Cyclin D2 Expression, Associated Kinase Activity and Effect of Phytohormones During Germination. Plant Cell Physiol. 46, 166-173.

Gutzat, R., Borghi, L., Futterer, J., Bischof, S., Laizet, Y., Hennig, L., Feil, R., Lunn, J., and Gruissem, W. (2011). RETINOBLASTOMA-RELATED PROTEIN controls the transition to autotrophic plant development. Development 138, 2977-2986.

Gutzat, R., Borghi, L., and Gruissem, W. (2012). Emerging roles of RETINOBLASTOMA-RELATED proteins in evolution and plant development. Trends Plant Sci. 17, 139-148.

Hallmann, A. (2009). Retinoblastoma-related proteins in lower eukaryotes. Commun. Integr. Biol. 2, 538-544.

Han, S., Qi, X., Sugihara, K., Dang, J.H., Endo, T.A., Miller, K.L., Kim, E., Miura, T., and Torii, K.U. (2018). MUTE Directly orchestrates Cell State switch and the Single Symmetric Division to create stomata. Dev. Cell 45, 303-315.

Harashima, H., and Sugimoto, K. (2016). Integration of developmental and environmental signals into cell proliferation and differentiation through RETINOBLASTOMA-RELATED 1. Curr. Opin. Plant Biol. 29, 95-103.

He, X., and Zhang, J. (2006). Why do hubs tend to be essential in protein networks? PLoS Genet. 2, 0826-0834.

Heyman, J., Kumpf, R.P., and De Veylder, L. (2014). A quiescent path to plant longevity. Trends Cell Biol. 24, 443-448.

Hirano, H., Harashima, H., Shinmyo, A., and Sekine, M. (2008). Arabidopsis Retinoblastoma-Related Protein 1 is involved in $\mathrm{G} 1$ phase cell cycle arrest caused by sucrose starvation. Plant Mol. Biol. $66,259-275$. 
Horvath, B.M., Kourova, H., Nagy, S., Nemeth, E., Magyar, Z., Papdi, C., Ahmad, Z., Sanchez-perez, G.F., Perilli, S., Blilou, I., et al. (2017). Arabidopsis RETINOBLASTOMA RELATED directly regulates DNA damage responses through functions beyond cell cycle control. EMBO J. 36, 1261-1278.

Huang, S. (2006). Multistability and multicellularity: Cell fates as high-dimensional attractors of gene regulatory networks. In Computational Systems Biology, A. Kriete, and R. Eils, eds. (Academic Press.), pp. 293-326.

Inzé, D., and De Veylder, L. (2006). Cell Cycle Regulation in Plant Development. Annu. Rev. Genet. 40, 77-105.

Ito, M., Iwase, M., Kodama, H., Lavisse, P., Komamine, A., Nishihama, R., Machida, Y., and Watanabe, A. (1998). A Novel cis-Acting Element in Promoters of Plant B-Type Cyclin Genes Activates M Phase-Specific Transcription. Plant Cell 10, 331-341.

Ito, M., Araki, S., Matsunaga, S., Itoh, T., Nishihama, R., Machida, Y., Doonan, J.H., and Watanabe, A. (2001). G2/M-phase-specific transcription during the plant cell cycle is mediated by c-Myb-like transcription factors. Plant Cell 13, 1891-1905.

Jeong, H., Mason, S.P., Barabási, A.L., and Oltvai, Z.N. (2001). Lethality and centrality in protein networks. Nature 411, 41-42.

Johnson, B.A., Aloor, H.L., and Moody, C.A. (2017). The Rb binding domain of HPV31 E7 is required to maintain high levels of DNA repair factors in infected cells. Virology 500, 22-34.

Johnston, A.J., Matveeva, E., Kirioukhova, O., Grossniklaus, U., and Gruissem, W. (2008). A Dynamic Reciprocal RBR-PRC2 Regulatory Circuit Controls Arabidopsis Gametophyte Development. Curr. Biol. 18, 1680-1686.

Jun, S.E., Okushima, Y., Nam, J., Umeda, M., and Kim, G.T. (2013). Kip-related protein 3 is required for control of endoreduplication in the shoot apical meristem and leaves of Arabidopsis. Mol. Cells $35,47-53$.

Kim, J.H., Ryu, T.H., Lee, S.S., Lee, S., and Chung, B.Y. (2019). lonizing radiation manifesting DNA damage response in plants: An overview of DNA damage signaling and repair mechanisms in plants. Plant Sci. 278, 44-53.

Knudson, A.G. (1971). Mutation and cancer: statistical study of retinoblastoma. Proc. Natl. Acad. Sci. U. S. A. $68,820-823$.

Kobayashi, K., Suzuki, T., Iwata, E., Nakamichi, N., Suzuki, T., Chen, P., Ohtani, M., Ishida, T., Hosoya, H., Müller, S., et al. (2015). Transcriptional repression by MYB 3R proteins regulates plant organ growth. EMBO J. 34, 1992-2007.

Kuo, L.J., and Yang, L.-X. (2008). p-H2AX - A Novel Biomarker for DNA Double-strand Breaks. In Vivo (Brooklyn). 22, 305-309.

Kuwabara, A., and Gruissem, W. (2014). Arabidopsis Retinoblastoma-related and Polycomb group proteins: Cooperation during plant cell differentiation and development. J. Exp. Bot. 65, 26672676.

La, H., Li, J., Ji, Z., Cheng, Y., Li, X., Jiang, S., Venkatesh, P.N., and Ramachandran, S. (2006). Genomewide analysis of cyclin family in rice (Oryza sativa L.). Mol. Genet. Genomics 275, 374-386.

Lane, D.P. (1992). p53, guardian of the genome. Nature 358, 15-16. 
Lara-Núñez, A., De Jesús, N., and Vázquez-Ramos, J.M. (2008). Maize D4;1 and D5 cyclin proteins in germinating maize. Associated kinase activity and regulation by phytohormones. Physiol. Plant. $132,79-88$.

De Lichtenberg, U., Jensen, T.S., Brunak, S., Bork, P., and Jensen, L.J. (2007). Evolution of cell cycle control: Same molecular machines, different regulation. Cell Cycle 6, 1819-1825.

Linke, S.P., Sengupta, S., Khabie, N., Jeffries, B.A., Buchhop, S., Miska, S., Henning, W., Pedeux, R., Wang, X.W., Hofseth, L.J., et al. (2003). p53 interacts with hRAD51 and hRAD54, and directly modulates homologous recombination. Cancer Res. 63, 2596-2605.

Lipinski, M.M., and Jacks, T. (1999). The retinoblastoma gene family in differentiation and development. Oncogene 18, 7873-7882.

Litovchick, L., Sadasivam, S., Florens, L., Zhu, X., Swanson, S.K., Velmurugan, S., Chen, R., Washburn, M.P., Liu, X.S., and DeCaprio, J.A. (2007). Evolutionarily Conserved Multisubunit RBL2/p130 and E2F4 Protein Complex Represses Human Cell Cycle-Dependent Genes in Quiescence. Mol. Cell 26, 539-551.

Lowndes, N.F., and Toh, G.W. (2005). DNA Repair: The Importance of Phosphorylating Histone H2AX. Curr. Biol. 15, R99-R102.

Luscombe, N.M., Babu, M.M., and Yu, H. (2004). Genomic analysis of regulatory network dynamics reveals large topological changes. Nature 431, 308-312.

Mages, C.F.S., Wintsche, A., Bernhart, S.H., and Müller, G.A. (2017). The DREAM complex through its subunit Lin37 cooperates with $\mathrm{Rb}$ to initiate quiescence. Elife 6, 1-23.

Magnard, J.L., Yang, M., Chen, Y.C.S., Leary, M., and McCormick, S. (2001). The Arabidopsis gene tardy asynchronous meiosis is required for the normal pace and synchrony of cell division during male meiosis. Plant Physiol. 127, 1157-1166.

Mahapatra, K., and Roy, S. (2020). An insight into the mechanism of DNA damage response in plantsrole of SUPPRESSOR OF GAMMA RESPONSE 1: An overview. Mutat. Res. - Fundam. Mol. Mech. Mutagen. 819-820, 111689.

Masubelele, N.H., Dewitte, W., Menges, M., Maughan, S., Collins, C., Huntley, R., Nieuwland, J., Scofield, S., and Murray, J.A.H. (2005). D-type cyclins activate division in the root apex to promote seed germination in Arabidopsis. Proc. Natl. Acad. Sci. U. S. A. 102, 15694-15699.

Matos, J.L., Lau, O.S., Hachez, C., Cruz-Ramírez, A., Scheres, B., and Bergmann, D.C. (2014). Irreversible fate commitment in the Arabidopsis stomatal lineage requires a FAMA and RETINOBLASTOMARELATED module. Elife 3, 1-15.

Menges, M., De Jager, S.M., Gruissem, W., and Murray, J.A.H. (2005). Global analysis of the core cell cycle regulators of Arabidopsis identifies novel genes, reveals multiple and highly specific profiles of expression and provides a coherent model for plant cell cycle control. Plant J. 41, 546-566.

Munro, S., Carr, S.M., and La Thangue, N.B. (2012). Diversity within the pRb pathway: Is there a code of conduct. Oncogene 31, 4343-4352.

Murphree, A.L., and Benedict, W.F. (1984). Retinoblastoma: Clues to human oncogenesis. Science (80-. ). 223, 1028-1033.

Nakamura, A.J., Rao, V.A., Pommier, Y., and Bonner, W.M. (2010). The complexity of phosphorylated 
H2AX foci formation and DNA repair assembly at DNA double-strand breaks. Cell Cycle 9, 389397.

Nieuwland, J., Maughan, S., Dewitte, W., Scofield, S., Sanz, L., and Murray, J.A.H. (2009). The D-type cyclin CYCD4;1 modulates lateral root density in Arabidopsis by affecting the basal meristem region. Proc. Natl. Acad. Sci. U. S. A. 106, 22528-22533.

Ning, Y., Liu, N., Lan, K., Su, Y., Li, L., Chen, S., and He, X. (2020). DREAM complex suppresses DNA methylation maintenance genes and precludes DNA hypermethylation. Nat. Plants 6, 942-956.

Nisa, M.U., Huang, Y., Benhamed, M., and Raynaud, C. (2019). The plant DNA damage response: Signaling pathways leading to growth inhibition and putative role in response to stress conditions. Front. Plant Sci. 10, 1-12.

Noir, S., Marrocco, K., Masoud, K., Thomann, A., Gusti, A., Bitrian, M., Schnittger, A., and Genschik, P. (2015). The control of arabidopsis thaliana growth by cell proliferation and endoreplication requires the F-box protein FBL17. Plant Cell 27, 1461-1476.

Nowack, M.K., Harashima, H., Dissmeyer, N., Zhao, X., Bouyer, D., Weimer, A.K., De Winter, F., Yang, F., and Schnittger, A. (2012). Genetic Framework of Cyclin-Dependent Kinase Function in Arabidopsis. Dev. Cell 22, 1030-1040.

Ogita, N., Okushima, Y., Tokizawa, M., Yamamoto, Y.Y., Tanaka, M., Seki, M., Makita, Y., Matsui, M., Okamoto-Yoshiyama, K., Sakamoto, T., et al. (2018). Identifying the target genes of SUPPRESSOR OF GAMMA RESPONSE 1, a master transcription factor controlling DNA damage response in Arabidopsis. Plant J. 94, 439-453.

Peres, A., Churchman, M.L., Hariharan, S., Himanen, K., Verkest, A., Vandepoele, K., Magyar, Z., Hatzfeld, Y., Van Der Schueren, E., Beemster, G.T.S., et al. (2007). Novel plant-specific cyclin-dependent kinase inhibitors induced by biotic and abiotic stresses. J. Biol. Chem. 282, 25588-25596.

Perilli, S., Perez-Perez, J.M., Di Mambro, R., Peris, C.L., Díaz-Triviño, S., Del Bianco, M., Pierdonati, E., Moubayidin, L., Cruz-Ramírez, A., Costantino, P., et al. (2013). RETINOBLASTOMA-RELATED protein stimulates cell differentiation in the Arabidopsis root meristem by interacting with cytokinin signaling. Plant Cell 25, 4469-4478.

Pillitteri, L.J., and Dong, J. (2013). Stomatal Development in Arabidopsis. In The Arabidopsis Book, p. e0162.

Pruneda-Paz, J.L.L., Breton, G., Nagel, D.H.H., Kang, S.E.E., Bonaldi, K., Doherty, C.J.J., Ravelo, S., Galli, M., Ecker, J.R.R., and Kay, S.A.A. (2014). A Genome-Scale Resource for the Functional Characterization of Arabidopsis Transcription Factors. Cell Rep. 8, 622-632.

Rubin, S.M. (2013). Deciphering the retinoblastoma protein phosphorylation code. Trends Biochem. Sci. 38, 12-19.

Ryu, T.H., Go, Y.S., Choi, S.H., Kim, J. Il, Chung, B.Y., and Kim, J.H. (2019). SOG1-dependent NAC103 modulates the DNA damage response as a transcriptional regulator in Arabidopsis. Plant J. 98, 83-96.

Sablowski, R., and Carnier Dornelas, M. (2014). Interplay between cell growth and cell cycle in plants. J. Exp. Bot. 65, 2703-2714.

Sadasivam, S., and DeCaprio, J.A. (2013). The DREAM complex: Master coordinator of cell cycle- 
dependent gene expression. Nat. Rev. Cancer 13, 585-595.

Salazar-Ciudad, I., Jernvall, J., and Newman, S.A. (2003). Mechanisms of pattern formation in development and evolution. Development 130, 2027-2037.

Sanidas, I., Morris, R., Fella, K.A., Rumde, P.H., Boukhali, M., Tai, E.C., Ting, D.T., Lawrence, M.S., Haas, W., and Dyson, N.J. (2019). A Code of Mono-phosphorylation Modulates the Function of RB. Mol. Cell 73, 985-1000.e6.

Sanz, L., Dewitte, W., Forzani, C., Patell, F., Nieuwland, J., Wen, B., Quelhas, P., de Jager, S., Titmus, C., Campilho, A., et al. (2011). The Arabidopsis D-Type Cyclin CYCD2;1 and the Inhibitor ICK2/KRP2 Modulate Auxin-Induced Lateral Root Formation. Plant Cell 23, 641-660.

Schmit, F., Cremer, S., and Gaubatz, S. (2009). LIN54 is an essential core subunit of the DREAM/LINC complex that binds to the cdc2 promoter in a sequence-specific manner. FEBS J. 276, 5703-5716.

Serrano-Mislata, A., Bencivenga, S., Bush, M., Schiessl, K., Boden, S., and Sablowski, R. (2017). DELLA genes restrict inflorescence meristem function independently of plant height. Nat. Plants 3 , 749-754.

Simmons, A.R., and Bergmann, D.C. (2016). Transcriptional control of cell fate in the stomatal lineage. Curr. Opin. Plant Biol. 29, 1-8.

Simmons, A.R., Davies, K.A., Wang, W., Liu, Z., and Bergmann, D.C. (2019). SOL1 and SOL2 regulate fate transition and cell divisions in the arabidopsis stomatal lineage. Dev. 146, dev171066.

Sizani, B.L., Kalve, S., Markakis, M.N., Domagalska, M.A., Stelmaszewska, J., AbdElgawad, H., Zhao, X., De Veylder, L., De Vos, D., Broeckhove, J., et al. (2019). Multiple mechanisms explain how reduced KRP expression increases leaf size of Arabidopsis thaliana. New Phytol. 221, 1345-1358.

Smith, H.C., Bottaro, A., Sowden, M.P., and Wedekind, J.E. (2004). Activation induced deaminase: The importance of being specific. Trends Genet. 20, 224-227.

Takahashi, N., Ogita, N., Takahashi, T., Taniguchi, S., Tanaka, M., Seki, M., and Umeda, M. (2019). A regulatory module controlling stress-induced cell cycle arrest in arabidopsis. Elife 8, 1-27.

Thompson, L.H., and Schild, D. (2001). Homologous recombinational repair of DNA ensures mammalian chromosome stability. Mutat. Res. - Fundam. Mol. Mech. Mutagen. 477, 131-153.

Vandepoele, K., Raes, J., De Veylder, L., Rouzé, P., Rombauts, S., and Inzé, D. (2002). Genome-wide analysis of core cell cycle genes in Arabidopsis. Plant Cell 14, 903-916.

Vanneste, S., Coppens, F., Lee, E., Donner, T.J., Xie, Z., Van Isterdael, G., Dhondt, S., De Winter, F., De Rybel, B., Vuylsteke, M., et al. (2011). Developmental regulation of CYCA2s contributes to tissuespecific proliferation in Arabidopsis. EMBO J. 30, 3430-3441.

Vázquez-Ramos, J.M., and Lara-Nuñez, A. (2008). Cyclins D, phytoregulators and cell cycle onset in germinating maize. Plant Signal. Behav. 3, 578-579.

Vélez-Cruz, R., and Johnson, D.G. (2017). The retinoblastoma (RB) tumor suppressor: Pushing back against genome instability on multiple fronts. Int. J. Mol. Sci. 18.

Vélez-Cruz, R., Manickavinayaham, S., Biswas, A.K., Clary, R.W., Premkumar, T., Cole, F., and Johnson, D.G. (2016). RB localizes to DNA double-strand breaks and promotes DNA end resection and homologous recombination through the recruitment of BRG1. Genes Dev. 30, 2500-2512. 
Wachsman, G., Heidstra, R., and Scheres, B. (2011). Distinct cell-autonomous functions of RETINOBLASTOMA-RELATED in Arabidopsis stem cells revealed by the brother of Brainbow Clonal analysis system. Plant Cell 23, 2581-2591.

Wang, Y., and Yang, M. (2014). Loss-of-function mutants and overexpression lines of the arabidopsis cyclin CYCA1;2/TARDY asynchronous meiosis exhibit different defects in prophase-I meiocytes but produce the same meiotic products. PLoS One 9, 1-8.

Wang, G., Kong, H., Sun, Y., Zhang, X., Zhang, W., Altman, N., DePamphilis, C.W., and Ma, H. (2004). Genome-wide analysis of the cyclin family in arabidopsis and comparative phylogenetic analysis of plant cyclin-like proteins. Plant Physiol. 135, 1084-1099.

Wang, K., Ndathe, R.W., Kumar, N., Zeringue, E.A., Kato, N., and Larkin, J.C. (2020). The CDK Inhibitor SIAMESE Targets Both CDKA;1 and CDKB1 Complexes to Establish Endoreplication in Trichomes. Plant Physiol. 184, 165-175.

Wang, S., Gu, Y., Zebell, S.G., Anderson, L.K., Wang, W., Mohan, R., and Dong, X. (2014). A noncanonical role for the CKI-RB-E2F cell-cycle signaling pathway in plant effector-triggered immunity. Cell Host Microbe 16, 787-794.

Wang, W., Sijacic, P., XU, P., Lian, H., and Liu, Z. (2018). Arabidopsis TSO1 and MYB3R1 form a regulatory module to coordinate cell proliferation with differentiation in shoot and root. Proc. Natl. Acad. Sci. U. S. A. 115, E3045-E3054.

Weimer, A.K., Nowack, M.K., Bouyer, D., Zhao, X., Harashima, H., Naseer, S., De Winter, F., Dissmeyer, N., Geldner, N., and Schnittger, A. (2012). RETINOBLASTOMA RELATED1 regulates asymmetric cell divisions in Arabidopsis. Plant Cell 24, 4083-4095.

Weimer, A.K., Biedermann, S., Harashima, H., Roodbarkelari, F., Takahashi, N., Foreman, J., Guan, Y., Pochon, G., Heese, M., Van Damme, D., et al. (2016). The plant-specific CDKB 1- CYCB 1 complex mediates homologous recombination repair in Arabidopsis. EMBO J. 35, 2068-2086.

Weimer, A.K., Matos, J.L., Sharma, N., Patell, F., Murray, J.A.H., Dewitte, W., and Bergmann, D.C. (2018). Lineage- and stage-specific expressed CYCD7;1 coordinates the single symmetric division that creates stomatal guard cells. Development 145, dev160671.

Wen, B., Nieuwland, J., and Murray, J.A.H. (2013). The Arabidopsis CDK inhibitor ICK3/KRP5 is rate limiting for primary root growth and promotes growth through cell elongation and endoreduplication. J. Exp. Bot. 64, 1135-1144.

Wildwater, M., Campilho, A., Perez-Perez, J.M., Heidstra, R., Blilou, I., Korthout, H., Chatterjee, J., Mariconti, L., Gruissem, W., and Scheres, B. (2005). The RETINOBLASTOMA-RELATED gene regulates stem cell maintenance in Arabidopsis roots. Cell 123, 1337-1349.

Willems, A., Heyman, J., Eekhout, T., Achon, I., Pedroza-Garcia, J.A., Zhu, T., Li, L., Vercauteren, I., Van den Daele, H., van de Cotte, B., et al. (2020). The cyclin CYCA3;4 is a postprophase target of the APC/CCCS52A2 E3-ligase controlling formative cell divisions in arabidopsis. Plant Cell 32, 2979-2996.

Williams, A.B., and Schumacher, B. (2016). p53 in the DNA-damage-repair process. Cold Spring Harb. Perspect. Med. 6, 1-16.

Xie, Q., Sanz-Burgos, A.P., Hannon, G.J., and Gutiérrez, C. (1996). Plant cells contain a novel member of 
the retinoblastoma family of growth regulatory proteins. EMBO J. 15, 4900-4908.

Yi, D., Kamei, C.L.A., Cools, T., Vanderauwera, S., Takahashi, N., Okushima, Y., Eekhout, T., Yoshiyama, K.O., Larkin, J., Van den Daele, H., et al. (2014). The Arabidopsis SIAMESE-RELATED cyclindependent Kinase Inhibitors SMR5 and SMR7 Regulate the DNA damage checkpoint in response to reactive oxygen species. Plant Cell 26, 296-309.

Yoshiyama, K., Conklin, P.A., Huefner, N.D., and Britt, A.B. (2009). Suppressor of gamma response 1 (SOG1) encodes a putative transcription factor governing multiple responses to DNA damage. Proc. Natl. Acad. Sci. U. S. A. 106, 12843-12848.

Yoshiyama, K.O., Kobayashi, J., Ogita, N., Ueda, M., Kimura, S., Maki, H., and Umeda, M. (2013). ATMmediated phosphorylation of SOG1 is essential for the DNA damage response in Arabidopsis. EMBO Rep. 14, 817-822.

Yoshiyama, K.O., Kaminoyama, K., Sakamoto, T., and Kimura, S. (2017). Increased phosphorylation of ser-gIn sites on SUPPRESSOR OF GAMMA RESPONSE1 strengthens the DNA damage response in Arabidopsis thaliana. Plant Cell 29, 3255-3268.

Zamora-Zaragoza, J., and Scheres, B. (2018). Tuning Division and Differentiation in Stomata: How to Silence a MUTE. Dev. Cell 45, 282-283.

Zhao, C., Lasses, T., Bako, L., Kong, D., Zhao, B., Chanda, B., Bombarely, A., Cruz-Ramírez, A., Scheres, B., Brunner, A.M., et al. (2017a). XYLEM NAC DOMAIN1, an angiosperm NAC transcription factor, inhibits xylem differentiation through conserved motifs that interact with RETINOBLASTOMARELATED. New Phytol. 216, 76-89.

Zhao, X., Harashima, H., Dissmeyer, N., Pusch, S., Weimer, A.K., Bramsiepe, J., Bouyer, D., Rademacher, S., Nowack, M.K., Novak, B., et al. (2012). A General G1/S-Phase Cell-Cycle Control Module in the Flowering Plant Arabidopsis thaliana. PLoS Genet. 8, e1002847.

Zhao, X., Bramsiepe, J., Van Durme, M., Komaki, S., Prusicki, M.A., Maruyama, D., Forner, J., Medzihradszky, A., Wijnker, E., Harashima, H., et al. (2017b). RETINOBLASTOMA RELATED1 mediates germline entry in Arabidopsis. Science (80-. ). 356.

Zhou, W., Lozano-Torres, J.L., Blilou, I., Zhang, X., Zhai, Q., Smant, G., Li, C., and Scheres, B. (2019). A Jasmonate Signaling Network Activates Root Stem Cells and Promotes Regeneration. Cell 177, 942-956.e14. 


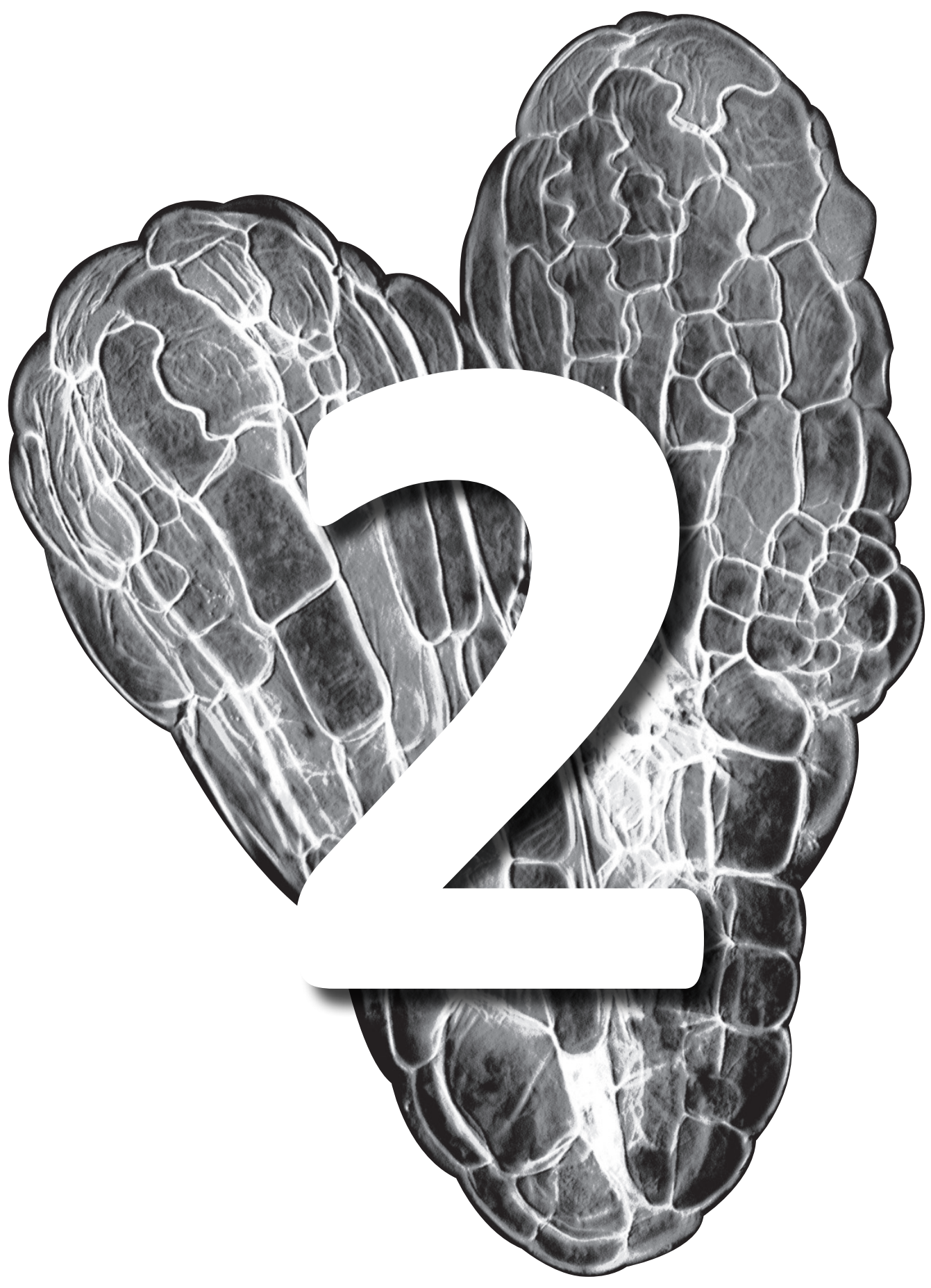




\section{Chapter 2}

\section{A phosphorylation code regulates the multi- functional protein RETINOBLASTOMA-RELATED1 in Arabidopsis thaliana}

Jorge Zamora-Zaragoza, Jaheli Sánchez-Pérez, Jean-Philippe Vielle-Calzada, Ben Scheres 


\begin{abstract}
The RETINOBLASTOMA-RELATED (RBR) protein plays a central role in higher eukaryotes, coordinating cell division and differentiation within an environmental and developmental context. The many RBR functions are context-dependent and reflect its ability to engage in multiple protein interactions. Despite their role in regulation of RBR, the functional implications of RBR phosphorylation patterns remain largely unexplored. We here tested whether phosphorylation is a fine-tuning mechanism that allows diversification of RBR functions and uncoupling of pleiotropy observed in rbr mutants. Using a collection of transgenic loss- and gain of function point mutations in RBR phospho-sites, we analysed their complementation capacity for stem cell maintenance, cell proliferation, and cell death in Arabidopsis thaliana root meristems and reproductive organs. While the number of mutated residues often correlated to the phenotypic strength of RBR phospho-variants, phospho-sites in different regions of the protein contributed unevenly to distinct RBR-linked phenotypes. Moreover, the effect of phopspho-sites was influenced by the phosphorylation state of other sites. Thus, additivity and specificity of phospho-sites on RBR activity define a combinatorial mechanism to control RBR functions. Moreover, a phospho-mimetic and a phospho-defective variant, both promoting cell death, pointed to distinct ways in which RBR controls similar cell fate choices. Finally, we show that a mutation disrupting RBR interactions with LXCXE-containing proteins partially suppresses dominant phosphodefective RBR phenotypes. Altogether, we show that RBR functions are defined and separable by a combinatorial phosphorylation code.
\end{abstract}




\section{Introduction}

Multicellular organisms coordinate cell division and differentiation in space and time to ensure proper development (Gutierrez, 2005; Sablowski and Carnier Dornelas, 2014). When the environment is variable, external cues need to be incorporated in this coordination process. Orchestration of developmental programs and environmental responses becomes particularly challenging in sessile species like plants. The multifunctional protein RETINOBLASTOMA-RELATED1 (RBR) of Arabidopsis, homolog of the human Retinoblastoma (RB) susceptibility gene product ( $\mathrm{pRb}$ ), acts as an integrator of environmental cues and internal programs into cell fate decisions (Gutierrez, 2005; Harashima and Sugimoto, 2016).

RBR belongs to the pocket-protein family, which function as protein interaction platforms that bring together multiple transcriptional and chromatin regulators, thus controlling genetic programs (Dick and Rubin, 2013; Gutzat et al., 2012). For example, RBR controls cell division by interacting with and inhibiting the E2F-DP heterodimeric transcription factors from activating the S-phase program. Stable repression of cell cycle genes leads to a quiescent state achieved by the DREAM complex (named after its constituents $\underline{D}$ P-E2F- $\underline{R} B R$ and the Multivuvla $B$ complex, MuvB), which regulates chromatin structure and DNA methylation (Kobayashi et al., 2015; Ning et al., 2020). RBR-mediated repression is alleviated by active CYCLIN-DEPENDENT KINASES (CDK): CDKA associates with D-type CYCLINS (CYCD), which contain a LXCXE motif to bind and phosphorylate RBR, thereby releasing E2F repression. RBR also controls formative divisions through similar mechanisms (Cruz-Ramírez et al., 2012; Han et al., 2018; Matos et al., 2014; Weimer et al., 2018) to couple cell division and fate decisions.

Promoted by CDKB-CYCB1 activity, RBR plays both a structural and transcriptional role in DNA repair (Biedermann et al., 2017; Horvath et al., 2017). The involvement of RBR, and distinct CYC-CDKs and CDK inhibitors (CKI) in both developmental and stress-related processes (Biedermann et al., 2017; Gutierrez, 2005; Horvath et al., 2017; Perilli et al., 2013; Sablowski and Carnier Dornelas, 2014; Wang et al., 2014a; Weimer et al., 2016; Wen et al., 2013; Yi et al., 2014; Zhao et al., 2017), some of which occur simultaneously, points to a central, as yet unspecified role for RBR phosphorylation in the integration of signaling inputs to orchestrate coordinated cell behavior.

Both human $\mathrm{pRb}$ and Arabidopsis RBR contain 16 putative CDK phosphorylation sites, most of them located in the inter-domain regions. Crystal structures of $\mathrm{pRb}$ fragments demonstrate that specific phosphorylated residues induce discrete structural changes that promote different intramolecular interactions to either prevent or compete with intermolecular interactions (Burke et al., 2010, 2012). Biochemical characterization of the effect of specific phosphorylation residues on the interaction with E2Fs and with the LXCXE motif indicates that the phospho-sites contribute differentially to regulate RBR-protein interactions (Burke 
et al., 2010, 2014; Rubin et al., 2005). These observations led researchers to speculate of a 'phosphorylation-code' where distinct phosphorylation events generate unique structural changes that influence pRb binding properties and functions (Munro et al., 2012; Rubin, 2013). Although attractive, the phosphorylation code hypothesis requires experimental evidence, particularly in plants.

Here, we took a systematic approach to study the biological relevance of RBR phosphorylation. Using a large collection of transgenic loss- and gain of function point mutations in RBR phospho-sites, we set out to disentangle RBR roles by specific phosphorylation combinations, and to address whether a phosphorylation code fine-tunes RBR activity. We found that, whereas phosphorylation within the N-domain of RBR seems less important for plant growth, phosphorylation within the pocket-domain has a greater influence on meristem cell proliferation, and the C-terminal region markedly associates with the stem cell maintenance activity of RBR. Surprisingly, specific combination of phosoho-defective mutations lead to hyper-active variants of RBR that promote cell death while restraining proliferation; and the contribution of a phospho-site to the function of RBR varies according the the phosphorylation state of other sites. Finally, we show that the strong dominant effects of non-phosphorylatable RBR variants are suppressed by interfering with the ability to bind LXCXE motif-containing proteins. Our findings provide new insights on the conserved mechanisms underlying RBR function, uncovering the combinatorial nature of RBR phosphorylation-dependent control of cell division, differentiation and survival.

\section{Results}

\section{A system to study phospho-variants by circumventing early lethality}

The substantial knowledge on plant RETINOBLASTOMA-RELATED (RBR) proteins derives from expression studies, null or hypomorphic alleles, and up- or down-regulation of the gene (Ach et al., 1997; Borghi et al., 2010; Chen et al., 2011; Cruz-Ramírez et al., 2013; Ebel et al., 2004; Grafi et al., 1996; Gutzat et al., 2011; Perilli et al., 2013; Wachsman et al., 2011; Wildwater et al., 2005; Xie et al., 1996). However, the functional outcome of RBR phosphorylation remains largely unexplored, in spite of being a major regulatory mechanism of RBR activity. We approached this subject by constructing a collection of transgenic RBR phospho-variants comprising all putative CDK-substrates (Desvoyes and Gutierrez, 2020; Desvoyes et al., 2014)(Fig. 1).

Tests of all possible phosphorylation states on 16 sites would entail the construction of $3^{16}$ ( 43 million) variants, so we simplified the analysis by taking a domain approach. Briefly, we split the coding sequence of RBR in three combinable modules named as " $N$ ", " $P$ ", and " $C$ " (after the $\underline{\mathbf{N}}$-terminal, AB-Pocket, and $\underline{\mathbf{C}}$-terminal protein domains), each bearing a subset of phosphosites in the one of three states: phosphorylatable (wild-type), phospho-defective, and 


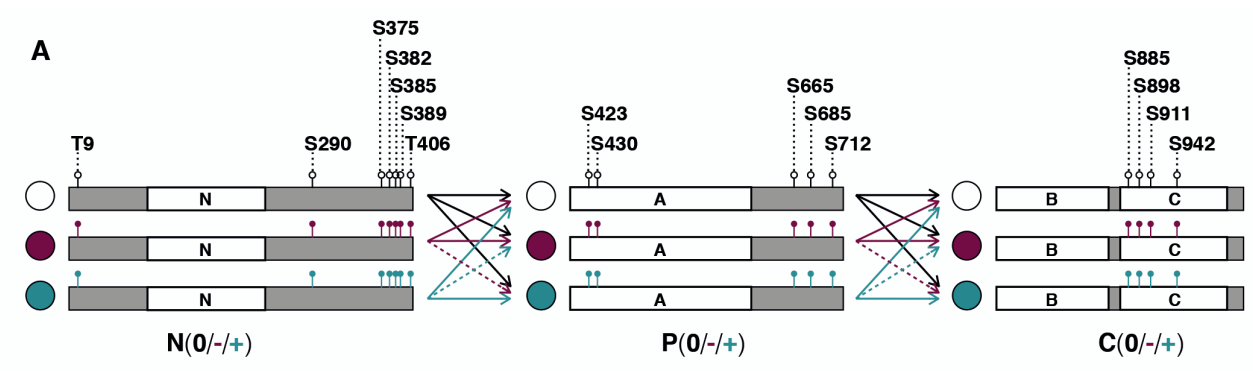

B

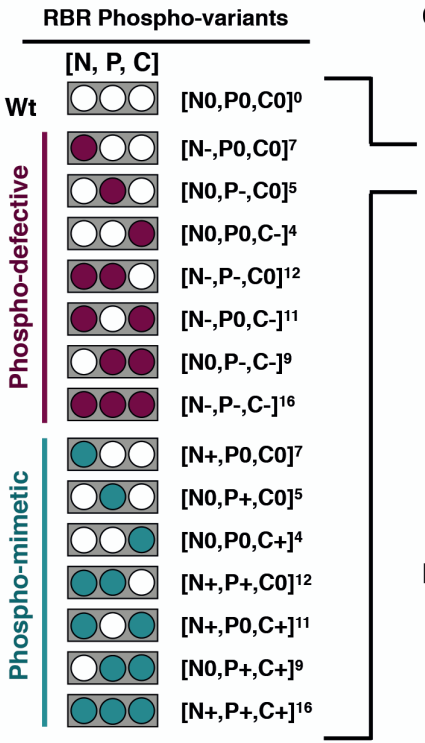

C

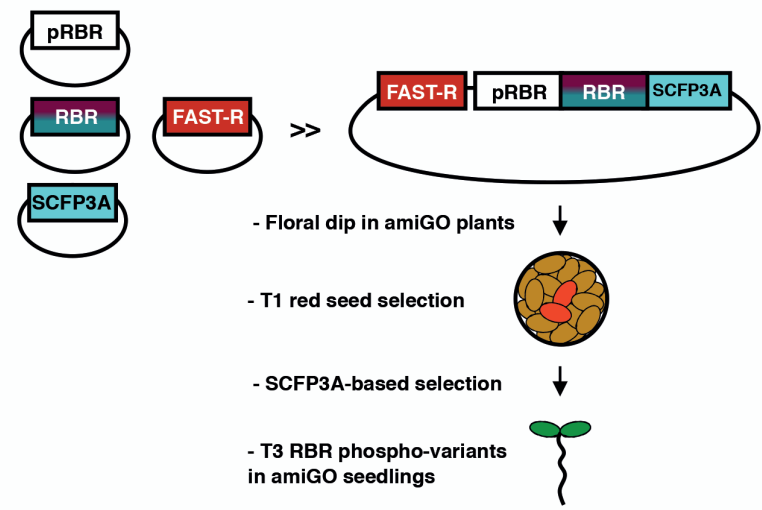

D

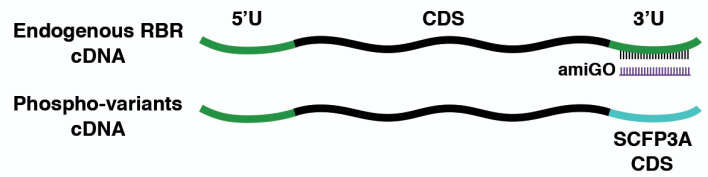

Figure 1: A system to study phospho-variants by circumventing gametophytic lethality.

A) We cloned three combinable fragments ( $N, P$, and $C$ ) comprising the full length RBR CDNA into the level -1 vector of the Golden Gate MoClo toolbox (Engler et al., 2014). White boxes represent RBR protein domains ( $\mathbf{N}$-terminal, $\mathbf{A}$ - and $\mathbf{B}$-pocket subdomains, and $\mathbf{C}$-terminal) as predicted by pfam server (https://pfam.xfam.org/), and gray boxes represent unstructured protein regions. Note that the $\mathrm{P}$ module contains all phospho-sites within the Pocket domain, but due to cloning convenience, the C-module encodes the B-pocket sub-domain. Each level-1 module encodes a subset of phosphorylation sites indicated by empty or colored lollipops, and the corresponding the amino acid residue (S/T) position. Since all phospho-sites within a module are in the same state, we use colored circles and the signs " 0 ", "-", and "+" to denote the module state: white/0 for phosphorylatable (Ser/Thr), dark red/for phospho-defective (Ala), and teal/+ for phosphomimetic. All combinations are possible (arrows), but we avoided phospho-defective with phosphomimetic combinations (dotted arrows). B) Color code and text nomenclature of phospho-variants. C) Generation and selection of transgenic RBR phosphovariants plants. Modules were assembled into the level 0 vector to generate full length RBR phosphovariants CDS, subsequently assembled with RBR promotor, the CDS of SCFP3A fluorescent tag, and a terminator (not illustrated) into Level 1 constructs. Level 2 constructs containing the FAST-R selection cassette and the corresponding phospho-variant were transformed in 35::amiGO-RBR plants (amiGO). T1 seedlings pre-selected by the red seed coat were selected for the best SCFP3A intensity and taken to T3 generation for complementation analysis. D) amiGO selectively down-regulates endogenous RBR transcripts by targeting the $3^{\prime}$-UTR, which is absent in the transgenic RBR:SCFP3A CDS. See Figure S1 for the full list of modules and phosphovariants generated. 
phospho-mimetic, the later resembling constitutive phosphorylation (Antonucci et al., 2014; Chen et al., 2017; Dissmeyer and Schnittger, 2011; Sanidas et al., 2019; Wang et al., 2014b), depicted by " 0 ", "--" and "+" signs, respectively (or by a colored circles code in figures, Fig 1A,B; $\mathrm{S} 1 \mathrm{~A})$. We refer to each RBR phospho-variant as the specific combination of modules, with a superscript indicating the total number of mutated sites. For example, $[\mathrm{NO}, \mathrm{PO}, \mathrm{CO}]^{0}$ refers to the fully phosphorylatable $\mathrm{RBR}$, while $[\mathrm{NO}, \mathrm{P}-, \mathrm{CO}]^{5}$ and $[\mathrm{NO}, \mathrm{P}+, \mathrm{CO}]^{5}$ respectively denote phosphodefective and phosho-mimetic versions of the five phosphor-sites in central module only (Fig 1B). We refrained from combining phospho-defective with phospho-mimetic modules and assembled all other possible variants with the native RBR promoter and a SCFP3A C-terminal tag (Fig. 1B,C, Fig S1B). All RBR phospho-variants were transformed into plants homozygous for the amiGO-RBR genetic construct (hereafter, amiGO; Fig 1C,D), an artificial microRNA driven by the $35 \mathrm{~S}$ promoter that selectively down-regulates endogenous RBR transcripts only after the gametophyte stage and early embryogenesis (Cruz-Ramírez et al., 2013). This late reduction in RBR levels bypasses early developmental stages and enhances cell proliferation and death similar to a true null RBR clone (Wachsman et al., 2011). Through analysis of the complementation capacity of all viable homozygous transgenic variants at stages when the amiGO phenotypes were fully penetrant (Fig S2), we could assess the effect of site-specific mutant combinations in RBR.

\section{Restriction of stem cell (SC) division is most sensitive to RBR C domain phosphorylation}

Since downregulation of RBR leads to supernumerary QC and SC (Cruz-Ramírez et al., 2013; Wildwater et al., 2005), we asked whether stem cell niche (SCN) proliferation is affected by specific RBR-phosphorylation events. Aberrant division planes hinder lineage separation in the absence of markers, so we quantified the pooled number of QC, cortex and endodermis initials (CEI), and columella stem cells (CSC) to explore the effect of the phospho-variants in SCN maintenance.

All viable phospho-defective variants displayed complementation of SCN overproliferation at least equal to the level of complementation of wildtype RBR, consistent with the dephoshoryated RBR as the repressor of SCN activity (Figure 2A,B). Among these variants, the combination of phospho-defective residues in $\mathrm{N}$ and $\mathrm{P}$ domains $[\mathrm{N}-\mathrm{P}-\mathrm{C}, \mathrm{CO}]^{12}$ showed a higher level of repression, hence the phosporylations in these domains have an additive effect. Thus, dephosphorylation is essential for RBR activity in the SCN, and single-domain dephosphorylation is not sufficient to maximize RBR mediated repression. 

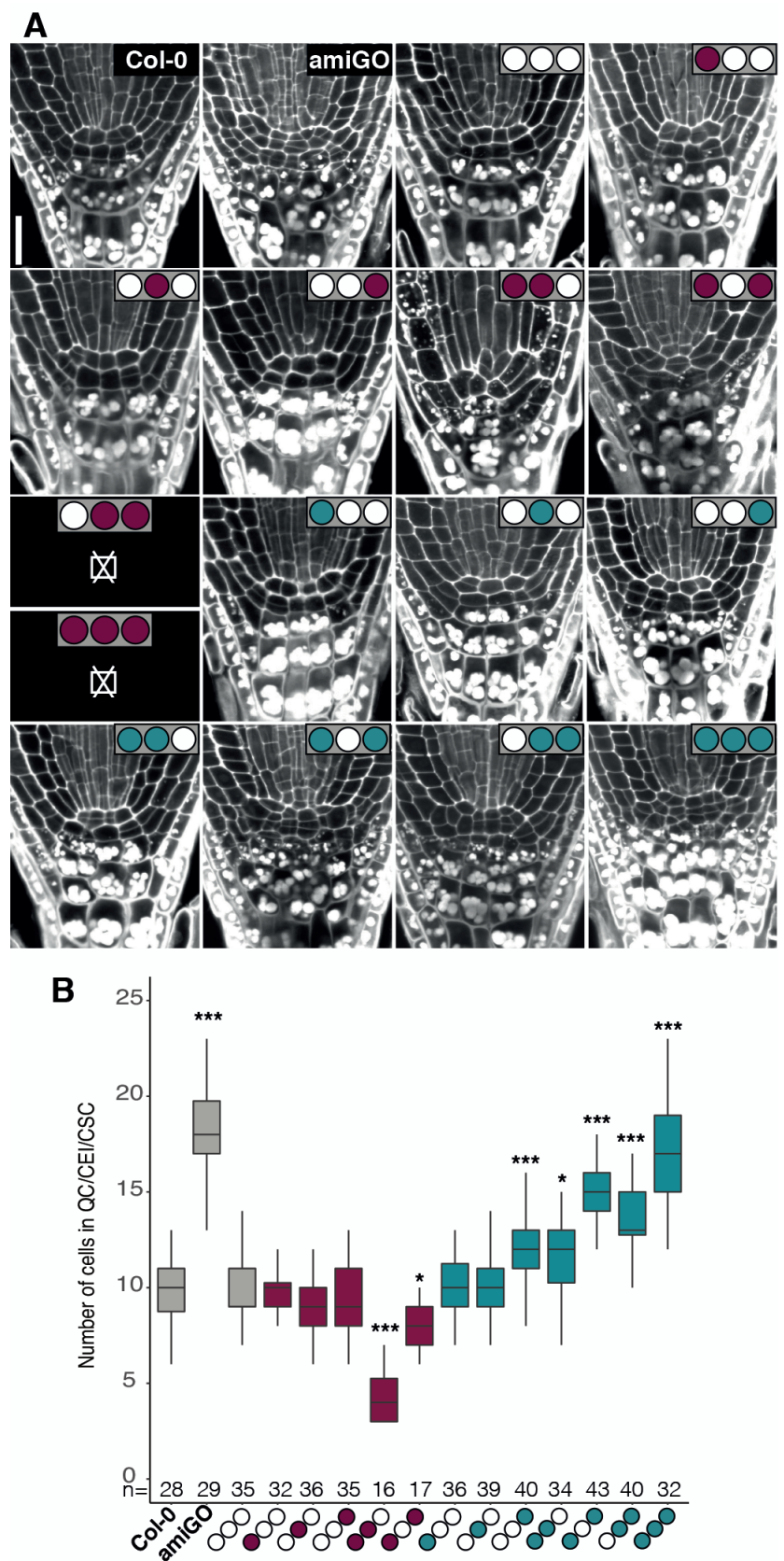

Figure 2: Restriction of stem cell (SC) division is most sensitive to RBR C domain phosphorylation. A) Representative confocal images of modified pseudo-Schiff propidium iodide (mPS-PI) stained root tips of the indicated genotypes. Sub-panels marked with $\otimes$ correspond to lethal genotypes. B) Box plot of pooled QC cells, CEI, and CSC number excluding cells with evident starch granules accumulation. Data from two biological replicates presented as median and interquartile range, $\mathrm{n}$ denotes total number of scored roots. Dunett's test against Col-0, $* * * p<0.001,{ }^{*} p<0.05$.

Scale bar, $20 \mu \mathrm{M}$. 
Consistent with a role for dephosphorylated RBR in repressing SCN activity, several variants with a phospho-mimetic module failed to complement SCN overproliferation. Overproliferation never exceeded that seen in the amiGO background, but increased with the number of domains containing phospho-mimetic residues. Thus, phosphorylations in more than one RBR domain are needed to release the repression of SCN divisions. However, $[\mathrm{NO}, \mathrm{PO}, \mathrm{C}+]^{4}$ revealed incomplete repression of $\mathrm{SCN}$ activity similar to $[\mathrm{N}+, \mathrm{P}+, \mathrm{CO}]^{12}$, despite having less phospho-mimetic residues, indicating that phosphorylation sites in the $\mathrm{C}$ domain have a larger influence on $\mathrm{SCN}$ regulation than those in the $\mathrm{N}$ and $\mathrm{P}$ domains. Taken together, a range of phospo-defective and phospho-mimetic mutant combinations reveals additive but differently sized contributions to the regulation of SCN activity by RBR phospho-sites in all three protein domains.

\section{Meristem size maintenance depends most strongly on the Pocket domain phosphorylation}

Similarly to their effect on SCN activity, down-and up-regulation of RBR have opposite effects on root meristem size (Perilli et al., 2013). To elucidate whether cell division activity is controlled by a similar 'phosphorylation code' in the transit amplifying cells of the root meristem than in the $\mathrm{SCN}$, we measured the effects of the phospho-site variants on the size of the transit amplifying cell pool in the meristem. As expected, amiGO meristems were slightly longer and contained more cells than Col-0, which could be fully complemented using the WT RBR version $[\mathrm{NO}, \mathrm{PO}, \mathrm{CO}]^{\circ}$ (Fig 3A, 3B).

Similar to the observations in the SCN, all phospho-defective variants complemented overproliferation in the meristem (Fig 3B). However, in this case mutations in the single Pocket domain [NO,P-,CO $]^{5}$ were sufficient to over-complement the amiGO mutants, giving rise to shorter meristems than $W T$, but without significant effect on the SCN (Fig 2B, 3B,C). Phospho-mimetic variants in any combination were all able to complement the amiGO meristem phenotype, except for $[\mathrm{NO}, \mathrm{PO}, \mathrm{C}+]^{4}$. Unlike observed for the SCN proliferation phenotype, no other variant containing the $\mathrm{C}+$ module exhibited significant changes; our data indicate distinct effects for RBR phosphorylation sites in control over SCN and meristem proliferation, with a larger role for the C-region phosphorylation in the $\mathrm{SCN}$, and a larger role for Pocket phosphorylation in the transit amplifying cells of the meristem.

Interestingly, despite presenting more cells (Fig 3B), [NO,PO,C+ $]^{4}$ did not increase meristem length (Fig $3 \mathrm{C}$ ), indicating that a compensatory mechanism maintains meristem size. Similar compensation effects were seen for $\left[\mathrm{N}-, \mathrm{PO}, \mathrm{C}_{-}\right]^{11}$, where less cells did not lead to a difference in meristem length compared to Col-0. Compensatory mechanisms did not sustain meristem size whenever the phospho-defective $\mathrm{P}$ module was present. Thus, phosphorylation of the Pocket domain is particularly important to maintain meristem size, consistent with a sitespecific component in the phosphorylation code. 

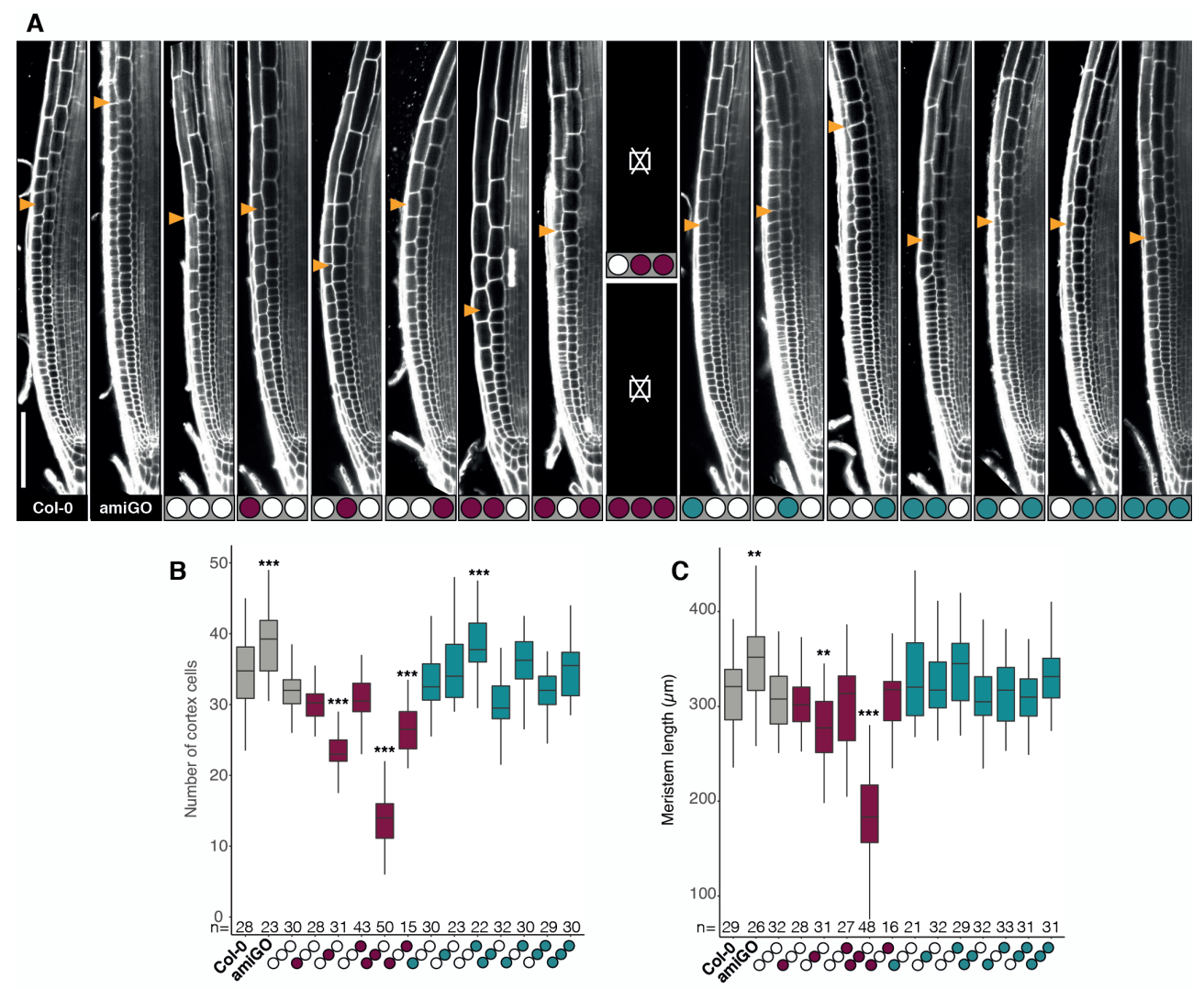

Figure 3: Meristem size maintenance depends most strongly on the Pocket domain phosphorylation. A) Representative confocal images of root meristems of the indicated genotypes; yellow arrowheads mark the end of the meristem proliferation zone. Sub-panels marked with $\otimes$ correspond to lethal genotypes. B,C) Box plots of meristem proliferation and size quantified as the number of cortex cells B) and length C) from QC to the first rapidly elongating cortex cell. Data from two biological replicates presented as median and interquartile range, $\mathrm{n}$ denotes total number of scored roots. Dunett's test against Col- $0, * * * p<0.001, * * p<0.01$. Scale bar, $100 \mu \mathrm{M}$.

\section{Suppression of cell death is rescued by all but two distinct RBR phosho variants.}

Spontaneous cell death in the root tip constitutes a hallmark of reduced RBR activity (CruzRamírez et al., 2013; Wildwater et al., 2005), likely due the inability to cope with intrinsic DNA damage (Biedermann et al., 2017; Horvath et al., 2017). We examined the protective role of RBR phosphorylation variants with propidium iodide (PI), which permeates only dead cells. As expected, all amiGO roots presented dead cells, while Col-0 and the vast majority of the phospho-variants had around $25 \%$ or less root tips with dead cells. Two phosphovariants reached a comparable cell death frequency to amiGO seedlings (Fig 4A, 4B). The full phospho-mimetic variant $[\mathrm{N}+, \mathrm{P}+, \mathrm{C}+]^{16}$ fits the paradigm of hyper-phosphorylated RBR being inactive. Accordingly, $[\mathrm{N}+, \mathrm{P}+, \mathrm{C}+]^{16}$ also presented overproliferation of $\mathrm{SCN}$ and meristematic cells (Figs. 2 and $3 A, B$ ), corroborating that phospho-mimetic mutations inactivate RBR. 
However, the phospho-defective variant $\left[\mathrm{N}-, \mathrm{PO}, \mathrm{C}_{-}\right]^{11}$ presented a striking outcome for a presumed active, less-phosphorylatable RBR isoform. [N-,PO,C-] ${ }^{11}$ over-complemented the amiGO cell proliferation phenotypes (Figs 2 and $3 A, B$ ) but failed to promote cell survival, in contrast with $[\mathrm{NO}, \mathrm{P}-, \mathrm{CO}]^{5}$ and $[\mathrm{N}-, \mathrm{P}-, \mathrm{CO}]^{12}$, that also over-complemented cell proliferation but fully restored the cell death phenotype (Fig 2B, 4A,B). Additionally, some phosphomimetics that failed to restrain SCN proliferation still suppressed cell death. Thus, cell proliferation is always promoted by RBR phosphorylation to a greater or lesser extent according to specific phospho-sites, but cell death emerges either upon constitutive RBR hyper-phosphorylation or with a specific combination of un-phosphorylated sites, implying two different mechanisms for RBR-promoted cell survival.
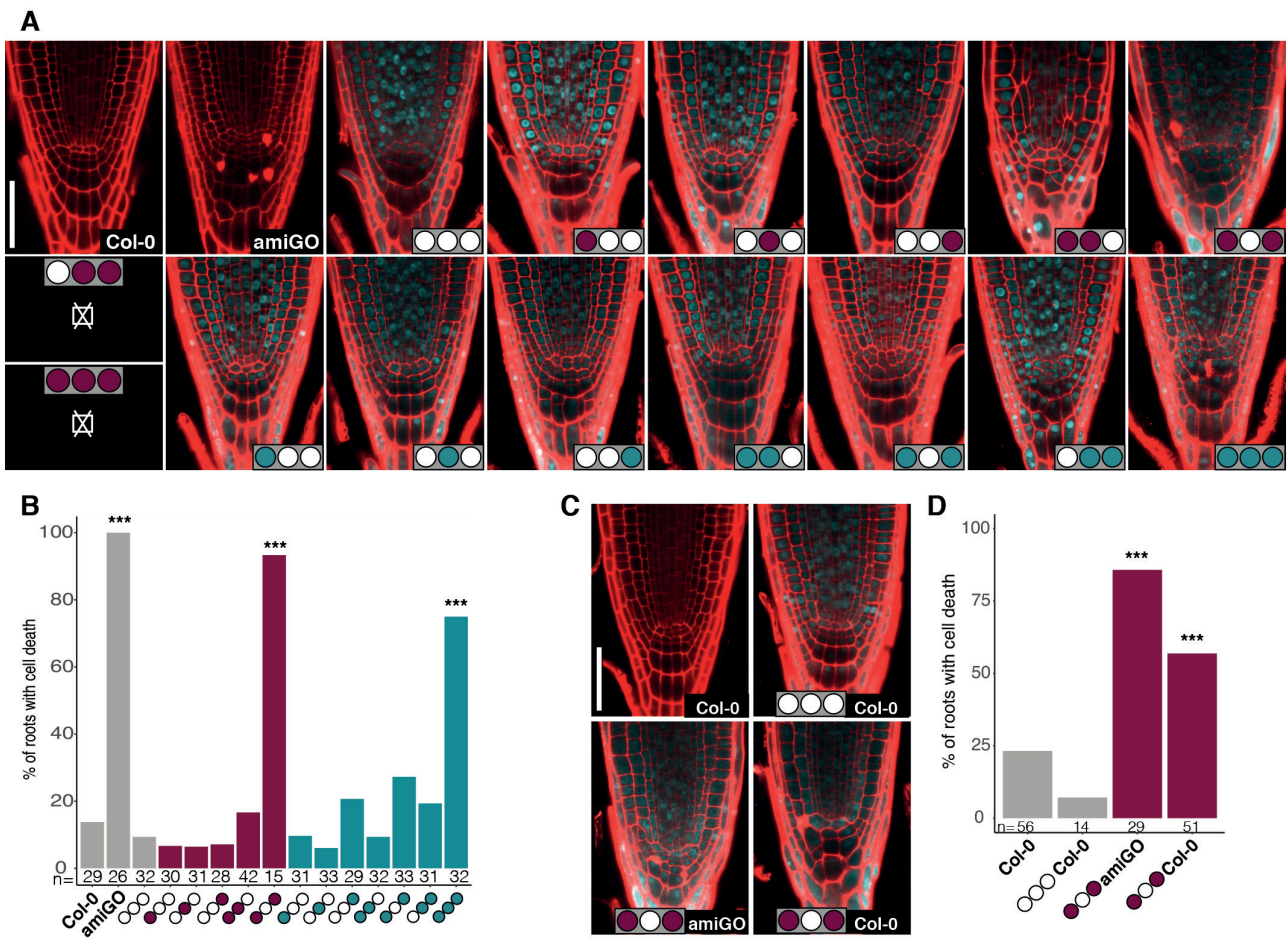

Figure 4: Suppression of cell death is rescued by all but two distinct RBR phosho variants.

$\mathrm{A}$ and $\mathrm{C}$ ) Representative confocal images of PI-stained root tips of the indicated genotypes. Sub-panels marked with $\bigotimes$ correspond to lethal genotypes. In C) the genetic background of phospho-variants is indicated in black text boxes. B and D) Bar graphs from A) and C), respectively, showing percentage of root tips with dead cells. Data from two biological replicates presented as means, $\mathrm{n}$ denotes total number of scored roots. Dunett's test against Col-0, ${ }^{* * *} p<0.001$. Scale bars, $50 \mu \mathrm{M}$.

Since phospho-defective [N-,PO,C-] ${ }^{11}$ hyper-actively restrains cell division, we asked whether the cell death phenotype is caused by the activity of RBR, or results from a reduced protective function. We out-crossed the amiGO background to assess the effect of $[\mathrm{N}-, \mathrm{PO}, \mathrm{C}-]^{11}$ and $[\mathrm{NO}, \mathrm{PO}, \mathrm{CO}]^{0}$ in the presence of endogenous RBR. While 4 copies (endogenous and 
transgenic) of wild-type RBR conferred a protective effect, more than $50 \%$ of the $[\mathrm{N}-, \mathrm{PO}, \mathrm{C}-]^{11}$ roots still displayed dead cells in the Col-0 genetic background (Fig 4 C,D). However, in the amiGO background the frequency increased to more than $80 \%$ (Fig $4 \mathrm{C}, \mathrm{D}$ ), indicating that $[\mathrm{N}-, \mathrm{PO}, \mathrm{C}-]^{11}$ is an RBR active isoform triggering the cell death program, possibly counteracted by the endogenous RBR.

\section{The specific phenotypic effect of an individual phospho-site is defined in combination with phospho-sites in other protein domains.}

The distinct contributions of phospho-sites in different RBR protein domains to cell division phenotypes (C-region sites to SNC activity and Pocket domain sites to meristem size) contrasts with the more equal contribution of sites to the cell death effect (Fig 4, compare $[\mathrm{N}-, \mathrm{PO}, \mathrm{C}-]^{11}$ to $[\mathrm{N}-, \mathrm{PO}, \mathrm{CO}]^{7}$ and $\left.[\mathrm{NO}, \mathrm{PO}, \mathrm{C}-]^{4}\right)$. To explore potential effects of a single specific phospho-site in one module to RBR phenotypes when combined with defective sites in other modules, we generated a new " $\mathrm{N}$ " phospho-module containing a single phosphodefective site on position T406, thus named as "406-" (Figs. 5A, S1A). All combinations of the 406- module with the WT and phospho-defective $P$ and $C$ modules were phenotyped -except for [406-,P-,C- ${ }^{10}$ that is not viable.

Similar to the fully phospho-defective $\mathrm{N}$-domain, meristem size was not affected by 406 on its own, but it was reduced by one third in [406-, P-,CO $]^{6}$ (Fig. 5C-E). Since this effect was milder than in $[\mathrm{N}-, \mathrm{P}-, \mathrm{CO}]^{12}$ (Fig 3), we conclude that T406 has an additive effect to the strong influence of the Pocket domain phosphorylation on meristem size. Noteworthy, [406,PO,C- $]^{5}$ showed an equally strong effect (Fig $5 \mathrm{C}-\mathrm{E}$ ), and even more severe than $[\mathrm{N}-, \mathrm{PO}, \mathrm{C}-]^{11}$ (Fig 3 ) suggesting that, when combined with those in the C-region, not all phospho-sites in the $\mathrm{N}$-domain are additive with respect to the repressive function of RBR in meristem size maintenance.

Unlike [406-,P-,C0 $]^{6},[406-, \mathrm{PO}, \mathrm{C}-]^{5}$ displayed increased cell death (Fig 5L), but to a lesser extent than its high order counterpart $[\mathrm{N}-, \mathrm{PO}, \mathrm{C}-]^{11}$ (Fig 4). Since $[\mathrm{NO}, \mathrm{PO}, \mathrm{C}-]^{4}$ and $[406-, \mathrm{PO}, \mathrm{CO}]^{1}$ showed full or even enhanced cell survival in the latter case (Fig 5 F,G; see Fig 4 A,B, for $\left.[\mathrm{NO}, \mathrm{PO}, \mathrm{C}-]^{4}\right)$, we conclude that none of the phospho-sites by their own, but the combination of de-phosphorylated sites in the $\mathrm{N}$ and $\mathrm{C}$ regions trigger cell death, and that individual sites in the $\mathrm{N}$ domain exhibit an additive effect on the phenotype penetrance.

In turn, [NT406-, $\mathrm{P}-, \mathrm{CO}]^{6}$ restricted SC divisions but to a lesser extent than $[\mathrm{N}-, \mathrm{P}-, \mathrm{C}-\mathrm{O}]^{12}$ (Fig $5 \mathrm{H}, \mathrm{I})$, suggesting the additive effect of $\mathrm{N}$ and Pocket domains phosphorylation on RBR activity, while the full complementation conveyed by $[\mathrm{N}-, \mathrm{PO}, \mathrm{CO}]^{7}$ and $[\mathrm{NO}, \mathrm{P}-, \mathrm{CO}]^{5}$ (Fig 2), indicates that combinatorial dephosphorylation of the RBR $\mathrm{N}$ and Pocket domains restricts SCN activity. Unfortunately, we could not assess the effect of [406-, P0,C- $]^{5}$ on SC divisions due to limited seed availability. Altogether, the phospho-defective 406 residue enhanced 
the activity of the $\mathrm{P}$ - and $\mathrm{C}$-contained phospho-sites to restrict cell division (to even a greater extent than the $\mathrm{N}$ - module when combined with $\mathrm{C}-$ ), and triggered cell death activation only in combination with the C-terminal phospho-defective module, indicating that the phenotypic effect of an individual phospho-site depends on the phosphorylation status of the remaining ones.

A

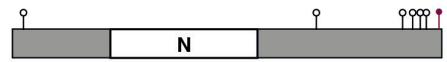

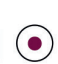

B

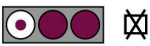

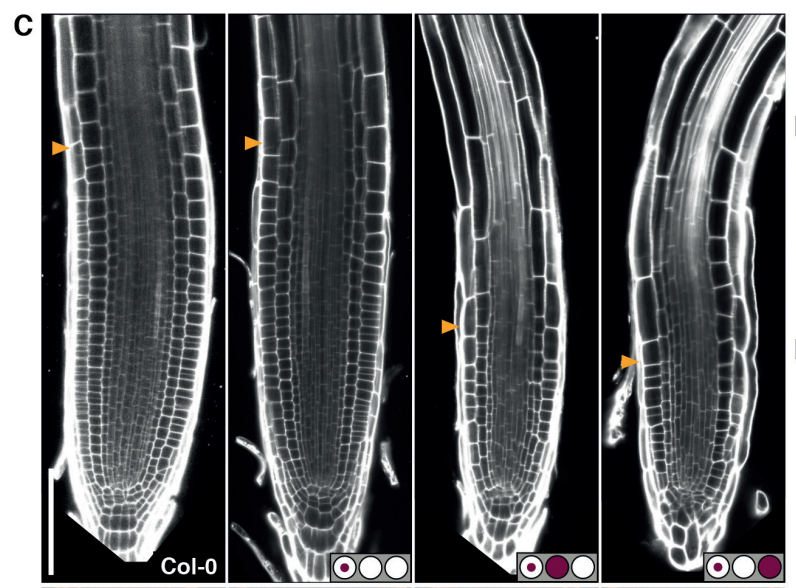
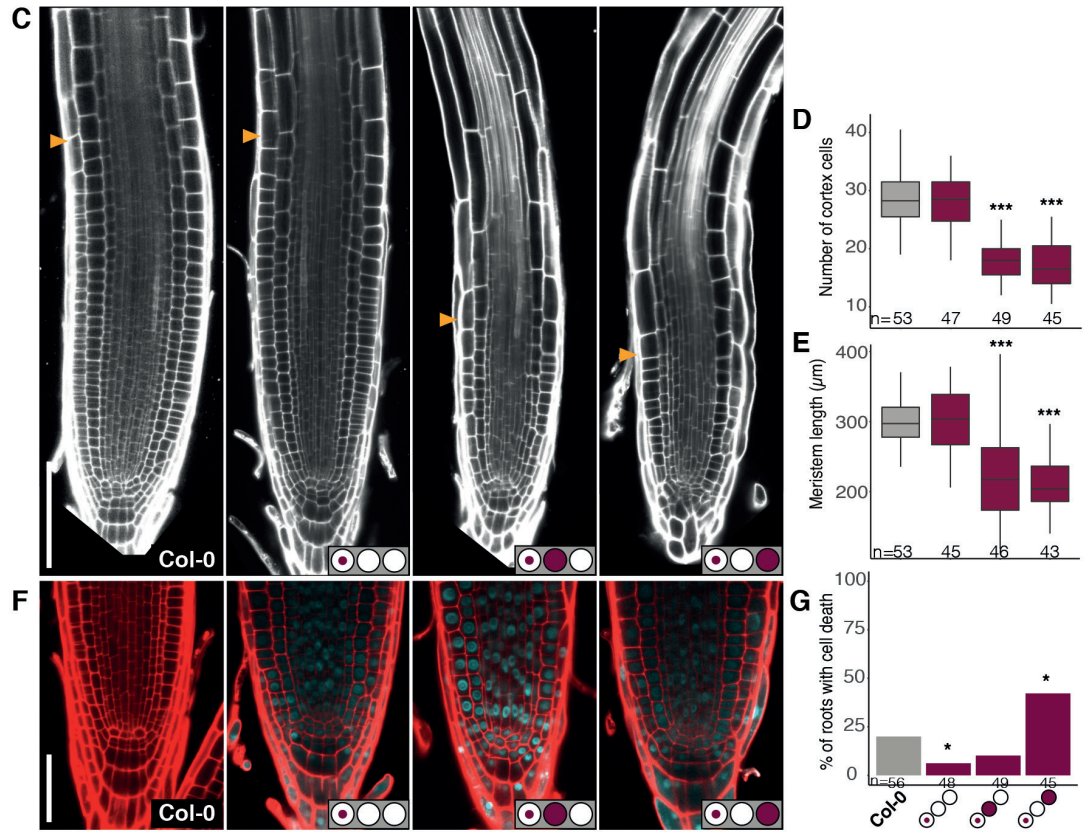

$\mathbf{H}$
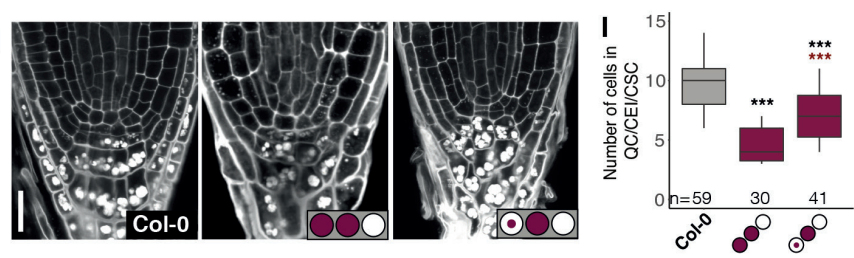

Figure 5: Combinatorial effects of phospho-defective T406 residue on RBR activity.

A) Schematic representation of the phospho-defective 406 module and its colored circle code. B) The $\square$ symbol indicates that the $[406-, \mathrm{P}-, \mathrm{C}-]^{10}$ phospho-variant is lethal. C, F, H) Representative confocal images of PI- $\mathrm{C}, \mathrm{F}$ ) or mPS-PI- H) stained root tips of the indicated genotypes; yellow arrowheads mark the end of the meristem proliferation zone. D and E) Box plots from $C$ ) of meristem proliferation and size quantified as the number of cortex cells $D$ ) and length $E$ ) from the $Q C$ to the first rapidly elongating cortex cell. $L$ ) Bar graph from F) showing the percentage of root tips with dead cells. I) Box plot from $\mathrm{H}$ ) quantifying the pooled QC cells, CEI, and CSC number excluding cells with evident starch granules accumulation. Data from two biological replicates presented as median and interquartile range $D, E, I$ ) or as means $G$ ); $\mathrm{n}$ denotes total number of scored roots. Dunett's test against Col-O D,E,G,I) and against $\left.[\mathrm{N}-, \mathrm{P}-, \mathrm{CO}]^{12} \mathrm{I}\right)$, $* * * \mathrm{p}<0.001$, black asterisks indicate significant differenced against Col-0; red asterisks in I) against [N-, $\mathrm{P}$ ,CO $]^{12}$. Shared labels in ' $x$ ' axis for D),E), G). Scale bars, $100 \mu \mathrm{M}$ in (C), $50 \mu \mathrm{M}$ in (F), $20 \mu \mathrm{M}$ in (H). 


\section{Ovule and embryo growth are compromised in highly substituted RBR phospho-defec- tive variants.}

Limited seed production in $[\mathrm{N}-\mathrm{T} 406, \mathrm{PO}, \mathrm{C}-]^{5},[\mathrm{~N}-, \mathrm{P}-, \mathrm{CO}]^{12}$ and $[\mathrm{N}-, \mathrm{PO}, \mathrm{C}-]^{11}$ suggested sterility due to defects during female reproductive development. To determine the nature of sterility defects found in some of these phospo-defective variants, we quantified and cytologically analyzed ovule development and seed formation in both $[\mathrm{N}-, \mathrm{P}-, \mathrm{CO}]^{12}$ and $[\mathrm{N}-, \mathrm{PO}, \mathrm{C}-]^{11}$ genotypes. Contrary to amiGO and Col-0 wild-type controls, the two genotypes showed at least $80 \%$ of non fertilized ovules following pollination in both genetic backgrounds, indicating an important degree of female sterility (Figure S4A). Both lines showed defects during ovule development. Although the initiation of ovule primordia appeared normal (Figure S4B), in $73 \%\left([\mathrm{~N}-, \mathrm{P}-, \mathrm{CO}]^{12}\right)$ and $55 \%\left([\mathrm{~N}-, \mathrm{PO}, \mathrm{C}-]^{11}\right)$ of developing ovules the integuments were short and had not covered the developing female gametophyte at the 4-nuclear stage (Figure S4C and S4D). This lack of integument growth was due to defective cell proliferation in the inner and outer integuments, impeding the ovule to complete anatropy (the inverted condition that brings the egg cell in close proximity to the funiculus for successful double fertilization), and pleiotropically causing defects in female gametophytic nuclear proliferation and cellularization. In some cases, the defective ovules also showed evidence of epidermal cell degeneration (Figure S4C). Male reproductive organs in both lines also showed growth defects, with smaller locular space and limited amount of viable pollen (Figures S4F to S4H). Moreover, the few [NO,P-,C- $]^{9}$ transformants obtained also showed high levels of sterility (Fig S3 A-D), confimirng the importance of phosphorylation in $\mathrm{P}$ and $\mathrm{C}$ regions to sustain plant reproduction. These results indicate that defective reproductive development results not only from reduced RBR activity as previously reported (Ebel et al., 2004; Zhao et al., 2017), but also from hyper-active isoforms, indicating that RBR is regulated by phosphorylation during ovule growth and development.

Since Agrobacterium-mediated transformation occurs specifically in the female reproductive tissues (Desfeux et al., 2000), gametophytic defects may account for the impossibility to recover transgenic seedlings expressing $\left[\mathrm{N}-, \mathrm{P}-, \mathrm{C}_{-}\right]^{16}$ or $\left[406-, \mathrm{P}-, \mathrm{C}_{-}\right]^{10}$ phospho-variants. But even if some transformed ovules could be successfully fertilized, embryo lethality can occur as RBR regulates embryonic genetic programs (Gutzat et al., 2011). To explore this possibility, we used the red fluorescent seed coat selection marker (see Fig 1C) to select $[\mathrm{N}-, \mathrm{P}-, \mathrm{C}-]^{16}$ primary transformants in both amiGO and Col-0 backgrounds, and recovered all embryos from non-germinated seeds. A small fraction of embryos ( $3.5 \%, n=318$ ) was arrested at heart- to torpedo stages and showed enlarged cells regardless the presence of endogenous RBR (Fig. 6 A). Some arrested embryos presented residual or absent radicles (Fig S3F,G), single or uneven cotyledons (Fig S3H,J), and signs of early differentiation like root hairs (Fig S3I). Conversely, we did not find any of these features in non-germinated seeds of Col-0 nor in primary transformants of a viable phospho-defective RBR variant (Fig. 6A, S3K). Considering the phenotypic similarities in arrested embryos of [NO,P-, C- $]^{9}$ transformants (Fig 
S3E), our results indicate that a dominant effect of phospho-defective mutants (particularly in the $\mathrm{P}$ and $\mathrm{C}$ regions) blocks embryonic development. Altogether, defective reproduction and early developmental arrest underlie the viability loss of highly substituted phosphodefective variants, leading us to conclude that RBR multi-phosphorylation, particularly on the Pocket domain and C-terminus, is essential for plant survival.

\section{A point mutation in the B-pocket sub-domain partially rescues highly substituted phosp- ho-defective mutants.}

If RBR phosphorylation disrupts its protein interactions, the dominant phenotypes of highly substituted phospho-defective RBR variants might reflect more stable protein interactions. Therefore, we introduced the point mutation N849F (human N757F, mouse N750F hereafter NF), which disrupts interactions with LXCXE motif-containing proteins in plants and animals (Bourgo et al., 2011; Chen and Wang, 2000; Cruz-Ramírez et al., 2013), into two " $\mathrm{C}$ " modules to generate two new phospho-defective RBR alleles: $\left[\mathrm{N}-, \mathrm{P}_{-},{ }^{\mathrm{NF}} \mathrm{CO}\right]{ }^{12}$ and $[\mathrm{N}-, \mathrm{P}-$ , $\left.{ }^{\mathrm{NF} C} \mathrm{C}\right]^{16}$ (Fig 6A, S1). Strikingly, we recovered viable plants and homozygous lines, even for the fully phospho-defective variant.

To investigate the suppressive effect of the NF mutation, we compared the phosphodefective NF variants alongside $p R B R: R^{2} R^{N F}: v Y F P$ (hereafter $R^{B} R^{N F}$ ), with both Col-0 and $[\mathrm{N}-, \mathrm{P}-, \mathrm{CO}]^{12}$. As reported previously (Cruz-Ramírez et al., 2013; Zhou et al., 2019), the RBR ${ }^{\mathrm{NF}}$ allele showed a slight overproliferation of the SCN (Fig 6 F,G). The NF mutation partially restored the meristem size phenotypes of the over-complementing $[\mathrm{N}-, \mathrm{P}-, \mathrm{CO}]^{12}$ variant (Fig 3 vs Fig 6 C-E); similarly, SCN differentiation was also partially rescued (Fig 2 vs Fig 6 F,G). Moreover, the fully phospho-defective $\left[\mathrm{N}-, \mathrm{P}_{-},{ }^{\mathrm{NF}} \mathrm{C}_{-}\right]{ }^{16}$ variant showed little, if any, phenotypic variation as compared with $\left[\mathrm{N}-, \mathrm{P}_{-},{ }^{\mathrm{NF}} \mathrm{CO}\right]^{12}$ (Fig $\left.6 \mathrm{C}-\mathrm{I}\right)$. Even non-germinating $\left[\mathrm{N}-, \mathrm{P}_{-},{ }^{\mathrm{NF}} \mathrm{C}_{-}\right]^{16}$ primary transformants showed more advanced development than $\left[\mathrm{N}-, \mathrm{P}-, \mathrm{C}_{-}\right]^{16}$ arrested embryos (Fig 6 A vs S3K). Thus, the partial rescue of highly substituted phospho-defective variants phenotypes by the NF mutation suggests that RBR-LXCXE protein interactions constitute a predominant component of RBR-mediated developmental processes regulated by phosphorylation. 
A

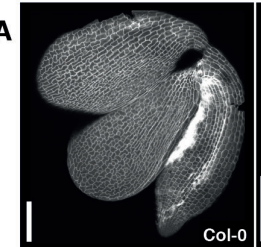

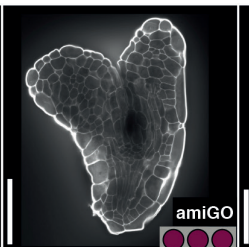
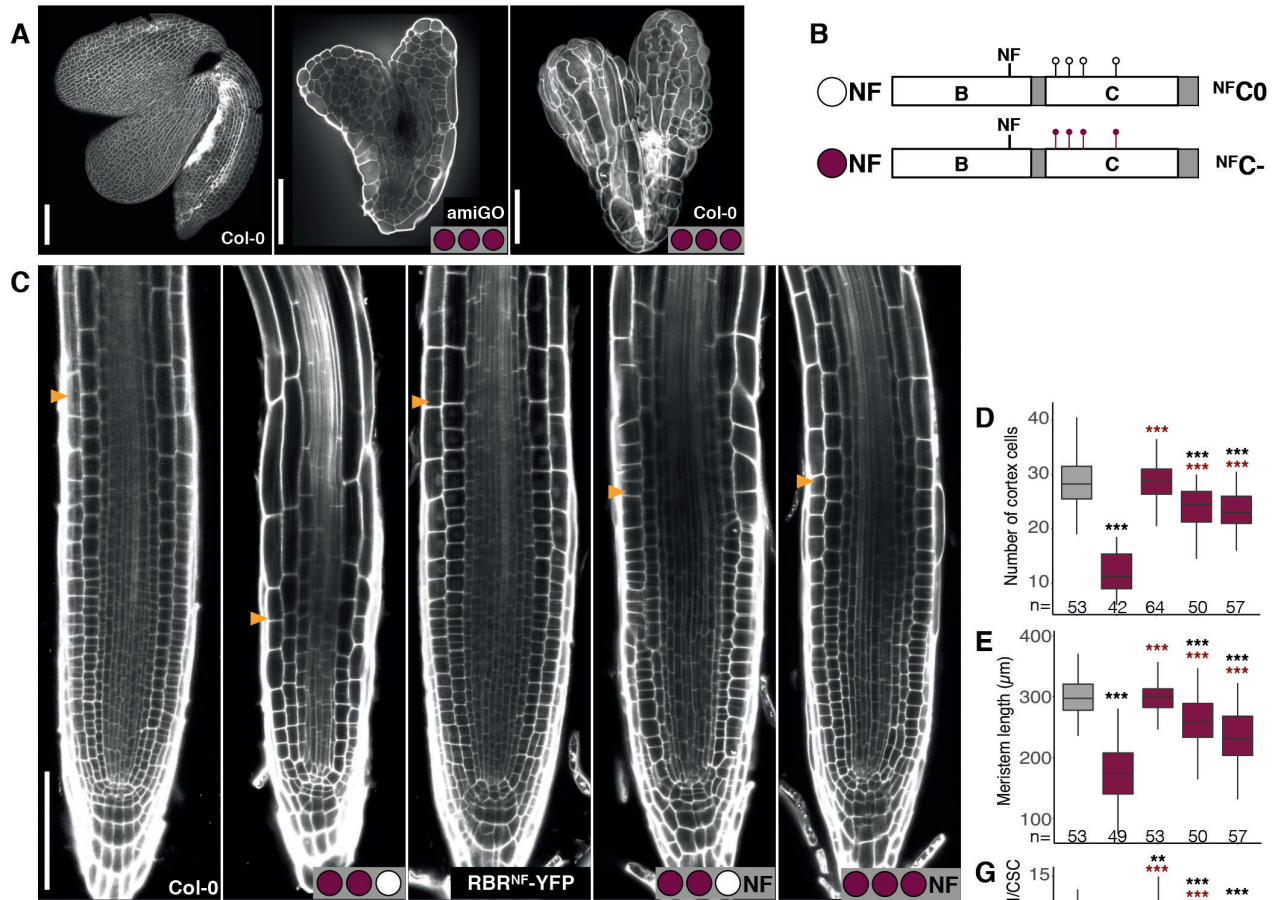

$\mathbf{F}$

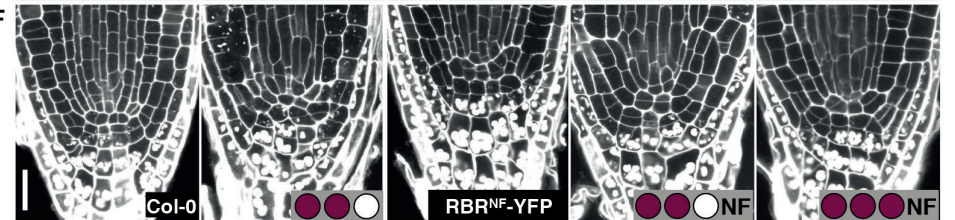

H
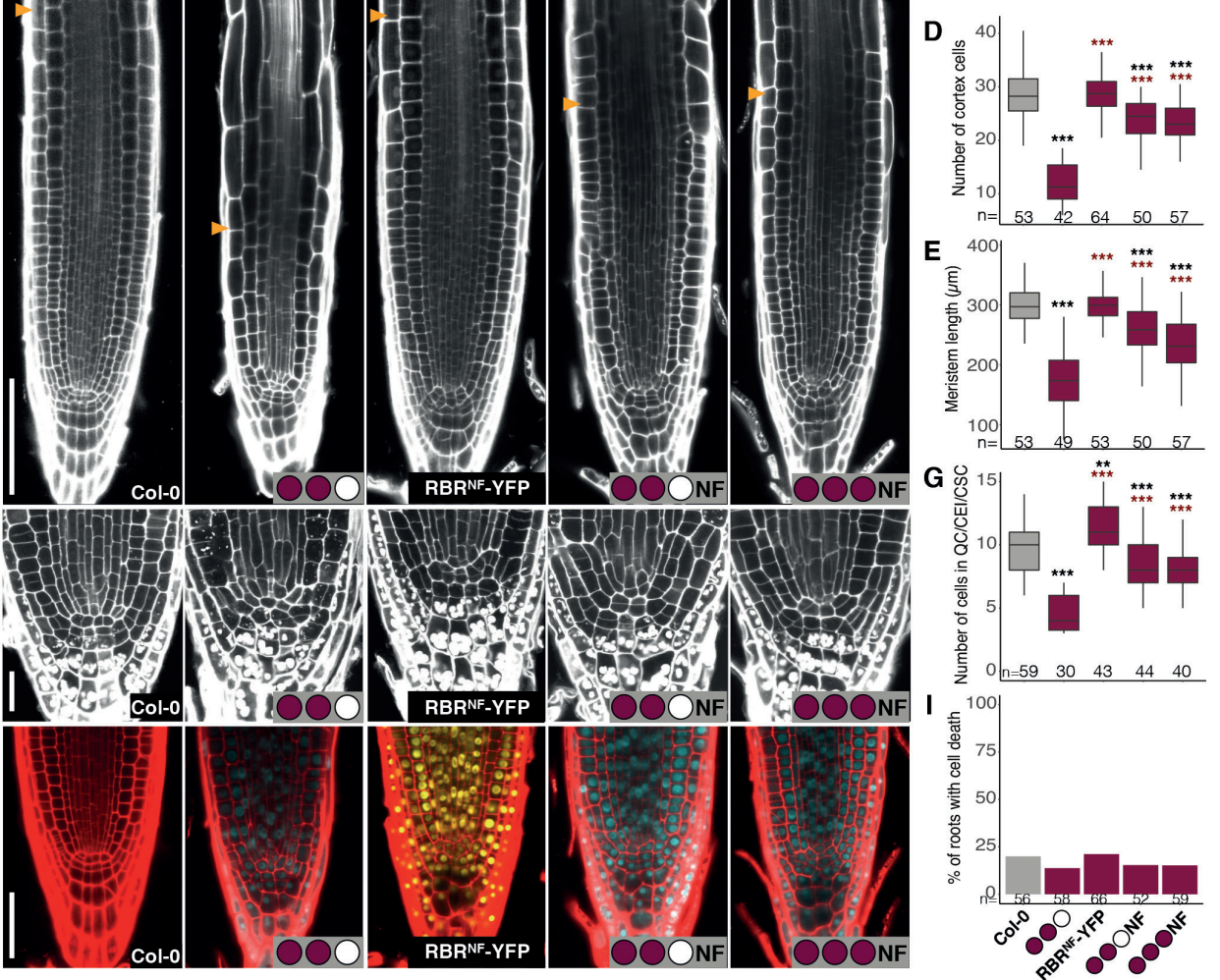

Figure 6: A point mutation in the B-pocket sub-domain partially rescues highly substituted phosphodefective mutants.

A) Confocal images of mPS-PI stained embryos from non-germinated seeds 4 days after sowing (das) stratified for 4 days of Col- 0 and primary transformants of $[\mathrm{N}-, \mathrm{P}-, \mathrm{C}-]^{16}$ in the genetic backgrounds amiGO and $\mathrm{Col}-\mathrm{O}$. B) Schematic representation of the ${ }^{\mathrm{NF}} \mathrm{CO}$ and ${ }^{\mathrm{NF}} \mathrm{C}$ - modules and its colored circle code. $\left.\mathrm{C}, \mathrm{F}, \mathrm{H}\right)$ Representative confocal images of PI- $\mathrm{C}, \mathrm{H}$ ) or mPS-PI- F) stained root tips of the indicated genotypes; yellow arrowheads mark the end of the meristem proliferation zone. D,E) Box plots from $C$ ) of meristem proliferation and size quantified as the number of cortex cells $D$ ) and length $E$ ) from the $Q C$ to the first rapidly elongating cortex cell. G) Box plot from F) quantifying the pooled QC cells, CEI, and CSC number excluding cells with evident starch granules accumulation. I) Bar graph from $\mathrm{H}$ ) showing the percentage of root tips with dead cells. Data from two biological replicates presented as median and interquartile range $\mathrm{D}, \mathrm{E}, \mathrm{G}$ ), or as means $\mathrm{I}$ ); $\mathrm{n}$ denotes total number of scored roots. Dunett's test against Col- 0 and against $[\mathrm{N}-, \mathrm{P}-, \mathrm{CO}]^{12}, * * * \mathrm{p}<0.001, * * \mathrm{p}<0.01$, black asterisks indicate significant difference against $\mathrm{Col}-0$; red asterisks, against $[\mathrm{N}-, \mathrm{P}-, \mathrm{CO}]^{12}$. Col- 0 and $[\mathrm{N}-, \mathrm{P}-, \mathrm{CO}]^{12}$ values are the same as in Figure 5 as experiments were performed in parallel sharing these controls. Shared labels in ' $x$ ' axis for $D), E), G), I)$. Scale bars, 100 $\mu \mathrm{M}$ in $(\mathrm{A}, \mathrm{C}), 20 \mu \mathrm{M}$ in $(\mathrm{F}), 50 \mu \mathrm{M}$ in $(\mathrm{H})$. 


\section{Discussion}

Here, we have explored the separability of roles for plant RBR phosphorylation, which has emerged as a prominent regulatory mechanism of RBR in the multitude of $R B$ proteins functions described so far. Taken together, our results support the notion that a phosphorylation code fine-tunes RBR activity and function. While our phospho-defective variants often showed dominant effects and over-complementation of 'amiGO' plants with reduced RBR levels (Figs. 2,3,4C,D,5, 6A, S3,S4A), the phenotypic strength of phosphomimetic variants ranged between those observed for wild-type and amiGO (Figs. 2-4), which supports the prevailing conception that an active, unphosphorylated RBR, is inactivated by regulatory phosphorylations. Our work provides evidence that three additions to this generic idea are to be made: phosphorylation events on RBR (1) are independent of each other, (2) unequally contribute to RBR activity, and (3) disentangle RBR functions.

\section{RBR phospho-sites are independent of each other}

We observed an additive effect in the phenotypic strength as the mutated phospho-sites on RBR variants increased. Together with the phenotypic differences between full phosphosite variants $\left(\left[\mathrm{N}-, \mathrm{P}-, \mathrm{C}_{-}\right]^{16}\right.$ and $\left.[\mathrm{N}+, \mathrm{P}+, \mathrm{C}+]^{16}\right)$ and all single phospho-module combinations, our findings exclude a nucleation mechanism for RBR hyper-phosphorylation, and demonstrate that phosphorylation events on RBR are independent of each other.

\section{Uneven contribution of phospho-sites to RBR activity regulation}

Unlike $[\mathrm{N}-, \mathrm{P}-, \mathrm{CO}]^{12}$ and $[\mathrm{N}-, \mathrm{PO}, \mathrm{C}-]^{11}$, the less substituted phospho-defective variant $[\mathrm{NO}, \mathrm{P}-$ ,C- $]^{9}$ was lethal. Therefore, the phosphorylatable Pocket domain and C-region, but not the $\mathrm{N}$-region of RBR protein, were sufficient to sustain plant growth and viability on their own despite bearing less phospho-sites. Moreover, phosphorylation within the Pocket domain and the C-region markedly influenced the proliferative activity of the meristem and SCN, respectively, whereas phosphorylation of the $\mathrm{N}$ domain seemed unimportant on its own (Figs 2,3). Accordingly, phosphorylation within the Pocket domain and C-region of $\mathrm{pRb}$ regulate E2F and LXCXE motif binding (Burke et al., 2010; Knudsen and Wang, 1997), while the relevance of phosphorylating the $\mathrm{N}$-domain has been shown to emerge upon stressful conditions (Gubern et al., 2016). Future research should unveil the functions of RBR $\mathrm{N}$-domain phosphorylation during plant stress responses.

\section{RBR functions are separable by phosphorylation}

While the phospho-defective variant $[\mathrm{NO}, \mathrm{P}-, \mathrm{CO}]^{5}$ over-complemented root meristem size but not SCN division, all three double phospho-mimetic modules combinations displayed overproliferation of the SCN but not of transit amplifying cells. Notably, several phopsho-mimetic variants that failed to restrict SCN activity complemented the cell death phenotype. On the other hand $[\mathrm{N}-, \mathrm{PO}, \mathrm{C}-]^{11}$ and $\left[\mathrm{N}^{-\mathrm{T} 406}, \mathrm{PO}, \mathrm{C}-\right]^{5}$ repressed cell division and frequently displayed 
dead cells, whereas $[\mathrm{N}-, \mathrm{P}-, \mathrm{CO}]^{12}$ and $\left[\mathrm{N}^{-{ }^{4} 406}, \mathrm{P}-, \mathrm{CO}^{6}\right.$ were equally, or even more actively blocking meristematic and stem cell division without inducing cell death (Figs 2-4). Contrary to previously observed pleiotropic effects in knock-out or altered expression approaches, our findings revealed the capacity of RBR to independently regulate cell division, differentiation and survival according to its phosphorylation state.

We found increased cell death in roots of both phosho-mimetic and phospho-defective variants. Accordingly, apoptotic stimuli can promote phosphorylation as well as de-phosphorylation of pRb (De Leon et al., 2008; Nath et al., 2003); pRb in turn, can either promote or inhibit apoptosis (Antonucci et al., 2014; Goodrich, 2006; lanari et al., 2009), a fate decision largely mediated by its phosphorylation state (Antonucci et al., 2014; Egger et al., 2016; Gubern et al., 2016; Lee et al., 2018; De Leon et al., 2008; Nath et al., 2003). Which particular phosphorylation state is preferred, and what outcome it takes might depend on circumstances. In plants, biotrophic attackers promote RBR hyper-phosphorylation to trigger immunity-related PCD (Wang et al., 2014a), correlating with our fully phospho-mimetic variant. We speculate that rapid immune responses to pathogen attack, sensed and signaled by phospho-relay cascades, prioritize an urgently required activation of PCD to avoid infection spread. On the other hand a proper balance between cell division, differentiation, and developmental PCD could involve a more accurate, finely-tuned mechanism. Probably this includes coordinated action of CDKs and phosphatases, reflected by the combinatorial specificity of our phospho-defective variants triggering cell death and inhibiting cell division (Fig 4, 5L). Thus, hyper-phosphorylation of RBR may well act "quick and dirty" to counteract stresses, while combinatorial phosphorylation entails a timely coordination of cell fate decisions.

Great endeavors in the late 90s utilized systematic mutagenesis to understand the functional nature of pRb phosphorylation (Barrientes et al., 2000; Brown et al., 1999; Knudsen and Wang, 1997, 1996; Knudsen et al., 1999), pointing to a combinatorial role in pRb regulation (Munro et al., 2012; Rubin, 2013). But this notion found defiance in recent years based on a report where $\mathrm{pRb}$ was found in only three states in cellular lines: un-phosphorylated, hyperphosphorylated and mono-phosphorylated (Narasimha et al., 2014). A more recent report (Sanidas et al., 2019), recaptured the concept of the phosphorylation code, but focused on mono-phosphorylated isoforms. In that study, the authors found that more than one third of the $\mathrm{pRb}$ interactome (434 proteins) bind neither un-phosphorylated nor any of the 14 mono-phosphorylated variants, and assumed that this portion of the interactions correspond to hyper-phosphorylated pRb (Sanidas et al., 2019). Since the phenotypes of our fully phospho-mimetic variant suggest that hyper-phosphorylated RBR is mostly inactive, we believe more evidence is needed before the possibility of intermediate phosphorylation states of RB proteins is overthrown. Particularly, investigation of $\mathrm{pRb}$ phosphorylation states in whole-organism context remains a future challenge. 
To our knowledge, this is the first systematic study of RBR phospho-variants in a full organismal context. We did not determine the existence of intermediate phosphorylation RBR isoforms, but our "artificial" phospho-variants recapitulated functional outcomes of RBR, implying its potential to "understand" a combinatorial phosphorylation code modulated by additive effects. We are aware that not all putative phospho-sites have been confirmed in vivo, but all phospho-defective variants showed at least a mild and additive effect, implying that at least the majority of phospho-sites are functional. Two shortcomings in our approach are the potential effect of residual RBR in the amiGO genetic background, and the static nature of the phosphorylation substitutions -contrasting with the dynamics entailed by phosphorylation-dependent regulation of a multifunctional protein, achieved by concerted action of CDKs and phosphatases. The former issue could be addressed by postembryonic gene editing to generate a postembryonic rbr null background; the latter would require thorough characterization of the endogenous phosphorylation isoforms of RBR within its diverse spatio-temporal contexts. In this regard, single-cell and single-molecule approaches promise an exciting future for RB protein biology.

Our results support a combinatorial RBR-phosphorylation code in plants -whose sessile nature requires precise coordination of cell fate decisions and environmental responsesand suggest that distinct CYC-CDKs complexes target RBR phospho-sites with distinct affinities as is the case for CYCDs on pRb (Paternot et al., 2006). Accordingly, residues T406 and S911 are preferentially phosphorylated by CYCA3;4, whose overexpression results in RBR-associated phenotypes (Willems et al., 2020); and CYCD6;1, a developmental and stress-responding gene (Bertolotti et al., 2020; Cruz-Ramírez et al., 2012; Zhou et al., 2019), drives the kinase activity of CDKB1 to the Pocket domain (Cruz Ramirez 2012). The distinct expression patterns of CYC genes (Collins et al., 2012; Menges et al., 2005), the intricate regulation of CDK activity (Sanz et al., 2011), and their substrate-specificity, all suggest a complex mechanism to orchestrate RBR multiple functions during the plant life cycle, posing new challenges to our understanding of RBR regulatory networks.

On the same track, RBR-protein interactions mediated by the B-pocket constitute a major component of phosphorylation-mediated functions of RBR (Fig 6), pointing out to proteins containing an LXCXE motif. Noteworthy, RB interactions with LXCXE-containing proteins, both in plants and animals, play prominent roles to sustain differentiation and growth arrest decisions (Chen and Wang, 2000; Cruz-Ramírez et al., 2012; Matos et al., 2014), and to withstand stressful growth conditions (Bourgo et al., 2011; Collins et al., 2015; CruzRamírez et al., 2013; Zhou et al., 2019). The partial rescue of all phenotypes associated to highly substituted phospho-defective variants by the NF mutation reveals the vast importance of LXCXE protein interactions. At the same time, it also points to the existence of a LXCXEindependent component in the phosphorylation-dependent functions of RBR; obvious candidates are the functions mediated by E2F proteins, central players not only in cell cycle, 
but in developmental and stress-related processes (Berckmans et al., 2011b, 2011a; Gómez et al., 2019; Henriques et al., 2013; Horvath et al., 2017; Magyar et al., 2005; Oszi et al., 2020; del Pozo et al., 2002; Wang et al., 2014a). Together with our findings and the role of CYCDs in both processes (Forzani et al., 2014; Han et al., 2018; Weimer et al., 2018; Zhou et al., 2019), the integrative functions of RBR (Harashima and Sugimoto, 2016) seem to rely on the dynamic phosphorylation-regulated RBR-LXCXE, and possibly RBR-E2F interactions.

Altogether, we have taken first steps to "decipher" RBR phosphorylation code. In addition, our RBR phospho-variants collection and combinable phospho-modules represent a steppingstone for future research. On the one hand, characterization of in vivo-phosphorylated sites under environmentally varying conditions may guide the choices to expand the collection. On the other hand, using the collection for cell-type specific, high-throughput experiments (proteomics, Chip-seq, INTACT, ATAC, RNA-seq), and studies on CYC-CDK specificities could help to understand RBR networks throughout development and stress responses. Since RBR is a multifunctional growth regulatory protein, implementation of RBR phosphorylation codes in crops could help to face future food security challenges.

\section{Materials and methods}

\section{Plant Material and growth conditions}

Arabidopsis thaliana ecotype Col-0 was used as wild-type control. Unless otherwise noticed, amiGO-RBR (Cruz-Ramírez et al., 2013) was used as genetic background for transgenic plants. Seeds were fume-sterilized in a sealed container with $100 \mathrm{ml}$ bleach and $3 \mathrm{ml}$ of $37 \%$ hydrochloric acid for $3-5 \mathrm{~h}$; then suspended in $0.1 \%$ agarose, stratified for $2 \mathrm{~d}$ (4 $\mathrm{d}$ for arrested embryos) at $4 \stackrel{\circ}{ } \mathrm{C}$ in darkness, plated on $0.5 \mathrm{x}$ Murashige and Skoog (MS) plus vitamins, $1 \%$ sucrose, $0.5 \mathrm{~g} / \mathrm{l} 2$-(N-morpholino) ethanesulfonic acid (MES) at $\mathrm{pH} 5.8$, and $0.8 \%$ plant agar, and grown vertically for $6 \mathrm{~d}\left(4 \mathrm{~d}\right.$ for arrested embryos) at $22^{\circ} \mathrm{C}$ with a $16 \mathrm{~h}$ light/8h dark cycle. For cytological analysis of reproductive organs seeds were germinated in Murashige and Skoog (MS) medium under short-day conditions (16 h light/8 h dark) at $25{ }^{\circ} \mathrm{C}$. Seedlings were then transplanted to soil and grown in a greenhouse under long-day conditions. Fully developed siliques containing seeds with cotyledonary embryos from at least five individuals per genotype were dissected before dehiscence and examined under a stereomicroscope Leica. The number of unfertilized ovules; normal and collapsed seeds were counted in each silique. Gyneocia were dissected longitudinally with hypodermic needles (1 $\mathrm{ml}$ insulin syringes; Becton Dickinson) and fixed with FAA buffer (50\% ethanol, $5 \%$ acetic acid, and $10 \%$ formaldehyde), dehydrated in increasing ethanol concentration, cleared in Herr's solution [phenol:chloral hydrate:85\% lactic acid:xylene:clove oil (1:1:1:0.5:1), and observed with a Leica microscope (Wetzlar, Germany) under Nomarski illumination. 


\section{RBR phospho-variants plasmid construction and Plant transformation and transgenic selection.}

The goldengate modular cloning (MoClo) system for plants (Engler et al., 2014) was used to generate all phospho-variants. A detailed description of phospho-variants cloning is offered in supplemental methods. Level 2 constructs were transformed in homozygous amiGO plants by flower dip method. Primary tansformants were selected for fuorescent red seed coats under a fluorescence microscope; at least 16 primary transformants were visualized with confocal laser scanning microscopy (CLSM) and selected for the presence of nuclear SCFP3A signal. At least two independent lines were taken to homozygous T3 generation for phenotyping.

\section{Microscopy}

A $10 \mu \mathrm{g} / \mathrm{mL}$ Propidium lodide staining solution was used for whole-mount visualization of live roots with CLSM using a Zeiss LSM 710 system as described in (Zhou et al., 2019). For arrested embryos, seed coats were removed as described in (Lee and Lopez-Molina, 2013); modified pseudo-Schiff propidium iodide (mPS-PI) staining of roots and embryos was performed as described in (Zhou et al., 2019). Images were taken with ZEN 2012 software (Zeiss) and processed with ImageJ software, using the Stitching Plug-in stitchin multiple images.Brightness and contrast of the final figures was enhanced to the exact same values except for figure S3B,C, where CLSM and brightness/contrast parameters were maximized due to the very weak SCFP3A signal. DIC images of gametophytes were obtained with a Nomarsky illumination Leica DRM system.

\section{Phenotypic analysis}

At least two independent transgenic lines for each genotype were analysed in at least two independent occasions. For the three phenotypes analysed (meristem size, stem cell proliferation and cell death), independent replicates of each line were compared among them; and independent lines of the same genotype we compared among them, with no significant difference. Each line was compared with the Col-0 control, obtaining similar results for each line of the same genotype. Only one line is presented for each genotype. Quantification of the root meristem size was done by imaging the median longitudinal section of the root tip and averaging the number of cortex cells from the $Q C$ to the first rapidly elongating cell in the two visible cortex layers; and by measuring and averaging the distance spanned by these cells. Cell death was quantified as the percentage of root tips presenting dead cells as visualized with PI and scanning throughout the Z-axis. Stem cells were visualized by mPS-PI staining and imaging the median longitudinal section of the root tip. Statistical analysis was performed by a One-way ANOVA followed by Dunnett's multiple comparisons test was performed using GraphPad Prism version 5.0.0 for Windows, GraphPad Software, San Diego, California USA www.graphpad.com. Histological analysis of female gametophytes was performed with one line per genotype as described above. 


\section{Cloning of RBR phospho-variants}

All primers used for cloning, carrying relevant restriction sites and 4 bp overhangs were designed using the Primer3 software (Untergasser et al., 2012) and are listed in Table S1.The CDS of Wt RBR was amplified in three fragments, namely NO, ABO, CO, with the primer pairs RBR_n1_WT_F / RBR_n3_WT_R, RBR_AB_F / RBR_AB_R, RBR_C_F / RBR_C_R. Each fragment was cloned in level -1 vector pAGM1311 (generating pAGM1311-RBR_N0, pAGM1311-RBR_AB0, and pAGM1311-RBR_C0). To clone the phospho-defective ( $\mathrm{N}-$ ) and phospho-mimetic $(\mathrm{N}+)$ mutant modules, we divided the $\mathrm{N}$ fragment it in three subfragments (namely $n 1, n 2, n 3$ ); fragments $n 1$ and $n 2$ were amplified with primers that introduced the corresponding mutation in the phospho-sites T9 and S290: RBR_n1_T9D F / RBR_n1_S290D_R, and RBR_n1_T9A_F / RBR_n1_S290A_R for n1; RBR_n2_S290D_F / RBR_ $n 2 \_R$, and RBR_n2_S290A_F / RBR_n2_R for n2. Mutations in the remaining phospho-sites of module $\mathrm{N}$, were introduced by a synthetic probe, corresponding to $\mathrm{n} 3$ fragment, carrying the corresponding mutant codons. The single stranded n3 probes were complemented to double stranded DNA using the n3RvComp primer in a Klenow fragment reaction (Thermo Scientific ${ }^{\mathrm{TM}}$, EP0421). Phospho-defective and phospho-mimetic fragments $n 1, n 2, n 3$ were assembled and cloned into pAGM1311 vector to generate $\mathrm{N}$ - and $\mathrm{N}+$ modules (pAGM1311RBR_N- and pAGM1311-RBR_N+). Phosphorylation mutations in the $A B$ and $C$ regions were obtained amplifying the relevant fragments from pre-existing unpublished phosphorylation mutants (generated by serial rounds of directed mutagenesis) with the same primer paris as for the wild type fragments. The amplicons were cloned into pAGM1311 (pAGM1311-RBR $A B+$, pAGM1311-RBR_AB-, pAGM1311-RBR_C+, pAGM1311-RBR_C-). The NT406 mutant modules were obtained by amplifying the corresponding wild type RBR CDS fragment with the primer pairs RBR_n1_WT_F / n3T406A_R, and RBR_n1_WT_F/n3T406E_R, and cloning into pAGM1311 (pAGM1311-RBR_NT406- and pAGM1311-RBR_NT406+). The N849F mutation was introduced in the $\mathrm{CO}$ and $\mathrm{C}$ - modules by amplifying two overlapping fragments from the corresponding level -1 modules with the primer pairs RBR_C_F / N849F_R for the first fragment, and N849F_F / RBR_C_R for the second one; both fragments for each $C$ module (wild type and phospho-defective) were assembled and cloned in pAGM1311 vector (pAGM1311-RBRNF_C0 and pAGM1311-RBRNF_C-).

The combinations of level -1 modules specified in figure S1 were assembled into level 0 vector pAGM1287, creating full length RBR CDS of the corresponding phospho-variant (pAGM1287-RBR_N*AB* $C^{*}$, where “*” indicates the diverse phospho-modules). For RBR promoter, the intergenic region comprising 1150 bp upstream of the ATG was amplified with primer pair GGpRBR_F / GGpRBR_R, that removed internal Bpil sites, and then cloned into level 0 pICH41295 vector (pICH41294-pRBR). The CDS of the SCFP3A fluorescent protein was amplified with the primer pair GGvYFP_F / GGvYFP_R from an existing clone and sub-cloned into level 0 pAGM1301 vector (pAGM1301-SCFP3A). Each pAGM1287-RBR_N*AB*C* was then combined with pICH41295-pRBR, pAGM1301-SCFP3A, and pICH41421-NosT (from the 
MoClo toolbox) into level 1 pICH47742 vector (pICH47742-pRBR_RBR_N*AB*C*_SCFP3A_ NosT). Level 1 phospho-variants were cloned into level 2 pAGM4723 vector together with the pICH47732-FAST-R selection marker cassette. All digestion-ligation reactions were performed using $30 \mathrm{fmol}$ of the relevant fragments, plasmids and vector, 1x Green buffer (Thermo Scientific ${ }^{\mathrm{TM}}$, No.), $1 \mu \mathrm{M}$ ATP (Thermo Scientific ${ }^{\mathrm{TM}}$ ), either 1 unit/ $\mu \mathrm{L}$ Bsal or Bpil enzymes (Thermo Scientific ${ }^{\mathrm{TM}}$ ), T4 DNA ligase (Thermo Scientific ${ }^{\mathrm{TM}}$ ) and water to a final volume of $15 \mu \mathrm{L}$. 


\section{References}

Ach, R.A., Durfee, T., Miller, A.B., Taranto, P., Hanley-Bowdoin, L., Zambryski, P.C., and Gruissem, W. (1997). RRB1 and RRB2 encode maize retinoblastoma-related proteins that interact with a plant D-type cyclin and geminivirus replication protein. Mol. Cell. Biol. 17, 5077-5086.

Antonucci, L.A., Egger, J. V., and Krucher, N.A. (2014). Phosphorylation of the Retinoblastoma protein (RB) on serine-807 is required for association with Bax. Cell Cycle 13, 3611-3617.

Barrientes, S., Cooke, C., and Goodrich, D.W. (2000). Glutamic acid mutagenesis of retinoblastoma protein phosphorylation sites has diverse effects on function. Oncogene 19, 562-570.

Berckmans, B., Lammens, T., Daele, H. Van Den, Magyar, Z., Bogre, L., and Veylder, L. De (2011a). LightDependent Regulation of DEL1 Is Determined by the Antagonistic Action of E2Fb and E2Fc. Plant Physiol. 157, 1440-1451.

Berckmans, B., Vassileva, V., Schmid, S.P.C., Maes, S., Parizot, B., Naramoto, S., Magyar, Z., Lessa Alvim Kamei, C., Koncz, C., Bögre, L., et al. (2011b). Auxin-Dependent cell cycle reactivation through transcriptional regulation of arabidopsis E2Fa by lateral organ boundary proteins. Plant Cell 23, 3671-3683.

Bertolotti, G., Unterholzner, S.J., Scintu, D., Salvi, E., Svolacchia, N., Di Mambro, R., Ruta, V., Linhares Scaglia, F., Vittorioso, P., Sabatini, S., et al. (2020). A PHABULOSA-Controlled Genetic Pathway Regulates Ground Tissue Patterning in the Arabidopsis Root. Curr. Biol. 31, 1-7.

Biedermann, S., Harashima, H., Chen, P., Heese, M., Bouyer, D., Sofroni, K., and Schnittger, A. (2017). The retinoblastoma homolog RBR1 mediates localization of the repair protein RAD51 to DNA lesions in Arabidopsis. EMBO J. 36, 1279-1297.

Borghi, L., Gutzat, R., Fütterer, J., Laizet, Y., Hennig, L., and Gruissem, W. (2010). Arabidopsis RETINOBLASTOMA-RELATED Is Required for Stem Cell Maintenance, Cell Differentiation, and Lateral Organ Production. Plant Cell 22, 1792-1811.

Bourgo, R.J., Thangavel, C., Ertel, A., Bergseid, J., Kathleen McClendon, A., Wilkens, L., Witkiewicz, A.K., Wang, J.Y.J., and Knudsen, E.S. (2011). RB Restricts DNA Damage-Initiated Tumorigenesis through an LXCXE-Dependent Mechanism of Transcriptional Control. Mol. Cell 43, 663-672.

Brown, V.D., Phillips, R.A., and Gallie, B.L. (1999). Cumulative Effect of Phosphorylation of pRB on Regulation of E2F Activity. Mol. Cell. Biol. 19, 3246-3256.

Burke, J.R., Deshong, A.J., Pelton, J.G., and Rubin, S.M. (2010). Phosphorylation-induced Conformational Changes in the Retinoblastoma Protein Inhibit E2F Transactivation Domain Binding. J. Biol. Chem. 285, 16286-16293.

Burke, J.R., Hura, G.L., and Rubin, S.M. (2012). Structures of inactive retinoblastoma protein reveal multiple mechanisms for cell cycle control. Genes Dev. 26, 1156-1166.

Burke, J.R., Liban, T.J., Restrepo, T., Lee, H.W., and Rubin, S.M. (2014). Multiple mechanisms for E2F binding inhibition by phosphorylation of the retinoblastoma protein C-terminal domain. J. Mol. Biol. 426, 245-255.

Chen, T., and Wang, J.Y.J. (2000). Establishment of Irreversible Growth Arrest in Myogenic Differentiation Requires the RB LXCXE-Binding Function. Mol. Cell. Biol. 20, 5571-5580. 
Chen, P., Takatsuka, H., Takahashi, N., Kurata, R., Fukao, Y., Kobayashi, K., Ito, M., and Umeda, M. (2017). Arabidopsis R1R2R3-Myb proteins are essential for inhibiting cell division in response to DNA damage. Nat. Commun. 8, 1-12.

Chen, Z., Higgins, J.D., Hui, J.T.L., Li, J., Franklin, F.C.H., and Berger, F. (2011). Retinoblastoma protein is essential for early meiotic events in Arabidopsis. EMBO J. 30, 744-755.

Collins, C., Dewitte, W., and Murray, J.A.H. (2012). D-type cyclins control cell division and developmental rate during Arabidopsis seed development. J. Exp. Bot. 63, 3571-3586.

Collins, C., Maruthi, M.N., and Jahn, C.E. (2015). CYCD3 D-type cyclins regulate cambial cell proliferation and secondary growth in Arabidopsis. J. Exp. Bot. 66, 4595-4606.

Cruz-Ramírez, A., Díaz-Triviño, S., Blilou, I., Grieneisen, V.A., Sozzani, R., Zamioudis, C., Miskolczi, P., Nieuwland, J., Benjamins, R., Dhonukshe, P., et al. (2012). A Bistable Circuit Involving SCARECROW- RETINOBLASTOMA Integrates Cues to Inform Asymmetric Stem Cell Division. Cell 150, 1002-1015.

Cruz-Ramírez, A., Diaz-trivino, S., Wachsman, G., Du, Y., Arteaga-Vazquez, M., Zhang, H., Benjamins, R., Blilou, I., Neef, A.B., Chandler, V., et al. (2013). A SCARECROW-RETINOBLASTOMA Protein Network Controls Protective Quiescence in the Arabidopsis Root Stem Cell Organizer. PLoS Biol. 11, e1001724.

Demesa-Arévalo, E., and Vielle-Calzada, J.P. (2013). The classical arabinogalactan protein AGP18 mediates megaspore selection in Arabidopsis. Plant Cell 25, 1274-1287.

Desfeux, C., Clough, S.J., and Bent, A.F. (2000). Female Reproductive Tissues Are the Primary Target of Agrobacterium-mediated Transformation by the Arabidopsis Floral-Dip Method. Plant Physiol. 123, 895-904.

Desvoyes, B., and Gutierrez, C. (2020). Roles of plant retinoblastoma protein: cell cycle and beyond. EMBO J. 39, 1-18.

Desvoyes, B., De Mendoza, A., Ruiz-Trillo, I., and Gutierrez, C. (2014). Novel roles of plant RETINOBLASTOMA-RELATED (RBR) protein in cell proliferation and asymmetric cell division. J. Exp. Bot. 65, 2657-2666.

Dick, F.A., and Rubin, S.M. (2013). Molecular mechanisms underlying RB protein function. Nat. Rev. Mol. Cell Biol. 14, 297-306.

Dissmeyer, N., and Schnittger, A. (2011). Use of Phospho-Site Substitutions to Analyze the Biological Relevance of Phosphorylation Events in Regulatory Networks. In Methods in Molecular Biology, N. Dissmeyer, and A. Schnittger, eds. (New York: Humana Press), pp. 93-138.

Ebel, C., Mariconti, L., and Gruissem, W. (2004). Plant retinoblastoma homologues control nuclear proliferation in the female gametophyte. Nature 429, 776-780.

Egger, J. V, Lane, M. V, Antonucci, L.A., Dedi, B., and Krucher, N.A. (2016). Dephosphorylation of the Retinoblastoma protein ( $\mathrm{Rb})$ inhibits cancer cell EMT via Zeb. Cancer Biol. Ther. 17, 1197-1205. Engler, C., Youles, M., Gruetzner, R., Ehnert, T.M., Werner, S., Jones, J.D.G., Patron, N.J., and Marillonnet, S. (2014). A Golden Gate modular cloning toolbox for plants. ACS Synth. Biol. 3, 839-843.

Forzani, C., Aichinger, E., Sornay, E., Willemsen, V., Laux, T., Dewitte, W., and Murray, J.A.H. (2014). WOX5 suppresses CYCLIN D activity to establish quiescence at the Center of the root stem cell 
niche. Curr. Biol. 24, 1939-1944.

Gómez, M.S., Falcone Ferreyra, M.L., Sheridan, M.L., and Casati, P. (2019). Arabidopsis E2Fc is required for the DNA damage response under UV-B radiation epistatically over the microRNA396 and independently of E2Fe. Plant J. 97, 749-764.

Goodrich, D.W. (2006). The retinoblastoma tumor-suppressor gene, the exception that proves the rule. Oncogene 25, 5233-5243.

Grafi, G., Burnett, R.J., Helentjaris, T.I.M., Larkins, B.A., DeCaprio, J.A., Sellers, W.R., and Kaelin Jr, W.G. (1996). A maize cDNA encoding a member of the retinoblastoma protein family: Involvement in endoreduplication. Proc. Natl. Acad. Sci. 93, 8962-8967.

Gubern, A., Joaquin, M., Marquès, M., Maseres, P., Garcia-Garcia, J., Amat, R., González-Nuñez, D., Oliva, B., Real, F.X., de Nadal, E., et al. (2016). The N-Terminal Phosphorylation of RB by p38 Bypasses Its Inactivation by CDKs and Prevents Proliferation in Cancer Cells. Mol. Cell 64, 25-36.

Gutierrez, C. (2005). Coupling cell proliferation and development in plants. Nat. Cell Biol. 7, 535-541.

Gutzat, R., Borghi, L., Futterer, J., Bischof, S., Laizet, Y., Hennig, L., Feil, R., Lunn, J., and Gruissem, W. (2011). RETINOBLASTOMA-RELATED PROTEIN controls the transition to autotrophic plant development. Development 138, 2977-2986.

Gutzat, R., Borghi, L., and Gruissem, W. (2012). Emerging roles of RETINOBLASTOMA-RELATED proteins in evolution and plant development. Trends Plant Sci. 17, 139-148.

Han, S., Qi, X., Sugihara, K., Dang, J.H., Endo, T.A., Miller, K.L., Kim, E., Miura, T., and Torii, K.U. (2018). MUTE Directly orchestrates Cell State switch and the Single Symmetric Division to create stomata. Dev. Cell 45, 303-315.

Harashima, H., and Sugimoto, K. (2016). Integration of developmental and environmental signals into cell proliferation and differentiation through RETINOBLASTOMA-RELATED 1. Curr. Opin. Plant Biol. 29, 95-103.

Henriques, R., Magyar, Z., and Bögre, L. (2013). S6K1 and E2FB are in mutually antagonistic regulatory links controlling cell growth and proliferation in Arabidopsis. Plant Signal. Behav. 8, 37-41.

Horvath, B.M., Kourova, H., Nagy, S., Nemeth, E., Magyar, Z., Papdi, C., Ahmad, Z., Sanchez-perez, G.F., Perilli, S., Blilou, I., et al. (2017). Arabidopsis RETINOBLASTOMA RELATED directly regulates DNA damage responses through functions beyond cell cycle control. EMBO J. 36, 1261-1278.

Ianari, A., Natale, T., Calo, E., Ferretti, E., Alesse, E., Screpanti, I., Haigis, K., Gulino, A., and Lees, J.A. (2009). Proapoptotic function of the retinoblastoma tumor suppressor protein. Cancer Cell 15, 184-194.

Knudsen, E.S., and Wang, J.Y. (1997). Dual mechanisms for the inhibition of E2F binding to RB by cyclindependent kinase-mediated RB phosphorylation. Mol. Cell. Biol. 17, 5771-5783.

Knudsen, E.S., and Wang, J.Y.J. (1996). Differential regulation of retinoblastoma protein function by specific Cdk phosphorylation sites. J. Biol. Chem. 271, 8313-8320.

Knudsen, K.E., Weber, E., Arden, K.C., Cavenee, W.K., Feramisco, J.R., and Knudsen, E.S. (1999). The retinoblastoma tumor suppressor inhibits cellular proliferation through two distinct mechanisms: Inhibition of cell cycle progression and induction of cell death. Oncogene 18, 5239-5245.

Kobayashi, K., Suzuki, T., Iwata, E., Nakamichi, N., Suzuki, T., Chen, P., Ohtani, M., Ishida, T., Hosoya, 
H., Müller, S., et al. (2015). Transcriptional repression by MYB 3R proteins regulates plant organ growth. EMBO J. 34, 1992-2007.

Lee, K.P., and Lopez-Molina, L. (2013). A Seed Coat Bedding Assay to Genetically Explore In Vitro How the Endosperm Controls Seed Germination in Arabidopsis thaliana. J. Vis. Exp. 81.

Lee, H.J., Lee, W.K., Kang, C.W., Ku, C.R., Cho, Y.H., and Lee, E.J. (2018). A selective cyclin-dependent kinase 4, 6 dual inhibitor, Ribociclib (LEE011) inhibits cell proliferation and induces apoptosis in aggressive thyroid cancer. Cancer Lett. 417, 131-140.

De Leon, G., Sherry, T.C., and Krucher, N.A. (2008). Reduced expression of PNUTS leads to activation of Rb-phosphatase and caspase-mediated apoptosis. Cancer Biol. Ther. 7, 833-841.

Magyar, Z., De Veylder, L., Atanassova, A., Bakó, L., Inzé, D., and Bögre, L. (2005). The role of the Arabidopsis E2FB transcription factor in regulating auxin-dependent cell division. Plant Cell 17, 2527-2541.

Matos, J.L., Lau, O.S., Hachez, C., Cruz-Ramírez, A., Scheres, B., and Bergmann, D.C. (2014). Irreversible fate commitment in the Arabidopsis stomatal lineage requires a FAMA and RETINOBLASTOMARELATED module. Elife 3, 1-15.

Menges, M., De Jager, S.M., Gruissem, W., and Murray, J.A.H. (2005). Global analysis of the core cell cycle regulators of Arabidopsis identifies novel genes, reveals multiple and highly specific profiles of expression and provides a coherent model for plant cell cycle control. Plant J. 41, 546-566.

Munro, S., Carr, S.M., and La Thangue, N.B. (2012). Diversity within the pRb pathway: Is there a code of conduct. Oncogene 31, 4343-4352.

Narasimha, A.M., Kaulich, M., Shapiro, G.S., Choi, Y.J., Sicinski, P., and Dowdy, S.F. (2014). Cyclin D activates the $\mathrm{Rb}$ tumor suppressor by mono-phosphorylation. Elife 3, 1-21.

Nath, N., Wang, S., Betts, V., Knudsen, E., and Chellappan, S. (2003). Apoptotic and mitogenic stimuli inactivate $\mathrm{Rb}$ by differential utilization of p38 and cyclin-dependent kinases. Oncogene 22, 5986-5994.

Ning, Y., Liu, N., Lan, K., Su, Y., Li, L., Chen, S., and He, X. (2020). DREAM complex suppresses DNA methylation maintenance genes and precludes DNA hypermethylation. Nat. Plants 6, 942-956.

Oszi, E., Papdi, C., Mohamed, B., Petkó-szandtner, A., Leviczky, T., Molnár, E., Galvan-ampudia, C., Khan, S., Lopez-Juez, E., Horváth, B., et al. (2020). E2FB Interacts with RETINOBLASTOMA RELATED and Regulates Cell Proliferation during Leaf Development. Plant Physiol. 182, 518-533.

Paternot, S., Arsenijevic, T., Coulonval, K., Bockstaele, L., Dumont, J.E., and Roger, P.P. (2006). Distinct specificities of pRb phosphorylation by CDK4 activated by cyclin D1 or cyclin D3: Differential involvement in the distinct mitogenic modes of thyroid epithelial cells. Cell Cycle 5, 61-70.

Perilli, S., Perez-Perez, J.M., Di Mambro, R., Peris, C.L., Díaz-Triviño, S., Del Bianco, M., Pierdonati, E., Moubayidin, L., Cruz-Ramírez, A., Costantino, P., et al. (2013). RETINOBLASTOMA-RELATED protein stimulates cell differentiation in the Arabidopsis root meristem by interacting with cytokinin signaling. Plant Cell 25, 4469-4478.

del Pozo, J.C., Boniotti, M.B., and Gutierrez, C. (2002). Arabidopsis E2Fc Functions in Cell Division and Is Degraded by the Ubiquitin-SCF AtSKP2 Pathway in Response to Light. Plant Cell 14, 3057-3071. Rubin, S.M. (2013). Deciphering the retinoblastoma protein phosphorylation code. Trends Biochem. 
Sci. 38, 12-19.

Rubin, S.M., Gall, A.L., Zheng, N., and Pavletich, N.P. (2005). Structure of the Rb C-terminal domain bound to E2F1-DP1: A mechanism for phosphorylation-induced E2F release. Cell 123, 1093-1106.

Sablowski, R., and Carnier Dornelas, M. (2014). Interplay between cell growth and cell cycle in plants. J. Exp. Bot. 65, 2703-2714.

Sanidas, I., Morris, R., Fella, K.A., Rumde, P.H., Boukhali, M., Tai, E.C., Ting, D.T., Lawrence, M.S., Haas, W., and Dyson, N.J. (2019). A Code of Mono-phosphorylation Modulates the Function of RB. Mol. Cell 73, 985-1000.e6.

Sanz, L., Dewitte, W., Forzani, C., Patell, F., Nieuwland, J., Wen, B., Quelhas, P., de Jager, S., Titmus, C., Campilho, A., et al. (2011). The Arabidopsis D-Type Cyclin CYCD2;1 and the Inhibitor ICK2/KRP2 Modulate Auxin-Induced Lateral Root Formation. Plant Cell 23, 641-660.

Untergasser, A., Cutcutache, I., Koressaar, T., Ye, J., Faircloth, B.C., Remm, M., and Rozen, S.G. (2012). Primer3-new capabilities and interfaces. Nucleic Acids Res. 40, 1-12.

Wachsman, G., Heidstra, R., and Scheres, B. (2011). Distinct cell-autonomous functions of RETINOBLASTOMA-RELATED in Arabidopsis stem cells revealed by the brother of Brainbow Clonal analysis system. Plant Cell 23, 2581-2591.

Wang, S., Gu, Y., Zebell, S.G., Anderson, L.K., Wang, W., Mohan, R., and Dong, X. (2014a). A noncanonical role for the CKI-RB-E2F cell-cycle signaling pathway in plant effector-triggered immunity. Cell Host Microbe 16, 787-794.

Wang, W., Zhang, J., Qin, Q., Yue, J., Huang, B., Xu, X., Yan, L., and Hou, S. (2014b). The six conserved serine/threonine sites of REPRESSOR OF ga1-3 protein are important for its functionality and stability in gibberellin signaling in Arabidopsis. Planta 240, 763-779.

Weimer, A.K., Biedermann, S., Harashima, H., Roodbarkelari, F., Takahashi, N., Foreman, J., Guan, Y., Pochon, G., Heese, M., Van Damme, D., et al. (2016). The plant-specific CDKB 1- CYCB 1 complex mediates homologous recombination repair in Arabidopsis. EMBO J. 35, 2068-2086.

Weimer, A.K., Matos, J.L., Sharma, N., Patell, F., Murray, J.A.H., Dewitte, W., and Bergmann, D.C. (2018). Lineage- and stage-specific expressed CYCD7;1 coordinates the single symmetric division that creates stomatal guard cells. Development 145, dev160671.

Wen, B., Nieuwland, J., and Murray, J.A.H. (2013). The Arabidopsis CDK inhibitor ICK3/KRP5 is rate limiting for primary root growth and promotes growth through cell elongation and endoreduplication. J. Exp. Bot. 64, 1135-1144.

Wildwater, M., Campilho, A., Perez-Perez, J.M., Heidstra, R., Blilou, I., Korthout, H., Chatterjee, J., Mariconti, L., Gruissem, W., and Scheres, B. (2005). The RETINOBLASTOMA-RELATED gene regulates stem cell maintenance in Arabidopsis roots. Cell 123, 1337-1349.

Willems, A., Heyman, J., Eekhout, T., Achon, I., Pedroza-Garcia, J.A., Zhu, T., Li, L., Vercauteren, I., Van den Daele, H., van de Cotte, B., et al. (2020). The cyclin CYCA3;4 is a postprophase target of the APC/CCCS52A2 E3-ligase controlling formative cell divisions in arabidopsis. Plant Cell 32, 2979-2996.

Xie, Q., Sanz-Burgos, A.P., Hannon, G.J., and Gutiérrez, C. (1996). Plant cells contain a novel member of the retinoblastoma family of growth regulatory proteins. EMBO J. 15, 4900-4908. 
Yi, D., Kamei, C.L.A., Cools, T., Vanderauwera, S., Takahashi, N., Okushima, Y., Eekhout, T., Yoshiyama, K.O., Larkin, J., Van den Daele, H., et al. (2014). The Arabidopsis SIAMESE-RELATED cyclindependent Kinase Inhibitors SMR5 and SMR7 Regulate the DNA damage checkpoint in response to reactive oxygen species. Plant Cell 26, 296-309.

Zhao, X., Bramsiepe, J., Van Durme, M., Komaki, S., Prusicki, M.A., Maruyama, D., Forner, J., Medzihradszky, A., Wijnker, E., Harashima, H., et al. (2017). RETINOBLASTOMA RELATED1 mediates germline entry in Arabidopsis. Science (80-. ). 356.

Zhou, W., Lozano-Torres, J.L., Blilou, I., Zhang, X., Zhai, Q., Smant, G., Li, C., and Scheres, B. (2019). A Jasmonate Signaling Network Activates Root Stem Cells and Promotes Regeneration. Cell 177, 942-956.e14. 


\section{Supplementary Information}
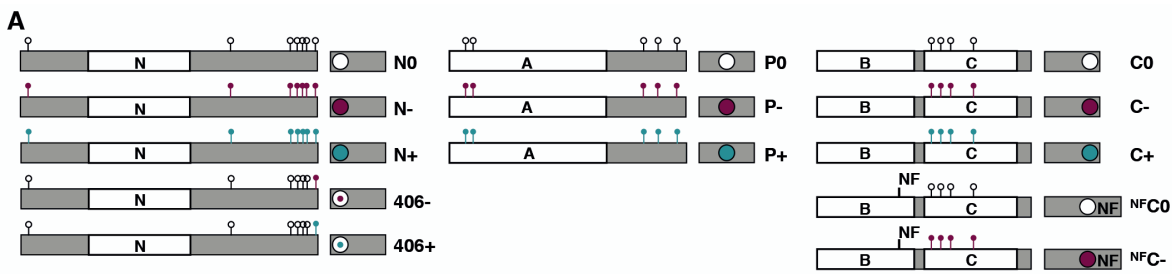

B

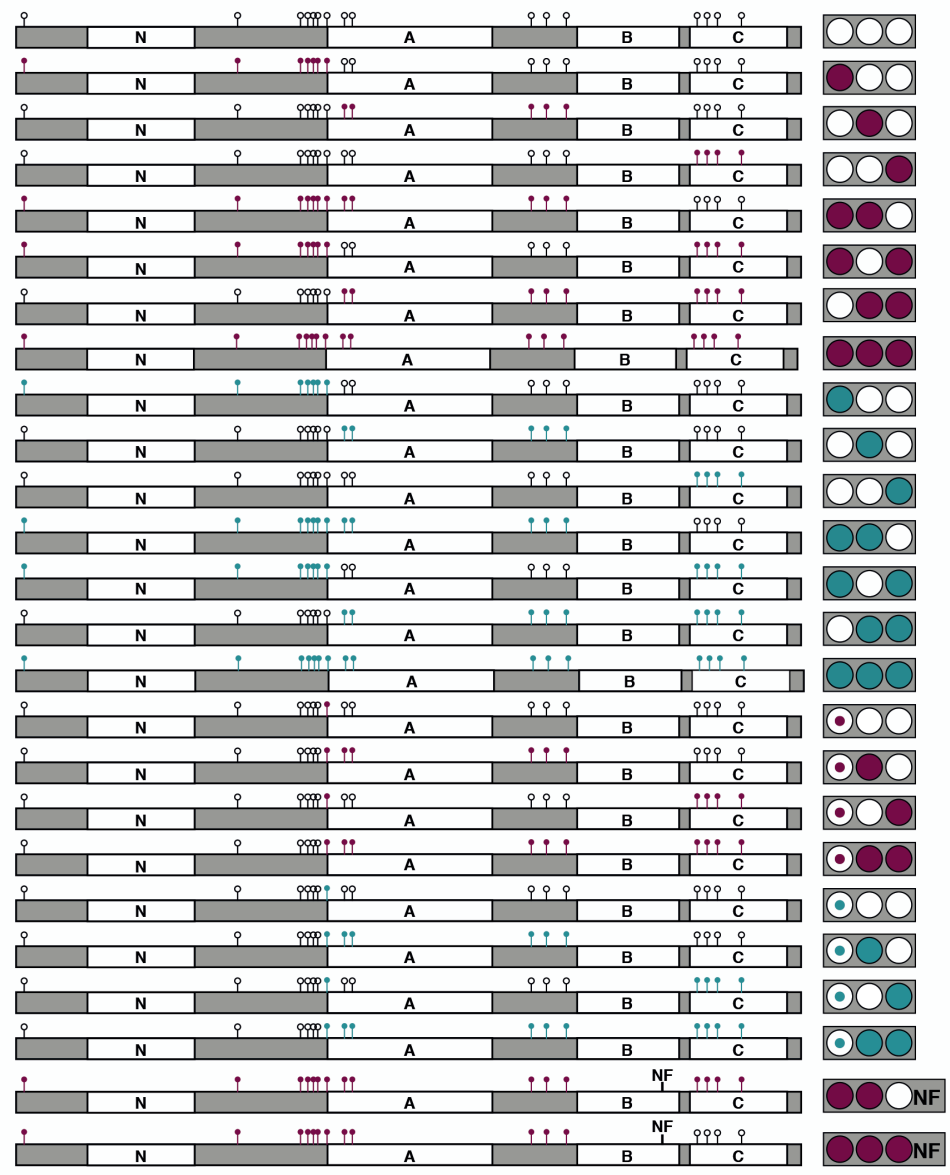

$[\mathrm{NO}, \mathrm{PO}, \mathrm{CO}]^{\mathrm{O}}$

$\left[\mathrm{N}-\mathrm{PO}, \mathrm{CO}^{7}\right.$

$[\mathrm{NO}, \mathrm{P}-, \mathrm{CO}]^{5}$

$[\mathrm{NO}, \mathrm{PO}, \mathrm{C}-]^{4}$

$[\mathrm{N}-, \mathrm{P}-, \mathrm{CO}]^{12}$

[N-,P0,C-]11

[N0,P-,C- $]^{9}$

[N-,P-,C-] ${ }^{16}$

$[\mathrm{N}+, \mathrm{PO}, \mathrm{CO}]^{7}$

$[\mathrm{NO}, \mathrm{P}+, \mathrm{CO}]^{5}$

[NO, PO,C+] ${ }^{4}$

$\left[\mathrm{N}+, \mathrm{P}+, \mathrm{CO}^{12}\right.$

$[\mathrm{N}+, \mathrm{PO}, \mathrm{C}+]^{11}$

$[\mathrm{NO}, \mathrm{P}+, \mathrm{C}+]^{9}$

$[\mathrm{N}+, \mathrm{P}+, \mathrm{C}+]^{16}$

${ }^{[406-, \mathrm{PO}, \mathrm{CO}]^{1}}$

[406-,P-,C0] ${ }^{6}$

[406-,P0,C- $]^{5}$

[406-,P-,C-] ${ }^{10}$

[406+,P0,Co] ${ }^{1}$

$\left[406+, \mathrm{P}+, \mathrm{CO}^{6}\right.$

$[406+, \mathrm{P0}, \mathrm{C}+]^{5}$

$[406+, \mathrm{P}+, \mathrm{C}+]^{10}$

$[\mathrm{N}-, \mathrm{P}-, \mathrm{NFCO}]^{12}$

$\left[\mathrm{N}-, \mathrm{P}-,{ }^{\mathrm{NFC}}-\right]^{16}$

Figure S1: List of RBR-phosphovariants.

A) Schematic list of all modules cloned in Level -1 of the GoldenGate MoClo system. Text nomenclature and colored circles and their relative position within the gray background box indicate the phosphorylation state and position of each module within the full length CDS of phosphovariants according to Fig 1 . Note that in modules "406" only the Thr406 residue is mutated, and in modules " ${ }^{2} \mathrm{C}$ " the Asn849 within the LXCXE binding cleft of the B-pocket sub-domain is mutated to Phe. B) Schematic list of all phospho-variants generated. All variants listed exist as Level 0, Level 1 (with RBR promotor, SCFP3A CDS and NOS terminator), and Level 2 (with FAST-R selection cassette in position 1) constructs, and as transgenic seed, except for those marked with the symbol $\odot$ on the left-most column, which were either not viable or not transformed and thus, only the plasmids are available. Note that $[406-, \mathrm{PO}, \mathrm{C}-]^{5}$ is marked with double circle because reduced fertility hindered propagation and all seed was used for the experiments reported in Fig 5. 
4
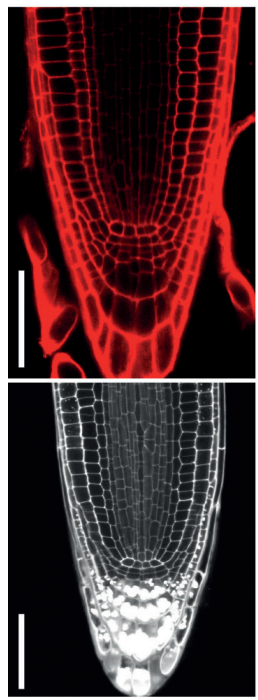

5
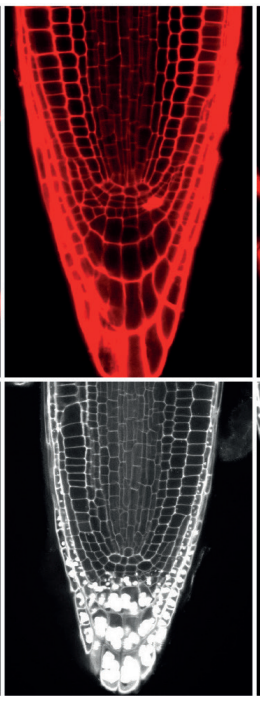

6
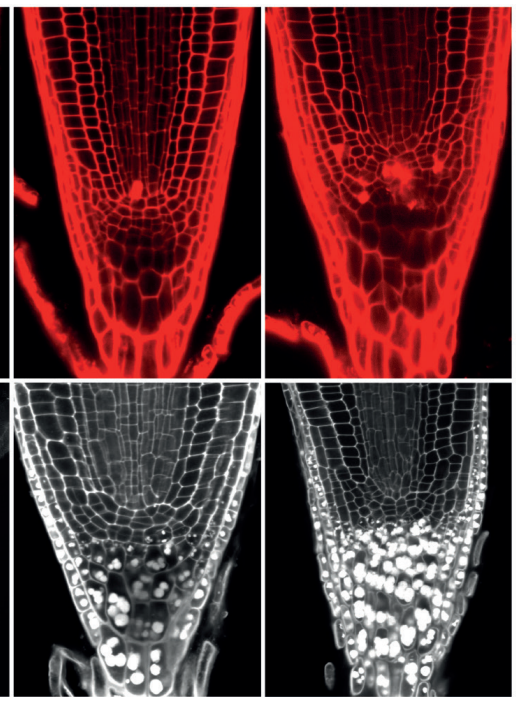

10

dag

Figure S2: amiGO-RBR penetrancy.

Confocal images of amiGO-RBR root tips by 4,5, 6 and 10 days after germination (dag). Top panels, mPS-PI staining; bottom panels, PI staining. Note that by 5 das we detected roots with very weak or no amigo-associated phenotypes. By 6 das, cell death and $\mathrm{SCN}$ extra divisions were evident in all roots. Scale bars, $50 \mu \mathrm{M}$. 


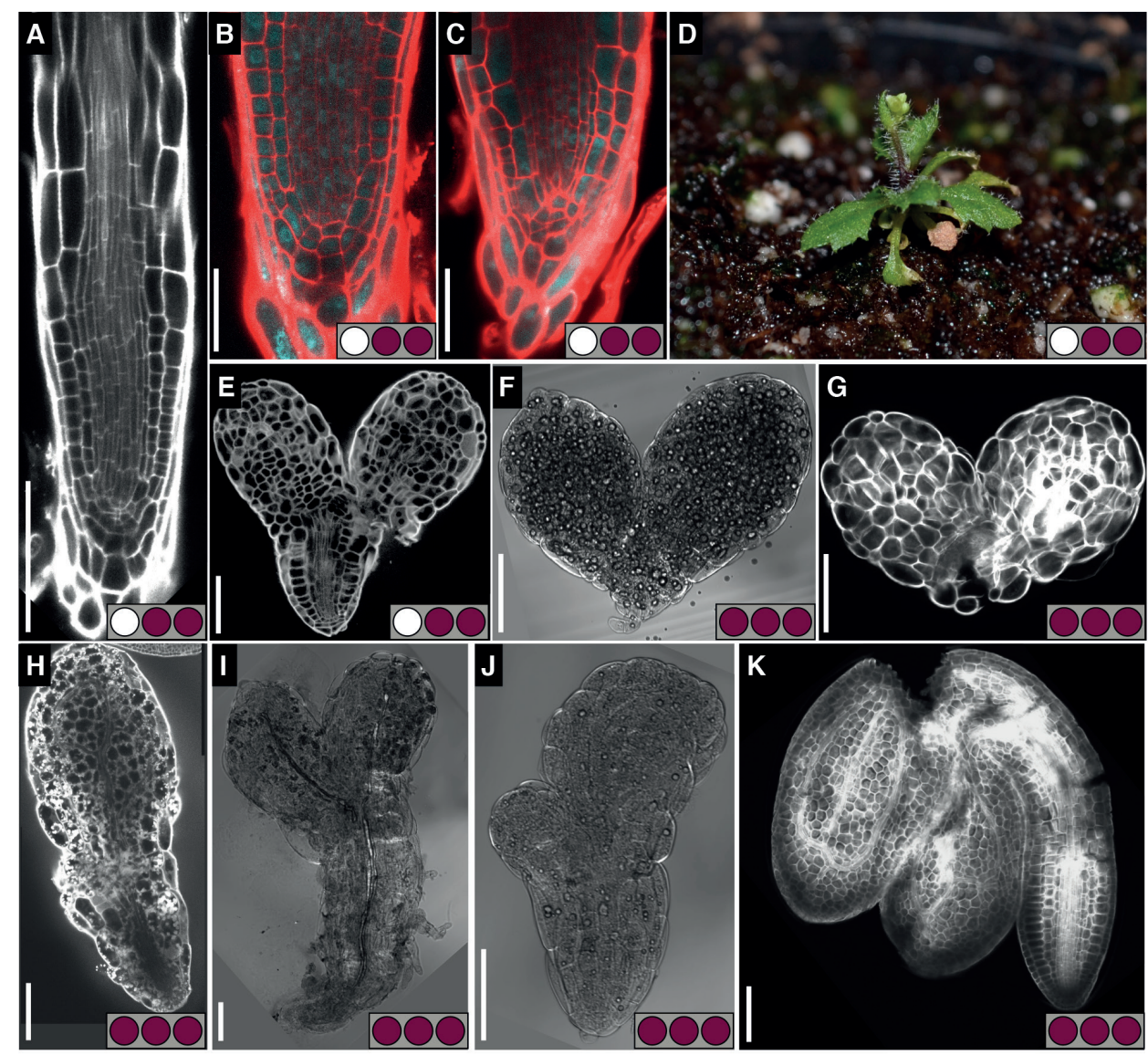

Figure S3: Primary transformants of lethal phospho-defective RBR variants.

A-C,E-K) Confocal images of PI stained root tips A-C), mPS-PI stained E, G,H,K), and transmitted light images $F, I, J)$ of embryos from non-germinated seeds 4 das stratified for 4 days. D) 3 week old seedling. Genotypes: $\left.\left.\left.[\mathrm{NO}, \mathrm{P}-, \mathrm{C}-]^{9} \mathrm{~A}-\mathrm{E}\right),[\mathrm{N}-, \mathrm{P}-, \mathrm{C}-]^{16} \mathrm{~F}-\mathrm{J}\right),\left[\mathrm{N}-\mathrm{P}^{\mathrm{NF}}, \mathrm{C}_{-}\right]^{16} \mathrm{~K}\right)$; Genetic background: Col-0 A,B,G, K), amiGO $C-F, H,-J)$. Max power and gain for CLSM settings and image brightness and contrast in $B, C)$ were set to in order to visualize sCFP signal from [NO,P-,C- $]^{9}$ expression. Scale bars, $100 \mu \mathrm{M}$ in $(\mathrm{A}, \mathrm{E}-\mathrm{K})$, $50 \mu \mathrm{M}$ in $(\mathrm{B}, \mathrm{C})$. 

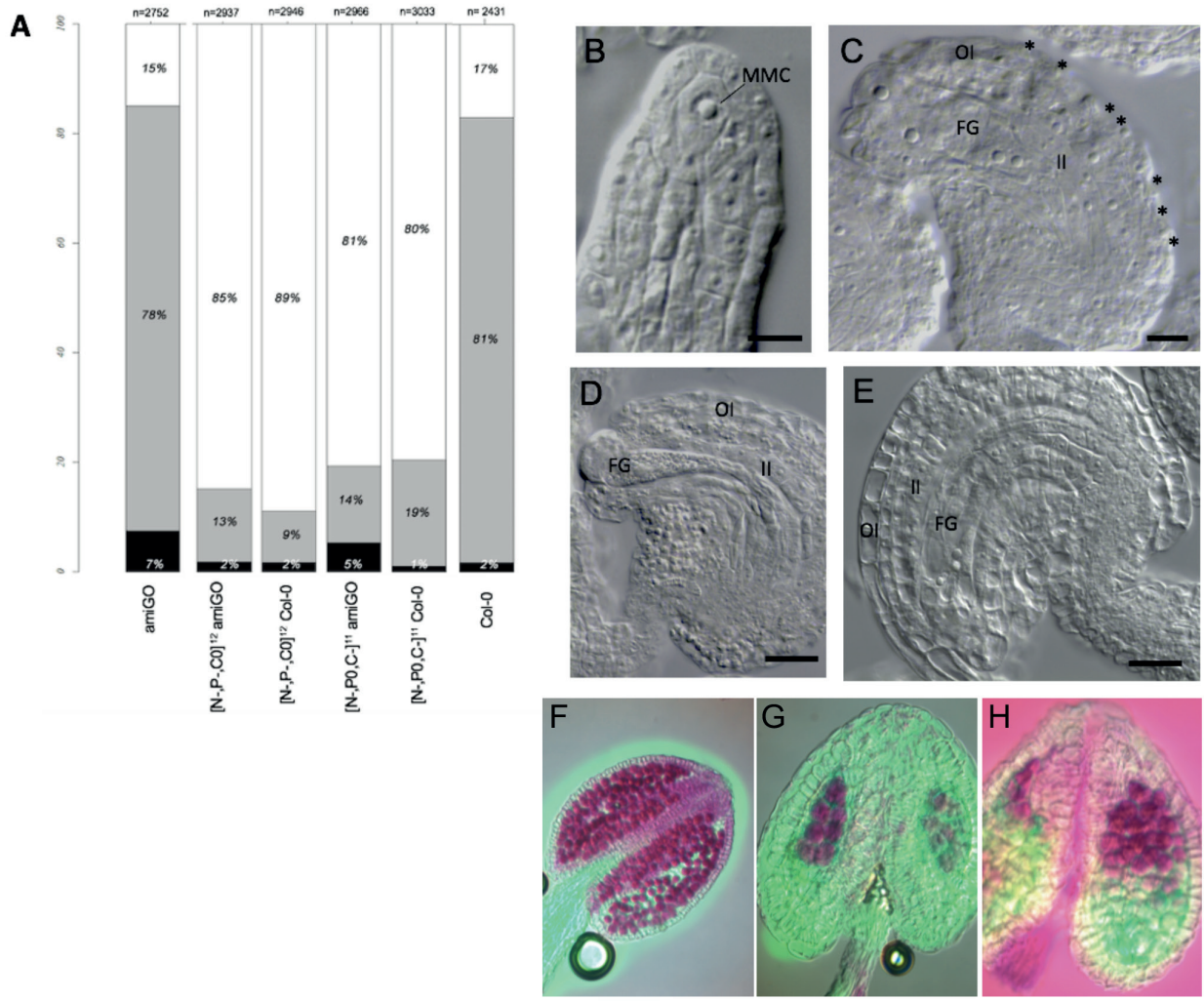

Figure S4: Reproductive defects in highly substituted RBR phospho-defective variants.

(A) Fertility analysis quantified as percentage of non-fertilized ovules (white), normally developed seeds (gray), and aborted seeds (black). (B) Ovule primordium of $[\mathrm{N}-, \mathrm{P}-, \mathrm{CO}]^{12}$ in amiGO background. (C) $[\mathrm{N}-, \mathrm{P}-, \mathrm{CO}]^{12}$ amiGO ovule showing a 4-nucleated female gametophyte and restricted growth of the inner and outer integuments; asterisks indicate degeneration of epidermal cells in the dorsal outer integument. (D) Fully differentiated $[\mathrm{N}-, \mathrm{P}-, \mathrm{CO}]^{12}$ amiGO ovule with extruded and collapsed female gametophyte and arrested growth of the inner and outer integument. (E) Fully differentiated Col-0 ovule showing a cellularized female gametophyte and normal growth of the integuments. (F) Alexander staining of a Col-0 anther showing normal locular space and viable pollen production.

(G) Alexander staining of $[\mathrm{N}-, \mathrm{P}-, \mathrm{CO}]^{12}$ anther showing restricted locular growth and limited amount of viable pollen. (H) Alexander staining of $[\mathrm{N}-, \mathrm{PO}, \mathrm{C}-]^{11}$ anther showing limited amount of viable pollen. Abbreviations: MMC, megaspore mother cell; FG, female gametophyte; II, inner integument; OI, outer integument. Scale bars: $B=7 \mu \mathrm{m} ; \mathrm{C}=14 \mu \mathrm{m} ; \mathrm{D}-\mathrm{E}=21 \mu \mathrm{m}$. 
Supplementary Table 1:

\begin{tabular}{|c|c|}
\hline Primer & Sequence \\
\hline RBR_n1_WT_F & AAAGGTCTCAACATAATGGAAGAAGTTCAGCCTCCAGT \\
\hline RBR_n3_WT_R & AAAGGTCTCAACAACTGGTGTTGCTGCCAACTTGGTA \\
\hline RBR_AB_F & AAAGGTCTCAACATCCAGTGAGCACAGCAATGACAAC \\
\hline RBR_AB_R & TTTGGTCTCTACAATCTGCACAAGTTTCTCCTCСАССTCC \\
\hline RBR_C_F & CCCGGTCTCGACATCAGAAACTGGAATCAATATTTTCTT \\
\hline RBR_C_R & TTTGGTCTCTACAACGAATCTGTTGGCTCGGTTTTAAGGG \\
\hline RBR_n1_T9D F & $\begin{array}{l}\text { AAAGGTCTCAACATAATGGAAGAAGTTCAGCCTCCAGTGGACCCGCCCATTGAACCAAATG- } \\
\text { GGAAA }\end{array}$ \\
\hline RBR_n1_T9A_F & $\begin{array}{l}\text { AAAGGTCTCAACATAATGGAAGAAGTTCAGCCTCCAGTGGCTCCGCCCATTGAACCAAATG- } \\
\text { GGAAA }\end{array}$ \\
\hline RBR_n1_S290D_R & CCCGGTCTCGATCTGGCTTTTTCTTCAGTATGGTTTCTA \\
\hline RBR_n1_S290A_R & GCGGGTCTCGAGCTGGCTTTTTCTTCAGTATGGTTTCTA \\
\hline RBR_n2_S290D_F & AAAGGTCTCAAGATCCAGCATCTGAGTGCCAAACTGACAAGCTA \\
\hline RBR_n2_S290A_F & AAAGGTCTCAAGCTCCAGCATCTGAGTGCCAAACTGACAAGCTA \\
\hline RBR_n2_R & CCCGGTCTCCGCTCAAAGCATCAATTTTTCCTCTTA \\
\hline n3T406A_R & taaGGTCTCtACAACTGGagctgctgccaacttggtagcac \\
\hline n3T406E_R & taaGGTCTCtACAACTGGctctgctgccaacttggtagcac \\
\hline GGpRBR_F & $\begin{array}{l}\text { aaGAAGACaaGGAGtgcctcgtgtcggaaatatctaattctctctctggatccactcacactcgaagatgacgaag- } \\
\text { tagacttaatctgaatccatc }\end{array}$ \\
\hline GGpRBR_R & $\begin{array}{l}\text { ccgaagacggcattagtctccaacgcagctgaaaacatgcaaaatcaagctaattttacttccaattaaactgctaactg- } \\
\text { tagacgaagaaaaagggacttttcaa }\end{array}$ \\
\hline GGvYFP_F & ttGAAGACaaTTCGtctgtgagcaagggcgaggagctgttc \\
\hline GGvYFP_R & gcGAAGACttAAGCttacttgtacagctcgtccat \\
\hline N849F_F & GAGGTCTCCactttgaaatatttattcctgccgtaaagccg \\
\hline N849F_R & GGGGTCTCCaagtagaatgtgatgatgtcaacatgatctg \\
\hline n3RvComp & TGGGGTCTCTACAACTGG \\
\hline \multicolumn{2}{|l|}{ n3 synthetic probes } \\
\hline RBR_n3-5E & $\begin{array}{l}\text { TTTGGTCTCTGAGCGATCCTGCAAGGACATTTATAGAACCACTTGATCCTCATAAGGACCCT- } \\
\text { GCTGCTAAGACAAATGGTATTAGCGGTGCTACCAAGTTGGCAGCAGAGCCAGTTGTAGAG- } \\
\text { ACCCCA }\end{array}$ \\
\hline RBR_n3-5A & $\begin{array}{l}\text { TTTGGTCTCTGAGCGCTCCTGCAAGGACATTTATAGCACCACTTGCTCCTCATAAGGCACCT- } \\
\text { GCTGCTAAGACAAATGGTATTAGCGGTGCTACCAAGTTGGCAGCAGCTCCAGTTGTAGAGAC- } \\
\text { CCCA }\end{array}$ \\
\hline
\end{tabular}




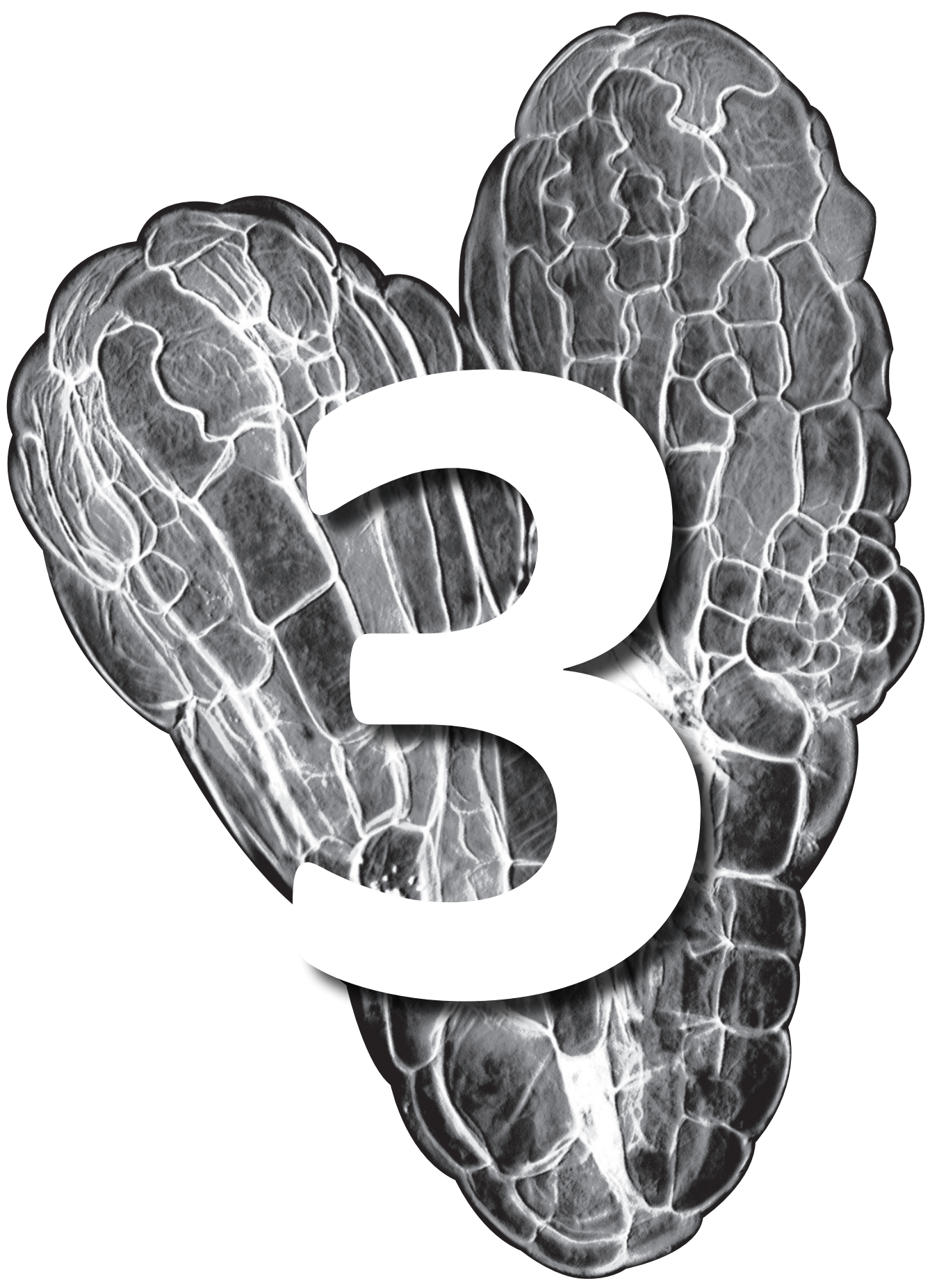




\section{Chapter 3}

\section{Binding properties of RETINOBLASTOMA- RELATED protein interactors reveal a central role in stress responsive pathways}




\section{Abstract}

Developmental and environmental signals are often integrated by hub proteins into genetic programs regulated by transcription factors. The RETINOBLASTOMA-RELATED (RBR) protein is an example of a transcriptional hub whose structure is affected by signalling events. The signals acting on RBR regulate its multiple interactions with transcription factors, thus coordinating a broad transcriptional output. RBR activity is regulated by phosphorylation on multiple CYCLIN-DEPENDENT KINASE substrate residues. However, the binding properties of (un)phosphorylated RBR with its protein interactors are poorly understood. By screening an arrayed library encoding 1956 Arabidopsis nuclear proteins in yeast, we analysed direct interactions of Arabidopsis RBR. As baits, we used the wild type version of RBR plus 4 phospho-defective variants, their 4 phospho-mimetic counterparts and RBR ${ }^{N F}$, the latter being a point mutation that disrupts interactions with the LXCXE motif present in multiple proteins that bind RBR. This mutant revealed that RBR binds to the LXCXE motif in the cysteine rich repeat proteins TCX6 and most likely TCX5, which participate in the DREAM complex, a major cell cycle regulator in eukaryotes. Moreover, a high number of the interactors are involved in responses to stress, pointing to a central role of RBR as an integrator of environmental inputs. While phosphorylation generally affected the binding properties of $R B R$, to our surprise some interactions were independent of the phosphorylation state of RBR. Our results provide a steppingstone for investigating how RBR phosphorylation helps to coordinate transcriptional programs such as growth and stress response in response to environmental signals. 


\section{Introduction}

Spatio-temporal coordination of cellular processes and responses requires the orchestratation of transcriptional programs. Such control can be exerted on transcription factors (TFs), nuclear proteins that bind DNA in a sequence specific-manner, and/or other TF in multimeric complexes that bridge gene promoters to the transcription machinery. Transcriptional regulation therefore depends on dynamic protein-DNA and protein-protein interactions (PPIs). On the other hand, transcriptional control is also exerted by chromatin structure, which determines the accessibility of TFs to their target genes. Chromatin modifiers do not bind DNA sequences, but interact with TFs, or with previously marked chromatin regions (Kouzarides, 2007; Narlikar et al., 2002; Vaissière et al., 2008).

A remarkable example of coordinating cell fate decisions through transcriptional and chromatin regulation surges upon DNA damage. The DNA damage response (DDR) evokes a plethora of events in the nucleus: cell cycle arrest, transcriptional activation of DNA repair genes, and chromatin remodelling at the lesion sites (Hu et al., 2016; Kim, 2019; Kim et al., 2019; Lorković et al., 2017; Nisa et al., 2019). If repair is successful, cell division is reactivated and repair genes repressed; if not, cell differentiation or death are transcriptionally activated to prevent the spread of mutations (Chen, 2016; Ciccia and Elledge, 2010; Hu et al., 2016). Likewise, cells coordinate division, differentiation and death within a developmental and environmental context (Abrash and Bergmann, 2009; Fox et al., 2018; Kumpf and Nowack, 2015; Tsukagoshi et al., 2010). As expected from a protein partner of multiple TFs and chromatin modifiers, the conserved RETINOBLASTOMA-RELATED (RBR) proteins participate in all aforementioned events in eukaryotes (Calo et al., 2010; Cao et al., 2010; Indovina et al., 2015; Litovchick et al., 2007; Perilli et al., 2013; Thomas et al., 2003; Wildwater et al., 2005).

RBR proteins are landing platforms that bridge chromatin regulators with DNA-specific TFs to control target gene expression (Dick and Rubin, 2013; Narlikar et al., 2002). The uncovering of RBR-TF interactions has fostered our understanding of how cell fate decisions are transcriptionally orchestrated. For example, in the cell cycle control, E2F-DP heterodimeric TFs reside on promoters and activate the expression of S-phase genes; RBR binds E2F, thus connecting multimeric chromatin modifiers to repress gene expression (Fiorentino et al., 2013; Raynaud et al., 2014; Sanchez et al., 2008; Zhang et al., 2000). CYCLIN (CYC) proteins activate CYCLIN-DEPENDENT KINASES (CDKs) to drive RBR phosphorylation in multiple sites; hyper-phosphorylated RBR releases E2F to allow target gene expression (Boniotti and Gutierrez, 2001; Burke et al., 2014; Gutierrez et al., 2002).

RBR protein controls other cell fate decisions in similar manners, where the corresponding TF determines the transcriptional program regulated by $R B R$, which is controlled by specific CYC-CDKs (Cruz-Ramírez et al., 2012; Matos et al., 2014) (Cruz-Ramírez et al., 2012; Weimer 
et al., 2012, 2018). Within the TFs regulating root ground tissue asymmetric cell division and stomata differentiation, a conserved LXCXE-motif hints at RBR-interaction, as this motif docks the B-pocket subdomain of RBR (Chan et al., 2001; Singh et al., 2005). Moreover, it suggests phosphorylation-mediated regulation, since crystal structures have demonstrated that the state of particular phospho-sites influences human pRb-LXCXE interactions (Burke et al., 2012).

RBR proteins are multifunctional, context-dependent transcriptional regulators whose functions are determined by PPIs (Desvoyes and Gutierrez, 2020; Dick and Rubin, 2013; Harashima and Sugimoto, 2016). Not surprisingly, several studies have focused on discovering RBR protein interactions (Morris and Dyson, 2001; Mushtaq et al., 2016; Sanidas et al., 2019). IP-MS experiments offer an insight into in vivo complexes but overlook direct interactions. Conversely, cDNA library screenings by Yeast two-hybrid (Y2H) tackle direct interactions but often dig up biologically irrelevant partners due to high abundance of cytosolic proteins. Here, we focused on discovering direct interactors of the Arabidopsis thaliana RBR, with high likelihood of biological meaning by focusing on nuclear proteins. By using a set of RBR point mutations in phosphorylation sites and the LXCXE-binding site, we gained additional insight into the regulation of these interactions.

\section{Results}

Although human pRb has cytoplasmic functions (Antonucci et al., 2014; Zhang et al., 2016), nuclear interactors are predominantly important for RBR-mediated processes because they regulate whole genetic programs (Morris and Dyson, 2001; Mushtaq et al., 2016). Thus, we set out to detect RBR protein partners by probing the $\mathrm{Y} 2 \mathrm{H}$ library of Arabidopsis transcription factors comprising 1956 nuclear proteins arrayed in 96-well plates (PrunedaPaz et al., 2014).

Besides the wild-type RBR $\left(R^{2} R^{W t}\right)$, we explored the interaction properties of diverse RBR mutants (Fig1). In a previous phenotypic analysis of our transgenic RBR phospho-variants collection, we observed stronger phenotypes associated to the highly substituted CDKphosphosite mutants (see Chapter 2), and therefore, we used such variants as baits (Fig 1). We also included the RBR-NF allele, a substitution of the conserved Asn849 for Phe that suppressed phospho-defective RBR variants (Chapter 2), and disrupts interactions with LXCXE motif-containing proteins in plants and animals (Bourgo et al., 2011; Chen and Wang, 2000; Cruz-Ramírez et al., 2013). In total, we included 10 RBR baits: RBR ${ }^{\mathrm{Wt}}, 4$ phosphodefective variants, their 4 phospho-mimetic counterparts and RBR ${ }^{\mathrm{NF}}$ (Figure 1). 


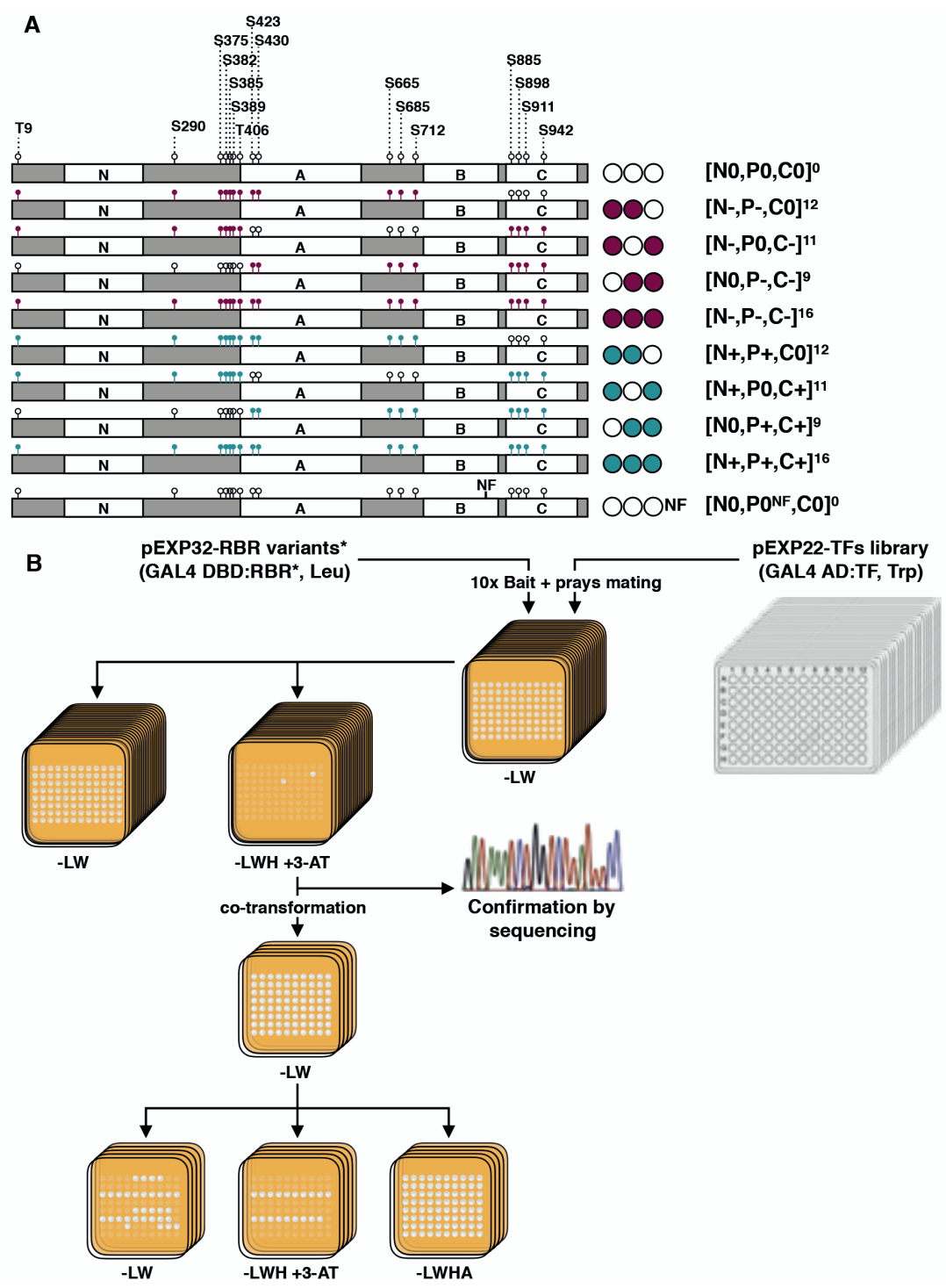

Figure 1: Schematic representation of the Arabidopsis pEXP22-TF library Y2H screenings with RBR-baits. A) We used total of 10 RBR variants cloned in the PDEST32 vector: RBR-Wt, four phospho-defective variants, four phospho-mimetic variants, and the RBR-NF allele, containing the N849F point mutation. Lollipops in the schemes of RBR structure represent the phosphorylation sites; empty, red and green lollipops depict WT, phospho-defective and phospho-mimetic state, respectively. The WT phosphosites positions are indicated above RBR-Wt scheme. Notation for each phospho-variant is taken from Chapter 1. B) Each bait was mated with the Arabidopsis pEXP22-TF containing 1956 TFs arrayed in 96 well plates. Plating on selection media for positive mating (SD -LW) was followed by plating on $\mathrm{SD}-\mathrm{LWH}+1.5 \mathrm{mM} 3 \mathrm{AT}$, and SD $-\mathrm{LW}$ to select positive protein interactions and confirming the presence of both plasmids, respectively. Plasmid DNA from grown yeast on interaction-selective medium was isolated and amplified to verify the identity of the pray by sequencing. Recovered pEXP22-TF plasmids were individually co-transformed in yeast along with each RBR bait and plated in selective media to confirm interaction patterns. 
Figure 1: List of prays that interacted with RBR baits in Y2H screenings. " $x$ " indicates interaction.

\begin{tabular}{|c|c|c|c|c|c|c|c|c|c|c|c|}
\hline \multirow[b]{2}{*}{ Prays } & \multirow[b]{2}{*}{ Gene ID } & \multicolumn{10}{|c|}{ Baits } \\
\hline & & $\mathrm{RBR}^{\mathrm{Wt}}$ & & ho & efec & & $\mathbf{P h}$ & ph & nir & tic & $\mathrm{RBR}^{\mathrm{NF}}$ \\
\hline GBF4* & AT1G03970 & $x$ & & & & & & & & & \\
\hline E2FC* & AT1G47870 & & $\mathrm{X}$ & $x$ & $x$ & $\mathrm{x}$ & $\mathrm{x}$ & & & & \\
\hline TCP3* & AT1G53230 & $\mathrm{x}$ & & $x$ & $\mathrm{x}$ & & & & & & \\
\hline TCP15 & AT1G69690 & & & $x$ & & $x$ & & $x$ & $x$ & $x$ & \\
\hline TCP22 & AT1G72010 & & & & & & & & $x$ & $x$ & \\
\hline DREB2D* & AT1G75490 & & & & $x$ & & & & & & \\
\hline HMGB4 & AT2G17560 & & & & & & & & & & $x$ \\
\hline TCX6* & AT2G20110 & $x$ & $x$ & $x$ & $x$ & $x$ & $x$ & & & & \\
\hline TKI1* & AT2G36960 & & & & $x$ & $x$ & & & & & \\
\hline NATA2 & AT2G39020 & & & $x$ & & & & & & & \\
\hline LBD15 & AT2G40470 & & & $x$ & X & $\mathrm{x}$ & & & & & \\
\hline TLP3 & AT2G47900 & $x$ & & & & & & & & & $x$ \\
\hline NAC044* & AT3G01600 & $x$ & $x$ & $x$ & $x$ & $x$ & $x$ & $x$ & $x$ & $x$ & \\
\hline ATL6 & AT3G05200 & & & & & & & & & & $x$ \\
\hline GRF5* & AT3G13960 & & & & & $x$ & & & & & \\
\hline TCP4 & AT3G15030 & $\mathrm{x}$ & $\mathrm{x}$ & $x$ & $\mathrm{x}$ & $\mathrm{x}$ & $\mathrm{x}$ & $x$ & $x$ & $\mathrm{x}$ & $x$ \\
\hline TCP14 & AT3G47620 & & $x$ & $x$ & $x$ & $x$ & & & $x$ & & \\
\hline POB1* & AT3G61600 & & & & & $x$ & & & & & \\
\hline UNE12 & AT4G02590 & $x$ & & & & & & & & & \\
\hline HD-like* & AT4G03250 & & & & $x$ & & & & & & \\
\hline OFP9 & AT4G04030 & & & & & $\mathrm{x}$ & & & & & \\
\hline ERF015 & AT4G31060 & & & & & & $x$ & & & & \\
\hline COP3 & AT4G37580 & & & & $\mathrm{x}$ & & & & & & \\
\hline ZFHD3 & AT5G15210 & & $x$ & & & & & & & & \\
\hline ARIA* & AT5G19330 & $\mathrm{x}$ & $\mathrm{x}$ & & & & $\mathrm{x}$ & & & & $\mathrm{x}$ \\
\hline NAC090* & AT5G22380 & & & & & & & & & & \\
\hline TCX7* & AT5G25790 & $x$ & $x$ & $x$ & $x$ & $\mathrm{x}$ & $\mathrm{x}$ & $X$ & & & \\
\hline XND1* & AT5G64530 & & & $X$ & $x$ & $x$ & & & & & \\
\hline Total int & tions per & 10 & 8 & 11 & 13 & 13 & 7 & 4 & 5 & 4 & 5 \\
\hline
\end{tabular}

${ }^{\star}$ Confirmed interactors (see Figure 1). 
From the 10 library screenings, we identified 28 interactors in total, ranging in frequency from 4 to 13 per bait (Table 1). Since both RBR ${ }^{\mathrm{NF}}$ and RBR phosphorylation disrupt RBR PPIs, it is not surprising that RBR-Wt detected more interactors than RBR ${ }^{\mathrm{NF}}$ and the phosphomimetic variants, but less than the phospho-defective ones in general. Among reported RBR-binding proteins, we found E2FC, XYLEM NAC DOMAIN1 (XND1), and TCX6 (Ning et al., 2020; del Pozo et al., 2002; Zhao et al., 2017), whereas SCARECROW, FAMA, and E2FA, direct partners of RBR (Cruz-Ramírez et al., 2012; Magyar et al., 2012; Matos et al., 2014), did not show interaction with any of the baits, indicating that the library screening yielded partial coverage of RBR PPIs. Moreover, neither E2FC nor XND1 arose with the RBR ${ }^{\text {Wt }}$ bait, similar to a report showing no binding between Arabidopis E2Fc and maize RBR in yeast (De Jager et al., 2001).Therefore, we decided to confirm the binding patterns by co-transforming the corresponding plasmids into the yeast instead of using the mating procedure (See Fig 1).

After confirming the identity of the 28 interactors (Fig 1), the co-transformed baits and prays growing in selective media displayed a different binding pattern than the one obtained in the original screenings (fig 2 vs Table 1 ). Strikingly, half of the interactions could not be confirmed (Table 1), suggesting that the 3-AT concentration was stringent enough to exclude weak interactions (and false positives) as E2FC and XND1 again failed to bind RBR ${ }^{\mathrm{Wt}}$. We nevertheless continued with these conditions because without 3-AT, the negative control grew and the effect of phospho-mimetic regulation was lost (data not shown). Thus, we are confident of the 14 remaining interactors and their binding pattern.

Phospho-defective variants established more interactions than phospho-mimetic variants, with the remarkable exception of $[\mathrm{NO}, \mathrm{AB}+, \mathrm{C}+]$. Since the root phenotypes induced by this variant in transgenic complementation related more to phospho-mimetic than to phosphodefective isoforms (see Chapter 2 ), we cannot readily explain its observed binding properties. On the other hand, with few exceptions, the binding capacity of the TFs differed drastically (Table 1, Fig 2). For example, GBF4, NAC090, and AT1G75490 interacted with only one bait in the screenings, but in the co-transformation experiment they bound strongly to all RBR versions (Table 1, Fig 2 B,C). Conversely, TCP4/14/15 were picked up by at least 5 different baits in the screenings, but interacted with none in the co-transformation experiment; meanwhile ARIA, NAC044, TCX6 and E2FC performed consistently across both experimental procedures (Table 1, Fig 2 B).

Noteworthy, ARIA interacted strongly and exclusively with all RBR variants containing an intact $\mathrm{N}$-domain, pinpointing to the specificity of this interaction (Fig $2 \mathrm{~B}, \mathrm{C}$ ). Unlike ARIA, the interaction of all RBR versions with GROWTH REGULATING FACTOR 5 (GRF5) was variable: along the three replicates, it interacted with all RBR variants in at least one replicate, but consistently only with $\mathrm{RBR}^{\mathrm{Wt}}$, [N-, ABO, C-], and [N-, AB-, C-] (Fig S1). Strikingly, in most positive cases, GRF5-RBR interaction was maintained in the most stringent condition, 
i.e. SD -LWHA (Fig S1). Other TFs with similar binding strength displayed a consistent phosphorylation-independent interaction with RBR, suggesting that GRF5 potentially binds RBR independently of its phosphorylation state, but perhaps other factors are needed to stabilize the RBR-GRF5 complex.

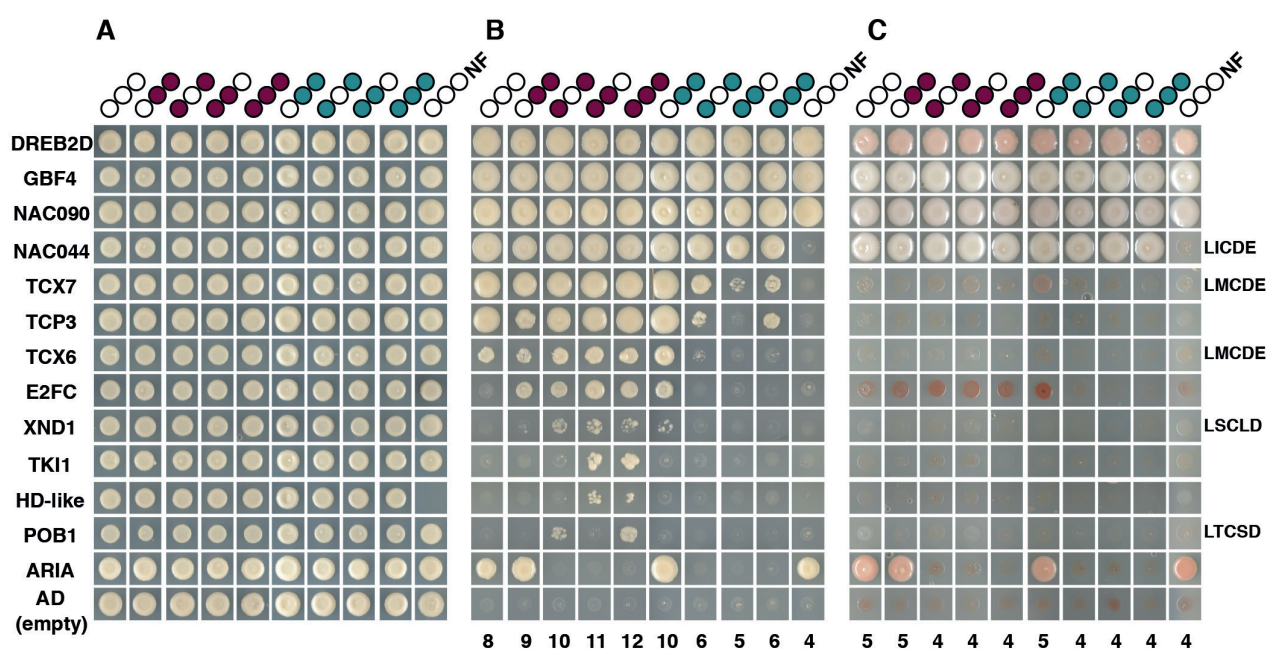

Figure 2: Interaction pattern of RBR variants with TFs.

Y2H analysis of co-transformed pEXP32-RBR*and pEXP22-TFs dropped on SD-LW A), SD-LWH $+1.5 \mathrm{mM}$ $3 A T B$ ) and SD -LWHA C). The identity and accession number of each TF fused to the GAL4 activating domain is indicated on the left column; if present, LXCXE and LXCXE-like motifs sequences are indicated in the rightmost column; the total number of interactions per RBR variant is indicated on the lowermost row. Negative control is the empty pDEST22 vector.

$\mathrm{RBR}^{\mathrm{NF}}$ failed to interact with 4 proteins that did bind to RBR ${ }^{\mathrm{Wt}}$, out of which all but TCP3 contain a canonical LXCXE motif (Fig 2 B). Two proteins bearing a divergent LXCXE-like motif, XND1 and POB1, failed to interact with both $\mathrm{RBR}^{\mathrm{NF}}$ and $\mathrm{RBR}^{\mathrm{Wt}}$, but showed interaction with phospho-defective variants (Fig 2 B). Among the canonical LXCXE-containing proteins, NAC044 established the strongest interaction without any evident effect of the phosphorylation state of RBR (Fig 2 B,C).

\section{RBR interacts with TCX proteins through a specific LXCXE motif. A showcase for DREAM complex assembly determinants.}

The multimeric DREAM complex (named after its constituents in animals, $\underline{D} P, \underline{R} B, \underline{E} 2 F$, and Multivulva B, MuvB complex), a conserved cell cycle regulatory complex, was recently also detected in Arabidopsis (Kobayashi et al., 2015). In mammals, the MuvB component LIN54 confers DNA-binding specificity to the DREAM complex by the recognition of cell cycle gene homology region (CHR) elements in promoters (Marceau et al., 2016; Schmit et al., 2009). LIN54 belongs to the Tesmin-like TCX family, that contains two tandem cysteine rich (CXC) rich domains (Sugihara et al., 1999). Phylogenetic analysis of the TCX family showed that 
the TCX5/6/7 clade resides closer to human LIN54 (Fig 3A). Accordingly, TCX5 and TCX6 are the only LIN54 orthologs identified in the plant DREAM complex so far (Kobayashi et al., 2015; Ning et al., 2020), indicating that not all TCX proteins take part in a DREAM complex. Since the direct interactions between TCX6/7 (TCX5 is absent of the library) and RBR are disrupted by the N849F mutation (Fig 2), we searched for LXCXE-like motifs, and found two likely candidates (Fig $3 \mathrm{~B}$ ). The first is a divergent IXCXE motif within the second CXC domain. TCX8, contains a similar aligning motif but did not interact with any RBR bait, suggesting that this motif is not mediating the interaction with RBR. The second one is a canonical LXCXE motif, located in the less conserved C-terminal region and only present in TCX5/6/7. To investigate whether RBR interacts with TCX5/6/7 proteins through any of these motifs, we mutated them both to GXCXG in TCX6, as they are identical in TCX5, TCX6 and TCX7 (Fig $3 B)$. Whereas disrupting the non-canonical IXCXE motif did not affect the interaction with RBR, mutating the canonical LXCXE abolished it (Fig 3C). We conclude that only the bonafide LXCXE mediates TCX5/6/7-RBR direct binding.

A

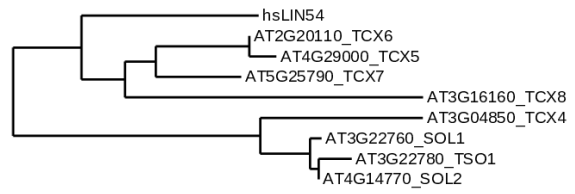

B
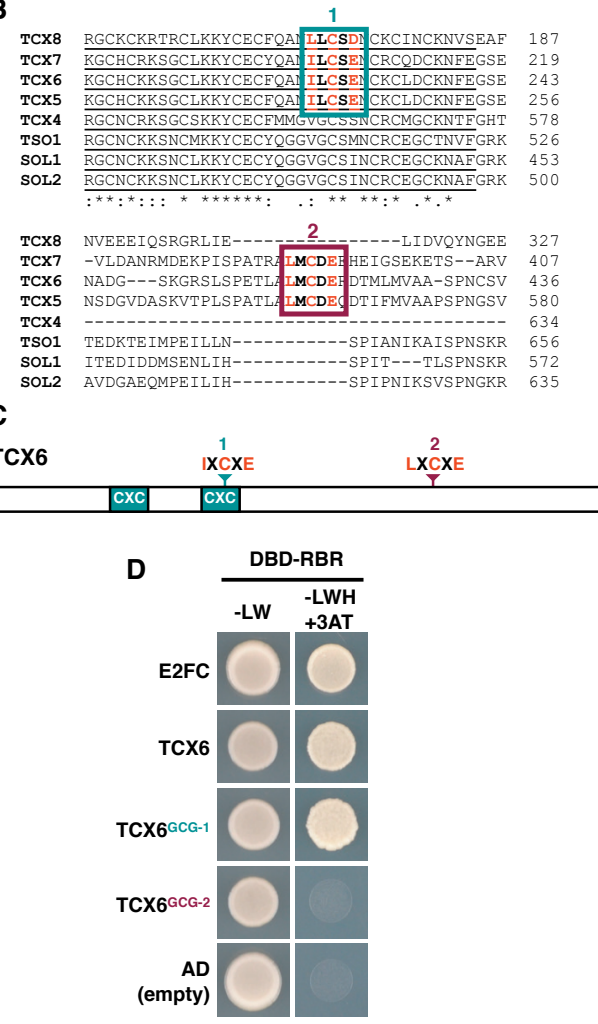

Figure 3: TCX6 protein binds to RBR through the second LxCXE motif.

A) Neighbor-joining phylogenetic tree of human LIN54 and Arabidopsis TCX proteins. B) Clustal omega multiple sequence alignment fragments of Arabidopsis TCX proteins showing LXCXElike motifs within the conserved CXC domain (highlighted in red) and LXCXE motifs (in green) within a less conserved region; asterisks and dots indicate identical and similar residues, respectively. C) Schematic representation of TCX6 protein organization as predicted by Pfam showing the relative positions of the cycteinrich domains (CXC) and LXCXE and LXCXE-like motifs. D) Yeast two-hybrid analysis showing that RBR interacts with TCX6 and a TCX mutated on the LXCXE-like motif ' 1 ' within the CXC domain, but not with TCX6 mutated on the canonical LXCXE motif ' 2 '. E2FC is positive control, and empty pDEST22 vector is negative control. Cotransformed yeast dropped on SD -LW to select transformants, and on SD - LWH +1.0 mM 3AT to select interactions. 


\section{DNA damage stress triggers CYCD6;1 expression.}

Besides few cell cycle regulators, most RBR-interactors identified are development and stress regulators, including components of the DDR, where RBR plays prominent roles (Biedermann et al., 2017; Gómez et al., 2019; Horvath et al., 2017; Takahashi et al., 2019). Since several of these interactions are affected by phosphorylation, we asked whether CYCDs, the canonical Cyclins driving RBR phosphorylation, respond to DNA stress. Strikingly, out of the ten Arabidopsis CYCDs, only CYCD6;1 was induced by treatment with the radiomimetic drug zeocin (Fig S2). CYCD6;1 phosphorylates RBR during stem cell division (Cruz-Ramírez et al., 2012), and it is implicated in stress-responsive networks along with RBR downstream of the JA signalling (Zhou et al., 2019), suggesting that CYCD6;1-driven RBR phosphorylation can be triggered by both developmental and environmental signals to coordinate development and stress response.

\section{Discussion}

In this study we identified direct nuclear interactors of RBR, whose functions are linked to transcriptional control. By screening the Arabidopsis pEXP22-TF library with ten different RBR baits, we recovered 28 proteins, out of which half were confirmed with high confidence (Table 1, Fig 2). The interaction between RBR phospho-variants and TFs revealed that not all RBR PPIs are regulated by phosphorylation, even when they are mediated by the LXCXE motif, as it is the case of NACO44. To our knowledge, this is the first example of an RBRLXCXE interaction not modified by phosphorylation.

The numerous interactions and phenotypes of phospho-defective variants in transgenic Arabidopsis seedlings (Chapter $\mathbf{2}$ ) indicate that a functional RBR protein structure is likely preserved despite the point mutations on phospho-sites. Still, ARIA only binds to RBR if the $\mathrm{N}$-domain is intact (Fig $2 \mathrm{~B}, \mathrm{C}$ ), suggesting that this protein docks closely to, or even on the phospho-sites without being necessarily affected by phospho-site variation in other domains. In contrast, other interactors bind to RBR domains devoid of phospho-sites, but are regulated by global structural changes induced by distal phosphorylation, such as some mediated by the B-pocket-LXCXE-motif bond (Burke et al., 2012; Liu and Marmorstein, 2007). Therefore, we interpret that ARIA-RBR interaction is regulated by local changes in the vicinity of phospho-sites within the $\mathrm{N}$-domain, unveiling an unknown mechanism of RBR PPIs regulation by phosphorylation.

Some known RBR interactors were not detected in the screenings (Table S1), with E2FA being a conspicuous case. Similarly, E2FC and XND1 failed to bind RBR ${ }^{W t}$ (Table 1, Fig 2). A recent study reported similar observations for the multifunctional transcriptional regulator GIBBELRELLIC ACID INSENSITIVE (GAI), a DELLA protein (Lantzouni et al., 2020), indicating that the $\mathrm{Y} 2 \mathrm{H}$ screenings of the arrayed TF library are prone to false negatives. False positives 
also occur, as our confirmation experiments by co-transformation ruled out half of the initial 28 interactions. For example, four out of five initially picked interactions with TCP proteins (TCP3/4/14/15/22) could not be confirmed. However, as they are cell division and morphogenetic regulators functionally linked to the plant cell cycle control involving the RBR pathway (Cubas et al., 1999; Davière et al., 2014; Kieffer et al., 2011; Li, 2015; Li et al., 2012; Sablowski and Carnier Dornelas, 2014), and as they may bind more tightly in cooperative multimeric complexes(Shimotohno et al., 2018), these interactions should be tested through different methods before discarding them.

The TCP3-RBR interaction remained strong, phosphorylation-regulated, and disrupted by the N849F mutation despite lacking a clear LXCXE motif, confirming that not all proteins bind the B-pocket sub-domain through an LXCXE motif (Binné et al., 2006; Longworth et al., 2008; Singh et al., 2005). Together with TCP4, TCP3 regulates plant morphogenesis and regeneration through the auxin and cytokinin pathways (Koyama et al., 2017; Li and Zachgo, 2013; Nag et al., 2009; Yang et al., 2020). RBR connections to auxin, cytokinin, and regeneration have been established (Cruz-Ramírez et al., 2012; Perilli et al., 2013; Wang and Ruan, 2013; Zhou et al., 2019), but whether RBR and TCP3 interact in these processes is unknown.

The variable binding of GRF5 revealed its potential to interact with all RBR variants (Fig. S1). Since GRF proteins functionality depend on binding their co-activator GRF-INTERACTING FACTOR/ANGUSTIFOLIA3 (GIF1/AN3), GIF1/AN3 may stabilize the interaction with RBR. The GRF5-GIF1 complex promotes cell proliferation, plant regeneration, and leaf morphogenesis (Horiguchi et al., 2005; Kim and Kende, 2004; Vercruyssen et al., 2015)(Debernardi et al., 2020; Kong et al., 2020). Interestingly, GIF1/AN3 recruits chromatin remodelers to gene promoters, including those of GRF genes, to control cell proliferation and differentiation in leaves (Vercruyssen et al., 2014). GRFs also interact with DELLA proteins to activate DREB1 genes (see below) to modulate growth in response to cold stress (Lantzouni et al., 2020). Thus, the GRF5-RBR interaction is worth further investigation given their potential to regulate chromatin structure in response to developmental and environmental growth control.

Remarkably, GBF4, NAC090, NAC044, and DREB2D, all involved in environment response pathways, interacted most strongly with RBR without being affected by phosphorylation. GBF4, a bZIP TF relative to the ABI5 gene (ABA-insensitive5), forms heterodimers with ABAinduced GBF2 and GBF3 to regulate gene expression in a DNA sequence-specific manner in response to cold and dehydration (Lu et al., 1996; Menkens and Cashmore, 1994). NAC090 inhibits leaf senescence by repressing reactive oxygen species (ROS) and salicylic acid (SA) responses together with NAC017 and NAC082 (Kim et al., 2018). Interestingly, NAC090, is also upregulated by ABA (Liu et al., 2015), and responsive to sound vibrations that elicit defence hormones, (Ghosh et al., 2016) a proposed mechanism to perceive herbivore chewing (Appel and Cocroft, 2014). NAC044 controls cell cycle progression in response to 
DNA damage and heat-stress (Takahashi et al., 2019). Finally, the dehydration-responsive element (DRE)-binding protein 2D (DREB2D), belongs to the DREB2 subfamily that mediates responses to dehydration, high salinity, and heat-stress (Liu et al., 1998)(Chen et al., 2010; Nakashima et al., 2000).

POB1 interacted with only two phospho-defective RBR variants. Both ARIA and POB1 contain a $\mathrm{BTB} / \mathrm{POZ}$ domain, present in E3 ligase components that promote protein degradation (Gingerich et al., 2005). Accordingly, POB1 takes part of an E3 ligase complexes that regulates a) growth in response to light through the Phytochrome $B$ and $D$ pathways (Christians et al., 2012); b) flowering time in response to vernalization through the FRIGIDA-FLC pathway (Hu et al., 2014); and c) plant susceptibility to pathogens through the jasmonate signaling pathway (Pogoda et al., 2020). ARIA in turn, mediates ABA responses by interacting with $A B F 2$, which directly controls $A B A$-responsive gene expression in a sequence specific manner (Kim et al., 2004). Thus ARIA and POB1 integrate environmental cues into plant growth, but wether they mediate RBR protein degradation, or to cooperate with it in coordinating physiological responses remains to be explored.

Finally, TKI and AT4G03250 interaction properties to RBR were similar, but not much is known about their function. The former interacts with a cell cycle regulated kinase (Ehsan et al., 2004), and the latter, encoding a homeodomain TF, was found to interact with the transcriptional co-repressor TOPLESS and with the DELLA protein GAI (Causier et al., 2012; Marín-de La Rosa et al., 2014), pointing to an environmentally controlled role during development. Altogether, RBR-TFs interactions point to a strong role in environmental signalling integration.

RBR often needs chromatin modifiers to exert transcriptional control (Johnston et al., 2008, 2010; Kuwabara and Gruissem, 2014; Mosquna et al., 2004). A conserved mechanism to bridge chromatin regulators to TFs and gene promoters involves the multimeric DREAM complex (Fischer and Müller, 2017), a cell cycle regulator that also participates in the DDR in animals (Engeland, 2018). In plants, the DREAM complex maintains DNA methylation landscapes (Ning et al., 2020), and its components E2FC and TCX proteins, regulate cell cycle, the DDR, and other stress responses (Takahashi et al., 2019; Wang et al., 2018) (Bourbousse et al., 2018; Gómez et al., 2019; Kobayashi et al., 2015).

We showed that RBR binds to the TCX6/7 proteins through a conserved LXCXE motif (Fig 3). In animals, the RB-like proteins p107/p130 interact with a different component, Lin52 protein, through an LXCXE-like motif, whereas the TCX homolog Lin54 provides DNA binding specificity to the DREAM complex but does not bind RB-like proteins (Guiley et al., 2015; Schmit et al., 2009). Whether plant TCX proteins bind DNA in a sequence specific manner is unknown, but our results indicate divergent structural assembly of the plant DREAM 
complex. The observations that a) RBR is the only pocket protein in Arabidopsis (Desvoyes et al., 2014), b) RBR phosphorylation regulates the interaction with E2FC and TCX6/7 proteins, and c) stress stimuli induces RBR phosphorylation and CYCD6;1 expression (Fig S2)(Wang et al., 2014; Zhou et al., 2019) lead us to pose the question whether stress-induced RBR phosphorylation promote alternative DREAM complexes formation.

Altogether, our data support a new emerging paradigm of RBR functions. The roles of RBR as an environmental and developmental integrator have been pointed out before (Harashima and Sugimoto, 2016). By discovering new direct RBR-TFs interactions, regulated or not by phosphorylation, and reviewing their known functions, we provided new entry points for research on the multiple functions of RBR.

\section{Materials and methods}

\section{Plasmid construction and Yeast transformation.}

pEXP32-RBR-Wt and pEXP32-RBRNF were reported previously (Cruz-Ramírez et al., 2013). The CDS of the eight phospho-variants listed in Figure 1 was amplified from the corresponding level 0 constructs pAGM1287-RBR_N*AB*C* (“*” indicates the diverse phospho-modules, reported in Chapter 2) with the primer pair cRBR-GWF/ CRBR-GWR. Purified PCR products carrying attB sites were cloned into pDONR221 vector with the Gateway BP clonase II enzyme mix (Invitrogen, 11789020), and the resulting pDONR221-RBR variants entry clones were recombined into pDEST32 by Gateway LR clonase II enzyme mix (Invitrogen, $11791020)$ according to the provider instructions. The bait plasmids ( $p E X P 32-R B R$ variants) were transformed into yeast strain PJ69-4 $\alpha$ as described in (De Folter and Immink, 2011).

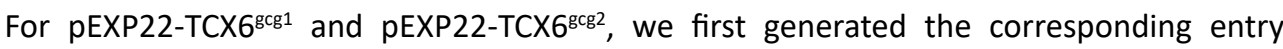
clones by amplifying the attB-flanked TCX6 CDS in a two-fragmentS overlapping PCR to mutagenize the LXCXE and LXCXE-like motifs with the primer pairs TCX6C-F/ TCX6gcg1-R and TCX6gcg1-F /TCX6C-R for TCX6" ${ }^{\text {gcg1 }}$ Table S2 and TCX6C-F/TCX6gcg2-R and TCX6gcg2-F /TCX6C-R for TCX6 ${ }^{\mathrm{gcg} 2}$, followed by BP-II clonase (Invitrogen) recombination reaction into pDONR-221 Vector. Entry clones were recombined into PDEST22 destination vector by LR-II clonase (Invitrogen) recombination.

\section{Y2H screenings and confirmation of interactions.}

An autoactivation test for all pEXP32-RBR variants was performed as described in (De Folter and Immink, 2011) for at least ten independent transformants; most colonies showed no autoactivation. One colony from each bait with no autoactivation in selective medium supplemented with OmM 3-AT was inoculated in liquid -L SD-glucose medium and grown $\mathrm{O} / \mathrm{N} .1 \mathrm{~mL}$ of the pre-culture was inoculated in $50 \mathrm{~mL}-\mathrm{L}$ SD-glucose medium and grown O/N. In parallel to bait pre-culture, $5 \mu \mathrm{L}$ of the arrayed Arabidopsis pEXP22-TF library (Pruneda- 
Paz et al., 2014) was spotted on -W SD-glucose agar plates from PJ69-4A glycerol stock, and grown for 2 days.

A multichannel pipet was used as replicator to transfer the spotted pEXP22-TF library to 96well plates containing $50 \mu \mathrm{L}$ of sterile $\mathrm{mQ}$ water. $5 \mu \mathrm{L}$ of the resuspended yeast was spotted on YPD agar plates, letting spots to dry before spotting $5 \mu \mathrm{L}$ of the pEXP32-RBR variant bait on top, letting spots to dry again and incubating $\mathrm{O} / \mathrm{N}$ for mating. The yeast was then transferred from YPD to 96-well plates containing $50 \mu \mathrm{L}$ of sterile $\mathrm{mQ}$ water, resuspended, and $5 \mu \mathrm{L}$ spotted on -LW SD-glucose agar plates and incubated for 3-4 days to select for the presence of both bait and pray plasmids. The transfer procedure was repeated from the -LW SD-glucose to fresh -LW SD-glucose and -LWH + 1 mM 3-AT SD-glucose agar plates, and incubated for 4-5 days. Selection of positive interaction was based on at least 3 colonies per spot. To confirm the identity of the positive interactors, plasmid was extracted from the yeast, transformed in chemically competent E. coli DH5- $\alpha$, selected in LB + ampicillin and mini-prepped again for sequencing. The accession numbers of all interactors are listed in Table 1.

To assess the interaction patterns, the bait plasmids (pEXP32-RBR variants) were transformed into yeast strain PJ69-4A as described in (De Folter and Immink, 2011). After proper selection of no autoactivatng colonies, PJ69-4A cells carrying each of the baits were made competent and transformed with the purified pEXP22-TF obtained from the screenings. The transformation was adapted from (De Folter and Immink, 2011) to be done in 96 deep well plates instead of $1.5 \mathrm{~mL}$ tubes. Transformed yeast was resuspended in $150 \mu \mathrm{L}$ of sterile $\mathrm{mQ}$ water and spotted in triplicate on -LW SD-glucose agar plates and incubated for 3 days. The yeast was then transferred from to 96 -well plates containing $50 \mu \mathrm{L}$ of sterile $\mathrm{mQ}$ water, resuspended, and $5 \mu \mathrm{L}$ spotted onto fresh -LW SD-glucose, $-\mathrm{LWH}+1.5 \mathrm{mM} 3-\mathrm{AT}$ SD-glucose, and -LWHA SD-glucose agar plates, and incubated for 5 days. Selection of positive interaction was based on at least 3 colonies per spot.

Small scale $\mathrm{Y} 2 \mathrm{H}$ assays for figure 3 (RBR-TCX6) was performed by co-transforming bait and pray plasmids as described in (De Folter and Immink, 2011), testing 12 independent cotransformations per interaction. All yeast incubations described above were at $30^{\circ} \mathrm{C}$. Plates were imaged at with a table top flatbed scanner (EPSON Expression 11,000 XL). 


\section{References}

Abrash, E.B., and Bergmann, D.C. (2009). Asymmetric Cell Divisions: A View from Plant Development. Dev. Cell 16, 783-796.

Antonucci, L.A., Egger, J. V., and Krucher, N.A. (2014). Phosphorylation of the Retinoblastoma protein (RB) on serine-807 is required for association with Bax. Cell Cycle 13, 3611-3617.

Appel, H.M., and Cocroft, R.B. (2014). Plants respond to leaf vibrations caused by insect herbivore chewing. Oecologia 175, 1257-1266.

Biedermann, S., Harashima, H., Chen, P., Heese, M., Bouyer, D., Sofroni, K., and Schnittger, A. (2017). The retinoblastoma homolog RBR1 mediates localization of the repair protein RAD51 to DNA lesions in Arabidopsis. EMBO J. 36, 1279-1297.

Binné, U.K., Classon, M.K., Dick, F.A., Wei, W., Rape, M., Jr, W.G.K., Näär, A.M., and Dyson, N.J. (2006). Retinoblastoma protein and anaphase-promoting complex physically interact and functionally cooperate during cell-cycle exit. Nat. Cell Biol. 9, 225-232.

Boniotti, M.B., and Gutierrez, C. (2001). A cell-cycle-regulated kinase activity phosphorylates plant retinoblastoma protein and contains, in Arabidopsis, a CDKA/cyclin D complex. Plant J. 28, 341350.

Bourbousse, C., Vegesna, N., and Law, J.A. (2018). SOG1 activator and MYB3R repressors regulate a complex DNA damage network in Arabidopsis. Proc. Natl. Acad. Sci. U. S. A. 115, E12453E12462.

Bourgo, R.J., Thangavel, C., Ertel, A., Bergseid, J., Kathleen McClendon, A., Wilkens, L., Witkiewicz, A.K., Wang, J.Y.J., and Knudsen, E.S. (2011). RB Restricts DNA Damage-Initiated Tumorigenesis through an LXCXE-Dependent Mechanism of Transcriptional Control. Mol. Cell 43, 663-672.

Burke, J.R., Hura, G.L., and Rubin, S.M. (2012). Structures of inactive retinoblastoma protein reveal multiple mechanisms for cell cycle control. Genes Dev. 26, 1156-1166.

Burke, J.R., Liban, T.J., Restrepo, T., Lee, H.W., and Rubin, S.M. (2014). Multiple mechanisms for E2F binding inhibition by phosphorylation of the retinoblastoma protein C-terminal domain. J. Mol. Biol. 426, 245-255.

Calo, E., Quintero-Estades, J.A., Danielian, P.S., Nedelcu, S., Berman, S.D., and Lees, J.A. (2010). Rb regulates fate choice and lineage commitment in vivo. Nature 466, 1110-1114.

Cao, L., Peng, B., Yao, L., Zhang, X., Sun, K., Yang, X., and Yu, L. (2010). The ancient function of RB-E2F Pathway: insights from its evolutionary history. Biol. Direct 5, 1-21.

Causier, B., Ashworth, M., Guo, W., and Davies, B. (2012). The TOPLESS interactome: A framework for gene repression in Arabidopsis. Plant Physiol. 158, 423-438.

Chan, H.M., Smith, L., and La Thangue, N.B. (2001). Role of LXCXE motif-dependent interactions in the activity of the retinoblastoma protein. Oncogene 20, 6152-6163.

Chen, J. (2016). The cell-cycle arrest and apoptotic functions of p53 in tumor initiation and progression. Cold Spring Harb. Perspect. Med. 6, 1-16.

Chen, T., and Wang, J.Y.J. (2000). Establishment of Irreversible Growth Arrest in Myogenic Differentiation Requires the RB LXCXE-Binding Function. Mol. Cell. Biol. 20, 5571-5580. 
Chen, H., Hwang, J.E., Lim, C.J., Kim, D.Y., Lee, S.Y., and Lim, C.O. (2010). Arabidopsis DREB2C functions as a transcriptional activator of HsfA3 during the heat stress response. Biochem. Biophys. Res. Commun. 401, 238-244.

Christians, M.J., Gingerich, D.J., Hua, Z., Lauer, T.D., and Vierstra, R.D. (2012). The light-response BTB1 and BTB2 proteins assemble nuclear ubiquitin ligases that modify phytochrome B and D signaling in Arabidopsis. Plant Physiol. 160, 118-134.

Ciccia, A., and Elledge, S.J. (2010). The DNA Damage Response: Making It Safe to Play with Knives. Mol. Cell 40, 179-204.

Cruz-Ramírez, A., Díaz-Triviño, S., Blilou, I., Grieneisen, V.A., Sozzani, R., Zamioudis, C., Miskolczi, P., Nieuwland, J., Benjamins, R., Dhonukshe, P., et al. (2012). A Bistable Circuit Involving SCARECROW- RETINOBLASTOMA Integrates Cues to Inform Asymmetric Stem Cell Division. Cell 150, 1002-1015.

Cruz-Ramírez, A., Diaz-trivino, S., Wachsman, G., Du, Y., Arteaga-Vazquez, M., Zhang, H., Benjamins, R., Blilou, I., Neef, A.B., Chandler, V., et al. (2013). A SCARECROW-RETINOBLASTOMA Protein Network Controls Protective Quiescence in the Arabidopsis Root Stem Cell Organizer. PLoS Biol. 11, e1001724.

Cubas, P., Lauter, N., Doebley, J., and Coen, E. (1999). The TCP domain: A motif found in proteins regulating plant growth and development. Plant J. 18, 215-222.

Davière, J.M., Wild, M., Regnault, T., Baumberger, N., Eisler, H., Genschik, P., and Achard, P. (2014). Class i TCP-DELLA interactions in inflorescence shoot apex determine plant height. Curr. Biol. 24, 1923-1928.

Debernardi, J.M., Tricoli, D.M., Ercoli, M.F., Hayta, S., Ronald, P., Palatnik, J.F., and Dubcovsky, J. (2020). A GRF-GIF chimeric protein improves the regeneration efficiency of transgenic plants. Nat. Biotechnol. 38, 1274-1279.

Desvoyes, B., and Gutierrez, C. (2020). Roles of plant retinoblastoma protein: cell cycle and beyond. EMBO J. 39, 1-18.

Desvoyes, B., De Mendoza, A., Ruiz-Trillo, I., and Gutierrez, C. (2014). Novel roles of plant RETINOBLASTOMA-RELATED (RBR) protein in cell proliferation and asymmetric cell division. J. Exp. Bot. 65, 2657-2666.

Dick, F.A., and Rubin, S.M. (2013). Molecular mechanisms underlying RB protein function. Nat. Rev. Mol. Cell Biol. 14, 297-306.

Ehsan, H., Reichheld, J.P., Durfee, T., and Roe, J.L. (2004). TOUSLED kinase activity oscillates during the cell cycle and interacts with chromatin regulators. Plant Physiol. 134, 1488-1499.

Engeland, K. (2018). Cell cycle arrest through indirect transcriptional repression by p53: I have a DREAM. Cell Death Differ. 25, 114-132.

Fiorentino, F.P., Marchesi, I., and Giordano, A. (2013). On the Role of Retinoblastoma Family Proteins in the Establishment and Maintenance of the Epigenetic Landscape. J. Cell. Physiol. 228, 276-284.

Fischer, M., and Müller, G.A. (2017). Cell cycle transcription control: DREAM/MuvB and RB-E2F complexes. Crit. Rev. Biochem. Mol. Biol. 52, 638-662.

De Folter, S., and Immink, R.G.H. (2011). Yeast protein-protein interaction assays and screens. Methods 
Mol. Biol. 754, 145-165.

Fox, S., Southam, P., Pantin, F., Kennaway, R., Robinson, S., Castorina, G., Sánchez-Corrales, Y.E., Sablowski, R., Chan, J., Grieneisen, V., et al. (2018). Spatiotemporal coordination of cell division and growth during organ morphogenesis. PLoS Biol. 16, 1-48.

Ghosh, R., Mishra, R.C., Choi, B., Kwon, Y.S., Bae, D.W., Park, S.C., Jeong, M.J., and Bae, H. (2016). Exposure to sound vibrations lead to transcriptomic, proteomic and hormonal changes in arabidopsis. Sci. Rep. 6, 33370.

Gingerich, D.J., Gagne, J.M., Salter, D.W., Hellmann, H., Estelle, M., Ma, L., and Vierstra, R.D. (2005). Cullins $3 a$ and $3 b$ assemble with members of the broad complex/tramtrack/ bric-a-brac (BTB) protein family to form essential ubiquitin-protein ligases (E3s) in arabidopsis. J. Biol. Chem. 280, 18810-18821.

Gómez, M.S., Falcone Ferreyra, M.L., Sheridan, M.L., and Casati, P. (2019). Arabidopsis E2Fc is required for the DNA damage response under UV-B radiation epistatically over the microRNA396 and independently of E2Fe. Plant J. 97, 749-764.

Guiley, K.Z., Liban, T.J., Felthousen, J.G., Ramanan, P., Litovchick, L., and Rubin, S.M. (2015). Structural mechanisms of DREAM complex assembly and regulation. Genes Dev. 29, 961-974.

Gutierrez, C., Ramirez-Parra, E., Castellano, M.M., and Pozo, J.C. del (2002). G1 to S transition: more than a cell cycle engine switch. Curr. Opin. Plant Biol. 5, 480-486.

Harashima, H., and Sugimoto, K. (2016). Integration of developmental and environmental signals into cell proliferation and differentiation through RETINOBLASTOMA-RELATED 1. Curr. Opin. Plant Biol. 29, 95-103.

Horiguchi, G., Kim, G., and Tsukaya, H. (2005). The transcription factor AtGRF5 and the transcription coactivator AN3 regulate cell proliferation in leaf primordia of Arabidopsis thaliana. Plant J. 43, 68-78.

Horvath, B.M., Kourova, H., Nagy, S., Nemeth, E., Magyar, Z., Papdi, C., Ahmad, Z., Sanchez-perez, G.F., Perilli, S., Blilou, I., et al. (2017). Arabidopsis RETINOBLASTOMA RELATED directly regulates DNA damage responses through functions beyond cell cycle control. EMBO J. 36, 1261-1278.

Hu, X., Kong, X., Wang, C., Ma, L., Zhao, J., Wei, J., Zhang, X., Loake, G.J., Zhang, T., Huang, J., et al. (2014). Proteasome-mediated degradation of FRIGIDA modulates flowering time in Arabidopsis during vernalization. Plant Cell 26, 4763-4781.

Hu, Z., Cools, T., and De Veylder, L. (2016). Mechanisms Used by Plants to Cope with DNA Damage. Annu. Rev. Plant Biol. 67, 439-462.

Indovina, P., Pentimalli, F., Casini, N., Vocca, I., and Giordano, A. (2015). RB1 dual role in proliferation and apoptosis: Cell fate control and implications for cancer therapy. Oncotarget 6, 17873-17890.

De Jager, S.M., Menges, M., Bauer, U.M., and Murray, J.A.H. (2001). Arabidopsis E2F1 binds a sequence present in the promoter of S-phase-regulated gene AtCDC6 and is a member of a multigene family with differential activities. Plant Mol. Biol. 47, 555-568.

Johnston, A.J., Matveeva, E., Kirioukhova, O., Grossniklaus, U., and Gruissem, W. (2008). A Dynamic Reciprocal RBR-PRC2 Regulatory Circuit Controls Arabidopsis Gametophyte Development. Curr. Biol. 18, 1680-1686. 
Johnston, A.J., Kirioukhova, O., Barrell, P.J., Rutten, T., Moore, J.M., Baskar, R., Grossniklaus, U., and Gruissem, W. (2010). Dosage-sensitive function of RETINOBLASTOMA RELATED and convergent epigenetic control are required during the Arabidopsis life cycle. PLoS Genet. 6, 1-12.

Kieffer, M., Master, V., Waites, R., and Davies, B. (2011). TCP14 and TCP15 affect internode length and leaf shape in Arabidopsis. Plant J. 68, 147-158.

Kim, J.H. (2019). Chromatin remodeling and epigenetic regulation in plant DNA damage repair. Int. J. Mol. Sci. 20, 4093.

Kim, J.H., and Kende, H. (2004). A transcriptional coactivator, AtGIF1, is involved in regulating leaf growth and morphology in Arabidopsis. Proc. Natl. Acad. Sci. U. S. A. 101, 13374-13379.

Kim, H.J., Park, J.H., Kim, J., Kim, J.J., Hong, S., Kim, J., Kim, J.H., Woo, H.R., Hyeon, C., Lim, P.O., et al. (2018). Time-evolving genetic networks reveal a nac troika that negatively regulates leaf senescence in arabidopsis. Proc. Natl. Acad. Sci. U. S. A. 115, E4930-E4939.

Kim, J.H., Ryu, T.H., Lee, S.S., Lee, S., and Chung, B.Y. (2019). lonizing radiation manifesting DNA damage response in plants: An overview of DNA damage signaling and repair mechanisms in plants. Plant Sci. 278, 44-53.

Kim, S., Choi, H.I., Ryu, H.J., Ji, H.P., Myoung, D.K., and Soo, Y.K. (2004). ARIA, an arabidopsis arm repeat protein interacting with a transcriptional regulator of abscisic acid-responsive gene expression, is a novel abscisic acid signaling component. Plant Physiol. 136, 3639-3648.

Kobayashi, K., Suzuki, T., Iwata, E., Nakamichi, N., Suzuki, T., Chen, P., Ohtani, M., Ishida, T., Hosoya, H., Müller, S., et al. (2015). Transcriptional repression by MYB 3R proteins regulates plant organ growth. EMBO J. 34, 1992-2007.

Kong, J., Martin-Ortigosa, S., Finer, J., Orchard, N., Gunadi, A., Batts, L.A., Thakare, D., Rush, B., Schmitz, O., Stuiver, M., et al. (2020). Overexpression of the Transcription Factor GROWTH-REGULATING FACTOR5 Improves Transformation of Dicot and Monocot Species. Front. Plant Sci. 11, 1-15.

Kouzarides, T. (2007). Chromatin Modifications and Their Function. Cell 128, 693-705.

Koyama, T., Sato, F., and Ohme-Takagi, M. (2017). Roles of miR319 and TCP transcription factors in leaf development. Plant Physiol. 175, 874-885.

Kumpf, R.P., and Nowack, M.K. (2015). The root cap: A short story of life and death. J. Exp. Bot. 66, 5651-5662.

Kuwabara, A., and Gruissem, W. (2014). Arabidopsis Retinoblastoma-related and Polycomb group proteins: Cooperation during plant cell differentiation and development. J. Exp. Bot. 65, 26672676.

Lantzouni, O., Alkofer, A., Falter-Braun, P., and Schwechheimer, C. (2020). Growth-regulating factors interact with dellas and regulate growth in cold stress. Plant Cell 32, 1018-1034.

Li, S. (2015). The Arabidopsis thaliana TCP transcription factors: A broadening horizon beyond development. Plant Signal. Behav. 10, e1044192.

Li, S., and Zachgo, S. (2013). TCP3 interacts with R2R3-MYB proteins, promotes flavonoid biosynthesis and negatively regulates the auxin response in Arabidopsis thaliana. Plant J. 76, 901-913.

Li, Z.Y., Li, B., and Dong, A.W. (2012). The arabidopsis transcription factor AtTCP15 regulates endoreduplication by modulating expression of key cell-cycle genes. Mol. Plant 5, 270-280. 
Litovchick, L., Sadasivam, S., Florens, L., Zhu, X., Swanson, S.K., Velmurugan, S., Chen, R., Washburn, M.P., Liu, X.S., and DeCaprio, J.A. (2007). Evolutionarily Conserved Multisubunit RBL2/p130 and E2F4 Protein Complex Represses Human Cell Cycle-Dependent Genes in Quiescence. Mol. Cell 26, 539-551.

Liu, X., and Marmorstein, R. (2007). Structure of the retinoblastoma protein bound to adenovirus E1A reveals the molecular basis for viral oncoprotein inactivation of a tumor suppressor. Genes Dev. 21, 2711-2716.

Liu, Q., Kasuga, M., Sakuma, Y., Abe, H., Miura, S., Yamaguchi-Shinozaki, K., and Shinozaki, K. (1998). Two transcription factors, DREB1 and DREB2, with an EREBP/AP2 DNA binding domain separate two cellular signal transduction pathways in drought- and low-temperature-responsive gene expression, respectively, in Arabidopsis. Plant Cell 10, 1391-1406.

Liu, S., Kracher, B., Ziegler, J., Birkenbihl, R.P., and Somssich, I.E. (2015). Negative regulation of ABA Signaling By WRKY33 is critical for Arabidopsis immunity towards Botrytis cinerea 2100. Elife 4, $1-27$.

Longworth, M.S., Herr, A., Ji, J.Y., and Dyson, N.J. (2008). RBF1 promotes chromatin condensation through a conserved interaction with the Condensin II protein dCAP-D3. Genes Dev. 22, 10111024.

Lorković, Z.J., Park, C., Goiser, M., Jiang, D., Kurzbauer, M.T., Schlögelhofer, P., and Berger, F. (2017). Compartmentalization of DNA Damage Response between Heterochromatin and Euchromatin Is Mediated by Distinct H2A Histone Variants. Curr. Biol. 27, 1192-1199.

Lu, G., Paul, A.L., McCarty, D.R., and Ferl, R.J. (1996). Transcription factor veracity: Is GBF3 responsible for ABA-regulated expression of arabidopsis Adh? Plant Cell 8, 847-857.

Magyar, Z., Horváth, B., Khan, S., Mohammed, B., Henriques, R., De Veylder, L., Bakó, L., Scheres, B., and Bögre, L. (2012). Arabidopsis E2FA stimulates proliferation and endocycle separately through RBR-bound and RBR-free complexes. EMBO J. 31, 1480-1493.

Marceau, A.H., Felthousen, J.G., Goetsch, P.D., Iness, A.N., Lee, H.W., Tripathi, S.M., Strome, S., Litovchick, L., and Rubin, S.M. (2016). Structural basis for LIN54 recognition of CHR elements in cell cycle-regulated promoters. Nat. Commun. 7, 1-11.

Marín-de La Rosa, N., Sotillo, B., Miskolczi, P., Gibbs, D.J., Vicente, J., Carbonero, P., Oñate-Sánchez, L., Holdsworth, M.J., Bhalerao, R., Alabadí, D., et al. (2014). Large-scale identification of gibberellinrelated transcription factors defines group VII ETHYLENE RESPONSE FACTORS as functional DELLA partners. Plant Physiol. 166, 1022-1032.

Matos, J.L., Lau, O.S., Hachez, C., Cruz-Ramírez, A., Scheres, B., and Bergmann, D.C. (2014). Irreversible fate commitment in the Arabidopsis stomatal lineage requires a FAMA and RETINOBLASTOMARELATED module. Elife 3, 1-15.

Menkens, A.E., and Cashmore, A.R. (1994). Isolation and characterization of a fourth Arabidopsis thaliana G-box- binding factor, which has similarities to Fos oncoprotein. Proc. Natl. Acad. Sci. U. S. A. $91,2522-2526$.

Morris, E.J., and Dyson, N.J. (2001). Retinoblastoma protein partners. Adv. Cancer Res. 82, 1-54.

Mosquna, A., Katz, A., Shochat, S., Grafi, G., and Ohad, N. (2004). Interaction of FIE, a Polycomb 
protein, with pRb: A possible mechanism regulating endosperm development. Mol. Genet. Genomics 271, 651-657.

Mushtaq, M., Gaza, H.V., and Kashuba, E. V (2016). Role of the RB-Interacting Proteins in Stem Cell Biology. In Advances in Cancer Research, pp. 133-157.

Nag, A., King, S., and Jack, T. (2009). miR319a targeting of TCP4 is critical for petal growth and development in Arabidopsis. Proc. Natl. Acad. Sci. U. S. A. 106, 22534-22539.

Nakashima, K., Shinwari, Z.K., Sakuma, Y., Seki, M., Miura, S., Shinozaki, K., and Yamaguchi-Shinozaki, K. (2000). Organization and expression of two Arabidopsis DREB2 genes encoding DRE-binding proteins involved in dehydration- and high-salinity-responsive gene expression. Plant Mol. Biol. 42, 657-665.

Narlikar, G.J., Fan, H.Y., and Kingston, R.E. (2002). Cooperation between complexes that regulate chromatin structure and transcription. Cell 108, 475-487.

Ning, Y., Liu, N., Lan, K., Su, Y., Li, L., Chen, S., and He, X. (2020). DREAM complex suppresses DNA methylation maintenance genes and precludes DNA hypermethylation. Nat. Plants 6, 942-956.

Nisa, M.U., Huang, Y., Benhamed, M., and Raynaud, C. (2019). The plant DNA damage response: Signaling pathways leading to growth inhibition and putative role in response to stress conditions. Front. Plant Sci. 10, 1-12.

Perilli, S., Perez-Perez, J.M., Di Mambro, R., Peris, C.L., Díaz-Triviño, S., Del Bianco, M., Pierdonati, E., Moubayidin, L., Cruz-Ramírez, A., Costantino, P., et al. (2013). RETINOBLASTOMA-RELATED protein stimulates cell differentiation in the Arabidopsis root meristem by interacting with cytokinin signaling. Plant Cell 25, 4469-4478.

Pogoda, M., Liu, F., Douchkov, D., Djamei, A., Reif, J.C., Schweizer, P., and Schulthess, A.W. (2020). Identification of novel genetic factors underlying the host-pathogen interaction between barley (Hordeum vulgare L.) and powdery mildew (Blumeria graminis f. sp. hordei). PLoS One 15, 1-23.

del Pozo, J.C., Boniotti, M.B., and Gutierrez, C. (2002). Arabidopsis E2Fc Functions in Cell Division and Is Degraded by the Ubiquitin-SCF AtSKP2 Pathway in Response to Light. Plant Cell 14, 3057-3071. Pruneda-Paz, J.L.L., Breton, G., Nagel, D.H.H., Kang, S.E.E., Bonaldi, K., Doherty, C.J.J., Ravelo, S., Galli, M., Ecker, J.R.R., and Kay, S.A.A. (2014). A Genome-Scale Resource for the Functional Characterization of Arabidopsis Transcription Factors. Cell Rep. 8, 622-632.

Raynaud, C., Mallory, A.C., Latrasse, D., Jégu, T., Bruggeman, Q., Delarue, M., Bergounioux, C., and Benhamed, M. (2014). Chromatin meets the cell cycle. J. Exp. Bot. 65, 2677-2689.

Sablowski, R., and Carnier Dornelas, M. (2014). Interplay between cell growth and cell cycle in plants. J. Exp. Bot. 65, 2703-2714.

Sanchez, M. de la P., Caro, E., Desvoyes, B., Ramirez-Parra, E., and Gutierrez, C. (2008). Chromatin dynamics during the plant cell cycle. Semin. Cell Dev. Biol. 19, 537-546.

Sanidas, I., Morris, R., Fella, K.A., Rumde, P.H., Boukhali, M., Tai, E.C., Ting, D.T., Lawrence, M.S., Haas, W., and Dyson, N.J. (2019). A Code of Mono-phosphorylation Modulates the Function of RB. Mol. Cell 73, 985-1000.e6.

Schmit, F., Cremer, S., and Gaubatz, S. (2009). LIN54 is an essential core subunit of the DREAM/LINC complex that binds to the cdc2 promoter in a sequence-specific manner. FEBS J. 276, 5703-5716. 
Shimotohno, A., Heidstra, R., Blilou, I., and Scheres, B. (2018). Root stem cell niche organizer specification by molecular convergence of PLETHORA and SCARECROW transcription factor modules. Genes Dev. 32, 1085-1100.

Singh, M., Krajewski, M., Mikolajka, A., and Holak, T.A. (2005). Molecular determinants for the complex formation between the retinoblastoma protein and LXCXE sequences. J. Biol. Chem. 280, 37868-37876.

Sugihara, T., Wadhwa, R., Kaul, S.C., and Mitsui, Y. (1999). A Novel Testis-Specific Metallothionein-like Protein,Tesmin,Is an Early Marker of Male Germ Cell Differentiation. Genomics 57, 130-136.

Takahashi, N., Ogita, N., Takahashi, T., Taniguchi, S., Tanaka, M., Seki, M., and Umeda, M. (2019). A regulatory module controlling stress-induced cell cycle arrest in arabidopsis. Elife 8, 1-27.

Thomas, D.M., Yang, H.-S., Alexander, K., and Hinds, P.W. (2003). Role of the Retinoblastoma Protein in Differentiation and Senescence. Cancer Biol. Ther. 2, 124-130.

Tsukagoshi, H., Busch, W., and Benfey, P.N. (2010). Transcriptional Regulation of ROS Controls Transition from Proliferation to Differentiation in the Root. Cell 143, 606-616.

Vaissière, T., Sawan, C., and Herceg, Z. (2008). Epigenetic interplay between histone modifications and DNA methylation in gene silencing. Mutat. Res. - Rev. Mutat. Res. 659, 40-48.

Vercruyssen, L., Verkest, A., Gonzalez, N., Heyndrickx, K.S., Eeckhout, D., Han, S.K., Jégu, T., Archacki, R., Van Leene, J., Andriankaja, M., et al. (2014). ANGUSTIFOLIA3 binds to SWI/SNF chromatin remodeling complexes to regulate transcription during Arabidopsis leaf development. Plant Cell $26,210-229$.

Vercruyssen, L., Tognetti, V.B., Gonzalez, N., Van Dingenen, J., De Milde, L., Bielach, A., De Rycke, R., Van Breusegem, F., and Inzé, D. (2015). Growth regulating factor5 stimulates arabidopsis chloroplast division, photosynthesis, and leaf longevity. Plant Physiol. 167, 817-832.

Wang, L., and Ruan, Y.L. (2013). Regulation of cell division and expansion by sugar and auxin signaling. Front. Plant Sci. 4, 1-9.

Wang, S., Gu, Y., Zebell, S.G., Anderson, L.K., Wang, W., Mohan, R., and Dong, X. (2014). A noncanonical role for the CKI-RB-E2F cell-cycle signaling pathway in plant effector-triggered immunity. Cell Host Microbe 16, 787-794.

Wang, W., Sijacic, P., Xu, P., Lian, H., and Liu, Z. (2018). Arabidopsis TSO1 and MYB3R1 form a regulatory module to coordinate cell proliferation with differentiation in shoot and root. Proc. Natl. Acad. Sci. U. S. A. 115, E3045-E3054.

Weimer, A.K., Nowack, M.K., Bouyer, D., Zhao, X., Harashima, H., Naseer, S., De Winter, F., Dissmeyer, N., Geldner, N., and Schnittger, A. (2012). RETINOBLASTOMA RELATED1 regulates asymmetric cell divisions in Arabidopsis. Plant Cell 24, 4083-4095.

Weimer, A.K., Matos, J.L., Sharma, N., Patell, F., Murray, J.A.H., Dewitte, W., and Bergmann, D.C. (2018). Lineage- and stage-specific expressed CYCD7;1 coordinates the single symmetric division that creates stomatal guard cells. Development 145, dev160671.

Wildwater, M., Campilho, A., Perez-Perez, J.M., Heidstra, R., Blilou, I., Korthout, H., Chatterjee, J., Mariconti, L., Gruissem, W., and Scheres, B. (2005). The RETINOBLASTOMA-RELATED gene regulates stem cell maintenance in Arabidopsis roots. Cell 123, 1337-1349. 
Yang, W., Choi, M.-H., Noh, B., and Noh, Y.-S. (2020). De Novo Shoot Regeneration Controlled by HEN1 and TCP3/4 in Arabidopsis. Plant Cell Physiol. 61, 1600-1613.

Zhang, H.S., Gavin, M., Dahiya, A., Postigo, A.A., Ma, D., Luo, R.X., Harbour, J.W., and Dean, D.C. (2000). Exit from $\mathrm{G} 1$ and $S$ phase of the cell cycle is regulated by repressor complexes containing HDACRb-hSWI/SNF and RB-hSWI/SNF. Cell 101, 79-89.

Zhang, J., Xu, K., Liu, P., Geng, Y., Wang, B., Gan, W., Guo, J., Wu, F., Chin, Y.R., Berrios, C., et al. (2016). Inhibition of Rb Phosphorylation Leads to mTORC2-Mediated Activation of Akt. Mol. Cell 62, 929-942.

Zhao, C., Lasses, T., Bako, L., Kong, D., Zhao, B., Chanda, B., Bombarely, A., Cruz-Ramírez, A., Scheres, B., Brunner, A.M., et al. (2017). XYLEM NAC DOMAIN1, an angiosperm NAC transcription factor, inhibits xylem differentiation through conserved motifs that interact with RETINOBLASTOMARELATED. New Phytol. 216, 76-89.

Zhou, W., Lozano-Torres, J.L., Blilou, I., Zhang, X., Zhai, Q., Smant, G., Li, C., and Scheres, B. (2019). A Jasmonate Signaling Network Activates Root Stem Cells and Promotes Regeneration. Cell 177, 942-956.e14. 


\section{Supplementary Information}

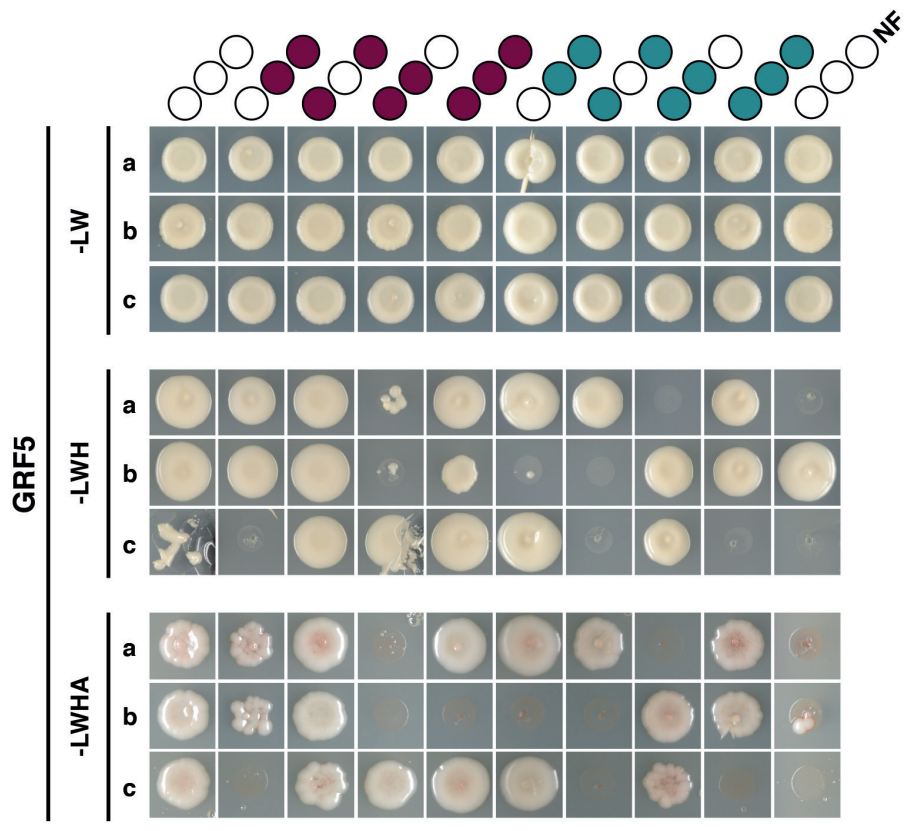

Figure S1: GRF5 potentially bind to all RBR variants.

From the $\mathrm{Y} 2 \mathrm{H}$ analysis in Figure 2, the three replicates denoted by lowcase letters show that the GRF5 TF interacted strongly but inconsistently to all RBR variants. Co-transformed yeast dropped on SD -LW to select transformants, and on SD -LWH +1.0 mM 3AT and SD -LWHA to select interactions. 


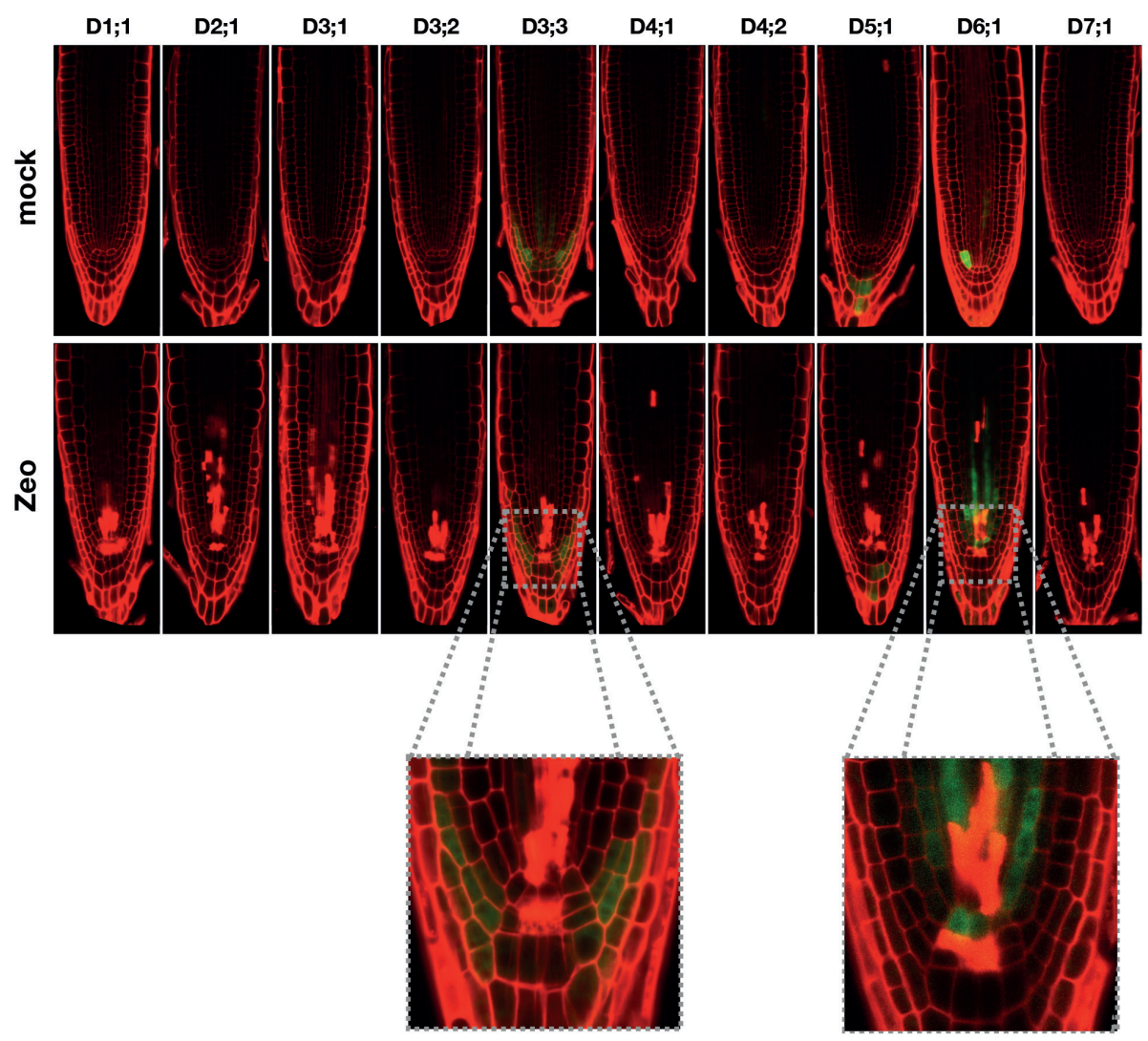

Figure S1: CYCD6;1 responds to DNA damage stress.

Confocal images of PI-stained root tips of PCYCD::GFP:GUS transcriptional reporters of the ten Arabidopsis CYCD gene family members. Seedlings germinated on $0.5 \mathrm{GM}$ medium for 4 days were transferred to $0.5 \mathrm{GM}$ medium (mock) or $0.5 \mathrm{GM}$ medium supplemented with Zeocin $10 \mu \mathrm{g} / \mathrm{mL}$ (Zeo) and imaged 24 hours later. Magnification insets show expression of CYCD6;1 but not CYCD3;3 in QC cells after Zeo treatment. Scale bar, $100 \mu \mathrm{M}$. 
Supplementary Table 1: Presence of selected RBR-interactors and related proteins in the Arabidopsis pExp22-TF library.

\begin{tabular}{llll}
\hline Accsession Number & TF & In the TF library & Found in screenings \\
\hline AT2G36010 & E2FA & Yes & No \\
AT5G22220 & E2FB & No & - \\
AT1G47870 & E2FC & Yes & Yes \\
AT3G48160 & DEL1 & No & - \\
AT5G14960 & DEL2 & No & - \\
AT3G01330 & DEL3 & Yes & No \\
AT3G54220 & SCR & Yes & No \\
AT3G24140 & FAMA & Yes & No \\
AT5G58230 & MSI & No & - \\
AT3G20740 & FIE & No & - \\
AT4G21070 & BRCA1 & No & - \\
AT5G07310 & ERF115 & Yes & No \\
AT3G22780 & TXC1/TSO1 & No & - \\
AT4G14770 & TCX2/SOL2 & Yes & No \\
AT3G22760 & TCX3/SOL1 & No & - \\
AT3G04850 & TCX4 & No & - \\
AT4G29000 & TCX5 & No & - \\
AT2G20110 & TCX6 & Yes & Yes \\
AT5G25790 & TCX7 & Yes & Yes \\
AT3G16160 & TCX8 & Yes & No \\
\hline & & & \\
\hline
\end{tabular}

Supplementary Table 2: List of primers.

\begin{tabular}{lll}
\hline Primer & Sequence & \\
\hline TCX6c-F & GGGGACAAGTTTGTACAAAAAAGCAGGCTATATGGGAGAAGGTGAAGAAGG & Gateway cloning \\
TCX6gcg1-F & CAAACGGTCTTTGTTCTGGGAACTGCAAATGCTTGGATTG & Gateway cloning \\
TCX6gcg1-R & CAGTTCCCAGAACAAAGACCGTTTGCTTGAAAGCACTCACA & Gateway cloning \\
TCX6gcg2-F & TGGCAGGGATGTGTGACGGACGGGACACAATGTTAATGGTT & Gateway cloning \\
TCX6gcg2-R & TCCCGTCCGTCACACATCCCTGCCAAAGTTTCTGGAGATAGTG & Gateway cloning \\
TCX6c-R & GGGGACCACTTTGTACAAGAAAGCTGGGTTTTAGAGGTCTTTCTTCTCAGACA & Gateway cloning \\
cRBR-GWF & GGGGACAAGTTTGTACAAAAAAGCAGGCTTAATGGAAGAAGTTCAGCCTCCAGT & RBR baits \\
& & Gateway cloning \\
cRBR-GWR & GGGGACCACTTTGTACAAGAAAGCTGGGTAcgaaTCTGTTGGCTCGGTTTTAAG & RBR baits \\
& & Gateway cloning
\end{tabular}




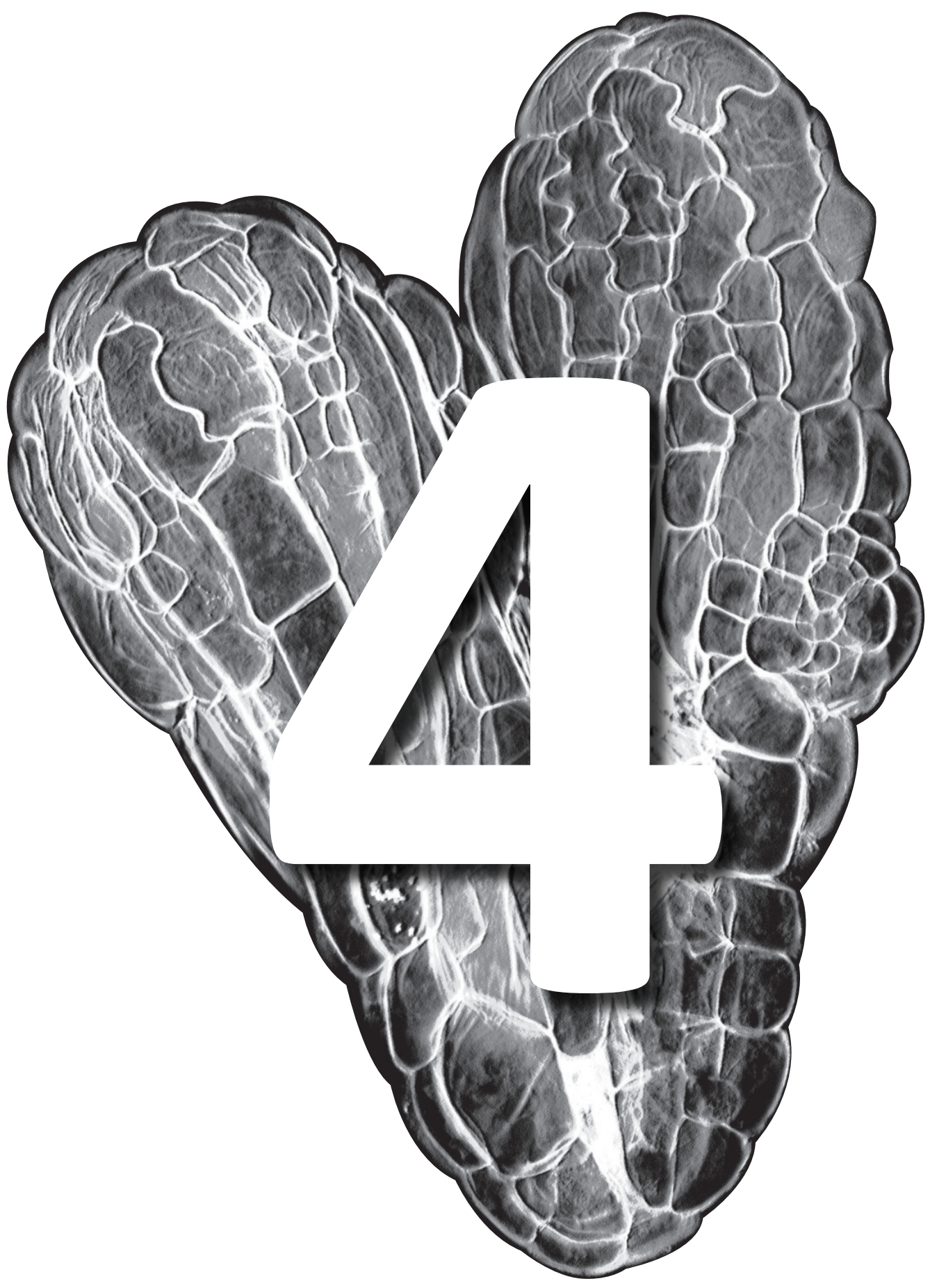




\section{Chapter 4}

\section{The dual role of the RETINOBLASTOMA-RELATED protein in the DNA damage response is spatio- temporally coordinated by the interaction with LXCXE-containing proteins}




\section{Abstract}

Living organisms face threats to genome integrity caused by environmental challenges or metabolic errors in proliferating cells. To avoid the spread of mutations, cell division is temporarily arrested while repair mechanisms deal with DNA lesions. Afterwards, cells either resume division or respond to unsuccessful repair by withdrawing from the cell cycle and undergoing cell death. How the success rate of DNA repair connects to the execution of cell death remains incompletely known, particularly in plants. Here we provide evidence that the Arabidopsis thaliana RETINOBLASTOMA-RELATED1 (RBR) protein, shown to play structural and transcriptional functions in the DNA damage response (DDR), coordinates these processes in time by successive interactions through its B-pocket sub-domain. Upon DNA damage induction, RBR forms nuclear foci; but the N849F substitution in the B-pocket, which specifically disrupts binding to LXCXE motif-containing proteins, abolishes RBR focus formation and leads to growth arrest. After RBR focus formation, the stress-responsive gene NACO44 arrests cell division. As RBR is released from nuclear foci, it can be bound by the conserved LXCXE motif in NAC044. RBR-mediated cell survival is inhibited by the interaction with NAC044. Disruption of NAC044-RBR interaction impairs the cell death response but is less important for NAC044 mediated growth arrest. Noteworthy, unlike many RBR interactors, NAC044 binds to RBR independent of RBR phosphorylation. Our findings suggest that the availability of the RBR B-pocket to interact with LXCXE-containing proteins couples the structural DNA repair functions and the transcriptional functions of RBR in the cell death program. 


\section{Introduction}

Living organisms encounter daily challenges to genome integrity that jeopardize survival and reproduction. In response to intrinsic or environmental factors (Chen et al., 2019; Tsegay et al., 2019; Yi et al., 2014), eukaryotic DNA damage triggers a variety of responses collectively known as DNA damage response (DDR): the ATM/ATR kinases initiate a phosphorelay system to tag the damage site, pause the cell cycle, and repair the lesion; if the damage is too extensive to repair, cells activate a suicidal program -apoptosis in animals, and Programmed Cell Death (PCD) in plants - to avoid propagation of mutations (Chen, 2016; Ciccia and Elledge, 2010; Hu et al., 2016; Kim et al., 2019; Lanz et al., 2019; Waterworth et al., 2019). In animals, DDR is largely mediated by p53, an transcription factor that activates the DNA repair machinery and the transcriptional responses leading to cell division arrest and, if necessary, senescence and apoptosis (Chen, 2016; Kastenhuber and Lowe, 2017; Williams and Schumacher, 2016). In plants, no p53 orthologs have been found, and DDR relies on the functional analog SUPPRESSOR OF GAMMA RESPONSE1 (SOG1), a member of the plant-specific NAC-transcription factor family (NAM-ATAF-CUC(Bourbousse et al., 2018; Mahapatra and Roy, 2020; Yoshiyama et al., 2009).

Previous studies identified direct and indirect targets of SOG1 upon DNA damage in Arabidopsis thaliana (Bourbousse et al., 2018; Ogita et al., 2018). Besides activating the majority of the DNA repair genes, SOG1 represses cell cycle and induces cell death by directly activating NAC044 and NAC085, the closest SOG1 paralogs (Bourbousse et al., 2018; Ogita et al., 2018; Takahashi et al., 2019). NAC044/NAC085 stabilize MYB3R3 repressor proteins that in turn bind to the MSA sequence present in G2/M gene promoters, arresting cell division (Chen et al., 2017; Kobayashi et al., 2015; Takahashi et al., 2019). However, how NAC044/NAC085 induce cell death in after DNA injury is unclear.

In recent years, another cell cycle regulator emerged as a central player in the DDR acting in parallel to SOG1: the transcriptional repressor RETINOBLASTOMA-RELATED1 protein (RBR), homolog of the human tumor suppressor $\mathrm{pRB}$ and a major regulator of the G1/S phase transition (Biedermann et al., 2017; Bouyer et al., 2018; Cruz-Ramírez et al., 2012; Horvath et al., 2017). RBR is a multifunctional protein that integrates environmental information into cell cycle and developmental programs by interacting with a plethora of transcriptional and chromatin regulators (Cruz-Ramírez et al., 2012; Desvoyes et al., 2014a; Gutierrez, 2005; Gutzat et al., 2012; Harashima and Sugimoto, 2016; Johnston et al., 2008; Matos et al., 2014)(Borghi et al., 2010; Chen et al., 2011; Cruz-Ramírez et al., 2012; Harashima and Sugimoto, 2016; Perilli et al., 2013). In proliferating cells, RBR binds to E2F-DP heterodimeric transcription factors to prevent S-phase onset until Cyclin D-CDKA kinases phosphorylate RBR to release E2F-DP, allowing cell cycle progression (Berckmans and De Veylder, 2009; Desvoyes et al., 2014b; Magyar et al., 2012; Polit et al., 2012; De Veylder et al., 2002). 
Upon DNA damage, RBR plays both a transcriptional and a structural function. It regulates the expression of repair genes and mediates the localization of the RAD51 repair protein to DNA damage sites, visualized as nuclear foci where other proteins such as E2FA and BRCA1 co-localize with RBR (Biedermann et al., 2017; Bouyer et al., 2018; Horvath et al., 2017). Reduction of RBR levels leads to genome instability, cell death, and hypersensitivity to DNA damaging treatments (Biedermann et al., 2017; Cruz-Ramírez et al., 2013; Horvath et al., 2017). Thus, it is likely that RBR participates in the mechanism mediating PCD following DNA damage.

RBR belongs to the 'pocket protein' family, characterized by the A- and B-pocket subdomains that fold into the 'pocket domain', a N-domain, a C-terminal region, and multiple sites for CDK-mediated phosphorylation (Desvoyes and Gutierrez, 2020; Dick and Rubin, 2013; Gutzat et al., 2012; Rubin, 2013). Pocket proteins functions rely on their ability to form protein interactions regulated by phosphorylation (Dick and Rubin, 2013; Narasimha et al., 2014; Sanidas et al., 2019). E2Fs bind to the A-B subdomains interface, while Cyclin D proteins and many others bearing the conserved LXCXE motif dock in the LXCXE-binding cleft located at the B-subdomain (DeCaprio, 2009; Flemington et al., 1993; Helin et al., 1993). A point mutation that specifically disrupts pRB-LXCXE interactions fails to irreversibly arrest cell division in human cell lines (Chen and Wang, 2000), and hampers anti-tumorigenic activity of pRB after induced DNA damage in mice (Bourgo et al., 2011). Here, we used the same amino acid change to dig deeper into the molecular determinants underlying Arabidopsis thaliana RBR roles during DDR. We show that the ability of RBR to interact with LXCXEcontaining proteins is crucial to withstand DNA damage. An as yet unidentified factor recruits RBR to nuclear foci early after DNA damage induction. Following clearance from foci, RBR interacts with NACO44 in a LXCXE dependent and phosphorylation-independent manner. Specific disruption of RBR-NACO44 interaction revealed that the SOG1 and RBR pathways converge on the transcriptional regulation of cell death. Collectively, our results support the existence of an LXCXE-coordinated timeframe for the dual RBR role during the DDR.

\section{Results}

Full length RBR interacts with LXCXE proteins to function in the DNA damage response.

The ability of mouse pRB to interact with LXCXE proteins is dispensable under ideal growth conditions, but it is essential when DNA is damaged (Bourgo et al., 2011). To investigate the role of RBR-LXCXE interactions in the plant DDR, we analysed the effect of mutating asparagine (N) 849 to phenylalanine (F) in Arabidopsis RBR, hereafter referred to as $R B R^{N F}$ (Cruz-Ramirez et al., 2013). N849 is a conserved residue of the RBR LXCXE-binding cleft located in the B-pocket subdomain (Gutzat et al., 2012), and other studies in mammals 
A

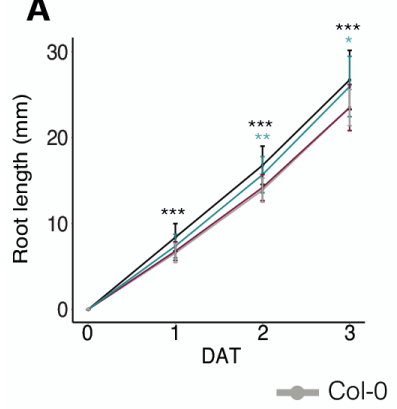

B

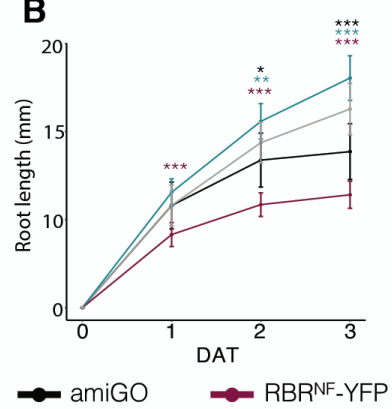

C

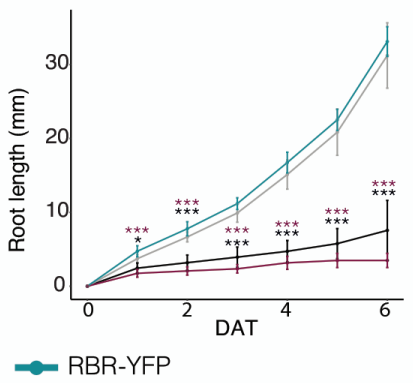

D

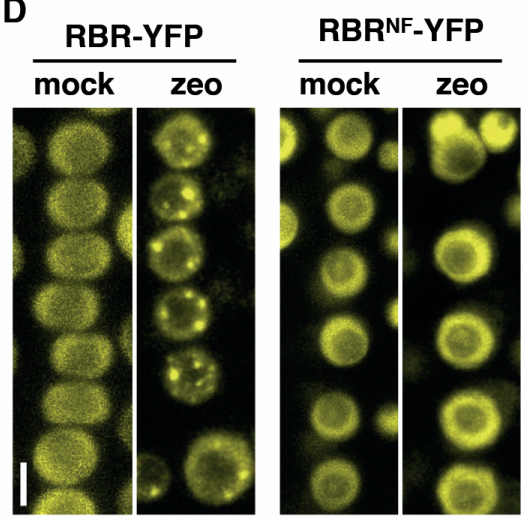

E
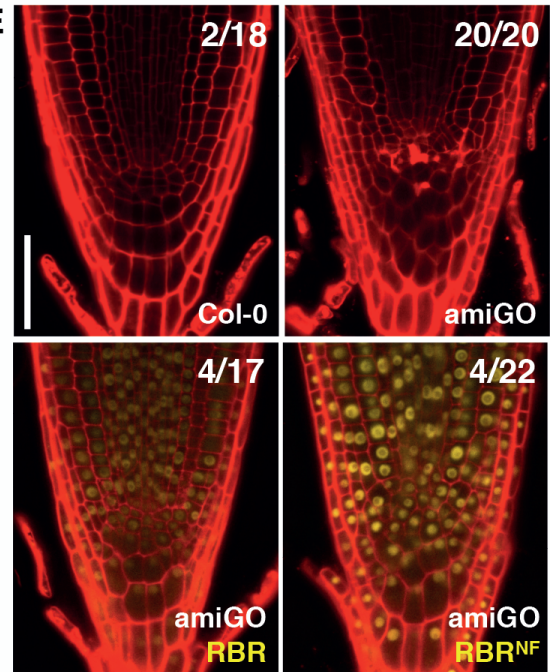

Figure 1: The LXCXE motif interacting domain of RBR is needed to cope with DNA damage.

(A-C) Root growth comparison of Col-0, amiGO, RBR-YFP and RBRNF-YFP. Seedlings germinated and grown on $0.5 \mathrm{GM}$ medium for 4-5 days were transferred to $0.5 \mathrm{GM}$ medium without (A) or with (B) $3 \mu \mathrm{g} / \mathrm{mL}$ zeocin (zeo) for 3 days after transfer (dat), or incubated on $10 \mu \mathrm{M}$ zeo for $20 \mathrm{~h}$ and transferred again to $0.5 \mathrm{GM}$ for recovery over 6 dat (C). Data in $A, B)$ presented as mean +SD of two independent replicates, in C) a single replicate is presented. $10<n<17$. ${ }^{* * *} p<0.001,{ }^{* *} p<0.01,{ }^{*} p<0.05$.

(D) Representative maximum-intensity projections of z-stack images from RBR-YFP and RBR ${ }^{\mathrm{NF}-Y F P}$ living roots nuclei after $16 \mathrm{~h}$ incubation in $0.5 \mathrm{GM}$ medium supplemented with without (mock) or with $10 \mu \mathrm{g} / \mathrm{mL}$ zeo.

(E) Cell death visualized by confocal imaging of longitudinal sections of propidium iodide (PI)-stained root tips 8 days post germination ( $\mathrm{dpg}$ ) on $0.5 \mathrm{GM}$ medium without zeocin; numbers indicate roots presenting dead cells in Col-0, amiGO and amiGO complemented with RBR-YFP or RBR ${ }^{\mathrm{NF}-Y F P}$.

Scale bars, $5 \mu \mathrm{M}$ in (D), $50 \mu \mathrm{M}$ in (E). See also Figure $\mathrm{S1}$.

(Bourgo et al., 2011; Chen and Wang, 2000) and Arabidopsis (Cruz-Ramírez et al., 2013) have used the NF allele to disrupt LXCXE interactions. We transformed pRBR::RBR ${ }^{N F}: v Y F P$ (RBR ${ }^{N F}$-YFP) into our previously reported amiGO-RBR line (hereafter amiGO), an RBRtargeted amiRNA that permits complementation with transgenic RBR lacking the 3'UTR (Cruz-Ramírez et al., 2013). In the same background, we generated two truncated versions 
lacking either the $\mathrm{N}$-domain ( $\left.\mathrm{RBR}^{\mathrm{\partial N}}-\mathrm{YFP}\right)$ or both the $\mathrm{N}$-domain and the $\mathrm{C}$-terminal region (RBR ${ }^{\text {pocket}}$ YFP), and a full length Wt RBR (RBR-YFP) to investigate the structural components of RBR protective function against genotoxic stress.

While the roots of all variants grew normally in standard conditions (Fig 1A, Fig 1SA), only RBR-YFP was able to sustain growth on medium supplemented with zeocin (Fig 1B, Fig 1SB), a radio-mimetic genotoxic agent that creates double strand breaks (DSB) in the DNA (Kim et al., 2019) and invariably leads to cell death (Fig. S1D). A recovery period after zeocin treatment revealed that a full length RBR with an intact B-pocket subdomain is necessary to cope with DNA damage (Fig 1C, Fig 1SC).

Since RBR aggregates in nuclear foci with histone $\mathrm{YH} 2 \mathrm{AX}$ and repair proteins RAD51 and BRCA1 (Biedermann et al., 2017; Horvath et al., 2017), we asked whether the inability of RBR variants to recover from DNA damage relates to this process. Both truncated variants displayed an altered accumulation of foci over time, with RBR ${ }^{\mathrm{DN}}$-YFP showing a reduced clearance rate, and RBR ${ }^{\text {pocket}}$-YFP having reduced foci formation and clearance (Fig S1E,F).

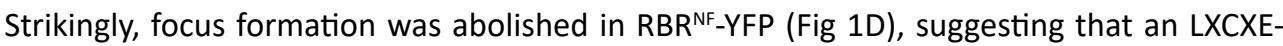
containing protein is required to tether RBR to DSB. A conserved LXCXE motif in RAD54 (fig S2A), a DNA repair protein that also forms repair foci with RAD51 in Arabidopsis (Hirakawa and Matsunaga, 2019; Hirakawa et al., 2017), led us to test whether RAD54 might recruit RBR to foci. We failed to demonstrate that RBR and RAD54 bind directly (Fig. S2B), and no co-localization of RAD54 and RBR zeocin-induced foci was observed, in contrast to the highly co-localized RBR/E2FA foci (Fig S2C-H). Since RBR forms foci in the absence of RAD54 (Fig S2I), RAD54 does not recruit RBR to the DNA damage sites. In sum, all RBR protein domains contribute to the DNA repair function of RBR, and the LXCXE-binding cleft is crucial for RBR foci formation and tethering by an as yet unidentified protein.

Root tips with reduced RBR levels display cell death even in unchallenging conditions, likely due to genome instability (Biedermann et al., 2017; Cruz-Ramírez et al., 2013; Horvath et al., 2017; Wildwater et al., 2005), but whether this phenotype relates to defective foci dynamics is unknown. Surprisingly, only the truncated RBR variants failed to suppress the spontaneous cell death observed in the amiGO roots (Fig. S1G), whereas the RBR ${ }^{\mathrm{NF}-Y F P}$ rescued this phenotype to the same extent that RBR-YFP (Fig 1E). Thus, the ability of RBR to form nuclear foci is dispensable to promote cell survival in standard growth conditions.

\section{RBR interacts with NAC044 through a conserved LXCXE motif regardless RBR phosphory- lation state.}

In a Y2H screening of the Arabidopsis transcription factors library (Pruneda-Paz et al., 2014) we identified NACO44 as a strong RBR interactor (Chapter 3). NACO44 is a direct transcriptional target of SOG1 and, along with NAC085, the closest homolog of SOG1 (Ogita et al., 2018; 
Takahashi et al., 2019). We noticed that NACO44 contains an LXCXE motif in the C-terminus (Fig 2A,B); such motif is conserved among NAC044 orthologs in monocots and dicots species but is absent in NAC085 and modified in SOG1 (Fig 2A). Noteworthy, the NAC044 LXCXE motif is identical to that of RAD54 (compare Fig $2 A$ and S2A). To test the RBR binding capacity of the NAC044 LXCXE motif, we performed $\mathrm{Y} 2 \mathrm{H}$ assays. Figure $2 \mathrm{C}$ shows that E2FC binds to RBR and $\mathrm{RBR}^{\mathrm{NF}}$, but NACO44 failed to interact with RBR ${ }^{\mathrm{NF}}$. When the LXCXE motif in NACO44 was changed into GXCXG (hereafter NAC044 ${ }^{\mathrm{GCG}}$ ) the interaction with RBR was abolished (Fig $2 \mathrm{C}$ ). Split-luciferase assays showed that, while E2FA, E2FB and E2FC interacted in planta with both RBR and RBR ${ }^{N F}$ (Fig S3A), NAC044-RBR binding was suppressed by either RBR ${ }^{\mathrm{NF}}$ or NAC044GCG mutations (Fig 2D). Moreover, RBR and NAC044 interacted in a LXCXE-dependent manner upon zeocin treatment as shown by a split-lucieferase assay in Arabidopsis stable transformants (Fig. S3B). In contrast, SOG1 was unable to interact with RBR (Fig 2C).

While both E2FC and NAC044 interacted with a fully phospho-defective RBR, a phosphomimetic RBR disrupted the binding to only E2FC (Fig 2E). Since NAC044 fosters stress-induced cell death and G2/M cell cycle arrest (Takahashi et al., 2019), and RBR is phosphorylated at the G1/S-phase transition (Boniotti and Gutierrez, 2001; Nakagami et al., 2002), there is a logical explanation that NACO44 should be able to bind the hyper-phosphorylated form of RBR. Altogether, our results demonstrate that RBR interacts with NACO44 in a LXCXEdependent manner but independent of RBR phosphorylation state -which is relevant in the likely scenario where both proteins act together after the $\mathrm{G} 1 / \mathrm{S}$ phase transition. 
A
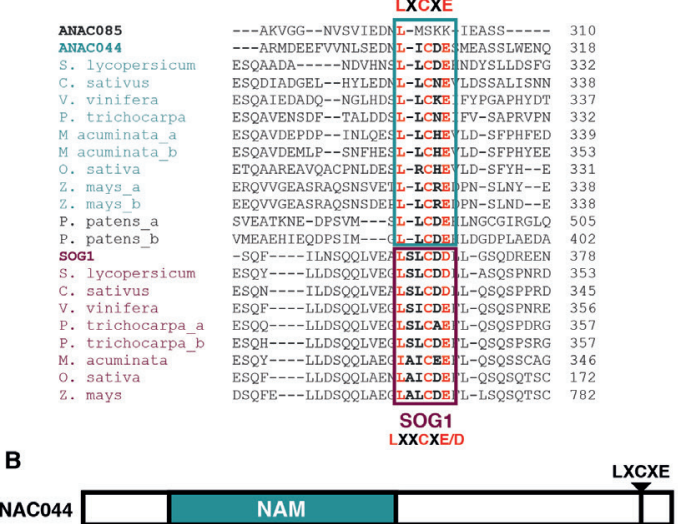

C

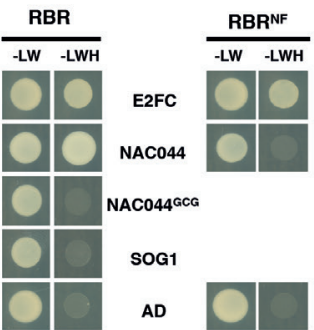

E

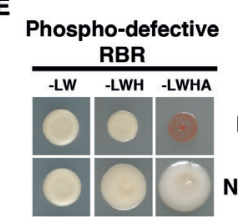

D

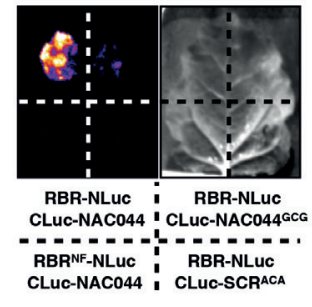

Figure 2 (part 2): RBR interacts with NAC044 through a conserved LXCXE motif regardless RBR phosphorylation state.

(A) Protein sequence alignment of Arabidopsis NAC044 (ANAC044) and SOG1 orthologs in the indicated plant species showing the fragment with LXCXE and LXXCXE/D motifs highlighted. A BLAST search using ANAC085 as query retrieved the same hits as when using ANAC044, and all presented the LXCXE motif. (B) Schematic representation of NAC044 protein organization as predicted by https://pfam.xfam. org/ showing the relative positions of the NAM domain and LXCXE motif. (C) Yeast two-hybrid analysis showing that BD-RBR, but not BD-RBR ${ }^{\mathrm{NF}}$, interacts with NAC044, and neither of them binds SOG1 nor an LXCXE-to-GXCXG-mutated NAC044 protein (NAC044GCG). E2FC and empty vector (AD) are positive and negative controls, respectively. Transformant yeast were dropped onto SD/-L/-W (-LW), SD/-L/W/-H/+1.5mM3AT (-LWH). AD and BD, GAL4 activation domain and DNA binding domain, respectively. (D) Split Luciferase assay of RBR binding to NAC044 in planta. N. benthamiana leaves were co-infiltrated with the plasmid combinations and in the order indicated by dashed-line divided quadrants. Luciferase activity and a bright field images are shown. Representative images of 6 independent replicates. (E) Yeast two-hybrid analysis reveals that NAC044 interacts with a non-phosphorylatable RBR mutant (phospho-defective RBR) and phospho-mimmetic RBR. All 16 putative CDK-phospho-sites in RBR were mutated to Ala (phospho-defective) or to Asp or Glu (Phospho-mimmetic). Transformant yeast were dropped onto SD/-L/-W (-LW), SD/-L/-W/-H/+1.5mM3AT (-LWH), SD/-L/-W/-H/-A (-LWHA). Data shown are representative of 3 independent replicates. See also Figures S2 and S3 
RBR is rapidly recruited to foci before NAC044 expression is induced by DNA damage.

Is NAC044 the protein that recruits RBR to foci? we first generated transcriptional and translational reporters controlled by a promoter that comprises the intergenic region and harbors the SOG1 binding site, a MSA element (mitosis-specific activator) and a E2F box (Fig S4A). pNAC044::GUS and pNAC044::3GFP-NLS resemble the previously reported expression pattern in the root tip (Takahashi et al., 2019), characteristic of cell cycle-regulated, and DNA damage-induced genes (Fig S4B) -contrasting with its age-dependent expression in the floral organ abscission zone (Fig. S4C).

A

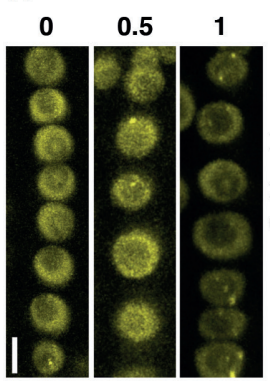

B

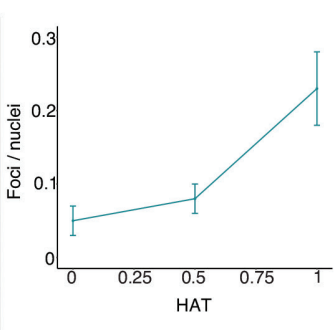

C

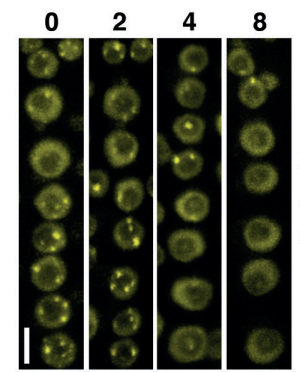

D

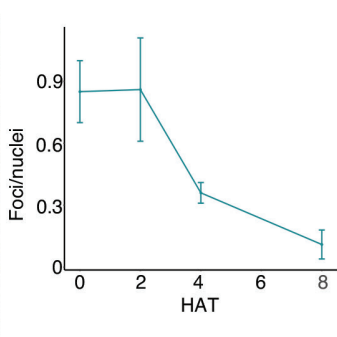

E Recovery time (hpz)

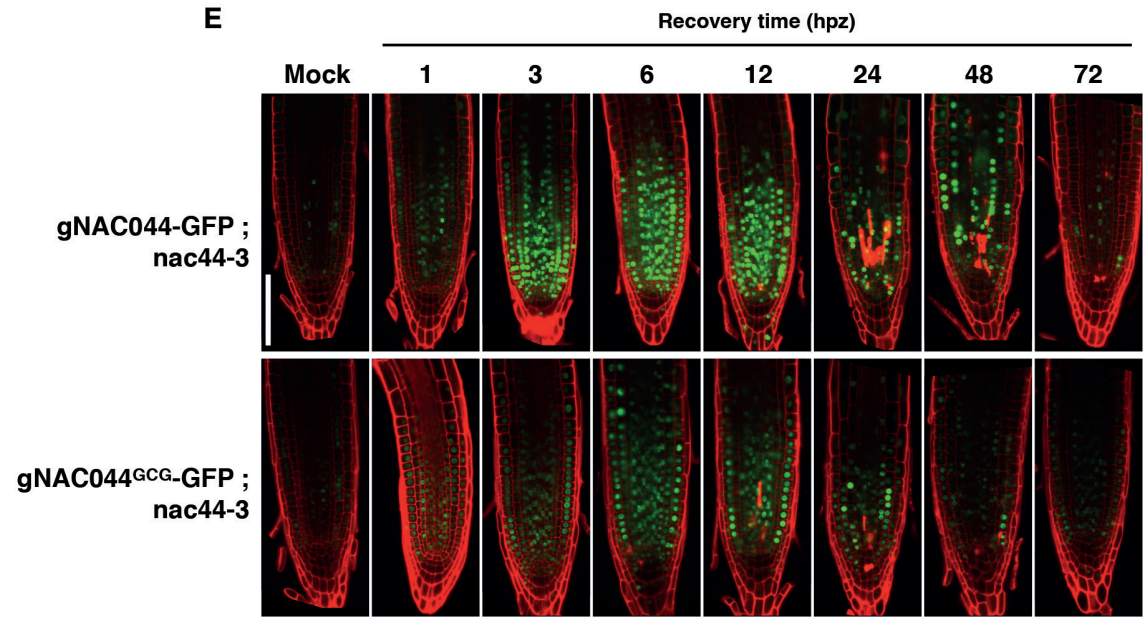

Figure 3: RBR is rapidly recruited to foci before NAC044 expression is induced by DNA damage.

(A-D) RBR-YFP foci at $0,0.5$ and $1 \mathrm{~h}(\mathrm{~A}, \mathrm{~B})$ or $0,2,4,8 \mathrm{~h}(\mathrm{C}, \mathrm{D})$ after zeo treatments: $20 \mu \mathrm{g} / \mathrm{mL}$ zeo for $2 \mathrm{~h}(\mathrm{~A}, \mathrm{~B})$ and $10 \mu \mathrm{g} / \mathrm{mL}$ zeo for $16 \mathrm{~h}(\mathrm{C}, \mathrm{D})$. Seedlings were transferred to $0.5 \mathrm{GM}$ for the indicated recovery time (hours after zeo treatment, hat) before imaging. Representative maximum-intensity projections of $z$-stack images from RBR-vYFP living roots nuclei $(A, C)$ and quantification $(B, D)$ of nuclear foci divided by the number of nuclei. Data in $(B, D)$ presented as mean $+S D$. $\ln (B) n>3$ roots, total nuclei per time point $>1000$; in (D) $n>4$, total nuclei per time point $>2000$. (E) Representative confocal images of longitudinal sections of roots from nac044-3 complementing translational fusions pNAC044::gNAC044:GFP and pNAC044::gNAC044 ${ }^{\mathrm{GCG}: G F P}$ after $2 \mathrm{~h}$ incubation on $20 \mu \mathrm{g} / \mathrm{mL}$ zeo. Seedlings were transferred to $0.5 \mathrm{GM}$ for the indicated recovery time before imaging. Scale bars, $5 \mu \mathrm{M}$ in $(A, C), 100 \mu \mathrm{M}$ in (E). See also Figure S4 and S5. See also Figure S4. 
pNAC044::NAC044:GFP (hereafter referred to as NAC044-GFP) never formed foci after a zeocin treatment that promoted RBR foci formation and NAC044-GFP accumulation in the same nuclei (Fig S4D), indicating that focal RBR is unable to bind NAC044. Moreover, RBR formed foci in the absence of NACO44 (Fig. S4E). Therefore, NAC044 is not the recruiter of RBR at foci, and more likely acts with RBR in the later transcriptional response rather than in the structural aspect of DNA repair. These roles are separated in the sub-nuclear space by LXCXE-binding constraints.

RBR repair functions are separated in time as well. RBR foci formation started immediately after a short exposure to zeocin and rapidly increased within $1 \mathrm{~h}$ (Fig. 3A,B), whereas a longer treatment induced a large amount of RBR foci that cleared out almost completely within 8 hours of recovery (Fig 3C,D). Noteworthy, histone $\mathrm{pH} 2 \mathrm{AX}$ foci formation and clearance kinetics are similar (Charbonnel et al., 2011). Conversely, the pNAC044 reporters increased only after 3 hours following a short zeocin treatment, peaking after $12 \mathrm{~h}$, and lasting for at least 3 days (Fig S4B). These results suggest that RBR is recruited to foci well before NAC044 is highly induced, preventing their interaction during the early stages of the DDR, but released to the nucleoplasm where, later on, both proteins are present.

\section{NAC044 interacts with RBR to induce cell death after DNA damage.}

To further explore the biological relevance of NAC044-RBR interaction, we generated both NAC044-GFP and its LXCXE-mutated version (pNAC044::NAC044 ${ }^{\mathrm{GCG}}$ :GFP; hereafter NAC044 ${ }^{\mathrm{GCG}}$-GFP) in the genetic background of nac044 knock-out alleles - nac044-3 (Fig S4F) and the reported nac044-1, both of which exhibited a similar insensitivity phenotype

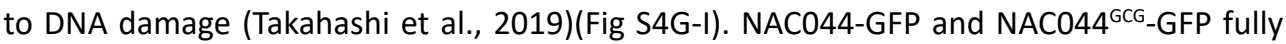
complemented nac044-3 when seedlings grew on sustained zeocin conditions (Fig $\mathrm{S} 4 \mathrm{H}, \mathrm{I}$ ). After a short zeocin exposure all reporters were induced, but the translational fusions displayed a broader expression domain than the promoter reporter (Fig 3E; Fig S4B) - maybe due to different protein stability or transcriptional regulatory elements within the gene body. Both NAC044-GFP and NAC044 ${ }^{\mathrm{GCG}}$-GFP gradually accumulated, reaching maximum levels between 6-12h, then they gradually decreased over the course of two days (Fig $3 \mathrm{E}$ ). Along with NACO44 accumulation, the meristem shrinks and the cell death increases during the first $24 \mathrm{~h}$.

We further tested the effect of a prolonged pulse of zeocin on root growth to address the physiological role of RBR-NACO44 interaction. Besides the strong effect of RBR ${ }^{\mathrm{NF}}$ in combination with reduced endogenous RBR levels showed in Figure $1 C$, the RBR ${ }^{\mathrm{NF}}-\mathrm{YFP}$ prevented roots to resume growth, even in the presence of the endogenous RBR or in the absence of NACO44, while extra copies of Wt RBR seemed to have a positive effect on root growth (Fig S5A), indicating that $\mathrm{RBR}^{\mathrm{NF}}$ is not only less active due to its inability to bind LXCXE proteins, but has dominant features. Therefore, failure to form foci and to interact 

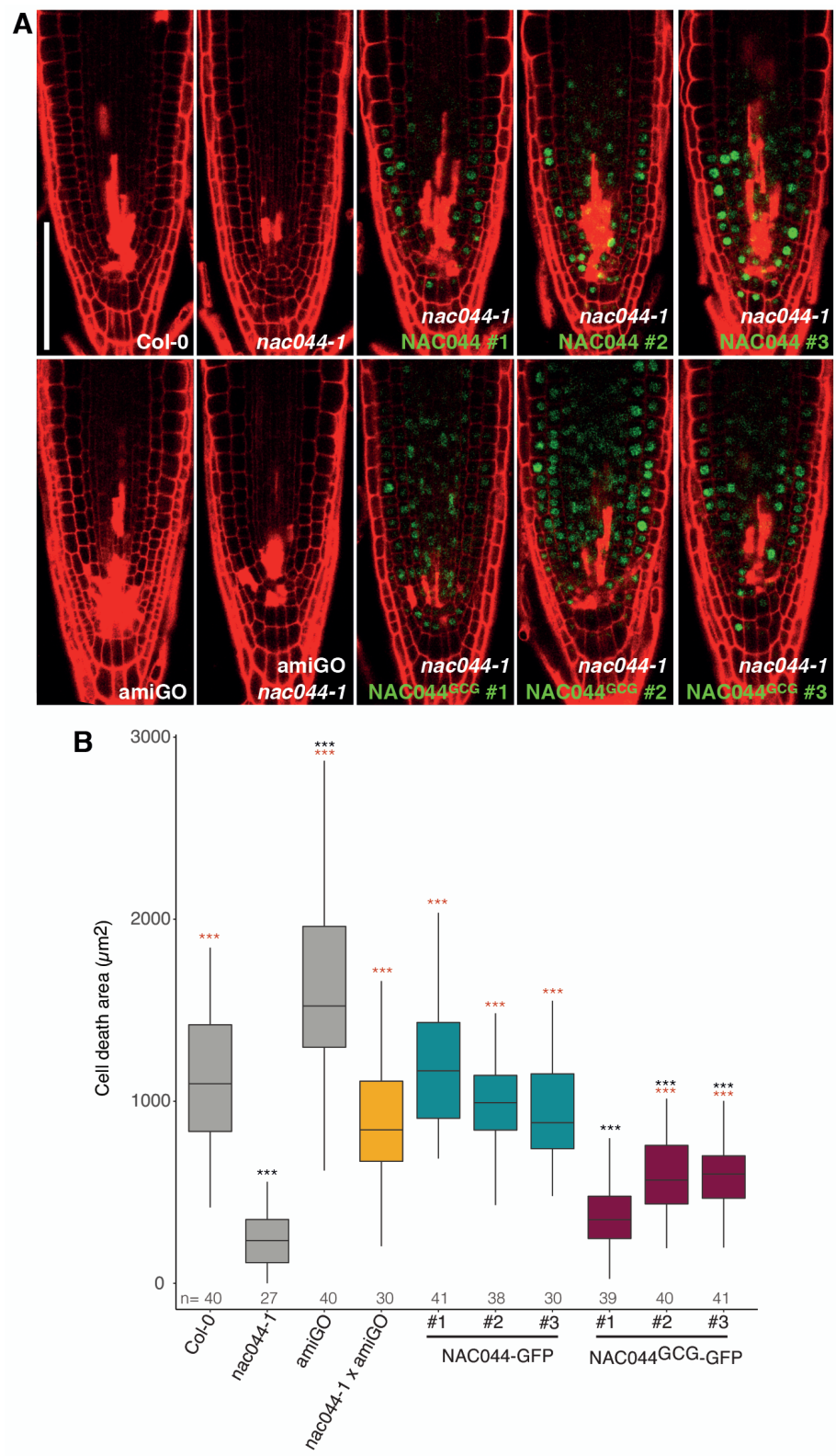

Figure 4: NAC044 interacts with RBR to induce cell death after DNA damage.

(A) Cell death visualized by $\mathrm{PI}$ accumulation in a representative confocal image of longitudinal sections of root tips from the indicated genotypes. Three independent transformant lines of NAC044-GFP and NAC044 ${ }^{G C G}$-GFP in nac044-1 mutant background are shown. $4 \mathrm{dpg}$ seedlings were incubated on $10 \mathrm{\mu g} / \mathrm{mL}$ zeo for $24 \mathrm{~h}$ before imaging. (B) Box plots of quantified cell death area related in the root tips mentioned in A). Data presented as median and interquartile range from two biological replicates, $n$ denotes total number of scored roots. A third biological replicate showed similar results. Black and red asterisks denote ${ }^{* * *} \mathrm{p}<0.01$ as compared to $\mathrm{Col}-0$ and nac044-1, respectively. Note that all NACO44 ${ }^{\mathrm{GCG}}$ but no NAC044-GFP lines are different than Col-0, and one NAC044 ${ }^{\mathrm{GCG}}$ line is not different than nac044-1. Scale bar, $100 \mu \mathrm{M}$. See also Figure S5. 
with NAC044 can only partially explain RBR ${ }^{\mathrm{NF}}$ 's defect. As previously determined (Takahashi et al., 2019), nac044-1kept growing after zeocin treatment, whereas several independent NAC044-GFP and NAC044 ${ }^{\mathrm{GCG}}$-GFP transgenic lines with varying accumulation levels consistently showed over-complementation of nac044 mutants (Fig S5B,C), suggesting that the function of NACO44 on root growth is modified by the GFP fusion. Moreover, NACO44 ${ }^{\text {GCG }}$ GFP behaved similar to NAC044-GFP (Fig S5B), indicating that the interaction with RBR does not influence the function of NACO44 on root growth.

NAC044 has a second function, as it also mediates SOG1-dependent cell death upon DNA damage (Takahashi et al., 2019). As cell death in standard and damaging conditions increases when RBR levels are down regulated, we asked whether NACO44 and RBR functions might converge in this process. After $24 \mathrm{~h}$ of treatment with zeocin, the cell death area was smaller in the nac044-1 mutant and larger in the amiGO root tips as compared to Wt (Fig 4). Noteworthy, NAC044-GFP but not NAC044 ${ }^{\mathrm{GCG}}$-GFP completely restored the induction of cell death in nac044-1. Furthermore, the introgression of nac044-1 in the amiGO line significantly reduced the cell death (Fig 4). Altogether, our results indicate that NAC044 binds to RBR to inhibit its promotion of cell survival upon DNA damage.

\section{Discussion}

We report here that the coordinated activities of RBR during the DDR are separated in space and time, establishing an orderly series of events that couples cell survival with DNA integrity. Quickly after DNA injury, RBR is recruited to nuclear foci by a protein-protein interaction requiring the B-pocket subdomain and, most likely, an LXCXE-containing protein. Meanwhile, the induction of NAC044 arrests cell proliferation and growth. If the damage persists, NAC044 represses the cell protective activity of RBR to promote cell death. We postulate that the dynamic aggregation and release of RBR from nuclear foci enables a spatio-temporal separation of events that determines the decision of resuming growth or undergoing cell death.

Unchallenging growth conditions revealed that truncated versions of RBR are unable to fully rescue spontaneous cell death arising from down-regulating the endogenous transcripts, whereas RBR-NF completely restored cell survival. After DNA damage, RBR ${ }^{\text {DN }}-$ YFP and $R B R^{\text {pocket }}$ YFP showed altered accumulation in foci and clearance. In animals, $p R b$ is recruited to nuclear foci in a E2F1-dependent manner and $\mathrm{pRb}$ foci kinetics are similar to those of histone $\mathrm{yH} 2 \mathrm{AX}$ (Vélez-Cruz et al., 2016). Strikingly, RBR ${ }^{\mathrm{NF}}$-YFP was unable to accumulate in nuclear foci despite being able to interact with E2F proteins, suggesting that in plants, a LXCXE-containing protein recruits RBR to the DNA damage site. Accordingly, the rbr1-2 allele, which lacks the B-pocket sub-domain, displays reduced sister chromatide crossover and DSB-dependent foci formation of meiotic proteins during prophase I (Chen et al., 
2011), highlighting the importance of the B-pocket-mediated interactions in programmed and stress-induced chromatin repair. We conclude that, when favorable growth conditions are maintained, the ability to interact with LXCXE proteins is somehow dispensable, but a full length RBR is necessary to prevent spontaneous cell death, which in turn arises from genomic instability upon RBR (or pRb in animals) depletion (Biedermann et al., 2017; Cook et al., 2015). When DNA damage occurs, the necessity for the full length RBR remains, and in addition LXCXE-mediated interactions become essential.

DNA repair foci are highly dynamic (Biedermann et al., 2017; Gentric et al., 2020; Nakamura et al., 2010; Polo and Jackson, 2011). Once at damage sites, RBR recruits and/or co-localizes with other proteins like E2F, F-BOX-LIKE PROTEIN 17 (FBL17) and the repair proteins BRCA1 and RAD51 (Biedermann et al., 2017; Gentric et al., 2020; Horvath et al., 2017). It is possible that RBR nuclear foci display a different composition and dynamics according to the cell cycle phase at the time when damage is perceived. The requirement for a full length RBR to withstand DNA damage and the altered foci kinetics of the truncated variants, likely reflect on its multiple protein interactions and binding regulation during DDR. Accordingly, the $\mathrm{N}$ domain of $\mathrm{pRb}$ binds components of the non-homologous end-joining DNA repair pathway (Cook et al., 2015) whereas the C-terminal region binds and regulates interaction with E2F proteins, conserved RBR partners that regulate cell cycle, cell death and DDR genes (Bouyer et al., 2018; Burke et al., 2012, 2014; Gómez et al., 2019; Horvath et al., 2017; Indovina et al., 2015; Lu et al., 2014; Magyar et al., 2012; Manickavinayaham et al., 2020; Oszi et al., 2020; del Pozo et al., 2002). Further research is required to discover the protein that recruits RBR to foci, and to characterize dynamic RBR focus composition. The structural role of RBR could be further elucidated using a null $r b r$ background for RBR ${ }^{\mathrm{NF}}$-YFP to follow the DNA repair process.

Our data reveal that RBR aggregates in nuclear foci during the first hour after DNA damage induction, and before NAC044 accumulates in root meristem cells. Nearly $90 \%$ of the RBR foci are cleared during the first $8 \mathrm{~h}$ of recovery, simultaneously with the NAC044 accumulation peak. Whether focus-released RBR immediately binds NACO44 is not clear, but the effects of disrupting the LXCXE motif in NACO44 are already evident during the first 24 hours after DNA damage, when cell death becomes visible. Apparently, the main biochemical constraint for NAC044 to bind RBR is the availability of the B-pocket sub-domain, while the phosphorylation state of RBR seems irrelevant for binding. However, the exact timing of the RBR-NAC044 interaction remains to be determined. Moreover, RBR-NAC044 dimers probably establish other protein interactions that influence the transcriptional outcome of the complex. On the one hand, NAC044 is expected to interact with its closest homologs NAC085 and SOG1, as the single, double and triple mutants have similar effects on cell death (Takahashi et al., 2019). On the other hand, the dominant effect of RBR ${ }^{N F}$-YFP likely reflects other non-LXCXE interactions of RBR, for example with E2FA. Whether these occur simultaneously to NAC044 binding remains an open question. 
NAC044 controls cell division by promoting accumulation of repressor MYB3R proteins in response to DNA damage (Takahashi et al., 2019), which in turn bind to the MSA element of G2/M-specific gene promoters to arrest cell cycle progression (Bourbousse et al., 2018; Chen et al., 2017; Ito et al., 1998, 2001; Kobayashi et al., 2015). The mechanism by which NAC044 promotes cell death is less clear, but also includes the action of repressor MYB3R proteins (Chen et al., 2017; Takahashi et al., 2019). Repressor MYB3R proteins are components of the Arabidopsis DREAM complex, a multimeric protein complex containing RBR and E2F proteins among others (Kobayashi et al., 2015; Ning et al., 2020). Thus, the SOG1 and RBR DDR pathways may use this protein complex to couple cell cycle and cell death decisions to DNA integrity.

The DNA damage and cell cycle-dependent expression pattern of NAC044, the presence of MSA, E2FA and SOG1 binding elements in the NAC044 promoter, and the fact that NACO44 is a target of SOG1, MYB3R3, E2FA and RBR (Bourbousse et al., 2018; Bouyer et al., 2018; Kobayashi et al., 2015; Ogita et al., 2018; Verkest et al., 2014), raises the question of whether different RBR protein complexes regulate DDR promoters independently, or converge in larger transcriptional regulatory complexes than previously thought. In animals, the SOG1 functional analog, p53, cross talks with the RBR and DREAM complex pathways during DDR. In this process, p53 induces the CDK inhibitor (CKI) p21 to facilitate the DREAM complex formation through hypo-phosphorylation of pRb-like proteins p130 and p107, promoting a transcriptional switch to repress DREAM complex targets (Engeland, 2018). Since SOG1 induces CKIs (Bourbousse et al., 2018; Ogita et al., 2018; Yi et al., 2014), it is possible that RBR plays a phosphorylation-regulated role in the DDR beyond the NAC044 interaction.

Altogether, our data indicate that RBR ability to interact with the LXCXE motif is not only essential for its structural and transcriptional functions during the DDR, but also imposes a timing mechanism to coordinate them in different sub-nuclear locations. Soon after damage is perceived, RBR is recruited to foci to aid DNA repair; the parallel activation of NACO44 triggers cell cycle arrest and cell death later on. The short-time dynamic accumulation of RBR in foci might create a flow of RBR between the damage site and the nucleoplasm where it can interact with NAC044. Both processes depend on the binding to LXCXE motif. The RBR-NAC044 interaction promotes cell death possibly by an inhibition of RBR protective function which, in turn seems to depend on binding E2FA (Horvath et al., 2017; Wang et al., 2014). Thus, LXCXE-mediated interactions of RBR lie at the interface between the DNA repair process and the life or death cellular decisions afterwards. 


\section{Materials and Methods}

\section{Plant material and growth conditions and treatments}

Arabidopsis thaliana ecotype Col-0 was used as wild-type control. Mutant lines nac0441 (Takahashi et al., 2019), nac044-3 (WiscDsLox293-296invF22), and rad54 (SALK124992) were obtained from The Nottingham Arabidopsis Stock Centre (NASC). RAD54-YFP (Hirakawa et al., 2017), E2FA-GFP (Magyar et al., 2012), amiGO-RBR (amiGO), pRBR::RBR:YFP (CruzRamírez et al., 2013), and pRBR::RBR:mRFP (Cruz-Ramírez et al., 2012) lines were previously published. Wild-type and all phospho-variants of pRBR::RBR:SCFP were reported in Chapter

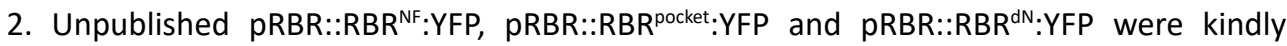
donated by Sara Diaz-Trivino. Unless otherwise noticed, amiGO was used as background for RBR transgenic plants, and nac044-3 or nac044-1 for gNAC044:GFP and gNAC044GCG:GFP. Homozygous pNAC044-GUS and pNAC044-3xGFP-NLS are in Col-0. Seeds were fume-sterilized in a sealed container with $100 \mathrm{ml}$ bleach and $3 \mathrm{ml}$ of $37 \%$ hydrochloric acid for $3-5 \mathrm{~h}$; then suspended in $0.1 \%$ agarose, stratified for $2 \mathrm{~d}$ at $4{ }^{\circ} \mathrm{C}$ in darkness, plated on $0.5 x$ Murashige and Skoog (MS) plus vitamins, $1 \%$ sucrose, $0.5 \mathrm{~g} / \mathrm{L} 2$-( $\mathrm{N}$-morpholino) ethanesulfonic acid (MES) at $\mathrm{pH} 5.8$, and $0.8 \%$ plant agar, and grown vertically for the 4-6 $\mathrm{d}$ (as indicated in each figure) at $22^{\circ} \mathrm{C}$ with a $16 \mathrm{~h}$ light/8h dark cycle. For DNA damaging treatments, a filtersterilized $20 \mathrm{mg} / \mathrm{mL}$ stock solution prepared from zeocin powder (Duchefa Biochemie) was diluted to $3 \mu \mathrm{g} / \mathrm{mL}, 10 \mu \mathrm{g} / \mathrm{mL}$, or $20 \mu \mathrm{g} / \mathrm{mL}$ in $0.5 x \mathrm{MS}+$ vits, $1 \%$ sucrose, $0.5 \mathrm{~g} / \mathrm{L} \mathrm{MES} \mathrm{at} \mathrm{pH}$ $5.8,0.8 \%$ plant agar before pouring into plates. Seedlings were transferred to zeocin plates for 2,16 , or $24 \mathrm{~h}$ as indicated in figure legends before imaging or transfering back to fresh non-treatment medium.

\section{Plasmid construction and plant transformation}

The constructs pNAC044::GUS, pNAC044::3xGFP:NLS, pNAC044::NAC044:GFP and pNAC044::NAC044GCG:GFP were cloned using the GreenGate system (Lampropoulos et al., 2013). Briefly, a 1 Kb fragment upstream of the ATG was amplified with the primers pANAC044 F and pANAC044 R1 for translational fusion or pANAC044 R2 for transcriptional fusions; the genomic segment of NACO44 without stop codon (gNAC044) was amplified with the primer pair gANAC044 F / gANAC044 R. Mutagenesis of the of the LXCXE motif was done by amplifying the gNAC044 in two fragments with primers pairs gANACO44 F/ mut gANAC044 R and mut gANAC044 F/ gANAC044 R (all primers are listed in Table S1). Promoter and gNAC044 PCR products were cloned together with the plasmids pGGD001, pGGE009 and pGGF001 (translational fusion), pGGB002, pGGC025, pGGD006, pGGE009, and pGGF001 (3xGFP-NLS transcriptional fusion), pGGB002, pGGC051, pGGD002, pGGE009, pGGF001 (GUS transcriptional fusion) into pGGZ003 by combining equimolar amounts of each part the relevant dig-lig reactions according to the GreenGate protocol. Construct were transformed into Arabidopsis plants by the flower dip method. 
Previously reported entry and expression clones are listed in Table S2. The pEXP22-NAC044 expression clone, and the product of a two fragments-overlapping PCR with primers pairs AttB cNAC44 F/mut cNAC44 R and mut cNAC44 F/AttB cNAC44 R that introduce attB sites and mutagenize the LXCXE motif to GXCXG on NAC044 CDS, were recombined into pDONR221 vector with Gateway BP clonase II enzyme mix (Invitrogen) to generate the corresponding entry clones. The CDS of E2FA, E2FB and E2FC, amplified with the corresponding primers listed in table s. were cloned into pGEMt-easy 221 vector by BP clonase reaction. We generated pDEST-NLuc and pDEST-CLuc Gateway-compatible destination vectors by conventional cloning of the attR-flanked Gateway cassette amplified with the primers GWcass_SplitLUC_F and GWcass_CLuc_R or GWcass_NLuc_R (Table S1) and digested with Bpil restriction enzyme (Thermo) to generate sticky ends compatible with BamHI/Sall digested pCAMBIA-NLUC and pCAMBIA-CLuc vectors (Chen et al., 2008). Entry clones were recombined into pDEST22 or pDEST32 destination vectors for $\mathrm{Y} 2 \mathrm{H}$ assays, and/or into pDEST-NLuc or pDEST-CLuc for SplitLuciferase assays with Gateway LR clonase II enzyme mix (Invitrogen).

\section{Microscopy and image processing}

A $10 \mu \mathrm{g} / \mathrm{mL}$ Propidium lodide staining solution (or $\mathrm{mQ}$ water for nuclear foci imaging) was used for whole-mount visualization of live roots with CLSM using a Zeiss LSM 710 system as described in (Zhou et al., 2019). Tissue clearing with ClearSee reagent was performed as described in (Kurihara et al., 2015). Images were taken with ZEN 2012 software (Zeiss) and processed with ImageJ. Brightness and contrast of the final figures was enhanced to the exact same values.

\section{Protein-proten interaction assays}

Protein-Protein interactions by $\mathrm{Y} 2 \mathrm{H}$ was performed using the ProQuest system (Thermo Scientific). Co-transformation of pEXP22 and pEXP32 expression clones into the PJ69-4A yeast strain was performed as described in (De Folter and Immink, 2011). Split-Luciferase assays were performed as described in (Chen et al., 2008) using an exposure time of $7 \mathrm{~min}$. For Split-LUC in Arabidopsis stable transformants, we used an exposure time of $10 \mathrm{~min}$.

\section{Protein sequence retrieval and alignments}

Arabidopsis thaliana NAC044, NAC085, and RAD54 protein sequences were retrieved from The Arabidopsis Information Resource (TAIR, arabidopsis.org) and used as query in a BLAST search on Gramene.org for plant orthologs, or on NCBI for non-plant orthologs. Annotated orthologs or the top score hit sequences were retrieved and Clustal-omega aligned with the corresponding Arabidopsis sequence. 


\section{References}

Berckmans, B., and De Veylder, L. (2009). Transcriptional control of the cell cycle. Curr. Opin. Plant Biol. 12, 599-605.

Biedermann, S., Harashima, H., Chen, P., Heese, M., Bouyer, D., Sofroni, K., and Schnittger, A. (2017). The retinoblastoma homolog RBR1 mediates localization of the repair protein RAD51 to DNA lesions in Arabidopsis. EMBO J. 36, 1279-1297.

Boniotti, M.B., and Gutierrez, C. (2001). A cell-cycle-regulated kinase activity phosphorylates plant retinoblastoma protein and contains, in Arabidopsis, a CDKA/cyclin D complex. Plant J. 28, 341350.

Borghi, L., Gutzat, R., Fütterer, J., Laizet, Y., Hennig, L., and Gruissem, W. (2010). Arabidopsis RETINOBLASTOMA-RELATED Is Required for Stem Cell Maintenance, Cell Differentiation, and Lateral Organ Production. Plant Cell 22, 1792-1811.

Bourbousse, C., Vegesna, N., and Law, J.A. (2018). SOG1 activator and MYB3R repressors regulate a complex DNA damage network in Arabidopsis. Proc. Natl. Acad. Sci. U. S. A. 115, E12453E12462.

Bourgo, R.J., Thangavel, C., Ertel, A., Bergseid, J., Kathleen McClendon, A., Wilkens, L., Witkiewicz, A.K., Wang, J.Y.J., and Knudsen, E.S. (2011). RB Restricts DNA Damage-Initiated Tumorigenesis through an LXCXE-Dependent Mechanism of Transcriptional Control. Mol. Cell 43, 663-672.

Bouyer, D., Heese, M., Chen, P., Harashima, H., Roudier, F., Gruttner, C., and Schnittger, A. (2018). Genome-wide identification of RETINOBLASTOMA RELATED 1 binding sites in Arabidopsis reveals novel DNA damage regulators. PLoS Genet. 14, 1-35.

Burke, J.R., Hura, G.L., and Rubin, S.M. (2012). Structures of inactive retinoblastoma protein reveal multiple mechanisms for cell cycle control. Genes Dev. 26, 1156-1166.

Burke, J.R., Liban, T.J., Restrepo, T., Lee, H.W., and Rubin, S.M. (2014). Multiple mechanisms for E2F binding inhibition by phosphorylation of the retinoblastoma protein C-terminal domain. J. Mol. Biol. 426, 245-255.

Charbonnel, C., Allain, E., Gallego, M.E., and White, C.I. (2011). Kinetic analysis of DNA double-strand break repair pathways in Arabidopsis. DNA Repair (Amst). 10, 611-619.

Chen, J. (2016). The cell-cycle arrest and apoptotic functions of p53 in tumor initiation and progression. Cold Spring Harb. Perspect. Med. 6, 1-16.

Chen, T., and Wang, J.Y.J. (2000). Establishment of Irreversible Growth Arrest in Myogenic Differentiation Requires the RB LXCXE-Binding Function. Mol. Cell. Biol. 20, 5571-5580.

Chen, H., Zou, Y., Shang, Y., Lin, H., Wang, Y., Cai, R., Tang, X., and Zhou, J.-M. (2008). Firefly Luciferase Complementation Imaging Assay for Protein-Protein Interactions in Plants. Plant Physiol. 146, 368-376.

Chen, P., Takatsuka, H., Takahashi, N., Kurata, R., Fukao, Y., Kobayashi, K., Ito, M., and Umeda, M. (2017). Arabidopsis R1R2R3-Myb proteins are essential for inhibiting cell division in response to DNA damage. Nat. Commun. 8, 1-12.

Chen, P., Sjogren, C.A., Larsen, P.B., and Schnittger, A. (2019). A multi-level response to DNA damage 
induced by aluminium. Plant J. 98, 479-491.

Chen, Z., Higgins, J.D., Hui, J.T.L., Li, J., Franklin, F.C.H., and Berger, F. (2011). Retinoblastoma protein is essential for early meiotic events in Arabidopsis. EMBO J. 30, 744-755.

Ciccia, A., and Elledge, S.J. (2010). The DNA Damage Response: Making It Safe to Play with Knives. Mol. Cell 40, 179-204.

Cook, R., Zoumpoulidou, G., Luczynski, M.T., Rieger, S., Moquet, J., Spanswick, V.J., Hartley, J.A., Rothkamm, K., Huang, P.H., and Mittnacht, S. (2015). Direct involvement of retinoblastoma family proteins in DNA repair by non-homologous end-joining. Cell Rep. 10, 2007-2019.

Cruz-Ramírez, A., Díaz-Triviño, S., Blilou, I., Grieneisen, V.A., Sozzani, R., Zamioudis, C., Miskolczi, P., Nieuwland, J., Benjamins, R., Dhonukshe, P., et al. (2012). A Bistable Circuit Involving SCARECROW- RETINOBLASTOMA Integrates Cues to Inform Asymmetric Stem Cell Division. Cell 150, 1002-1015.

Cruz-Ramírez, A., Diaz-trivino, S., Wachsman, G., Du, Y., Arteaga-Vazquez, M., Zhang, H., Benjamins, R., Blilou, I., Neef, A.B., Chandler, V., et al. (2013). A SCARECROW-RETINOBLASTOMA Protein Network Controls Protective Quiescence in the Arabidopsis Root Stem Cell Organizer. PLoS Biol. 11, e1001724.

DeCaprio, J.A. (2009). How the Rb tumor suppressor structure and function was revealed by the study of Adenovirus and SV40. Virology 384, 274-284.

Desvoyes, B., and Gutierrez, C. (2020). Roles of plant retinoblastoma protein: cell cycle and beyond. EMBO J. 39, 1-18.

Desvoyes, B., De Mendoza, A., Ruiz-Trillo, I., and Gutierrez, C. (2014a). Novel roles of plant RETINOBLASTOMA-RELATED (RBR) protein in cell proliferation and asymmetric cell division. J. Exp. Bot. 65, 2657-2666.

Desvoyes, B., Fernández-marcos, M., Sequeira-mendes, J., Otero, S., Vergara, Z., and Gutierrez, C. (2014b). Looking at plant cell cycle from the chromatin window. Front. Plant Sci. 5, 369.

Dick, F.A., and Rubin, S.M. (2013). Molecular mechanisms underlying RB protein function. Nat. Rev. Mol. Cell Biol. 14, 297-306.

Engeland, K. (2018). Cell cycle arrest through indirect transcriptional repression by p53: I have a DREAM. Cell Death Differ. 25, 114-132.

Flemington, E.K., Speck, S.H., and Kaelin, W.G. (1993). E2F-1-mediated transactivation is inhibited by complex formation with the retinoblastoma susceptibility gene product. Proc. Natl. Acad. Sci. 90, 6914-6918.

De Folter, S., and Immink, R.G.H. (2011). Yeast protein-protein interaction assays and screens. Methods Mol. Biol. 754, 145-165.

Gentric, N., Masoud, K., Journot, R.P., Cognat, V., Chabouté, M.E., Noir, S., and Genschik, P. (2020). The f-box-like protein FBL17 is a regulator of DNA-damage response and colocalizes with RETINOBLASTOMA RELATED1 at DNA lesion sites. Plant Physiol. 183, 1295-1305.

Gómez, M.S., Falcone Ferreyra, M.L., Sheridan, M.L., and Casati, P. (2019). Arabidopsis E2Fc is required for the DNA damage response under UV-B radiation epistatically over the microRNA396 and independently of E2Fe. Plant J. 97, 749-764. 
Gutierrez, C. (2005). Coupling cell proliferation and development in plants. Nat. Cell Biol. 7, 535-541. Gutzat, R., Borghi, L., and Gruissem, W. (2012). Emerging roles of RETINOBLASTOMA-RELATED proteins in evolution and plant development. Trends Plant Sci. 17, 139-148.

Harashima, H., and Sugimoto, K. (2016). Integration of developmental and environmental signals into cell proliferation and differentiation through RETINOBLASTOMA-RELATED 1. Curr. Opin. Plant Biol. 29, 95-103.

Helin, K., Harlow, E.D., and Fattaey, A.L. (1993). Inhibition of E2F-1 Transactivation by Direct Binding of the Retinoblastoma Protein. Mol. Cell. Biol. 13, 6501-6508.

Hirakawa, T., and Matsunaga, S. (2019). Characterization of DNA Repair Foci in Root Cells of Arabidopsis in Response to DNA Damage. Front. Plant Sci. 10, 990.

Hirakawa, T., Hasegawa, J., White, C.I., and Matsunaga, S. (2017). RAD54 forms DNA repair foci in response to DNA damage in living plant cells. Plant J. 90, 372-382.

Horvath, B.M., Kourova, H., Nagy, S., Nemeth, E., Magyar, Z., Papdi, C., Ahmad, Z., Sanchez-perez, G.F., Perilli, S., Blilou, I., et al. (2017). Arabidopsis RETINOBLASTOMA RELATED directly regulates DNA damage responses through functions beyond cell cycle control. EMBO J. 36, 1261-1278.

Hu, Z., Cools, T., and De Veylder, L. (2016). Mechanisms Used by Plants to Cope with DNA Damage. Annu. Rev. Plant Biol. 67, 439-462.

Indovina, P., Pentimalli, F., Casini, N., Vocca, I., and Giordano, A. (2015). RB1 dual role in proliferation and apoptosis: Cell fate control and implications for cancer therapy. Oncotarget 6, 17873-17890.

Ito, M., Iwase, M., Kodama, H., Lavisse, P., Komamine, A., Nishihama, R., Machida, Y., and Watanabe, A. (1998). A Novel cis-Acting Element in Promoters of Plant B-Type Cyclin Genes Activates M Phase-Specific Transcription. Plant Cell 10, 331-341.

Ito, M., Araki, S., Matsunaga, S., Itoh, T., Nishihama, R., Machida, Y., Doonan, J.H., and Watanabe, A. (2001). G2/M-phase-specific transcription during the plant cell cycle is mediated by c-Myb-like transcription factors. Plant Cell 13, 1891-1905.

Johnston, A.J., Matveeva, E., Kirioukhova, O., Grossniklaus, U., and Gruissem, W. (2008). A Dynamic Reciprocal RBR-PRC2 Regulatory Circuit Controls Arabidopsis Gametophyte Development. Curr. Biol. 18, 1680-1686.

Kastenhuber, E.R., and Lowe, S.W. (2017). Putting p53 in Context. Cell 170, 1062-1078.

Kim, J.H., Ryu, T.H., Lee, S.S., Lee, S., and Chung, B.Y. (2019). Ionizing radiation manifesting DNA damage response in plants: An overview of DNA damage signaling and repair mechanisms in plants. Plant Sci. 278, 44-53.

Kobayashi, K., Suzuki, T., Iwata, E., Nakamichi, N., Suzuki, T., Chen, P., Ohtani, M., Ishida, T., Hosoya, H., Müller, S., et al. (2015). Transcriptional repression by MYB 3R proteins regulates plant organ growth. EMBO J. 34, 1992-2007.

Kurihara, D., Mizuta, Y., Sato, Y., and Higashiyama, T. (2015). ClearSee: A rapid optical clearing reagent for whole-plant fluorescence imaging. Dev. 142, 4168-4179.

Lampropoulos, A., Sutikovic, Z., Wenzl, C., Maegele, I., Lohmann, J.U., and Forner, J. (2013). GreenGate - A novel, versatile, and efficient cloning system for plant transgenesis. PLoS One 8, e83043.

Lanz, M.C., Dibitetto, D., and Smolka, M.B. (2019). DNA damage kinase signaling: checkpoint and 
repair at 30 years. EMBO J. 38, e101801.

Lu, Z., Bauzon, F., Fu, H., Cui, J., Zhao, H., Nakayama, K., Nakayama, K.I., and Zhu, L. (2014). Skp2 suppresses apoptosis in Rb1-deficient tumours by limiting E2F1 activity. Nat. Commun. 5, 3463.

Magyar, Z., Horváth, B., Khan, S., Mohammed, B., Henriques, R., De Veylder, L., Bakó, L., Scheres, B., and Bögre, L. (2012). Arabidopsis E2FA stimulates proliferation and endocycle separately through RBR-bound and RBR-free complexes. EMBO J. 31, 1480-1493.

Mahapatra, K., and Roy, S. (2020). An insight into the mechanism of DNA damage response in plantsrole of SUPPRESSOR OF GAMMA RESPONSE 1: An overview. Mutat. Res. - Fundam. Mol. Mech. Mutagen. 819-820, 111689.

Manickavinayaham, S., Velez-Cruz, R., Biswas, A.K., Chen, J., Guo, R., and Johnson, D.G. (2020). The E2F1 transcription factor and RB tumor suppressor moonlight as DNA repair factors. Cell Cycle 19, 2260-2269.

Matos, J.L., Lau, O.S., Hachez, C., Cruz-Ramírez, A., Scheres, B., and Bergmann, D.C. (2014). Irreversible fate commitment in the Arabidopsis stomatal lineage requires a FAMA and RETINOBLASTOMARELATED module. Elife 3, 1-15.

Nakagami, H., Kawamura, K., Sugisaka, K., Sekine, M., and Shinmyo, A. (2002). Phosphorylation of retinoblastoma-related protein by the cyclin $\mathrm{D} /$ cyclin-dependent kinase complex is activated at the G1/S-phase transition in tobacco. Plant Cell 14, 1847-1857.

Nakamura, A.J., Rao, V.A., Pommier, Y., and Bonner, W.M. (2010). The complexity of phosphorylated H2AX foci formation and DNA repair assembly at DNA double-strand breaks. Cell Cycle 9, 389397.

Narasimha, A.M., Kaulich, M., Shapiro, G.S., Choi, Y.J., Sicinski, P., and Dowdy, S.F. (2014). Cyclin D activates the Rb tumor suppressor by mono-phosphorylation. Elife 3, 1-21.

Ning, Y., Liu, N., Lan, K., Su, Y., Li, L., Chen, S., and He, X. (2020). DREAM complex suppresses DNA methylation maintenance genes and precludes DNA hypermethylation. Nat. Plants 6, 942-956.

Ogita, N., Okushima, Y., Tokizawa, M., Yamamoto, Y.Y., Tanaka, M., Seki, M., Makita, Y., Matsui, M., Okamoto-Yoshiyama, K., Sakamoto, T., et al. (2018). Identifying the target genes of SUPPRESSOR OF GAMMA RESPONSE 1, a master transcription factor controlling DNA damage response in Arabidopsis. Plant J. 94, 439-453.

Oszi, E., Papdi, C., Mohamed, B., Petkó-szandtner, A., Leviczky, T., Molnár, E., Galvan-ampudia, C., Khan, S., Lopez-Juez, E., Horváth, B., et al. (2020). E2FB Interacts with RETINOBLASTOMA RELATED and Regulates Cell Proliferation during Leaf Development. Plant Physiol. 182, 518-533.

Perilli, S., Perez-Perez, J.M., Di Mambro, R., Peris, C.L., Díaz-Triviño, S., Del Bianco, M., Pierdonati, E., Moubayidin, L., Cruz-Ramírez, A., Costantino, P., et al. (2013). RETINOBLASTOMA-RELATED protein stimulates cell differentiation in the Arabidopsis root meristem by interacting with cytokinin signaling. Plant Cell 25, 4469-4478.

Polit, J.T., Kaźmierczak, A., and Walczak-Drzewiecka, A. (2012). Cell cycle-dependent phosphorylation of pRb-like protein in root meristem cells of Vicia faba. Protoplasma 249, 131-137.

Polo, S.E., and Jackson, S.P. (2011). Dynamics of DNA damage response proteins at DNA breaks: A focus on protein modifications. Genes Dev. 25, 409-433. 
del Pozo, J.C., Boniotti, M.B., and Gutierrez, C. (2002). Arabidopsis E2Fc Functions in Cell Division and Is Degraded by the Ubiquitin-SCF AtSKP2 Pathway in Response to Light. Plant Cell 14, 3057-3071. Pruneda-Paz, J.L.L., Breton, G., Nagel, D.H.H., Kang, S.E.E., Bonaldi, K., Doherty, C.J.J., Ravelo, S., Galli, M., Ecker, J.R.R., and Kay, S.A.A. (2014). A Genome-Scale Resource for the Functional Characterization of Arabidopsis Transcription Factors. Cell Rep. 8, 622-632.

Rubin, S.M. (2013). Deciphering the retinoblastoma protein phosphorylation code. Trends Biochem. Sci. 38, 12-19.

Sanidas, I., Morris, R., Fella, K.A., Rumde, P.H., Boukhali, M., Tai, E.C., Ting, D.T., Lawrence, M.S., Haas, W., and Dyson, N.J. (2019). A Code of Mono-phosphorylation Modulates the Function of RB. Mol. Cell 73, 985-1000.e6.

Takahashi, N., Ogita, N., Takahashi, T., Taniguchi, S., Tanaka, M., Seki, M., and Umeda, M. (2019). A regulatory module controlling stress-induced cell cycle arrest in arabidopsis. Elife 8, 1-27.

Tsegay, P.S., Lai, Y., and Liu, Y. (2019). Replication stress and consequential instability of the genome and epigenome. Molecules 24, 1-20.

Vélez-Cruz, R., Manickavinayaham, S., Biswas, A.K., Clary, R.W., Premkumar, T., Cole, F., and Johnson, D.G. (2016). RB localizes to DNA double-strand breaks and promotes DNA end resection and homologous recombination through the recruitment of BRG1. Genes Dev. 30, 2500-2512.

Verkest, A., Abeel, T., Heyndrickx, K.S., Van Leene, J., Lanz, C., Van De Slijke, E., De Winne, N., Eeckhout, D., Persiau, G., Van Breusegem, F., et al. (2014). A generic tool for transcription factor target gene discovery in Arabidopsis cell suspension cultures based on tandemchromatinaffinity purification. Plant Physiol. 164, 1122-1133.

De Veylder, L., Beeckman, T., Beemster, G.T.S., De Almeida Engler, J., Ormenese, S., Maes, S., Naudts, M., Van der Schueren, E., Jacqmard, A., Engler, G., et al. (2002). Control of proliferation, endoreduplication and differentiation by the Arabidopsis E2Fa-DPa transcription factor. EMBO J. 21, 1360-1368.

Wang, S., Gu, Y., Zebell, S.G., Anderson, L.K., Wang, W., Mohan, R., and Dong, X. (2014). A noncanonical role for the CKI-RB-E2F cell-cycle signaling pathway in plant effector-triggered immunity. Cell Host Microbe 16, 787-794.

Waterworth, W.M., Wilson, M., Wang, D., Nuhse, T., Warward, S., Selley, J., and West, C.E. (2019). Phosphoproteomic analysis reveals plant DNA damage signalling pathways with a functional role for histone H2AX phosphorylation in plant growth under genotoxic stress. Plant J. 100, 1007-1021.

Wildwater, M., Campilho, A., Perez-Perez, J.M., Heidstra, R., Blilou, I., Korthout, H., Chatterjee, J., Mariconti, L., Gruissem, W., and Scheres, B. (2005). The RETINOBLASTOMA-RELATED gene regulates stem cell maintenance in Arabidopsis roots. Cell 123, 1337-1349.

Williams, A.B., and Schumacher, B. (2016). p53 in the DNA-damage-repair process. Cold Spring Harb. Perspect. Med. 6, 1-16.

Yi, D., Kamei, C.L.A., Cools, T., Vanderauwera, S., Takahashi, N., Okushima, Y., Eekhout, T., Yoshiyama, K.O., Larkin, J., Van den Daele, H., et al. (2014). The Arabidopsis SIAMESE-RELATED cyclindependent Kinase Inhibitors SMR5 and SMR7 Regulate the DNA damage checkpoint in response 
Chapter 4

to reactive oxygen species. Plant Cell 26, 296-309.

Yoshiyama, K., Conklin, P.A., Huefner, N.D., and Britt, A.B. (2009). Suppressor of gamma response 1 (SOG1) encodes a putative transcription factor governing multiple responses to DNA damage. Proc. Natl. Acad. Sci. U. S. A. 106, 12843-12848.

Zhou, W., Lozano-Torres, J.L., Blilou, I., Zhang, X., Zhai, Q., Smant, G., Li, C., and Scheres, B. (2019). A Jasmonate Signaling Network Activates Root Stem Cells and Promotes Regeneration. Cell 177, 942-956.e14. 


\section{Supplementary Information}
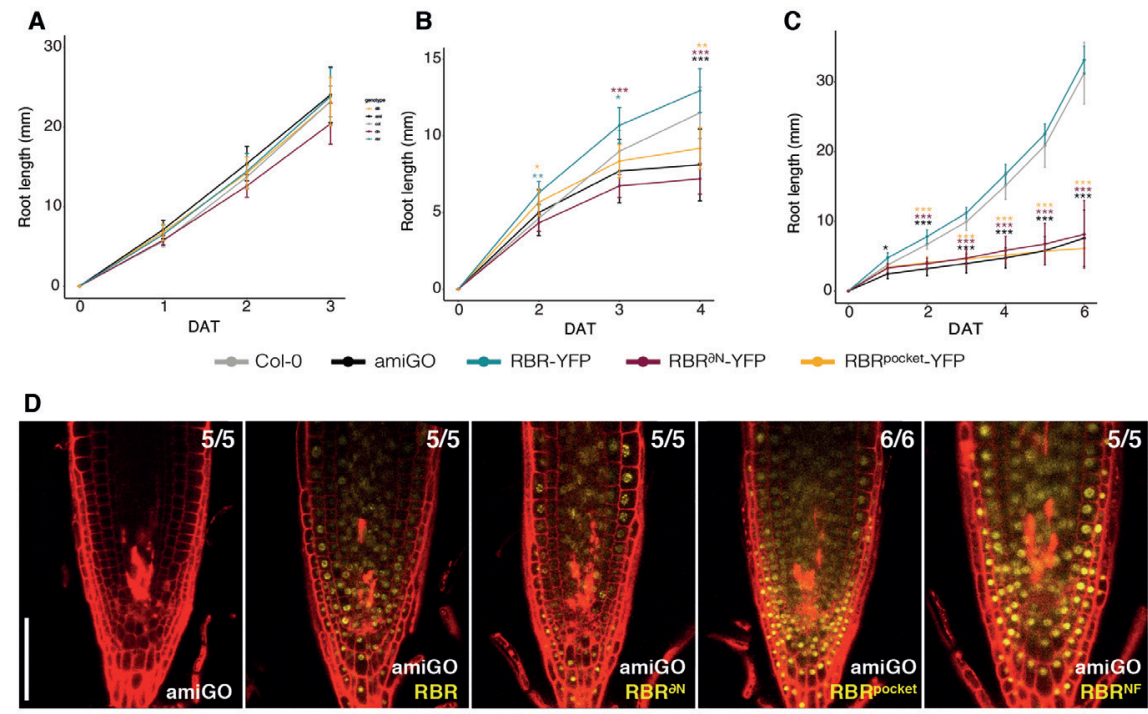

E

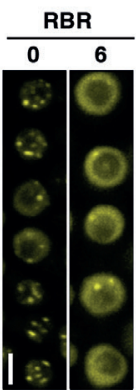

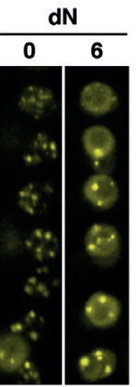

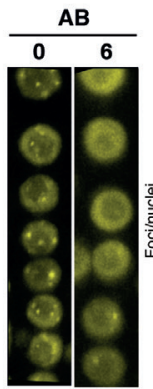

$\mathbf{F}$

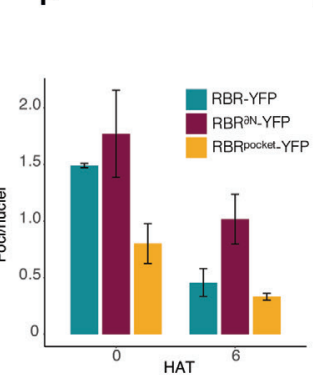

G

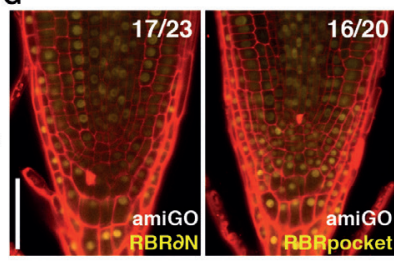

Figure S1: Full-length RBR is required in the DNA damage response.

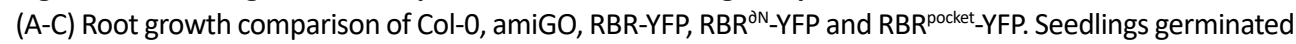
and grown on $0.5 \mathrm{GM}$ medium for 4-5 days were transferred to $0.5 \mathrm{GM}$ medium without (A) or with (B) 3 $\mu \mathrm{g} / \mathrm{mL}$ zeocin (zeo) for 3 days after transfer (DAT), or incubated on $10 \mu \mathrm{g} / \mathrm{mL}$ zeo for $20 \mathrm{~h}$ and transferred again to $0.5 \mathrm{GM}$ for recovery over $6 \mathrm{DAT}$ (C). Data presented as mean +SD of two independent replicates, in C) a single replicate is presented though three independent replicates showed similar trend $17>n>10 .{ }^{* * *} \mathrm{p}$ $<0.001,{ }^{* *} p<0.01,{ }^{*} p<0.05$. This dataset is derived from the same experiments presented in Fig 1 and the same Col-0, amiGO, and RBR-YFP are presented. (D) Cell death visualized by confocal imaging of PI-stained root tips of the indicated gentypes $6 \mathrm{dpg}$ after a $24 \mathrm{~h}$ treatment with $10 \mu \mathrm{g} / \mathrm{mL}$ zeo; numbers indicate roots presenting dead cells. (E) Representative maximum-intensity projections of z-stack images from RBR-YFP,

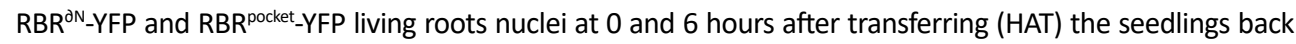
to $0.5 \mathrm{GM}$ medium for recovery following $16 \mathrm{~h}$ incubation in $0.5 \mathrm{GM}$ medium supplemented with $10 \mu \mathrm{g} /$ $\mathrm{mL}$ zeo. (F) Bar graphs related to (E) showing the quantification of nuclear foci divided by the number of

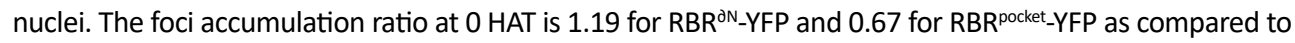
RBR-YFP; the cleared foci fraction for each RBR version at 6 HAT as compared to 0 HAT is $0.7,0.4$, and 0.6 for RBR-YFP, RBR ${ }^{\text {DN }}-$ YFP, and RBR ${ }^{\text {pocket-YFP, respectively. Data presented as mean }+S D . ~} n>3$ roots, total nuclei per time $>1300$. (G) Cell death visualized by confocal imaging of longitudinal sections of PI-stained root tips $8 \mathrm{dpg}$ on $0.5 \mathrm{GM}$ medium without zeocin; numbers indicate roots presenting dead cells in RBR ${ }^{\mathrm{dN}}$-YFP and

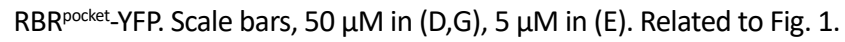



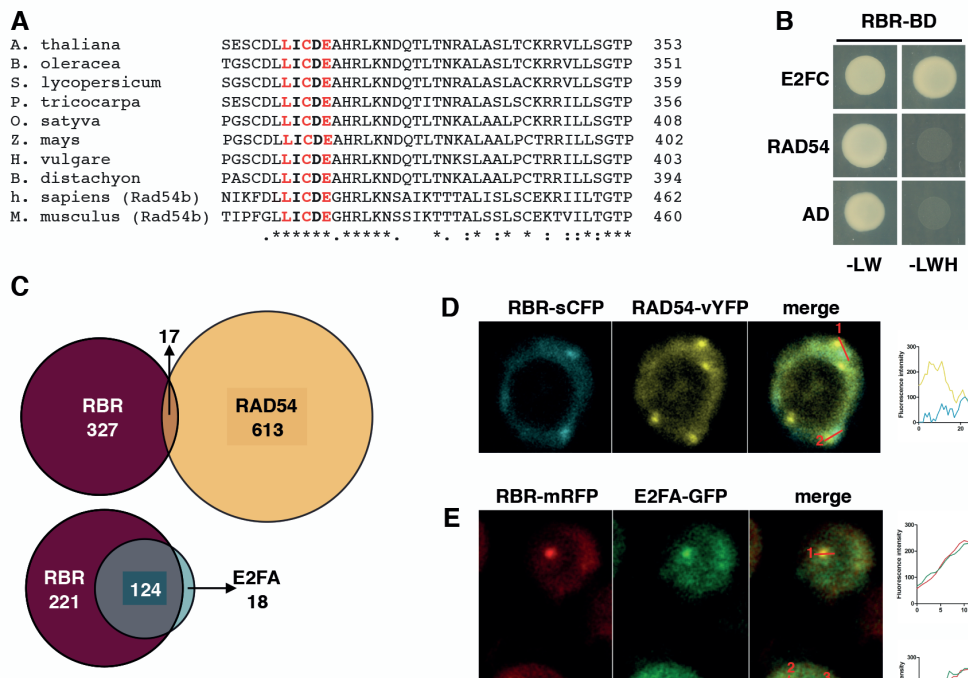

$\mathbf{F}$

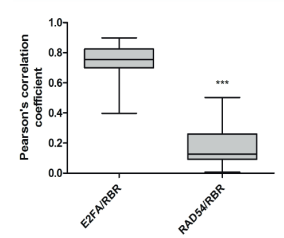

I

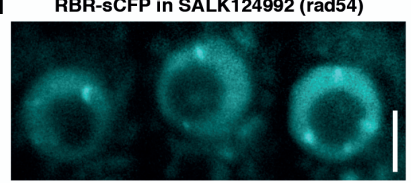

G
D
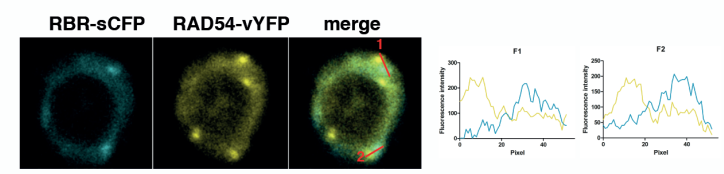

E
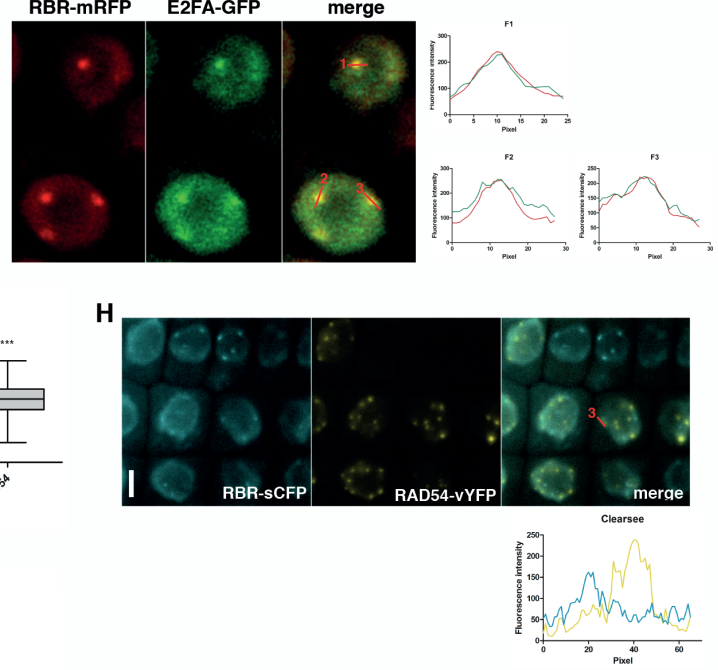

Figure S2: RAD54 and RBR act independently in DNA damage repair.

(A) Protein sequence alignment of RAD54 orthologs in the indicated species showing the conserved LXCXE motif in red. (B) Yeast two-hybrid analysis showing that RAD54 and RBR do not interact. E2FC and empty vector (AD) are positive and negative controls, respectively. Transformant yeast were dropped onto SD/L/-W (-LW), SD/-L/-W/-H/+1.5mM3AT (-LWH). AD and BD, GAL4 activation domain and DNA binding domain, respectively. (C) Venn diagrams showing the number of RBR foci overlapping with RAD54 or E2FA foci. Confocal images from $>5$ roots from the RBR-sCFP/RAD54-vYFP and RBR-mRFP/E2FA-GFP genotypes were used for pooled-counting after $16 \mathrm{~h}$ incubation on $10 \mu \mathrm{g} / \mathrm{mL}$ zeo. The 17 RBR-sCFP/RAD54-vYFP overlapping foci resemble those highlighted in $D$ ), with only partial or no actual colocalization. (D,E) Confocal images (single section) of root cells showing colocalization of RAD54-VYFP and RBR-sCFP D) and E2FA-GFP and RBR-mRFP E). (F,G) Comparison of Pearson correlation coefficients of E2FA-GFP/RBR-mRFP vs RAD54-vYFP/RBR-sCFP (E) and Manders coefficients indicating the fraction of RBR-mRFP overlapping with E2FA-GFP vs the fraction of RBR-sCFP overlapping with RAD54-vYFP (F). Data presented as median and interquartile range, $n=30$ foci from $>5$ roots. $(H)$ Maximum-intensity projection of $z$-stack confocal images of a clearsee treated root showing RAD54-vYFP and RBR-sCFP foci after $16 \mathrm{~h}$ incubation on $10 \mu \mathrm{g} / \mathrm{mL}$ zeo. (I) Confocal image (single section) of living root cells showing RBR-sCFP foci in rad54 T-DNA insertion allele SALK_124992 genetic background after $16 \mathrm{~h}$ incubation on $10 \mu \mathrm{g} / \mathrm{mL}$ zeo. Representative image of $>5$ independent replicates. Fluorescence intensity profiles of the indicated foci in $(C, D, I)$ show colocalization of RBR (red) and E2FA (green), or RBR (blue) and RAD54 (yellow). 

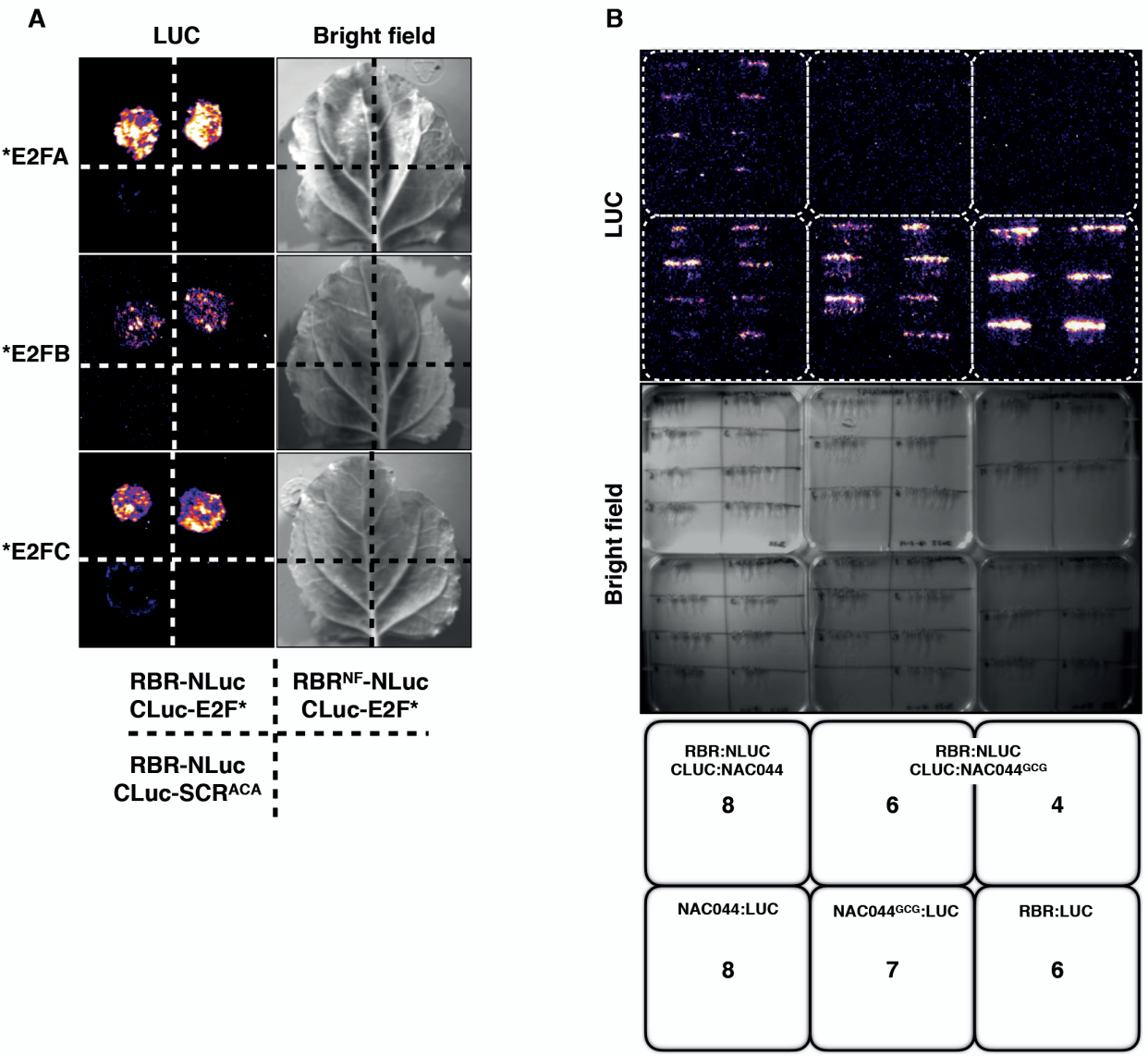

Figure S3: In planta Split-LUCIFERASE assays show that RBR ${ }^{\mathrm{NF}}$ interacts with E2FA, E2FB and E2FC and NAC044 interacts with RBR through the LXCXE motif.

(A) Split Luciferase assay showing that RBR ${ }^{\mathrm{NF}}$ interacts with E2FA, E2FB and E2FC in $N$. benthamiana leaves that were co-infiltrated with the combinations and in the order indicated in quadrants. The LXCXE-mutated SCRACA is used as negative control. LUC activity and the corresponding bright field images of a representative leaf from 3 independent replicates are shown. (B) Luciferase activity and the corresponding bright field images of several Arabidopsis $\mathrm{T} 2$ independent stable transformant lines with the plasmids bearing the constructs indicated in the schematic representation at the bottom. Since the constructs contain a Red-seed coat selection marker, only seeds containing the constructs were germinated on $0.5 \mathrm{GM}$ medium plates. $4 \mathrm{dpg}$, seedlings were treated with $0.5 \mathrm{GM}$ liquid medium supplemented with $20 \mu \mathrm{g} / \mathrm{mL}$ for $2 \mathrm{~h}$ and imaged $24 \mathrm{~h}$ later. Note that the top plates contain SplitLUC constructs between RBR and NACO44 or NACO44 ${ }^{G C G}$, and the bottom plates contain single gene fusions with a full length LUCIFERASE tag. Numbers indicate the number of independent lines for each genotype. 
$$
\text { A }
$$

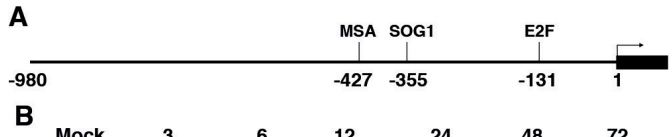

.
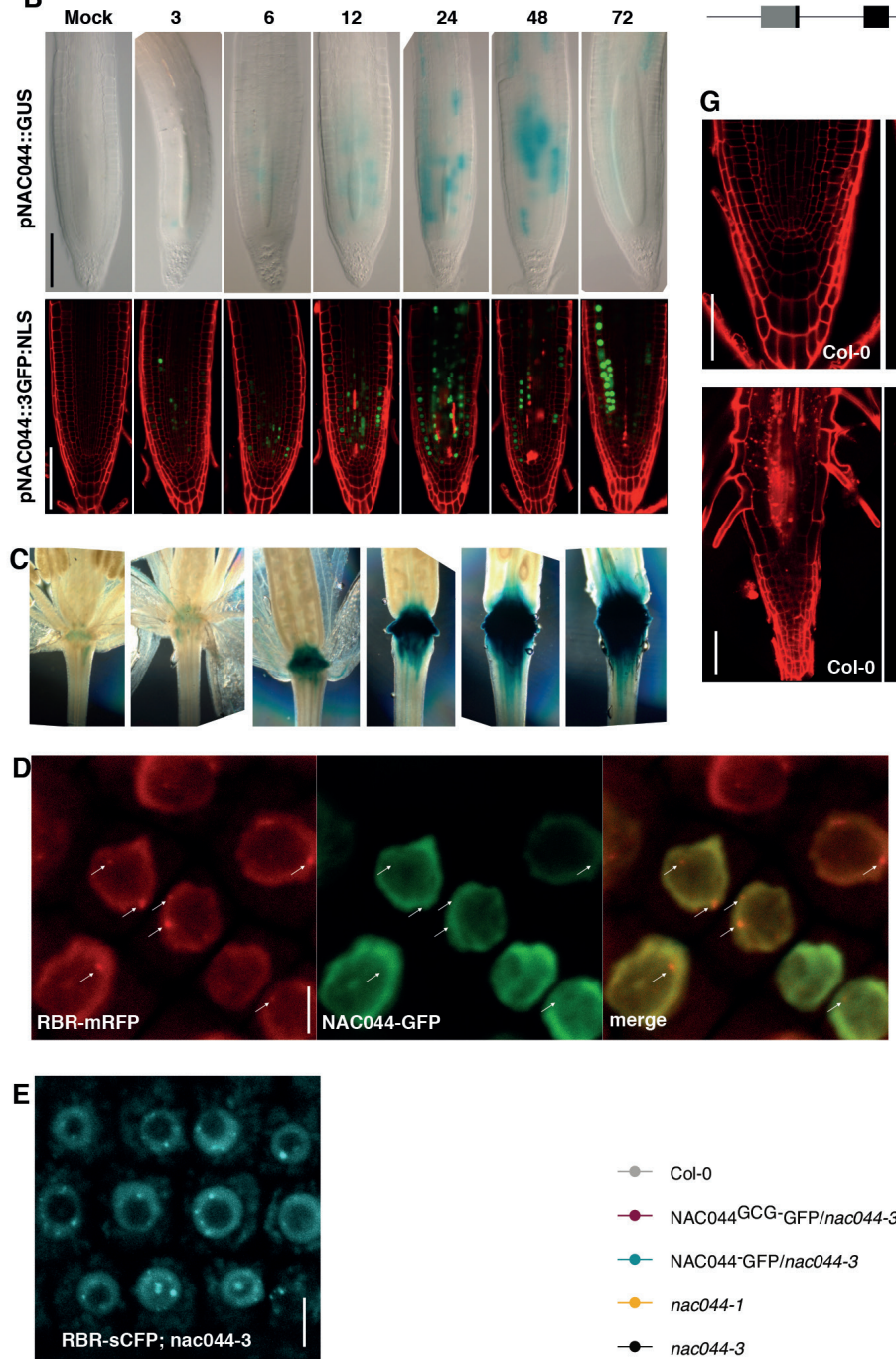

F
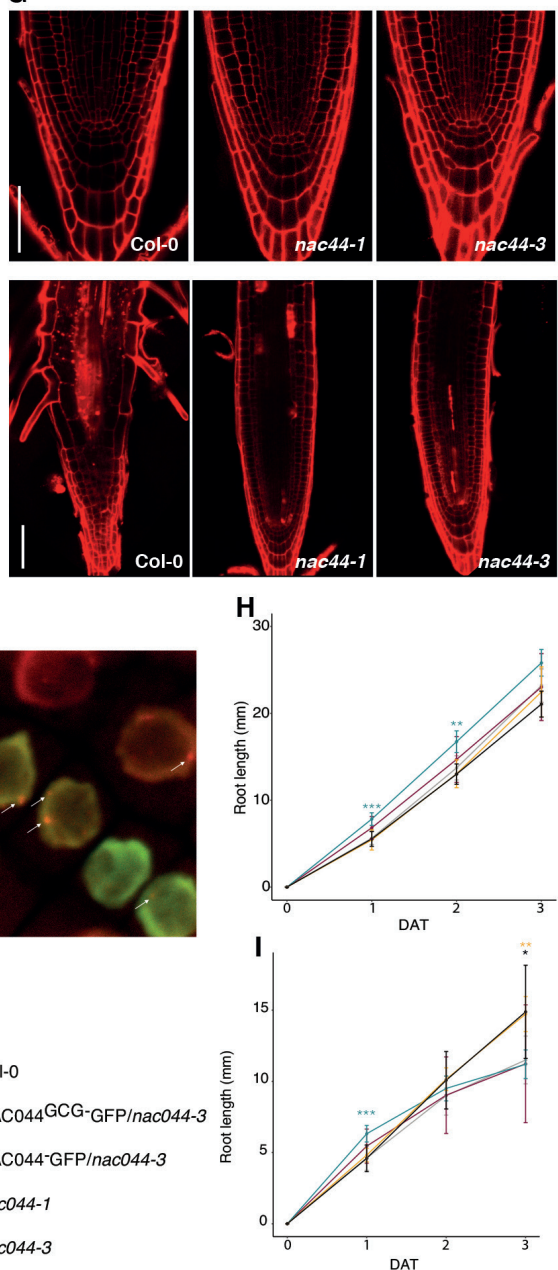
Figure S4: NAC044 is expressed after DNA damage, does not recruit RBR to nuclear foci and inhibits root growth.

(A) Schematic representation of the NAC044 promoter cloned for transcriptional and translational fusions that was sufficient to recapitulate the previously reported expression pattern of NACO44 and to complement the nac044 null mutants. The position of the MSA, SOG1 and E2F elements are indicated. (B) NAC044 promoter activity at the indicated times after mock treatment or $2 \mathrm{~h}$ incubation on 20 $\mathrm{\mu g} / \mathrm{mL}$ zeo as shown by transcriptional fusions with GUS (pNAC044::GUS) and a nuclear localized 3xGFP (pNAC044::3GFP:NLS). (C) Age dependent pNAC044::GUS activity in the abscission zone of inflorescences. (D) Confocal image (single section) of a Clearsee treated root showing NAC044-GFP and RBR-mRFP colocalization in nuclei after $16 \mathrm{~h}$ incubation on $10 \mu \mathrm{g} / \mathrm{mL}$ zeo. White arrows indicate the position of RBR foci in nuclei with NAC044-GFP signal. Representative image of $>5$ independent replicates. We never observed NAC044-GFP foci. (E) Confocal image (single section) of living root cells showing RBR-SCFP foci in nac044-3 genetic background after $16 \mathrm{~h}$ incubation on $10 \mu \mathrm{g} / \mathrm{mL}$ zeo. Representative image of $>5$ independent replicates. (F) Schematic representation of the NAC044 gene showing the T-DNA insertion sites of nac044-1, nac044-2 and nac044-3. Exons and introns are represented as black boxes and lines, respectively. (G) Confocal images of longitudinal sections of $\mathrm{PI}$-stained root tips from 4-5 dpg Col-0, nac044-1 and nac044-3 seedlings germinated and grown in $0.5 \mathrm{GM}$ medium (top panel), or transferred to $0.5 \mathrm{GM}$ supplemented with $3 \mu \mathrm{g} / \mathrm{mL}$ zeo for 3 days (lower panel). $(\mathrm{H}, \mathrm{I})$ Root growth comparison of Col-0, nac044-1, and nac044-3 complemented with pNAC044::NAC044:GFP (NAC044-GFP) and pNAC044::NAC044 ${ }^{\text {GCG }}$ GFP (NAC044 ${ }^{\text {GCG }}$-GFP). Seedlings germinated and grown on $0.5 \mathrm{GM}$ medium for 5 days were transferred to $0.5 \mathrm{GM}$ medium without (H) or with (I) $3 \mu \mathrm{g} / \mathrm{mL}$ zeo for 3 days. Data presented as mean $+\mathrm{SD}$ of a single replicate (due to high variability between independent replicates), $14>n>10 .{ }^{* *} p<0.001,{ }^{* *} p<0.01,{ }^{*} p<0.05$ (Student's t-test). Scale bars, $100 \mu \mathrm{M}$ in (B,C), $5 \mu \mathrm{M}$ in (D,E), $50 \mu \mathrm{M}(\mathrm{G})$. 

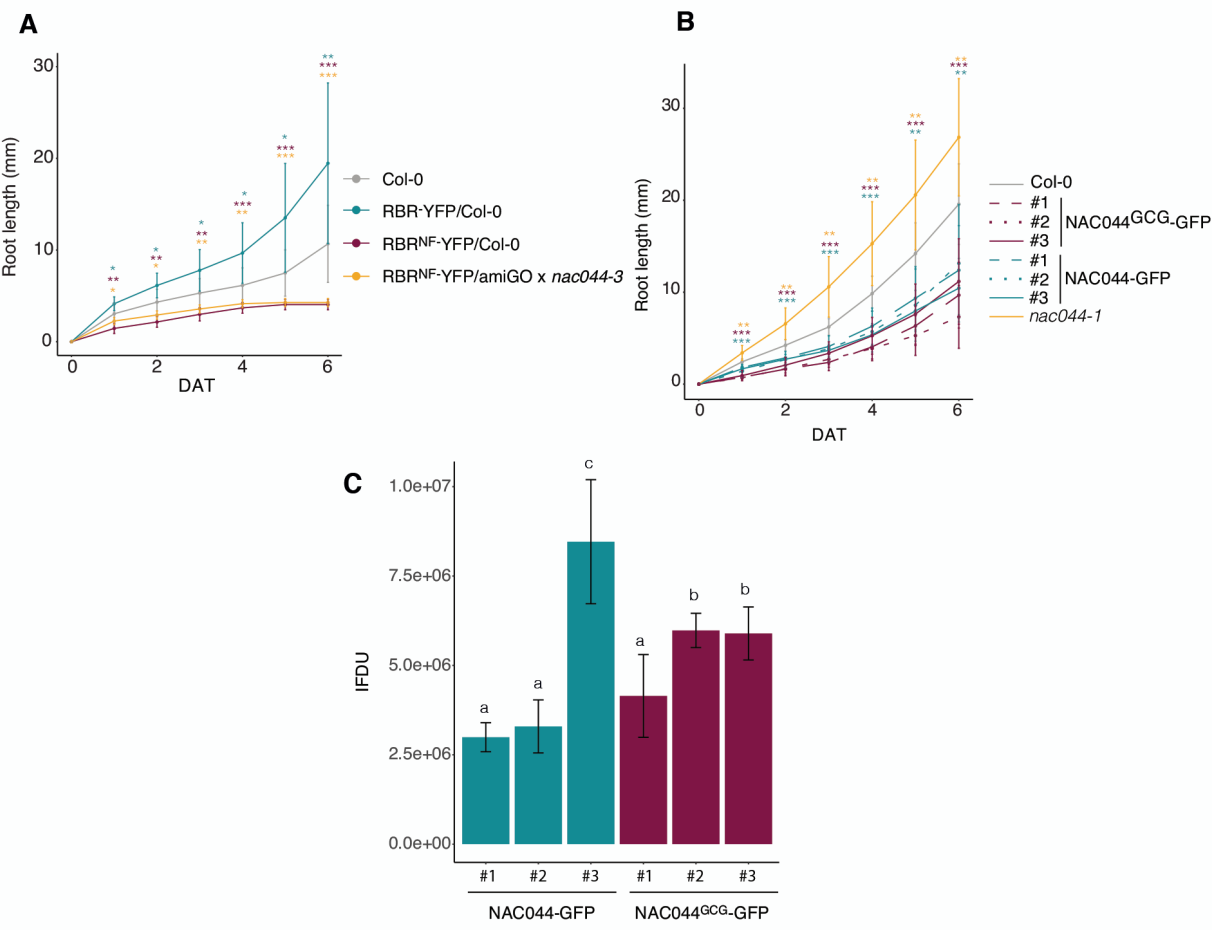

Figure S2: RBRNF dominantly affects the DNA damage response through a different mechanism than binding NAC044.

$(A, B)$ Root growth after DNA damage. 4 dpg seedlings were incubated on $10 \mu \mathrm{g} / \mathrm{mL}$ zeo for $20-24$ $\mathrm{h}$ and transferred again to $0.5 \mathrm{GM}$ medium plates for recovery over 6 days. Due to the variability between replicates, a single representative biological replicate is shown. Root growth was scored for 6 days after zeo treatment (dat). Genotypes in (A) are Col-0, homozygous RBR-YFP in Col-0 background,

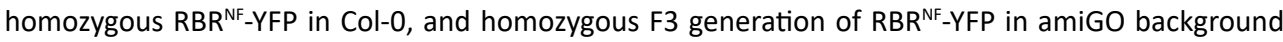
crossed with nac044-3; in (B) Col-0, nac044-1, three independent transformant lines of NAC044-GFP in nac044-1, and three independent transformant lines of NAC044 ${ }^{\mathrm{GCG}}$-GFP transformed in nac0441 (similar results obtained in the nac044-2 background). In B) the complementing NAC044-GFP and NAC044 ${ }^{G C G}$-GFP form a single statistically similar group. Data presented as mean +SD of a single replicate (due to high variability between independent replicates); $n>12 . * * * p<0.001,{ }^{* *} p<0.01,{ }^{*} p$ $<0.05$ (Wilcoxon signed rank test). (C) Bar graph showing the quantification of integrated fluorescence density of the transformant lines of NAC044-GFP and NAC044 ${ }^{\text {GCG }}$-GFP in nac044-1 mentioned in (B) and Figure $4.4 \mathrm{dpg}$ seedlings were incubated on $10 \mu \mathrm{g} / \mathrm{mL}$ zeo for $24 \mathrm{~h}$ before imaging. At least 8 roots per line were used for quantification using imageJ software. Lowercase letters denote ststistically different groups $p<0.05$ (Kruskal-Wallis). 
Supplementary Table 1: List of primers.

\begin{tabular}{|c|c|c|}
\hline Primer & Sequence & \\
\hline GWcass_SplitLUC_F & tgGAAGACcggatctggttccgcgtccat & $\begin{array}{l}\text { Split LUC to } \\
\text { Gateway }\end{array}$ \\
\hline GWcass_CLuc_R & gtGAAGACtaTCGAtttgttagcagccggatcccg & $\begin{array}{l}\text { Split LUC to } \\
\text { Gateway }\end{array}$ \\
\hline GWcass_NLuc_R & gtGAAGACtaTCGAtttgttggcagccggatcccgggtcgaatgaaaccactttgtacaag & $\begin{array}{l}\text { Split LUC to } \\
\text { Gateway }\end{array}$ \\
\hline pANAC044 F & agGGTCTCTACCTagccatgatctcattatcactaccac & GreenGate \\
\hline pANAC044 R1 & gtGGTCTCATGATtcccaaaacagagagagg & $\begin{array}{l}\text { GreenGate } \\
\text { translational }\end{array}$ \\
\hline pANAC044 R2 & gtGGTCTCATGTTtcccaaaacagagagagg & $\begin{array}{l}\text { GreenGate } \\
\text { transcriptional }\end{array}$ \\
\hline gANAC044 F & gtGGTCTCAATCATGGCGAGgtaagctttgaac & $\begin{array}{l}\text { GreenGate } \\
\text { cloning }\end{array}$ \\
\hline gANAC044 R & cgGGTCTCGCTGAAGTTCCATTGAATTTTCCGAAAGTAA & $\begin{array}{l}\text { GreenGate } \\
\text { cloning }\end{array}$ \\
\hline mut gANACO44 R & gaGGTCTCTTCCGTTATCTTCACTTAGGTTCA & $\begin{array}{l}\text { GreenGate } \\
\text { cloning }\end{array}$ \\
\hline mut gANAC044 F & aaGGTCTCACGGAATATGCGACGGAAGCATGGAAGCTTCGTCT & $\begin{array}{l}\text { GreenGate } \\
\text { cloning }\end{array}$ \\
\hline AttB cNAC44 F & $\begin{array}{l}\text { GGGGACAAGTTTGTACAAAAAAGCAGGCTgcATGGCGAGGGCTTG- } \\
\text { GATTGT }\end{array}$ & Gateway cloning \\
\hline AttB cNAC44 R & $\begin{array}{l}\text { GGGGACCACTTTGTACAAGAAAGCTGGGTtTTAAGTTCCATTGAATTT- } \\
\text { TCCGA }\end{array}$ & Gateway cloning \\
\hline mut cNAC44 F & ATAACGGAATATGCGACGGAAGCATGGAAGCTTCGTCT & Gateway cloning \\
\hline mut cNAC44 R & TGCTTCCGTCGCATATTCCGTTATCTTCACTTAGGTTC & Gateway cloning \\
\hline gnac044-3 F & TTCCATTTCGTTCACTGTTCC & $\begin{array}{l}\text { Genotyping } \\
\text { nac044-3 }\end{array}$ \\
\hline gnac044-3 R & ATTGATGCAGAACCCAGTTTG & $\begin{array}{l}\text { Genotyping } \\
\text { nac044-3 }\end{array}$ \\
\hline gnac044-1 F & TTCAGGTACTGATTCCATGGC & $\begin{array}{l}\text { Genotyping } \\
\text { nac044-1 }\end{array}$ \\
\hline gnac044-1 R & CAAAGAGACGAAGCTTCCATG & $\begin{array}{l}\text { Genotyping } \\
\text { nac044-3 }\end{array}$ \\
\hline cE2FA AttB F & $\begin{array}{l}\text { GGGGACAAGTTTGTACAAAAAAGCAGGCTTAATGTCCGGTGTCGTAC- } \\
\text { GATCTT }\end{array}$ & Gateway cloning \\
\hline cE2FA AttB R & $\begin{array}{l}\text { GGGGACCACTTTGTACAAGAAAGCTGGGTCTCCTCTCGGGGTTGAGT- } \\
\text { CAACA }\end{array}$ & Gateway cloning \\
\hline cE2FB AttB F & $\begin{array}{l}\text { GGGGACAAGTTTTGTACAAAAAAGCAGGCTTCATGTCTGAAGAAG- } \\
\text { TACCTCAACAATTC }\end{array}$ & Gateway cloning \\
\hline cE2FB AttB R & $\begin{array}{l}\text { GGGGACCACTTTTGTACAAGAAAGCTGGGTATCCGCTACCTGTAGGT- } \\
\text { GATCT }\end{array}$ & Gateway cloning \\
\hline cE2FC AttB F & $\begin{array}{l}\text { GGGGACAAGTTTGTACAAAAAAGCAGGCTTCATGGCCGCGACAT- } \\
\text { CAAAC }\end{array}$ & Gateway cloning \\
\hline cE2FC AttB R & GGGGACCACTTTGTACAAGAAAGCTGGGTATCCGCTGTTGAAGTTGCTC & Gateway cloning \\
\hline
\end{tabular}




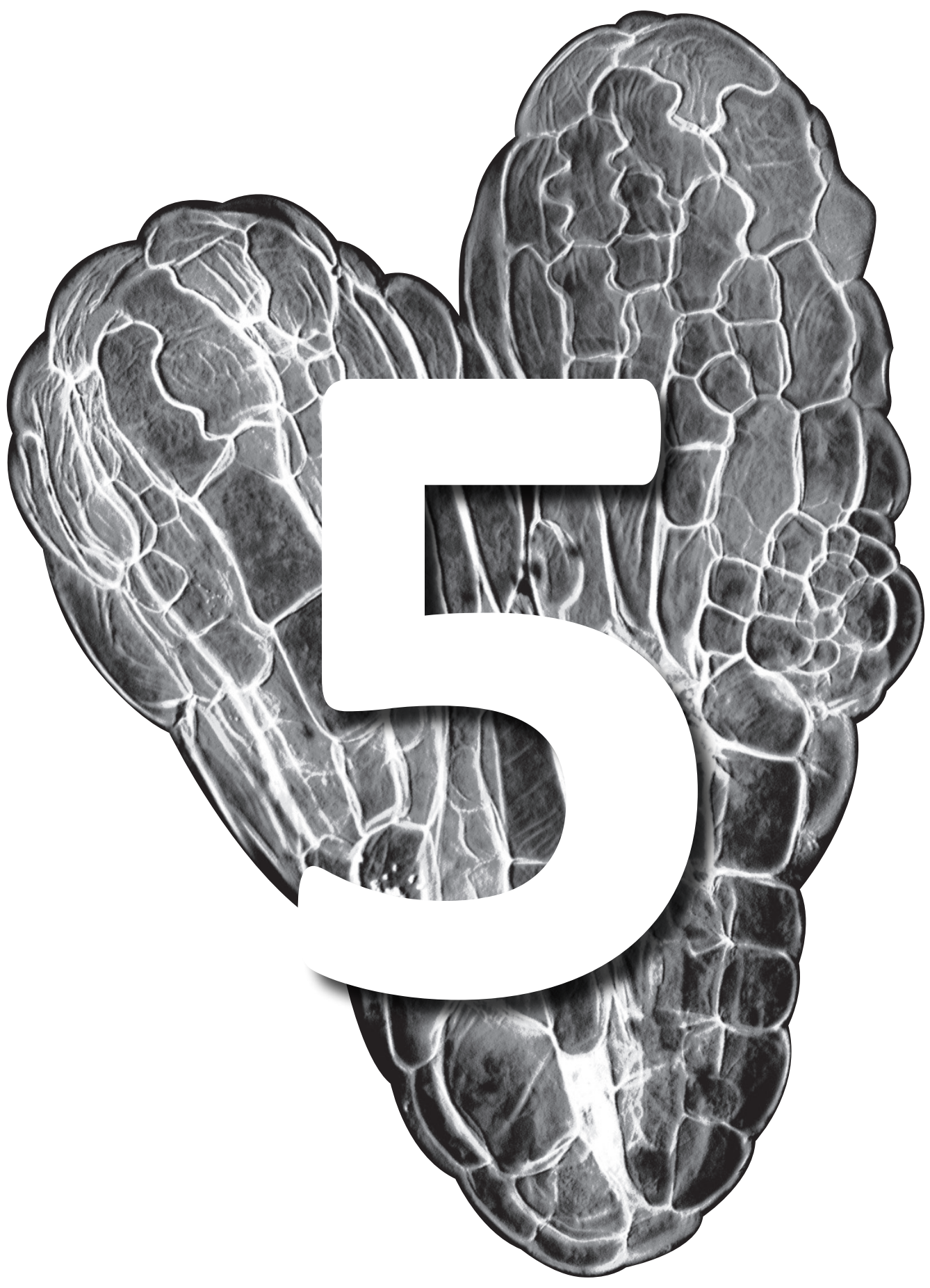




\section{Chapter 5}

General Discussion 
Chapter 5 


\section{General Discussion}

"Seen in the light of evolution, biology is, perhaps, intellectually the most satisfying and inspiring science. Without that light it becomes a pile of sundry facts -some of them interesting or curious but making no meaningful picture as a whole" THEODOSIUS DOBZHANSKY

Whether it is a single cell, a multicellular self-conscious organism, or an entire ecosystem, living systems are formed by elements that establish dynamic connections with each other. The elements of living systems organize themselves in complex networks that not only have to remain stable and robust, but that evolve and with them does life (Capra, 2005). In protein networks and transcriptional networks, so-called hub nodes connect a number of proteins and genes. The RETINOBLASTOMA-RELATED (RBR) proteins, prime examples of such hub proteins, establish multiple protein-protein interactions (PPI) that bridge, among others, transcription factors (TFs) and chromatin remodelers to exert transcriptional regulation. In turn, these PPIs are regulated by phosphorylation on multiple RBR sites, offering a potential mechanism to coordinate transcriptional networks and chromatin structure.

Phylogenetic evidence suggests that RBR genes existed in the last eukaryotic common ancestor (LECA)(Desvoyes et al., 2014), possibly coordinating basic unicellular processes such as cell division, cell size, and DNA damage repair. In the following sections we expose a view on an RBR-centric module to which other genes might have been connected alongside the increasing complexity in eukaryotic evolution. Taking the plant perspective, I focus on the role of RBR phosphorylation as a regulation mechanism to control this expanding module within a developmental and environmental context. Revisiting the experimental results described in this thesis, I discuss the implications, unexplored questions, and future perspectives of RBR research in plant biology.

\section{RBR/E2Fs/CDKs/CYC/CKIs are ancient elements of a network coupling the DNA damage response (DDR) to cell division.}

Whereas DNA mutations are the engine of evolution, life could have only thrived by ensuring high fidelity of DNA replication, sensing and repair of damaged DNA, and by providing a unidirectional sequence of events to generate two cells with equal genetic information. In higher organisms that better withstand mutations (Wahl and Carr, 2001; Wilke and Adami, 2003), a sophisticated phosphorelay system surveys the DNA integrity to coordinate repair mechanisms with cell division (Abraham, 2001). For example, the Checkpoint kinase1 (Chk1) couples DNA damage perception to the DDR activation, a transcriptional cascade leading to DNA repair, cell cycle arrest, and programmed cell death (PCD) (Patil et al., 2013). Interestingly, the driving force of the eukaryotic cell cycle is provided by CYCLIN-DEPENDENT KINASES (CDKs), which evolved from the Chk1 clade likely present in LECA (Krylov et al., 
2003); they participate in the DDR to maintain genome stability in plants and animals (Lim and Kaldis, 2013; Weimer et al., 2016).

Together with E2F TFs, RBR proteins function alongside Chk and CDKs in coupling cell cycle transcriptional programs to the DDR (Coschi and Dick, 2012; Gómez et al., 2019; Horvath et al., 2017; Manickavinayaham et al., 2021). Similarly, the CDK regulatory subunits A-, B- and D-type CYCLIN (CYC) proteins, and CDK-inhibitors (CKIs) play central roles in the core cell cycle regulation system, while some of them are transcriptionally induced by and participate in the DDR (Abroudi et al., 2017; Schnittger and De Veylder, 2018; Yi et al., 2014). Their presence in plants, animals, and unicellular eukaryotes indicate their existence in LECA, while the origin of RBR likely dates to a pre-eukaryotic organism (Takemura, 2005).

Although some of these elements are not present in fungi, the cell cycle regulatory network topology of such fungi strikingly resembles that represented by RBR/E2F/CYC/CDK/CKI (Cross et al., 2011; Zhao et al., 2012), suggesting that RBR network topology conveys robust cell cycle control (Figure 1). Noteworthy, the repressive function of RBR is covered by Whi5 in budding yeast, a non-homologous protein that contains 12 phosphorylation sites for CDKmediated inactivation (Costanzo et al., 2004), indicating convergent evolution of multi-site phosphorylation as a strategy for modulating the activity of signal-integrating transcriptional regulators.

Multicellular

(mammals)

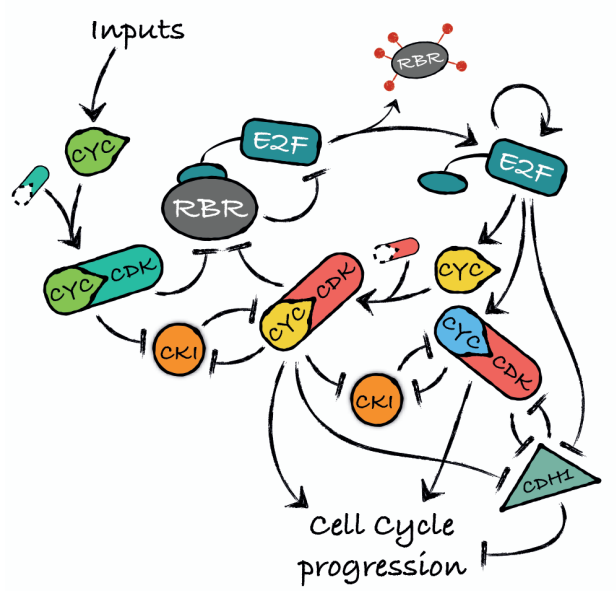

unicellular

(fungi)

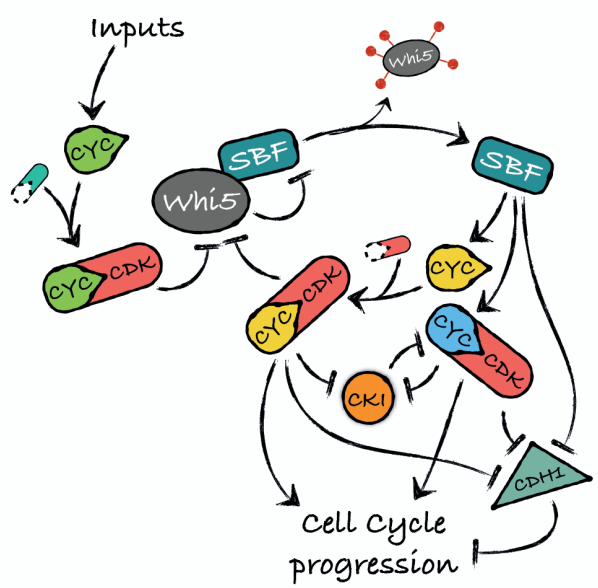

Figure 1: The conserved topology of the cell cycle control network in eukaryotes.

Schematic representation of the mammalian and budding yeast circuits that control the G1/S phase transition. Although there is no sequence homology between some fungal and mammalian proteins, the function and connections established by the fungi-specific proteins are conserved as compared with their mammalian counterparts, rendering similar regulatory network topologies (Adapted from Cross et al., 2011). 


\section{Cell size-dependent cell division.}

Optimal cell size ensures high efficiency of nutrient usage for cell division and prevents troublesome genome duplication in too small cells. Studies in unicellular eukaryotes revealed that cell cycle progression depends on critical cell size checks during G1/S and again in G2; but after the size threshold is reached, a cell size-independent mechanism drives cell division (Fantes, 1977; Matsumura et al., 2003; Sveiczer et al., 1996). Of these two phases (dependent and independent of a critical cell size) known as 'sizer' and 'timer', respectively, the cell sizer has a stronger influence on cell division control (Matsumura et al., 2003). The cell sizer relies on CDK activity modulated not only by CYCs and CKIs (Alberghina et al., 2004; Qu et al., 2003), but also by a membrane-growth and metabolism sensing system (Anastasia et al., 2012; Dante et al., 2014; Harashima et al., 2013).

Similar sizer mechanisms exist in higher eukaryotes (Jones et al., 2017; Willis et al., 2016; Xie and Skotheim, 2020). Proliferating cells in the Arabidopsis thaliana shoot apical meristem (SAM) grow cell-autonomously at a rate that depends on their initial size after division (Willis et al., 2016), whereas cell size at the moment of division is determined by the growth rate and accumulation of CDK activity (Jones et al., 2017). Moreover, dilution of the G1/S $\mathrm{CDK}$ and the RBR homologous protein controls cell cycle progression in unicellular and higher eukaryotes (Fang et al., 2006; Schmoller et al., 2015). Similarly, mutants in the RBR orthologous gene MAT3 divide more and at smaller cell size in unicellular algae; and mat3 phenotypes are suppressed by mutations in the E2F and DP TFs (Fang et al., 2006). Thus, the CYC-CDK/CKI/RB/E2F-DP network likely integrates cell growth and cell cycle control to establish a size-dependency on cell division commitment.

Although not incorporated in current models, it is difficult to imagine a CDK-dependent mechanism coupling cell size and division not involving RBR phosphorylation, especially because in Arabidopsis, most phenotypes associated to down-regulation of the canonical cell cycle CDKA are rescued by depleting RBR (Nowack et al., 2012). The omission of RBR in models may be due to the fact that RBR is required for multiple processes and its less pleiotropic associated factors are more easily identified as instructive components for these processes.

Altogether, the RBR network integrates DNA integrity, cell growth, and cell division control, probably supporting complexity gain in eukaryotic living systems. Accordingly, the D-type CYC gene family correlates with multicellularity emergence, and the expression of MAT3 gene from a colonial unicellular algae is enough to convey colonial behavior in otherwise unicellular disaggregate species, a phenotype suppressed by mutating the Dimerization Partner (DP) of E2F (Hanschen et al., 2016). 


\section{Implications of an RBR-centric network in higher eukaryotes}

In higher eukaryotes, organ size and shape homeostasis emerges from the spatiotemporal coordination of growth and cell division (Whitewoods and Coen, 2017). De-regulation of CYC-CDK/CKI/RBR/E2F network elements trigger similar effects than those observed in unicellular disaggregated algae (for example, rbr/mat3 mutants divide more at smaller cell size). Thus, it seems that information critical for tissue self-organization was cryptically encoded in the RBR network before the emergence of multicellularity. The consequence of coupling cell size with cell division manifests in multicellular organisms as compensatory effects that ensure organ size and shape homeostasis.

\section{Compensatory effects}

Increased cell division compensates for reduced cell size to reach normal organ size in mutants of LOSS OF GIANT CELLS FROM ORGANS (LGO), a CKI gene that promotes mitotic exit, endoreplication, and cell size expansion in Arabidopsis (Moreno et al., 2020). Compensatory effects also contribute to meristem size maintenance in mutants and/or over-expressers of CDKA, CYCD3, and other CKIs (Cheng et al., 2015; Horiguchi and Tsukaya, 2011; Truskina and Vernoux, 2018). But compensation is limited, as strong overexpression or reduction of CKIs lead to evident changes in organ size (Cheng et al., 2015; Noir et al., 2015; Verkest et al., 2005).

In Chapter 2 (Fig 2) we observed that root meristem size was often maintained by similar compensatory effects. Moreover, highly-substituted RBR phospho-defective variants displayed phenotypes resembling $c d k a$ loss of function mutants (Nowack et al., 2012; Weimer et al., 2012) (Chapter 2, Fig 3), pointing to RBR phosphorylation as an integrator of CDK and CKI activity. Consistently, reduction of CKI leads to high CDK activity, elevated levels of phosohorylated RBR, and upregulation of E2FA target genes in Arabidopsis (Cheng et al., 2015).

Compensatory effects were also observed upon de-regulation of the proliferation-promoting gene GROWTH-REGULATING FACTOR5 (GRF5) (Horiguchi et al., 2005; Kim and Kende, 2004). Noteworthy, whereas GRF5 confers low nitrate tolerance in leaves (Vercruyssen et al., 2015), LGO gene expression and Igo leaf phenotypes depend on nitrate concentration, with low nitrate triggering compensatory cell division (Moreno et al., 2020). Thus, GRF5 is antagonistic to the LGO and KRP2 CKIs in leaf organogenesis (Kim and Kende, 2004; Vercruyssen et al., 2015; Verkest et al., 2005), and their functions might be integrated in the RBR-centric network.

We found that GRF5 binds to all RBR phospho-variants, but the interaction was inconsistent throughout replicates (Chapter 3, Fig S1). This stochasticity may suggest that other factors could stabilize this PPI. Likely candidates are the GRF-INTERACTING FACTOR1 (GIF1) and E2F proteins, and they might influence the effectivity of RBR-GRF5 complex. E2FA promotes cell proliferation and, together with RBR, represses differentiation in actively dividing cells, 
but activates endoreplication as cells transit towards a differentiation zone (Magyar et al., 2012). E2FB in turn, represses proliferation in dividing cells, but it reactivates cell cycle in differentiating cells when ectopically expressed, bypassing RBR repression (Oszi et al., 2020). E2FC also represses cell division, promotes endoreplication and cell expansion (Pozo et al., 2006). Whether E2Fs work together with an RBR-GRF5 complex downstream of CKI/ CDK requires further investigation.

Besides GRF5, the RBR network has likely expanded through other PPIs. In Chapter $\mathbf{2}$ we observed that the N849F mutation only partially suppresses the phenotypes of phosphodefective RBR variants. Thus, the phosphorylation-regulated functions of RBR are mediated by both LXCXE-dependent and an LXCXE-independent components. As CYCD3 overexpression leads to similar phenotypes than CKI downregulation (Dewitte et al., 2003), which in turn induces the E2F-controlled genetic program (Cheng et al., 2015), E2F TFs are candidates for the LXCXE-independent component. Conversely, the DREAM complex members TCX5/6 proteins regulate cell division, differentiation, and organ size (Ning et al., 2020). We showed that RBR-TCX6 (and most likely RBR-TCX5/7) interaction is mediated by the LXCXE motif and regulated by phosphorylation. Thus, these LXCXE-dependent and independent components of phosphorylation-regulated RBR functions might converge in the DREAM complex.

\section{Morphogenetic and developmental properties}

Besides organ size, the RBR-centric network conveys other morphogenetic characteristics. For example, fluctuation of the aforementioned compensatory effects during sepal development can create cell size variability which contributes to the three-dimensional organ shape emergence (Roeder et al., 2010).

In roots, new lateral root meristems initiate from differentiated pericycle cells, where E2FA promotes cell cycle re-entry downstream of auxin-dependent LBD18/LBD33 activation (Berckmans et al., 2011). Conversely, RBR interaction with the chromatin remodeler PICKLE represses LBD16 expression and inhibits LR formation, which is overcome by exogenous auxin (Ötvös et al., 2019), suggesting that RBR acts upstream of E2FA during LR initiation. As KRP2 and CYCD2;1-CDKA act antagonistically in the pericycle cells to modulate lateral root density (Sanz et al., 2011), the CYC-CDK/RBR/E2F/CKI network might be linked to the auxin signaling pathway that regulates LR density.

Coordination of cell division, size, and differentiation is also crucial for female gametophyte specification from a sporophytic cell cluster, where only one cell will form the megaspore mother cell (MMC) (Berger and Twell, 2011). MMC specification is mediated by RBR directly binding and repressing the promoter of the SAM maintainance regulator WUSCHEL (WUS), and by the balanced activities of CKIs and CYC-CDKs (Cao et al., 2018; Zhao et al., 2017). Strikingly, e2fabc triple mutants display similar phenotypes in the MMC specification to 
those of $r b r$ and $c k i$ loss of function alleles (Yao et al., 2018), suggesting that E2FA, E2FB and E2FC act redundantly to ensure proper gametophyte development, but the network is wired diferently. Whether E2Fs also control WUS expression remains an open question.

Although no obvious gametophytic defects were manifested in our RBR phospho-variant collection (Chapter 2), technical limitations likely influenced our observations, as the 35 s promoter driving our RBR artificial miRNA is not active at this developmental stage. Furthermore, as phenotyping was performed after MMC specification, phenotypes of dominant phospho-defective variants could have been masked by early sporophytic defects. An inducible CRISPRed rbr null background could aid the study of RBR phosphorylation during early germline specification.

Yet another question is whether RBR also regulates WUS in the context of the SAM. On the one hand, RBR is necessary to maintain SC activity in the root meristem and in the SAM (Borghi et al., 2010; Wildwater et al., 2005). On the other hand, WUS sustains indeterminate growth and the SC pool from a more restricted expression domain in the SAM (Laux et al., 1996; Schoof et al., 2000). We observed aerial rosettes in the shoots of some phosphodefective RBR variants (not shown), indicating a reproductive to vegetative phase reversion. Since this phenotype occurs in wus-1 mutants (Ishiguro et al., 2002; Laux et al., 1996), a phosphorylation-regulated RBR repression on WUS might also operate in the SAM.

In a nutshell, the CYC-CDK/CKI/RBR/E2F network is an evolutionarily conserved system that acquired additional roles as eukaryotes gained complexity. This network couples DNA damage, cell size, and cell division, and operates cell-autonomously to confer global tissue organization. As an integrator of CYC-CDK and CKI activities, RBR phosphorylation and its morphogenetic properties should be investigated in detail. In particular, as CYC and CKI gene families have expanded and gained considerable control over developmental and environmental processes in plants, future research should reveal the importance of combinatorial RBR phosphorylation for network functioning, as the phosphorylation code hypothesis suggests.

\section{An environment-interactive network}

In unicellular algae, changing temperatures alter cell division due to variable CDK activity (Zachleder et al., 2019); and favorable light conditions promote G1/S-phase transition through CycA, a checkpoint bypassed by downregulating RB (Moulager et al., 2010). These observations suggest that RB phosphorylation integrates environmental inputs conveyed by CYC-CDK activity.

In plants, a centralized system regulated by growth regulator (hormone) crosstalk has been postulated to mediate stress responses (Chapin III, 1991). Accordingly, hormone synthesis, 
distribution, and signaling meet to modulate every aspect of plant development, with many hormonal pathways being directly involved in environment perception and response (Depuydt and Hardtke, 2011; Vanstraelen and Benkov, 2012).

The DELLA growth regulators are central hubs in the hormone- and stress-responsive networks (Achard et al., 2006, 2008; Scheres and Van Der Putten, 2017). At the expense of growth, DELLA proteins promote survival under stressful conditions by preventing ROS accumulation (Achard et al., 2008), which mediates a broad range of biotic and abiotic stress responses (Choudhury et al., 2017; Das and Roychoudhury, 2014; Ben Rejeb et al., 2014). Interestingly, ROS levels are internally regulated to maintain SC identity, growth, and division-differentiation gradients in meristems (Kong et al., 2018; Tsukagoshi et al., 2010; Zeng et al., 2017). Thus, the meristematic function is intimately linked to environmental sensing and response.

This plant growth regulator network is integrated into gene expression regulation of CYCS, CKIs, and cell cycle-dependent proteolytic complexes (Takatsuka and Umeda, 2014). For example, the DELLA protein GIBBERELLIC ACID INSENSITIVE (GAI) and ROS activate CKI expression to regulate cell division in meristems (Kasili et al., 2010; Noir et al., 2015; SerranoMislata et al., 2017; Yi et al., 2014). Moreover, other stressful stimuli such as DNA damage, drought, cold and cytoplasmic acidification, induce the expression of CKIs (Dletrich et al., 2017; Peres et al., 2007; Yi et al., 2014). In turn, CKI-induced endoreplication associates with plant defense: whereas higher ploidy correlates with responses to stress and stress-related hormones, less ploidy correlates with response to developmental hormones (Bhosale et al., 2018); and DNA oxidative damage upon abiotic stress triggers CKI-mediated endoreplication (Matsuda et al., 2018; Yi et al., 2014)

\section{Phosphorylation-dependent and independent roles of RBR in stress response}

The prominent role of CKIs in stress responses points to RBR phosphorylation as a possible integrator of stress signaling into cell division and growth, as previously suggested (Harashima and Sugimoto, 2016). On the other hand, many of the RBR interactors described in Chapter 3 that belong to stress-responsive pathways showed no evident regulation by the phosphorylation state of RBR. Thus, RBR may hold at least two roles in stress response, one dependent and one independent of phosphorylation.

In Chapters $\mathbf{3}$ and $\mathbf{4}$ we uncovered the first indications for phosphorylation-independent roles of RBR. In the DDR, these seem intertwined with its phosphorylation-regulated ones. For instance, RBR-NACO44 interaction is independent of RBR-phosphorylation (Chapter 3), but the expression of NACO44 is probably regulated by RBR in a phosphorylation-dependent manner. On the one hand, RBR-phosphorylation regulates the interaction with E2Fs and TCX5/6 (Chapter 3), which form DREAM complexes together with the MSA element-binding 
proteins, MYB3Rs (Kobayashi et al., 2015; Ning et al., 2020). On the other hand, the spotty expression pattern of NAC044, the presence of E2F and MSA elements in its promoter, and the fact that NACO44 is a direct target of both RBR and MYB3R3 (Bourbousse et al., 2018; Bouyer et al., 2018), indicate a cell cycle-dependent regulation by DREAM complexes, where RBR phosphorylation may be crucial.

In mammals, the most prominent regulatory hub in the DDR is p53. A p53-induced CKI prevents $\mathrm{pRb}$ phosphorylation by $\mathrm{CDKs}$, promoting a transcriptional switch from an activator B-MYB-MuvB complex (MMB) to a repressor DREAM complex (Engeland, 2018; Fischer and Müller, 2017). In plants, CKIs are activated by SOG1, the presumed functional homolog of p53 (Ogita et al., 2018). Although no MMB complexes have been reported, activator and repressor DREAM complexes are formed by the alternative incorporation of activator and repressor MYB3R and E2Fs (Kobayashi et al., 2015; Ning et al., 2020). Whether RBR (de)phosphorylation is relevant for an activator-to-repressor DREAM complex switch remains unexplored.

The phosphorylation-dependent role of RBR in biotic stress has been investigated in more detail for the process of effector triggered immunity (ETI), a hypersensitive reaction at a pathogen infection site that manifests as DNA fragmentation and cell death. ETI signaling is partly transduced by the nuclear envelope protein CPR5, which releases CKIs into the nucleus to promote RBR hyper-phosphorylation and E2FA-mediated activation of defense genes and PCD (Wang et al., 2014). This mechanism could be conserved, as mutations in RB and in nuclear envelope proteins lead to genomic instability in animals and plants (Biedermann et al., 2017; Camborde et al., 2019; Horvath et al., 2017; Vélez-Cruz and Johnson, 2017). CKIs promoting RBR phosphorylation during ETI is counter-intuitive, but few observations suggest a possible explanation. First, moderate levels of CKIs can promote RBR phosphorylation (Wang et al., 2014); second, CKIs confer nuclear localization to CYC proteins (Sanz et al., 2011); and third, RBR phosphorylation is promoted by the F-BOX LIKE PROTEIN 17 (FBL17) protein, which mediates CKI degradation (Noir et al., 2015). Thus, a speculative hypothesis is that released CKIs from the nuclear envelope could internalize CYC proteins into the nucleus, where FBL17 promotes CKI degradation to allow RBR phosphorylation.

ETI and DDR seem intimately related, as some animal and plant pathogens elicit genotoxic effectors to damage the host DNA (Camborde et al., 2019). Moreover, the DNA repair proteins RAD51 and BRCA1, bind to defense genes promoters to activate their expression during ETI (Camborde et al., 2019). Whether BRCA1 and RAD51 also regulate transcription in DDR is unknown, but it seems that DNA breaks and effector-eliciting pathogens trigger similar transcriptional responses in the plant. The transcriptional and structural roles of RBR, E2FA, BRCA1 and RAD51 during DDR and ETI begs the question whether such roles are two separate functions. 


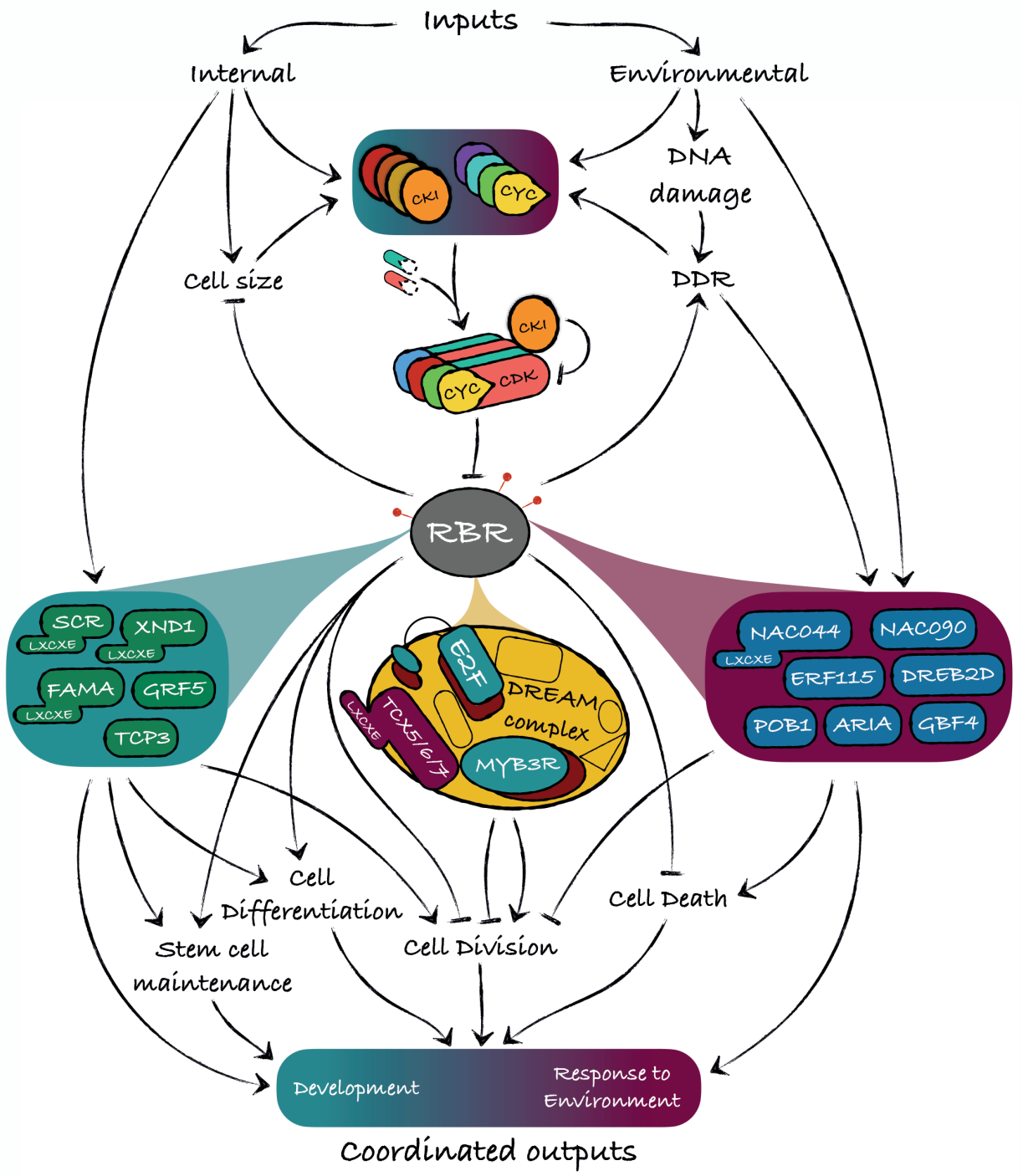

Figure 2: The RBR-centric network integrates internal and environmental inputs into cellular programs to coordinate the responses and developmental outputs.

Internal inputs such as developmental programs, cell size and the internal energetic status are simultaneously perceived together with the environmental inputs like biotic and abiotic stresses, both of which cause DNA damage. All mentioned inputs regulate the accumulation of several Cyclin (Cyc) and CDK-inhibitor (CKI) proteins belonging to multiple sub-families, which in turn modulate the kinase activity of CDKs on RBR. RBR activity feedback on the DNA damage response (DDR) and the cell size. Similarly, some transcription factors that directly bind RBR (grouped in coloured boxes; most of which, we described in Chapter 3) participate in developmental and stress-responsive networks. The most studied and conserved interactors of RBR are E2F proteins, which could also bind as members of the DREAM complex. In general, the interaction of RBR within the DREAM complex and with developmental TFs is modulated by phosphorylation, while many stress-responsive TFs bind RBR regardless its phosphorylation state. RBR and its interactors regulate the transcriptional programs of cell fate decisions like stem cell maintenance, cell division, cell differentiation, and cell death. Thus, RBR participates in orchestrating the transcriptional programs leading to a coordinated developmental and environment-responsive outputs. 


\section{Integration and future perspectives.}

The co-option of genes and their encoded proteins into preexisting networks, often preceded by gene duplication, and the deployment of a network into a new cellular context are general mechanisms of evolution (McQueen and Rebeiz, 2020; True and Carroll, 2002). Network co-option leads to morphological and physiological novelties, but also to trade-offs and trait linkage. This "complexity cost" constrains the independent evolution of traits, but is alleviated by modularity and additional transcriptional regulation (Capra, 2005; Hansen, 2003; McQueen and Rebeiz, 2020; True and Carroll, 2002).

Above, I have depicted the accumulating knowledge on RBR function in the framework of a conserved cell-autonomous RBR-centric network linking cell cycle progression with cell size and DNA integrity. I have argued that this network was likely co-opted to aid multicellularity and morphogenetic homeostasis. As RBR gene families are notably small, with many species having a single member (Desvoyes et al., 2014), it seems that RBR has been co-opted almost without gene duplication. One way to explain this remarkable finding is that a complex organism may need at least some control points that integrate multiple sources of information at a single node of the network. As new connections were built through RBR PPIs, the complexity cost of using a single protein as an integrator of traits and environmental responses would increase unless additional regulation layers counteract it.

The multiple overlapping but coordinated functions of CYC-CDKs, CKIs, RBR, and E2Fs suggest that RBR-phosphorylation regulates network dynamics within cellular and environmental contexts. CYC and CKI gene family expansion in plants, their divergent gene expression, and different specificities for RBR phospho-sites indicate that transcriptional regulation is integrated by RBR phosphorylation (Menges et al., 2005; Peres et al., 2007; Vandepoele et al., 2002; Willems et al., 2020). In addition, the phosphorylation code of RBR represents a way to reduce the complexity cost by reducing pleiotropy (Chapter 2). Modulation of RBR PPIs reduces network connectivity in a coordinated manner, which is predicted to favor the evolvability of traits (Hansen, 2003). CKIs-CDKs-CYCs complexes could be regarded as writers, and phosphatases as erasers of the RBR phosphorylation code, with plants harboring a large genetic pool as CYC and CKI families have expanded notably.

In summary, I postulate that RBR is a multifunctional protein whose biochemical properties set the basis for emergence of interdependent traits throughout eukaryotic evolution, in constant interaction with their environment. The work presented in this thesis contributes to an appreciation of the complexity of RBR regulation while it acts as an orchestrator of cellular processes, and constitutes a steppingstone to further explore RBR networks. Our phospho-variants, $\mathrm{RBR}^{\mathrm{NF}}$, and truncated RBR versions are now available as tools to use in combination with other new methods to fill the knowledge gaps in RBR biology. 
Future efforts should focus on understanding the regulation of RBR networks by phosphorylation. Our current knowledge on RBR functions was obtained by gene expression, up or down-regulation, loss of function alleles, transcriptomics, proteomics, ChIP-seq, and $\mathrm{Y} 2 \mathrm{H}$ experiments, resulting in an incomplete picture of RBR target genes, protein interactors, and biological functions. To complete this picture, the dynamic connections between these elements are yet to be fully understood.

Special attention should be paid to the physiological role of RBR in environmental signaling integration and response. For example, RBR-LXCXE interactions were once considered less relevant because organisms carrying the NF allele grow relatively normal in lab conditions (Morris and Dyson, 2001). But stress treatments proved the $\mathrm{RBR}^{\mathrm{NF}}$ allele to be deleterious in both plants and animals (Chapter 4) (Bourgo et al., 2011), suggesting that RBR-LXCXE interactions are essential in real-life situations. Similarly, a list of RBR target genes obtained from proliferating protoplasts comprises mostly cell cycle and DDR genes (Bouyer et al., 2018). This view may change after investigation of distinct physiological and developmental contexts in which a more diverse set of RBR-TF interactions and chromatin landscapes matter.

Expression studies of CYC and CKI genes, analysis of CYC-CDK specificities on RBR phosphosites, and phospho-proteomics could render a comprehensive map of RBR phosphorylation. Additionally, determining RBR interactomes can also be worthwhile: a high throughput viability screen in human cell lines revealed that gene essentiality is context-specific, and is determined at the module or complex level rather than at the single gene or protein level (Bertomeu et al., 2018). Therefore, characterizing in vivo RBR-PPIs and multimeric complexes could be valuable. Besides IP-MS and Y2H, Proximity Labeling-MS offers an alternative approach for mapping dynamic interactions in space and time, and is able to detect low abundant, cell type-specific, and transient interactions in vivo (Lobingier et al., 2017; Mair et al., 2019; Zhou and Zou, 2021). In this sense, resolving of the highly dynamic composition of DNA repair foci is particularly relevant.

Finally, integrative approaches are necessary to unveil the big picture of RBR networks. For instance, integration of yeast gene networks and PPI networks uncovered connections not seen by analyzing each network separately, and defined a core network underlying cellular function (VanderSluis et al., 2018). By integrating in vivo phosphorylation maps, accurate protein structure prediction, interactomes, and downstream transcriptional effects on target genes, we should be able to decipher the molecular mechanisms underlying functions of coordinating hub proteins like RBR. For only if we are able to understand how nature deals with the optimization of vast regulatory integration and the avoidance of pleiotropic effects, can we hope to use such knowledge in medicine or agriculture. 


\section{References}

Abraham, R.T. (2001). Cell cycle checkpoint signaling through the ATM and ATR kinases. Genes Dev. 15, 2177-2196.

Abroudi, A., Samarasinghe, S., and Kulasiri, D. (2017). A comprehensive complex systems approach to the study and analysis of mammalian cell cycle control system in the presence of DNA damage stress. J. Theor. Biol. 429, 204-228.

Achard, P., Cheng, H., De Grauwe, L., Decat, J., Schoutteten, H., Moritz, T., Van Der Straeten, D., Peng, J., and Harberd, N.P. (2006). Integration of plant responses to environmentally activated phytohormonal signals. Science (80-. ). 311, 91-94.

Achard, P., Renou, J., Berthome, R., Harberd, N.P., and Genschik, P. (2008). Report Plant DELLAs Restrain Growth and Promote Survival of Adversity by Reducing the Levels of Reactive Oxygen Species. Curr. Biol. 18, 656-660.

Alberghina, L., Rossi, R.L., Querin, L., Wanke, V., and Vanoni, M. (2004). A cell sizer network involving $\mathrm{Cln} 3$ and Far 1 controls entrance into $S$ phase in the mitotic cycle of budding yeast. J. Cell Biol. 167, 433-443.

Anastasia, S.D., Nguyen, D.L., Thai, V., Meloy, M., Macdonough, T., and Kellogg, D.R. (2012). A link between mitotic entry and membrane growth suggests a novel model for cell size control. J. Cell Biol. 197, 89-104.

Berckmans, B., Vassileva, V., Schmid, S.P.C., Maes, S., Parizot, B., Naramoto, S., Magyar, Z., Lessa Alvim Kamei, C., Koncz, C., Bögre, L., et al. (2011). Auxin-Dependent cell cycle reactivation through transcriptional regulation of arabidopsis E2Fa by lateral organ boundary proteins. Plant Cell 23, 3671-3683.

Berger, F., and Twell, D. (2011). Germline Specification and Function in Plants. Annu. Rev. Plant Biol. $62,461-484$.

Bertomeu, T., Coulombe-Huntington, J., Chatr-aryamontri, A., Bourdages, K.G., Coyaud, E., Raught, B., Xia, Y., and Tyers, M. (2018). A High-Resolution Genome-Wide CRISPR/Cas9 Viability Screen Reveals Structural Features and Contextual Diversity of the Human Cell-Essential Proteome. Mol. Cell. Biol. 38, 1-24.

Bhosale, R., Boudolf, V., Cuevas, F., Lu, R., Eekhout, T., Hu, Z., Van Isterdael, G., Lambert, G.M., Xu, F., Nowack, M.K., et al. (2018). A spatiotemporal dna endoploidy map of the arabidopsis root reveals roles for the endocycle in root development and stress adaptation. Plant Cell 30, 23302351.

Biedermann, S., Harashima, H., Chen, P., Heese, M., Bouyer, D., Sofroni, K., and Schnittger, A. (2017). The retinoblastoma homolog RBR1 mediates localization of the repair protein RAD51 to DNA lesions in Arabidopsis. EMBO J. 36, 1279-1297.

Borghi, L., Gutzat, R., Fütterer, J., Laizet, Y., Hennig, L., and Gruissem, W. (2010). Arabidopsis RETINOBLASTOMA-RELATED Is Required for Stem Cell Maintenance, Cell Differentiation, and Lateral Organ Production. Plant Cell 22, 1792-1811.

Bourbousse, C., Vegesna, N., and Law, J.A. (2018). SOG1 activator and MYB3R repressors regulate 
a complex DNA damage network in Arabidopsis. Proc. Natl. Acad. Sci. U. S. A. 115, E12453E12462.

Bourgo, R.J., Thangavel, C., Ertel, A., Bergseid, J., Kathleen McClendon, A., Wilkens, L., Witkiewicz, A.K., Wang, J.Y.J., and Knudsen, E.S. (2011). RB Restricts DNA Damage-Initiated Tumorigenesis through an LXCXE-Dependent Mechanism of Transcriptional Control. Mol. Cell 43, 663-672.

Bouyer, D., Heese, M., Chen, P., Harashima, H., Roudier, F., Gruttner, C., and Schnittger, A. (2018). Genome-wide identification of RETINOBLASTOMA RELATED 1 binding sites in Arabidopsis reveals novel DNA damage regulators. PLoS Genet. 14, 1-35.

Camborde, L., Raynaud, C., Dumas, B., and Gaulin, E. (2019). DNA-Damaging Effectors: New Players in the Effector Arena. Trends Plant Sci. 24, 1094-1101.

Cao, L., Wang, S., Venglat, P., Zhao, L., Cheng, Y., Ye, S., Qin, Y., Datla, R., Zhou, Y., and Wang, H. (2018). Arabidopsis ICK/KRP cyclin-dependent kinase inhibitors function to ensure the formation of one megaspore mother cell and one functional megaspore per ovule. PLoS Genet. 14, 1-30.

Capra, F. (2005). Complexity and Life. Theory, Cult. Soc. 22, 33-44.

Chapin III, F.S. (1991). Integrated Responses of Plants to Stress. Bioscience 41, 29-36.

Cheng, Y., Cao, L., Wang, S., Li, Y., Shi, X., Liu, H., Li, L., Zhang, Z., Fowke, L.C., Wang, H., et al. (2015). Downregulation of multiple CDK inhibitor ICK/KRP genes upregulates the E2F pathway and increases cell proliferation, and organ and seed sizes in Arabidopsis. Plant J. 75, 642-655.

Choudhury, F.K., Rivero, R.M., Blumwald, E., and Mittler, R. (2017). Reactive oxygen species, abiotic stress and stress combination. Plant J. 90, 856-867.

Coschi, C.H., and Dick, F.A. (2012). Chromosome instability and deregulated proliferation: An unavoidable duo. Cell. Mol. Life Sci. 69, 2009-2024.

Costanzo, M., Nishikawa, J.L., Tang, X., Millman, J.S., Schub, O., Breitkreuz, K., Dewar, D., Rupes, I., Andrews, B., and Tyers, M. (2004). CDK activity antagonizes Whi5, an inhibitor of G1/S transcription in yeast. Cell 117, 899-913.

Cross, F.R., Buchler, N.E., and Skotheim, J.M. (2011). Evolution of networks and sequences in eukaryotic cell cycle control. Philos. Trans. R. Soc. B Biol. Sci. 366, 3532-3544.

Dante, R.A., Larkins, B.A., and Sabelli, P.A. (2014). Cell cycle control and seed development. Front. Plant Sci. 5, 1-14.

Das, K., and Roychoudhury, A. (2014). Reactive oxygen species (ROS) and response of antioxidants as ROS-scavengers during environmental stress in plants. Front. Environ. Sci. 2, 1-13.

Depuydt, S., and Hardtke, C.S. (2011). Hormone signalling crosstalk in plant growth regulation. Curr. Biol. 21, R365-R373.

Desvoyes, B., De Mendoza, A., Ruiz-Trillo, I., and Gutierrez, C. (2014). Novel roles of plant RETINOBLASTOMA-RELATED (RBR) protein in cell proliferation and asymmetric cell division. J. Exp. Bot. 65, 2657-2666.

Dewitte, W., Riou-khamlichi, C., Scofield, S., Healy, J.M.S., Jacqmard, A., Kilby, N.J., and Murray, J.A.H. (2003). Altered Cell Cycle Distribution, Hyperplasia, and Inhibited Differentiation in Arabidopsis Caused by the D-Type Cyclin CYCD3. Plant Cell 15, 79-92.

Dletrich, D., Pang, L., Kobayashi, A., Fozard, J.A., Boudolf, V., Bhosale, R., Antoni, R., Nguyen, T., 
Hiratsuka, S., Fujii, N., et al. (2017). Root hydrotropism is controlled via a cortex-specific growth mechanism. Nat. Plants 3, 1-8.

Engeland, K. (2018). Cell cycle arrest through indirect transcriptional repression by p53: I have a DREAM. Cell Death Differ. 25, 114-132.

Fang, S.C., De Los Reyes, C., and Umen, J.G. (2006). Cell size checkpoint control by the retinoblastoma tumor suppressor pathway. PLoS Genet. 2, 1565-1579.

Fantes, P.A. (1977). Control of cell size and cycle time in Schizosaccharomyces pombe. J. Cell Sci. Vol.24, 51-67.

Fischer, M., and Müller, G.A. (2017). Cell cycle transcription control: DREAM/MuvB and RB-E2F complexes. Crit. Rev. Biochem. Mol. Biol. 52, 638-662.

Gentric, N., Masoud, K., Journot, R.P., Cognat, V., Chabouté, M.E., Noir, S., and Genschik, P. (2020). The f-box-like protein FBL17 is a regulator of DNA-damage response and colocalizes with RETINOBLASTOMA RELATED1 at DNA lesion sites. Plant Physiol. 183, 1295-1305.

Gómez, M.S., Falcone Ferreyra, M.L., Sheridan, M.L., and Casati, P. (2019). Arabidopsis E2Fc is required for the DNA damage response under UV-B radiation epistatically over the microRNA396 and independently of E2Fe. Plant J. 97, 749-764.

Hanschen, E.R., Marriage, T.N., Ferris, P.J., Hamaji, T., Toyoda, A., Fujiyama, A., Neme, R., Noguchi, H., Minakuchi, Y., Suzuki, M., et al. (2016). The Gonium pectorale genome demonstrates co-option of cell cycle regulation during the evolution of multicellularity. Nat. Commun. 7, 11370.

Hansen, T.F. (2003). Is modularity necessary for evolvability? Remarks on the relationship between pleiotropy and evolvability. BioSystems 69, 83-94.

Harashima, H., and Sugimoto, K. (2016). Integration of developmental and environmental signals into cell proliferation and differentiation through RETINOBLASTOMA-RELATED 1. Curr. Opin. Plant Biol. 29, 95-103.

Harashima, H., Dissmeyer, N., and Schnittger, A. (2013). Cell cycle control across the eukaryotic kingdom. Trends Cell Biol. 23, 345-356.

Horiguchi, G., and Tsukaya, H. (2011). Organ size regulation in plants: Insights from compensation. Front. Plant Sci. 2, 1-6.

Horiguchi, G., Kim, G., and Tsukaya, H. (2005). The transcription factor AtGRF5 and the transcription coactivator AN3 regulate cell proliferation in leaf primordia of Arabidopsis thaliana. Plant J. 43, 68-78.

Horvath, B.M., Kourova, H., Nagy, S., Nemeth, E., Magyar, Z., Papdi, C., Ahmad, Z., Sanchez-perez, G.F., Perilli, S., Blilou, I., et al. (2017). Arabidopsis RETINOBLASTOMA RELATED directly regulates DNA damage responses through functions beyond cell cycle control. EMBO J. 36, 1261-1278.

Ishiguro, S., Watanabe, Y., Ito, N., Nonaka, H., Takeda, N., Sakai, T., Kanaya, H., and Okada, K. (2002). SHEPHERD is the Arabidopsis GRP94 responsible for the formation of functional CLAVATA proteins. EMBO J. 21, 898-908.

Jones, A.R., Forero-Vargas, M., Withers, S.P., Smith, R.S., Traas, J., Dewitte, W., and Murray, J.A.H. (2017). Cell-size dependent progression of the cell cycle creates homeostasis and flexibility of plant cell size. Nat. Commun. 8, 1-13. 
Kasili, R., Walker, J.D., Simmons, L.A., Zhou, J., De Veylder, L., and Larkin, J.C. (2010). SIAMESE cooperates with the CDH1-like protein CCS52A1 to establish endoreplication in Arabidopsis thaliana trichomes. Genetics 185, 257-268.

Kim, J.H., and Kende, H. (2004). A transcriptional coactivator, AtGIF1, is involved in regulating leaf growth and morphology in Arabidopsis. Proc. Natl. Acad. Sci. U. S. A. 101, 13374-13379.

Kobayashi, K., Suzuki, T., Iwata, E., Nakamichi, N., Suzuki, T., Chen, P., Ohtani, M., Ishida, T., Hosoya, H., Müller, S., et al. (2015). Transcriptional repression by MYB 3R proteins regulates plant organ growth. EMBO J. 34, 1992-2007.

Kong, X., Tian, H., Yu, Q., Zhang, F., Wang, R., Gao, S., Xu, W., Liu, J., Shani, E., Fu, C., et al. (2018). PHB3 Maintains Root Stem Cell Niche Identity through ROS-Responsive AP2/ERF Transcription Factors in Arabidopsis. Cell Rep. 22, 1350-1363.

Krylov, D.M., Nasmyth, K., and Koonin, E. V (2003). Evolution of eukaryotic cell cycle regulation: Stepwise addition of regulatory kinases and late advent of the CDKs. Curr. Biol. 13, 173-177.

Laux, T., Mayer, K.F.X., Berger, J., and Jürgens, G. (1996). The WUSCHEL gene is required for shoot and floral meristem integrity in Arabidopsis. Development 122, 87-96.

Lim, S., and Kaldis, P. (2013). Cdks, cyclins and CKIs: Roles beyond cell cycle regulation. Dev. 140, 30793093.

Lobingier, B.T., Hüttenhain, R., Eichel, K., Miller, K.B., Ting, A.Y., von Zastrow, M., and Krogan, N.J. (2017). An Approach to Spatiotemporally Resolve Protein Interaction Networks in Living Cells. Cell 169, 350-360.e12.

Magyar, Z., Horváth, B., Khan, S., Mohammed, B., Henriques, R., De Veylder, L., Bakó, L., Scheres, B., and Bögre, L. (2012). Arabidopsis E2FA stimulates proliferation and endocycle separately through RBR-bound and RBR-free complexes. EMBO J. 31, 1480-1493.

Mair, A., Xu, S.L., Branon, T.C., Ting, A.Y., and Bergmann, D.C. (2019). Proximity labeling of protein complexes and cell type specific organellar proteomes in Arabidopsis enabled by TurbolD. Elife 8, 1-45.

Manickavinayaham, S., Dennehey, B.K., and Johnson, D.G. (2021). Direct Regulation of DNA repair by E2F and RB in mammals and plants: Core function or convergent evolution? Cancers (Basel). 13, 1-14.

Matsuda, M., Iwata, Y., Koizumi, N., and Mishiba, K.-I. (2018). DNA double-strand breaks promote endoreduplication in radish cotyledon. Plant Cell Rep. 37, 913-921.

Matsumura, K., Yagi, T., and Yasuda, K. (2003). Role of timer and sizer in regulation of Chlamydomonas cell cycle. Biochem. Biophys. Res. Commun. 306, 1042-1049.

McQueen, E., and Rebeiz, M. (2020). On the specificity of gene regulatory networks: How does network co-option affect subsequent evolution? In Current Topics in Developmental Biology, (Elsevier Inc.), pp. 375-405.

Menges, M., De Jager, S.M., Gruissem, W., and Murray, J.A.H. (2005). Global analysis of the core cell cycle regulators of Arabidopsis identifies novel genes, reveals multiple and highly specific profiles of expression and provides a coherent model for plant cell cycle control. Plant J. 41, 546-566.

Moreno, S., Canales, J., Hong, L., Robinson, D., Roeder, A.H.K., and Gutiérrez, R.A. (2020). Nitrate 
Defines Shoot Size through Compensatory Roles for Endoreplication and Cell Division in Arabidopsis thaliana. Curr. Biol. 30, 1988-2000.e3.

Morris, E.J., and Dyson, N.J. (2001). Retinoblastoma protein partners. Adv. Cancer Res. 82, 1-54.

Moulager, M., Corellou, F., Verge, V., Escande, M., and Bouget, F.-Y. (2010). Integration of Light Signals by the Retinoblastoma Pathway in the Control of S Phase Entry in the Picophytoplanktonic Cell Ostreococcus. PLoS Genet. 6, 1-13.

Ning, Y., Liu, N., Lan, K., Su, Y., Li, L., Chen, S., and He, X. (2020). DREAM complex suppresses DNA methylation maintenance genes and precludes DNA hypermethylation. Nat. Plants 6, 942-956.

Noir, S., Marrocco, K., Masoud, K., Thomann, A., Gusti, A., Bitrian, M., Schnittger, A., and Genschik, P. (2015). The control of arabidopsis thaliana growth by cell proliferation and endoreplication requires the F-box protein FBL17. Plant Cell 27, 1461-1476.

Nowack, M.K., Harashima, H., Dissmeyer, N., Zhao, X., Bouyer, D., Weimer, A.K., De Winter, F., Yang, F., and Schnittger, A. (2012). Genetic Framework of Cyclin-Dependent Kinase Function in Arabidopsis. Dev. Cell 22, 1030-1040.

Ogita, N., Okushima, Y., Tokizawa, M., Yamamoto, Y.Y., Tanaka, M., Seki, M., Makita, Y., Matsui, M., Okamoto-Yoshiyama, K., Sakamoto, T., et al. (2018). Identifying the target genes of SUPPRESSOR OF GAMMA RESPONSE 1, a master transcription factor controlling DNA damage response in Arabidopsis. Plant J. 94, 439-453.

Oszi, E., Papdi, C., Mohamed, B., Petkó-szandtner, A., Leviczky, T., Molnár, E., Galvan-ampudia, C., Khan, S., Lopez-Juez, E., Horváth, B., et al. (2020). E2FB Interacts with RETINOBLASTOMA RELATED and Regulates Cell Proliferation during Leaf Development. Plant Physiol. 182, 518-533.

Ötvös, K., Miskolczi, P., Marhavý, P., Cruz-Ramírez, A., Benková, E., Robert, S., and Bakó, L. (2019). PICKLE recruits RETINOBLASTOMA RELATED 1 to Control Lateral Root Formation in Arabidopsis. Int. J. Mol. Sci. 22, 3862.

Patil, M., Pabla, N., and Dong, Z. (2013). Checkpoint kinase 1 in DNA damage response and cell cycle regulation. Cell. Mol. Life Sci. 70, 4009-4021.

Peres, A., Churchman, M.L., Hariharan, S., Himanen, K., Verkest, A., Vandepoele, K., Magyar, Z., Hatzfeld, Y., Van Der Schueren, E., Beemster, G.T.S., et al. (2007). Novel plant-specific cyclin-dependent kinase inhibitors induced by biotic and abiotic stresses. J. Biol. Chem. 282, 25588-25596.

Pozo, J.C. del, Diaz-trivino, S., Cisneros, N., and Gutierrez, C. (2006). The Balance between Cell Division and Endoreplication Depends on E2FC-DPB, Transcription Factors Regulated by the UbiquitinSCF SKP2A Pathway in Arabidopsis. Plant Cell 18, 2224-2235.

Qu, Z., MacLellan, W.R., and Weiss, J.N. (2003). Dynamics of the Cell Cycle: Checkpoints, Sizers, and Timers. Biophys. J. 85, 3600-3611.

Ben Rejeb, I., Pastor, V., and Mauch-Mani, B. (2014). Plant responses to simultaneous biotic and abiotic stress: Molecular mechanisms. Plants 3, 458-475.

Roeder, A.H.K., Chickarmane, V., Cunha, A., Obara, B., Manjunath, B.S., and Meyerowitz, E.M. (2010). Variability in the control of cell division underlies sepal epidermal patterning in Arabidopsis thaliana. PLoS Biol. 8, e1000367.

Sanz, L., Dewitte, W., Forzani, C., Patell, F., Nieuwland, J., Wen, B., Quelhas, P., de Jager, S., Titmus, C., 
Campilho, A., et al. (2011). The Arabidopsis D-Type Cyclin CYCD2;1 and the Inhibitor ICK2/KRP2 Modulate Auxin-Induced Lateral Root Formation. Plant Cell 23, 641-660.

Scheres, B., and Van Der Putten, W.H. (2017). The plant perceptron connects environment to development. Nature 543, 337-345.

Schmoller, K.M., Turner, J.J., Kõivomägi, M., and Skotheim, J.M. (2015). Dilution of the cell cycle inhibitor Whi5 controls budding-yeast cell size. Nature 526, 268-272.

Schnittger, A., and De Veylder, L. (2018). The Dual Face of Cyclin B1. Trends Plant Sci. 23, 475-478.

Schoof, H., Lenhard, M., Haecker, A., Mayer, K.F.X., Jürgens, G., and Laux, T. (2000). The stem cell population of Arabidopsis shoot meristems is maintained by a regulatory loop between the CLAVATA and WUSCHEL genes. Cell 100, 635-644.

Serrano-Mislata, A., Bencivenga, S., Bush, M., Schiessl, K., Boden, S., and Sablowski, R. (2017). DELLA genes restrict inflorescence meristem function independently of plant height. Nat. Plants 3 , 749-754.

Sveiczer, A., Novak, B., and Mitchison, J.M. (1996). The size control of fission yeast revisited. J. Cell Sci. 109, 2947-2957.

Takatsuka, H., and Umeda, M. (2014). Hormonal control of cell division and elongation along differentiation trajectories in roots. J. Exp. Bot. 65, 2633-2643.

Takemura, M. (2005). Evolutionary history of the retinoblastoma gene from archaea to eukarya. BioSystems 82, 266-272.

True, J.R., and Carroll, S.B. (2002). Gene co-option in physiological and morphological evolution. Annu. Rev. Cell Dev. Biol. 18, 53-80.

Truskina, J., and Vernoux, T. (2018). The growth of a stable stationary structure: coordinating cell behavior and patterning at the shoot apical meristem. Curr. Opin. Plant Biol. 41, 83-88.

Tsukagoshi, H., Busch, W., and Benfey, P.N. (2010). Transcriptional Regulation of ROS Controls Transition from Proliferation to Differentiation in the Root. Cell 143, 606-616.

Vandepoele, K., Raes, J., De Veylder, L., Rouzé, P., Rombauts, S., and Inzé, D. (2002). Genome-wide analysis of core cell cycle genes in Arabidopsis. Plant Cell 14, 903-916.

VanderSluis, B., Costanzo, M., Billmann, M., Ward, H.N., Myers, C.L., Andrews, B.J., and Boone, C. (2018). Integrating genetic and protein-protein interaction networks maps a functional wiring diagram of a cell. Curr. Opin. Microbiol. 45, 170-179.

Vanstraelen, M., and Benkov, E. (2012). Hormonal interactions in the regulation of plant development. Annu. Rev. Cell Dev. Biol. 28, 463-487.

Vélez-Cruz, R., and Johnson, D.G. (2017). The retinoblastoma (RB) tumor suppressor: Pushing back against genome instability on multiple fronts. Int. J. Mol. Sci. 18, 1776.

Vercruyssen, L., Tognetti, V.B., Gonzalez, N., Van Dingenen, J., De Milde, L., Bielach, A., De Rycke, R., Van Breusegem, F., and Inzé, D. (2015). Growth regulating factor5 stimulates arabidopsis chloroplast division, photosynthesis, and leaf longevity. Plant Physiol. 167, 817-832.

Verkest, A., Mane, C.-L. de O., Vercruysse, S., Maes, S., Schueren, E. Van Der, Beeckman, T., Genschik, P., Kuiper, M., Inze, D., and De Veylder, L. (2005). The Cyclin-Dependent Kinase Inhibitor KRP2 Controls the Onset of the Endoreduplication Cycle during Arabidopsis Leaf Development 
through Inhibition of Mitotic CDKA ; 1 Kinase Complexes. Plant Cell 17, 1723-1736.

Wahl, G.M., and Carr, A.M. (2001). The evolution of diverse biological responses to DNA damage: Insights from yeast and p53. Nat. Cell Biol. 3.

Wang, S., Gu, Y., Zebell, S.G., Anderson, L.K., Wang, W., Mohan, R., and Dong, X. (2014). A noncanonical role for the CKI-RB-E2F cell-cycle signaling pathway in plant effector-triggered immunity. Cell Host Microbe 16, 787-794.

Weimer, A.K., Nowack, M.K., Bouyer, D., Zhao, X., Harashima, H., Naseer, S., De Winter, F., Dissmeyer, N., Geldner, N., and Schnittger, A. (2012). RETINOBLASTOMA RELATED1 regulates asymmetric cell divisions in Arabidopsis. Plant Cell 24, 4083-4095.

Weimer, A.K., Biedermann, S., Harashima, H., Roodbarkelari, F., Takahashi, N., Foreman, J., Guan, Y., Pochon, G., Heese, M., Van Damme, D., et al. (2016). The plant-specific CDKB 1- CYCB 1 complex mediates homologous recombination repair in Arabidopsis. EMBO J. 35, 2068-2086.

Whitewoods, C.D., and Coen, E. (2017). Growth and Development of Three-Dimensional Plant Form. Curr. Biol. 27, R910-R918.

Wildwater, M., Campilho, A., Perez-Perez, J.M., Heidstra, R., Blilou, I., Korthout, H., Chatterjee, J., Mariconti, L., Gruissem, W., and Scheres, B. (2005). The RETINOBLASTOMA-RELATED gene regulates stem cell maintenance in Arabidopsis roots. Cell 123, 1337-1349.

Wilke, C.O., and Adami, C. (2003). Evolution of mutational robustness. Mutat. Res. - Fundam. Mol. Mech. Mutagen. 522, 3-11.

Willems, A., Heyman, J., Eekhout, T., Achon, I., Pedroza-Garcia, J.A., Zhu, T., Li, L., Vercauteren, I., Van den Daele, H., van de Cotte, B., et al. (2020). The cyclin CYCA3;4 is a postprophase target of the APC/CCCS52A2 E3-ligase controlling formative cell divisions in arabidopsis. Plant Cell 32, 2979-2996.

Willis, L., Refahi, Y., Wightman, R., Landrein, B., Teles, J., Huang, K.C., Meyerowitz, E.M., and Jönsson, H. (2016). Cell size and growth regulation in the Arabidopsis thaliana apical stem cell niche. Proc. Natl. Acad. Sci. U. S. A. 113, E8238-E8246.

Xie, S., and Skotheim, J.M. (2020). A G1 Sizer Coordinates Growth and Division in the Mouse Epidermis. Curr. Biol. 30, 916-924.e2.

Yao, X., Yang, H., Zhu, Y., Xue, J., Wang, T., Song, T., Yang, Z., and Wang, S. (2018). The canonical E2Fs are required for germline development in Arabidopsis. Front. Plant Sci. 9, 1-10.

Yi, D., Kamei, C.L.A., Cools, T., Vanderauwera, S., Takahashi, N., Okushima, Y., Eekhout, T., Yoshiyama, K.O., Larkin, J., Van den Daele, H., et al. (2014). The Arabidopsis SIAMESE-RELATED cyclindependent Kinase Inhibitors SMR5 and SMR7 Regulate the DNA damage checkpoint in response to reactive oxygen species. Plant Cell 26, 296-309.

Zachleder, V., Ivanov, I., Vítová, M., and Bisova, K. (2019). Effects of cyclin-dependent kinase activity on the coordination of growth and the cell cycle in green algae at different temperatures. J. Exp. Bot. 70, 845-858.

Zeng, J., Dong, Z., Wu, H., Tian, Z., and Zhao, Z. (2017). Redox regulation of plant stem cell fate. EMBO J. 36, 2844-2855.

Zhao, X., Harashima, H., Dissmeyer, N., Pusch, S., Weimer, A.K., Bramsiepe, J., Bouyer, D., Rademacher, 
S., Nowack, M.K., Novak, B., et al. (2012). A General G1/S-Phase Cell-Cycle Control Module in the Flowering Plant Arabidopsis thaliana. PLoS Genet. 8, e1002847.

Zhao, X., Bramsiepe, J., Van Durme, M., Komaki, S., Prusicki, M.A., Maruyama, D., Forner, J., Medzihradszky, A., Wijnker, E., Harashima, H., et al. (2017). RETINOBLASTOMA RELATED1 mediates germline entry in Arabidopsis. Science (80-. ). 356.

Zhou, Y., and Zou, P. (2021). The evolving capabilities of enzyme-mediated proximity labeling. Curr. Opin. Chem. Biol. 60, 30-38. 


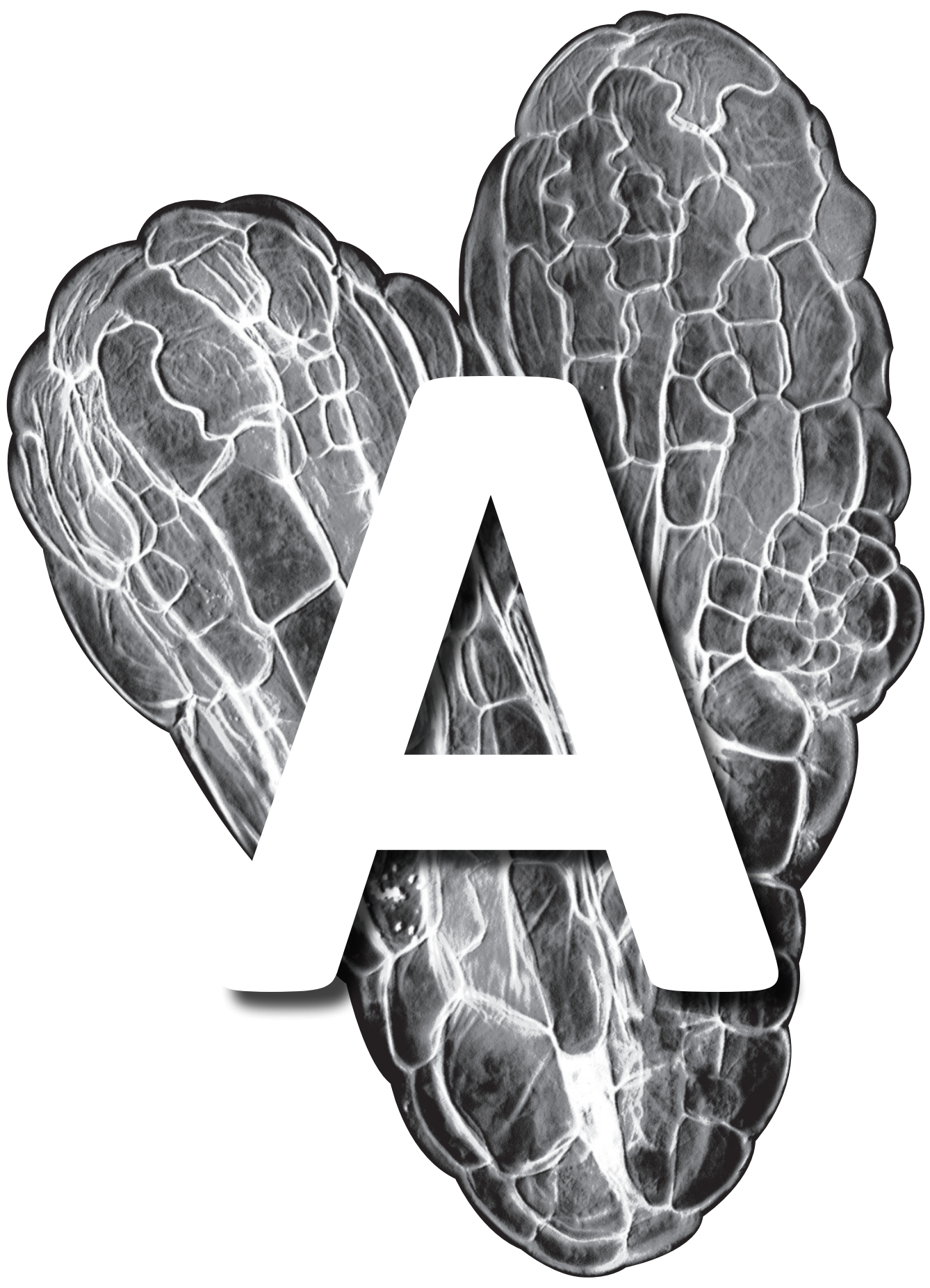




\title{
Appendix
}

\section{Tuning division and differentiation in stomata: How to silence a mute}

\author{
Jorge Zamora-Zaragoza ${ }^{1}$ and Ben Scheres ${ }^{1,2,{ }^{*}}$ \\ ${ }^{1}$ Wageningen University \& Research, Wageningen, The Netherlands \\ ${ }^{2}$ Rijk Zwaan Department of Biotechnology, Fijnaart,The Netherlands \\ *Correspondence: ben.scheres@wur.nl
}

Published in Developmental Cell 45 (2018)3. - ISSN 1534-5807 - p. 282 - 283. 
Appendix 


\section{Precise coordination of cell differentiation and division within a tissue context is critical for plant development. In this issue of Developmental Cell, Han et al. (2018) report a transcriptional switch that ensures proper patterning, the final cell division and terminal differentiation of stomata.}

Plant cells are kept in place by stiff cell walls and maintain their relative position within a tissue throughout their life. Thus, cell patterning in plants requires a precise spatiotemporal balance of cell division and differentiation where the number of cell cycles must be coordinated with cell differentiation. During female gametogenesis, the functional megaspore divides three times before cellularization and cell specialization. Male gamete development requires one asymmetric cell division (ACD) followed by a symmetric cell division (SCD) of only one of the products while the other exits the cell cycle (Berger \& Twell, 2011). Within the Arabidopsis root stem cell niche (SCN), a cortex and endodermis initial daughter cell (CEID) undergoes only a single periclinal ACD to form two different tissue layers (Cruz-Ramírez et al., 2012). Stomata, which are plant epidermal valves regulating water loss and gas exchange, are formed by a pair of kidney-shaped Guard Cells (GC). Stomata are patterned over the leaf surface by an even more intriguing cascade of divisions controlled by the sequential activity of three bHLH transcription factors SPEECHLESS, MUTE, and_FAMA (Simmons \& Bergmann, 2016). In this issue of Developmental Cell, Han et al. (2018) show that MUTE directly links differentiation and cell division in this process via a transcriptional incoherent type 1 feed forward loop (I1-FFL).

SPCH activity in the epidermis arises in dispersed cells through a network that combines local self-activation of SPCH where at least one of its targets, the extracellular ligand EPIDERMAL PATTERNING FACTOR2 (EPF2), executes long-range inhibition much like a self-organizing Turing system (Horst et al., 2015) (Figure 1). SPCH initiates the stomatal lineage by triggering the first ACD to form a meristemoid, the stem-cell-like precursor of the Guard Mother Cell (GMC). After ACD, SPCH expression is restricted to the meristemoid, which either reiterates ACDs or stops dividing to become a GMC. The latter fate transition is coordinated with cell cycle control promoted by MUTE. A final fate transition then occurs when GMC symmetric division generates the two cells terminally differentiating into mature GCs.

By comparing transcriptomic atlases of induced MUTE and SPCH, Han et al. (2018) determined that MUTE partially takes over the genetic program initiated by SPCH including a subset of important stomatal regulators, which turn out to be direct SPCH and MUTE targets. Particularly interesting is that the secreted EPF2 is directly upregulated by SPCH but directly repressed by MUTE (Figure 1), thus acting as a brake on the aforementioned Turing type patterning mechanism. On the other hand, both bHLH proteins bind and upregulate EPF2 receptors ERECTA-LIKE1 and 2 and TOO MANY MOUTHS, thus maintaining the perception system for subsequent spatial signaling through the EPF2 homologue EPF1. This observation indicates that MUTE constitutes a transcriptional switch for the cell-cell 
communication system that ensures proper stomata spacing in a tissue context.

Han et al. (2018) also show that MUTE induces promoters of GMC symmetric division including CDKB1;1 and CYCA2s, typical G2/M cell cycle regulators (De Veylder, Beeckman, \& Inzé, 2007). It is also noteworthy that the canonical G1- and G1/S-regulating CYCD family member CYCD5; 1 is a MUTE target, providing a candidate to promote SCD commitment in a MUTE-dependent manner. Interestingly, specific expression and function of CYCD7;1 in the stomatal lineage cells have also been reported (Adrian et al., 2015), suggesting the presence of more than one SCD trigger. Nonetheless, CYCD7; 1 is not regulated by MUTE, implying that there is an independent pathway to promote GMC division (Han et al., 2018). This notion is further supported by recent evidence that CYCD7;1 expression, though reduced, is not abolished in a mute mutant background (Weimer et al., 2018).

FAMA and FOUR LIPS repress cell cycle genes and GMC division, and their expression is directly induced in a slightly delayed manner by MUTE. To explain the timing of differentiation and division induced by MUTE function, the authors provide a theoretical model in which a MUTE-initiated feed-forward loop gives rise to a single strong pulse of cell cycle genes sufficient to trigger and ensure a single SCD (Han et al., 2018; Figure 1). While details remain to be resolved between the initial stomatal lineage commitment and the execution of the final division to create the guard cell pair, this and previous work demonstrates remarkable progress in understanding the logic behind the circuitry of complex patterning and differentiation networks in plants.

The canonical module for $\mathrm{G} 1 / \mathrm{S}$ control requires active CYCD-CDK complexes to inactivate RETINOBLASTOMA RELATED (RBR) protein via hyper-phosphorylation to release and derepress E2F transcription factors, which promotes cell cycle progression (De Veylder et al., 2007). Loss of CDKB1 activity or disruption of the RBR-CYCD7;1 interaction is enough to abolish ectopic GC divisions caused by extra copies of CYCD7;1, suggesting that CYCD7;1 effects result from RBR phosphorylation (Weimer et al., 2018). It is reasonable to assume that CYCD5;1 could also promote SCD through RBR inhibition. However, neither CYCD5;1 nor CYCD7; 1 ectopic expression triggers as many GC divisions as RBR suppression (Matos et al., 2014), suggesting that they don't fully inactivate RBR. To further understand the specific role of CYCD5;1 and D7;1 in this context, it would be interesting to determine whether they phosphorylate different RBR phospho-sites.

Besides being a likely CYCD target to trigger SCD, RBR interacts with FAMA to ensure GC fate commitment (Figure 1), likely by altering chromatin structure of early stomatal lineage regulators (Matos et al., 2014). Do cell cycle programs and cell fate decisions converge on the same RBR complexes? Perhaps not, because both CYCDs and FAMA interaction with RBR depend on the same RBR-binding motif. Thus, MUTE-dependent CYCD5;1 and MUTE- 
independent CYCD7;1 activation may trigger SCD without interfering with later FAMARBR-mediated GC fate establishment. Consistently, CYCDs ectopic expression causes extra divisions without affecting cell fate whereas specific FAMA-RBR disruption leads to fate reversion (Han et al., 2018; Matos et al., 2014; Weimer et al., 2018).

It is worth nothing that the three examples where plants coordinate cell cycle and fate decisions mentioned above (female and male gametogenesis, SCN divisions, and stomatal lineage) require RBR to ensure proper division and patterning. Accordingly, RBR has been proposed as a central hub that integrates external and internal cues into development and cell cycle (Harashima \& Sugimoto, 2016). The findings of Han et al. (2018) may therefore be part of a bigger picture of intricate molecular mechanisms linking environmental responses to development and cell cycle.

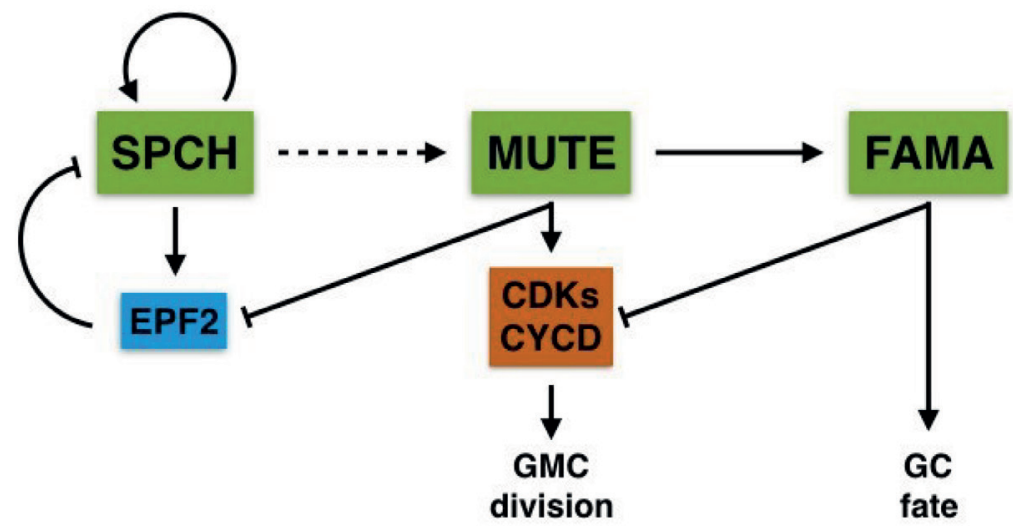

Figure 1: Three network motifs in stomatal development:

Local activation - long range inhibition in guard cell lineage selection; EPF2 promoter regulation to switch signalling pathway; and incoherent feedforward to create a single pulse of cell division. 


\section{References}

Adrian, J., Chang, J., Ballenger, C. E., Bargmann, B. O. R., Alassimone, J., Davies, K. A., ... Bergmann, D. C. (2015). Transcriptome dynamics of the stomatal lineage: Birth, amplification, and termination of a self-renewing population. Developmental Cell, 33(1), 107-119. https://doi.org/10.1016/j. devcel.2015.01.025

Berger, F., \& Twell, D. (2011). Germline Specification and Function in Plants. Annual Review of Plant Biology, 62(1), 461-484. https://doi.org/10.1146/annurev-arplant-042110-103824

Cruz-Ramírez, A., Díaz-Triviño, S., Blilou, I., Grieneisen, V. A., Sozzani, R., Zamioudis, C., ... Scheres, B. (2012). A bistable circuit involving SCARECROW-RETINOBLASTOMA integrates cues to inform asymmetric stem cell division. Cell, 150(5), 1002-1015. https://doi.org/10.1016/j. cell.2012.07.017

De Veylder, L., Beeckman, T., \& Inzé, D. (2007). The ins and outs of the plant cell cycle. Nature Reviews Molecular Cell Biology, 8(8), 655-665. https://doi.org/10.1038/nrm2227

Han, S., Qi, X., Sugihara, K., Dang, J. H., Endo, T. A., Kristen, L., ... Biology, C. (2018). Direct orchestration od Cell State switch and the Single Symmetric Division to create stomata. Developmental Cell.

Harashima, H., \& Sugimoto, K. (2016). Integration of developmental and environmental signals into cell proliferation and differentiation through RETINOBLASTOMA-RELATED 1. Current Opinion in Plant Biology, 29, 95-103. https://doi.org/10.1016/j.pbi.2015.12.003

Horst, R. J., Fujita, H., Lee, J. S., Rychel, A. L., Garrick, J. M., Kawaguchi, M., ... Torii, K. U. (2015). Molecular Framework of a Regulatory Circuit Initiating Two-Dimensional Spatial Patterning of Stomatal Lineage. PLoS Genetics, 11(7), 1-23. https://doi.org/10.1371/journal.pgen.1005374

Matos, J. L., Lau, O. S., Hachez, C., Cruz-Ramírez, A., Scheres, B., \& Bergmann, D. C. (2014). Irreversible fate commitment in the Arabidopsis stomatal lineage requires a FAMA and RETINOBLASTOMARELATED module. eLife, 3(October2014), 1-15. https://doi.org/10.7554/eLife.03271

Simmons, A. R., \& Bergmann, D. C. (2016). Transcriptional control of cell fate in the stomatal lineage. Current Opinion in Plant Biology, 29, 1-8. https://doi.org/10.1016/j.pbi.2015.09.008

Weimer, A. K., Matos, J. L., Sharma, N., Patell, F., Murray, J. A. H., Dewitte, W., \& Bergmann, D. C. (2018). Lineage- and stage-specific expressed $C Y C D 7 ; 1$ coordinates the single symmetric division that creates stomatal guard cells. Development, 145(6), dev160671. https://doi.org/10.1242/ dev.160671 


\section{Summary}

The development of multicellular organisms relies on an accurate coordination of cell division, differentiation and programed cell death. De-regulation of these processes could lead to aberrant development and malformations. For example, uncontrolled cell division and dedifferentiation results in tumor formation and cancer development. The RETINOBLASTOMA susceptibility gene (RB) was the first tumor suppressor gene characterized as the causal mutation for eye cancer in children. The clinical importance of RB attracted particular attention to its role as a cell cycle regulator, creating a research bias that masked its properties as a coordinator of distinct cell processes for decades. The study of RETINOBLASTOMA-RELATED (RBR) proteins in other organisms and cellular processes has expanded the picture of the RBR functions as an integrator of environmental and developmental signals in cell division and differentiation. This thesis is framed within an emerging paradigm, and contributes to our understanding of how a single, conserved protein regulates multiple processes that often occur simultaneously, while sometimes being exclusive.

In Chapter 1 we introduce the conserved function of RBR in cell cycle as an example of how RBR activity is regarded as the ability to interact with other proteins such as transcription factors (TF) and chromatin remodelers. RBR activity is regulated by CYCLIN-DEPENDENT KINASE-mediated phosphorylation on multiple sites, which in turn promotes structural changes that interfere with RBR-protein interactions. We also present the current understanding of RBR functions in plant development and the recent description of its role in the plant DNA damage response (DDR), and focusing on the Arabidopsis root meristem, where cell division and differentiation processes are partly coordinated by RBR.

In Chapter 2 we addressed the functional relevance of the 16 putative phosphorylation sites in the Arabidopsis RBR protein. The text book mechanism of RBR regulation by phosphorylation assumes that only an un- or hypo-phosphorylated RBR is active. By analyzing the complementation capacity of a systematic collection of transgenic RBR phosphovariants, both phospho-defective and phospho-mimetic, we show that the pleiotropic effects of RBR can be partially disentangled by its phosphorylation state, supporting the notion of a 'phosphorylation code' that governs RBR activity. Moreover, phosphorylationregulated functions of RBR partially depend on its ability to interact with the LXCXE motif, as revealed by the point mutation N849F (RBR $\left.{ }^{\mathrm{NF}}\right)$.

As an attempt to understand the molecular basis of the observed phenotypic effects in the previous chapter, in Chapter $\mathbf{3}$ we set out to discover nuclear proteins that interact directly with RBR. In a series of Yeast two-hybrid screenings, we used the most substituted phospho-variants, the $\mathrm{RBR}^{\mathrm{NF}}$ allele, and the wild type RBR as baits to probe an arrayed library encoding nearly 2000 Arabidopsis nuclear proteins. Our results revealed that the 
binding properties of RBR are not affected by phosphorylation in some cases. Interestingly, the proteins that bind RBR regardless its phosphorylation state are related to stressresponsive transcriptional programs. Actually, the majority of the interactors participate in stress responses. On the other hand, few interactors are canonical cell cycle regulators, like E2FC and the DREAM complex members, TCX 6 and 7. For these, we demonstrated that an LXCXE motif is responsible for the interaction with RBR, providing an insight on the divergent molecular determinants of the DREAM complex assembly in plants.

From the list of interactors obtained in Chapter 3, we paid special attention to NAC044 protein because it is the closest homolog and direct target of the SUPPRESSOR OF GAMMA RESPONSE 1, a plant specific TF that controls the DDR. NACO44 binds RBR in a LXCXEdependent manner but independently of RBR phosphorylation, challenging the prevalent paradigm that RBR-LXCXE interactions are regulated by phosphorylation. Since the role of NACO44 is to arrest the cell cycle upon DNA damage and other stresses, in Chapter 4 we set out to elucidate the relevance of its interaction with RBR. RBR has a chromatin-structural role and a transcriptional role in the DDR, and we determined that both are separated by the ability to bind LXCXE-containing proteins. On the one hand, the RBR ${ }^{\mathrm{NF}}$ mutation abolishes the recruitment of RBR to nuclear foci right after DNA injury, suggesting that a yet unknown LXCXE-containing protein recruits RBR to repair foci. On the other hand, NAC044 expression is induced by DNA damage but slower than RBR recruitment to foci. Therefore, after RBR has been cleared from repairing foci it binds NAC044. We determined that the RBR-NACO44 interaction contributes to the activation of cell death. Thus, we believe that the structural and transcriptional roles of RBR in the DDR are linked through an integrative feature that informs the transcriptional machinery, that decides between cell death and cell division resumption, about the success of the DNA repair process.

Finally, in Chapter $\mathbf{5}$ we take an evolutionary perspective to contextualize the possible implications of a conserved RBR-centric network in coordinating eukaryotic cellular processes. For instance, we discuss how RBR activity on E2F TFs and its regulation by CYCCDKs and CDK-inhibitors couples cell size to cell division both in lower and higher eukaryotes. But in higher eukaryotes, the activity of the RBR network is also important for the overall organ size and shape emergence. Moreover, as the development of plants is particularly sensitive to the environmental conditions, we emphasize the integration of environmental inputs by the RBR network to contribute to a coordinated response. To close the general discussion, we also provide experimental perspectives and open questions to be addressed in the coming future of the RBR research field. 


\section{Samenvatting}

De ontwikkeling van meercellige organismen is afhankelijk van een nauwkeurige coördinatie van celdeling, differentiatie en geprogrammeerde celdood. Deregulering van deze processen kan leiden tot afwijkende ontwikkeling en misvormingen. Ongecontroleerde celdeling en dedifferentiatie resulteert bijvoorbeeld in tumorvorming en kankerontwikkeling. Het RETINOBLASTOMA (RB) gen was het eerste tumorsuppressorgen dat werd gekarakteriseerd als de causale mutatie van oogkanker bij kinderen. Het klinische belangrijkheid van RB trok met name aandacht voor zijn rol als regulator van de celcyclus, waardoor een onderzoeksstigma ontstond dat zijn eigenschappen als coördinator van verschillende celprocessen decennialang heeft gemaskeerd. Studies naar RETINOBLASTOMA-RELATED (RBR) eiwitten in andere organismen en cellulaire processen heeft een breder beeld gegeven waarbij RBR functioneert als integrator van omgevings- en ontwikkelingssignalen in celdeling en differentiatie. Dit proefschrift is gekaderd binnen een opkomend paradigma, en draagt bij aan ons begrip hoe een enkel, geconserveerd eiwit meerdere processen reguleert die vaak gelijktijdig plaatsvinden, maar soms exclusief zijn.

In Hoofdstuk 1 introduceren we de geconserveerde functie van RBR in de celcyclus als een voorbeeld van hoe RBR-activiteit wordt beschouwd als het vermogen om te interacteren met andere eiwitten zoals transcriptiefactoren (TF) en chromatine-remodelers. RBR-activiteit wordt gereguleerd door CYCLIN-DEPENDENT KINASE (CDK)-gemedieerde fosforylering op meerdere plaatsen, wat op zijn beurt structurele veranderingen bevordert die interfereren met RBReiwitinteracties. We bespreken ook de huidige kennis van RBR-functies in de ontwikkeling van planten, de recent beschreven rol van RBR in de DNA-schadereactie van planten (DDR), en de gedeeltelijk door RBR gecoördineerde celdelings- en differentiatieprocessen in het Arabidopsiswortelmeristeem.

In Hoofdstuk 2 hebben we de functionele relevantie van de 16 vermeende fosforylatieplaatsen in het Arabidopsis RBR eiwit onderzocht. Het tekstboekmechanisme van RBR regulatie door fosforylering gaat ervan uit dat alleen een niet- of hypo-gefosforyleerd RBR actief is. Door de mate van complementatie te analyseren van een systematische verzameling transgene RBR fosfovarianten, zowel fosfo-defecte als fosfomimetische, laten we zien dat de pleiotrope effecten van RBR gedeeltelijk kunnen worden ontward door zijn fosforyleringstoestand, wat het idee ondersteunt van een 'fosforyleringscode' die de RBR activiteit regelt. Bovendien hangen de door fosforylering gereguleerde functies van RBR gedeeltelijk af van zijn vermogen om te interacteren met het LXCXE-motief, zoals onthuld door de N849F puntmutatie (RBR $\left.{ }^{\mathrm{NF}}\right)$.

In een poging om de moleculaire basis van de waargenomen fenotypische effecten in het vorige hoofdstuk te begrijpen, gingen we in hoofdstuk $\mathbf{3}$ op zoek naar nucleaire eiwitten die direct interacteren met RBR. In een reeks van inteactie screenings in gist gebruikten we als lokaas de meest gesubstitueerde fosfovarianten, het RBR ${ }^{\mathrm{NF}}$-allel en het wildtype RBR, om een bank van 
bijna 2000 nucleaire Arabidopsis eiwitten te onderzoeken. Onze resultaten lieten zien dat de bindingseigenschappen van RBR in sommige gevallen niet worden beïnvloed door fosforylering. Interessant is dat de eiwitten die RBR binden, ongeacht de fosforyleringstoestand, gerelateerd zijn aan op stress reagerende transcriptieprogramma's. In feite is de meerderheid van de interactoren betrokken bij stressreacties. Er zijn echter maar weinig interactoren behorende tot de typische celcyclusregulatoren, zoals E2FC of de DREAM complexleden TCX 6 en 7. Voor deze eiwitten hebben we aangetoond dat een LXCXE-motief verantwoordelijk is voor de interactie met RBR, wat inzicht geeft in de uiteenlopende moleculaire determinanten van de DREAMcomplexassemblage in planten.

Uit de lijst van interactoren verkregen in hoofdstuk 3, hebben we in het bijzonder gekeken naar het NACO44 eiwit omdat het de naaste homoloog is van, en direct gereguleerd is door de SUPPRESSOR VAN GAMMA REACTIE 1, een plant specifieke TF die de DDR controleert. NAC044 bindt RBR op een LXCXE-afhankelijke manier, maar onafhankelijk van RBR-fosforylering, in tegenstelling tot het heersende paradigma dat RBR-LXCXE-interacties worden gereguleerd door fosforylering. Gezien de rol van NACO44 in het stoppen van de celcyclus bij DNA-schade en andere stress, hebben we ons in hoofdstuk 4 ten doel gesteld om de relevantie van zijn interactie met RBR op te helderen. RBR heeft een chromatine-structurele rol en een transcriptionele rol in de DDR en we hebben vastgesteld dat deze worden onderscheiden door het vermogen om LXCXE-bevattende eiwitten te binden. Enerzijds elimineert de RBR $^{\mathrm{NF}}$ mutatie de rekrutering van RBR naar nucleaire foci direct na DNA-beschadiging, wat suggereert dat een nog onbekend LXCXE-bevattend eiwit RBR rekruteert om foci te repareren. Anderzijds wordt NAC044 expressie geïnduceerd door DNA-schade, maar langzamer dan de rekrutering van RBR naar foci. Dit betekent dat RBR bindt aan NACO44 nadat de foci zijn gerepareerd. We hebben vastgesteld dat de RBR-NACO44 interactie bijdraagt aan de activering van gepregrammeerde celdood. We zijn daarom van mening dat de structurele en transcriptionele rollen van RBR in de DDR zijn gekoppeld in een integratieve functie die de transcriptionele machinerie informeert over het kansen van het DNA-herstelproces, en van daaruit kiest voor celdood of hervatting van de celdeling.

Tenslotte kijken we in hoofdstuk 5 vanuit een evolutionair perspectief om de mogelijke implicaties van een geconserveerd RBR-gecentreerd netwerk voor het coördineren van eukaryotische cellulaire processen in context te plaatsen. We bespreken bijvoorbeeld hoe RBR-activiteit op E2FTF's, en de regulatie door CYC-CDK's en CDK-remmers, celgrootte koppelt aan celdeling in zowel lagere als hogere eukaryoten. Maar in hogere eukaryoten is de activiteit van het RBR-netwerk ook belangrijk voor het bepalen van de algehele orgaangrootte en vorm. Omdat de ontwikkeling van planten bovendien bijzonder gevoelig is voor de leefomgeving, leggen we de nadruk op de integratie van omgevingsfactoren door het RBR-netwerk als bijdrage aan een gecoördineerde reactie. Om de algemene discussie af te sluiten, bieden we experimentele perspectieven en stellen open vragen om te beantwoorden in de nabije toekomst van het RBR-onderzoeksveld. 


\section{Acknowledgements}

When it comes to express gratitude, words and paper are helplessly limited. I would love to thank every single person who contributed to this journey. To my colleagues, friends and family, who made me realize that a PhD, as everything else in life, is anything but an individual journey. Unfortunately, it is impossible to mention them all. I apologize for failing to mention so many of you.

First of all, I want to thank my promotor and supervisor Ben, who has also been an actual teacher and guide in the broadest sense. It is fair to just say that I have received an excess of value from just doing a PhD under your guidance. You can be sure my gratefulness does not fall short to acknowledge your input during these almost seven years. I also feel honored to keep a close collaboration with you in a setting that I could have not imagined at the beginning of my PhD.

Despite the unavoidable struggle that comes with doing a PhD, I can fairly say that being at PDB group was a soft landing. That is thanks to the great scientific and human atmosphere created by all the people in it, particularly well preserved by the great efforts and kindness of Ikram, Viola, and Renze. It was kind of a bittersweet feeling to see Ikram leaving, to whom I am very grateful for her support of all kinds. The same is true for Viola, a source of inspiration on how to be supportive and resilient for anyone around you. And when it comes to acknowledge the support I got from Renze, I am just wordless. Not only did you contribute with very clever discussions and ideas, or with technical advice during the whole period of my PhD, but also with friendly help that became essential in the final phase.

I want to thank to all members of PDB group, starting with those who made me feel welcome at my arrival: Marie-José, Maria, Sara, Serena, Stephen, Luca, Du, Ming, Sabine, Bandan and Wenkun (specially Wenkun for the collaboration on the painful zeocin experiments). Your welcoming could only translate in my intention of welcoming the ones who arrived later to PDB, and with whom I spent so many good times but also shared my frustrations: Menno, Kavya, Anneke, Hugo, Ale, Nadia, Renan, Merijn, and particularly to Vera, as you provided lots of support throughout the second half of my PhD. Also to those who came after I left the regular work at the lab: Jana, Jordi, Honglei, Qian, Roman, Zhuang, Andrea. And of course, to the students, especially those who had to struggle with my supervision: Katinka (twice), Sietske, Jonathan and Sergio. Similarly, those few members of MolBio with whom I shared my time at Radix: Rik, Jeroen, Tingting, Arjan, Olga, Henk, Asma, Tian, Han, Titis, Defeng, Fengjiao, Huchen, Jieyu, Wouter, Jelle, Yuda, Lucas, Jac. Big thanks to our collaborators: JeanPhilippe and his group members, who welcomed me for a nice and fruitful collaboration; and to Alex Jones and her group members, who hosted me in the frame of the EMBO short term fellowship. 
I also want to thank all the good moments and friendships I made during this time with the Mexican gang in Wageningen, (and some fake Mexicans, like Michele) that brought so much understanding and shared nostalgias in easy and difficult moments. Particularly to Moi, Chava and Fa, from the very first time I arrived in Wageningen till the present, I'm grateful for having you around. I was also very fortunate to get to know a bunch of awesome people in Nijmegen. I feel grateful for the moments shared with Dorien, Paulo, Rossana, Omar and Chris. Lo mismo va para los que quedaron después e hicieron más llevaderos y divertidos los últimos meses, y que han sido un apoyo en esta fase de mi vida. Especialmente las tardes que empezábamos a las meras cuatro y veinte pm con Moi, el tocayo, Alan y el country. Y aunque ya de manera extemporánea, también ha sido parte del doctorado el tiempo compartido con Andrea, Katia, Indi, Tony, Vicky, Gianmarco y mis sobrinos Miche y Francesco, una gran familia fugaz que me recuerda lo impermanente que es la vida.

Aunque estuvimos físicamente lejos, siempre han sido parte y testigos de mi vida grandes amigas y amigos que han sido familia para mí.. Desafortunadamente me limito a mencionarles porque para explicar los motivos de mi gratitud necesitaría escribir otro libro el doblemente grueso. Adriana, Sylvia, Mau, Nico, Diego, Vale, Jus, Pau, Daniel, Lilia, Ale, Rosa... Simplemente muchas gracias por estar en mi vida y por esos momentos realmente inolvidables que hemos vivido. De ustedes he aprendido el valor de compartir la vida. Espero que la vida nos permita estar cada vez más juntos.

Aunque mis familias son muy extensas como para mencionar a todas y todos, cada miembro de esas familias son un regalo enorme que ha contribuido en este gran viaje de mi vida. Agradezco el regalo enorme de mis dos grandes linajes, los Zamora y los Zaragoza (y allegados jaja), que son una gran fuente de cariño que me ha nutrido desde el inicio de mis días y que siempre me acompañan a donde quiera que vaya, por lejos que me encuentre, porque a tod@s।@s llevo en el corazón. Especialmente agradezco la presencia de mi mamá, papá, Geor, Julio, Mony, Adriana, Citlalli y Diego. Ustedes son un gran motor y fuente de fortaleza y sabiduría en mi vida.

También agradezco la oportunidad de haber tenido una familia prestada, y de la que ser parte me dio grandes alegrías y recuerdos. Gracias por estar en mi vida a mis suegros, Mony, Eri, Vero, Pepe y sus hijos Marianita y Pepito, Dany, Viry, Silvia, Gábor, Gaby, y los Ricardos. Me los llevo en el corazón.

$Y$ hablando de familia, solo me resta agradecer la oportunidad de haber formado una pequeña familia de dos. Yessica, antes que nada, gracias por el apoyo con estadísticas y gráficas; sin ti hubiera sido mucho más difícil llegar a este momento. Pero gracias también por todas las otras formas de apoyo que recibí de ti, ¿cómo expresar mi gratitud sin escribir una carta de amor? Simplemente imposible, como imposible es expresar con palabras lo 
agradecido que estoy por haber caminado contigo, por lo que compartimos estos casi siete años de doctorado, por los casi siete anteriores, por lo que seguimos compartiendo; y por tu vida. Estoy corto de palabras, pero me consuela saber que, sin saberlo a ciencia cierta, sabes bien lo que significa cuando te digo GRACIAS desde el corazón, con todo mi ser. Ha sido, sin lugar a dudas, una gran aventura compartir la vida contigo en todos aspectos. De alguna manera sabíamos que el doctorado sería un parteaguas en nuestra vida, pero no imaginamos hasta qué punto. Me llena de alegría haberte tenido como COMPAÑERA para vivir los grandes altibajos por los que pasamos. Muchas GRACIAS por ser y hacer un gran EQUIPO conmigo; por ser tan compañera, por compartir, por crecer, por tu presencia, por formar un hogar en donde sea que nos encontráramos, y simplemente por ser la persona que eres. Gracias por dejarme ser testigo de tus locas formas de bailar, de reír, de llorar, de sentir, de enojarte, de alegrarte, de limpiar (arriesgando el pellejo), de disfrutar la comida y la música. En fin, muchas gracias, mi loca compañera, por la alegría de vivir a tu lado. 


\section{About the Author}

Jorge Zamora Zaragoza was born in Irapuato, Guanajuato, Mexico in 1987. After finishing his 4 years long specialty in High School studies, in the city of Guanajuato, he moved to Mexico City in 2006 to study the BSc program of Pharmaceutical and Biological Chemistry at the Faculty of Chemistry of the National Autonomous University of Mexico, but he barely studied beyond the exams week. Instead, he spent numerous hours enjoying the company of his friends and ladyfriend Yessica, with whom he shared the great moments and frustrations of their academic career. In the same institution, he completed his BSc internship, service and thesis within the informally named "paquete titules" program, relentlessly westernblotting the maize Cyclin D6;1 protein during maize germination with a self-developed antibody (raised in a rabbit though), a project that was continued from 2012 to 2015 during his MSc degree in Biochemistry at the same Faculty of Chemistry doing many more western blots. Towards the end of his 5 years long project, his research was scooped in an elegant publication by Prof. Dr. Ben Scheres' group, leading him to a plea for a position in Scheres' lab. For his PhD, he obtained a scholarship from the Consejo Nacional de Ciencia y Tecnología (Conacyt, Mexico) to investigate the role of the RETINOBLASTOMA-RELATED1-DELLA protein interaction in Arabidopsis thaliana, under the supervision of Ben Scheres. This project was dismissed on the very first day he joined Scheres' group in Wageningen University in The Netherlands, pushing him to unwillingly accept the frightening challenge of investigating the regulation of RBR1 protein by phosphorylation. The RBR1 phosphorylation project led him to a number of very exciting results and a tremendous lower back pain from sitting long hours behind the confocal microscope, though only the results are reported in the present PhD dissertation. Since February 2020, he joined the crop breeding company Rijk Zwaan as a Molecular Biology Researcher, coping with the final stage of the PhD and starting a new job located (fairly said) nearby the middle of nowhere in Noord Brabant province. 


\section{Education Statement of the Graduate School Experimental Plant Sciences}

$\begin{array}{ll}\text { Issued to: } & \text { Jorge Zamora Zaragoza } \\ \text { Date: } & \text { 19 November 2021 } \\ \text { Group: } & \text { Plant Developmental Biology } \\ \text { University: } & \text { Wageningen University \& Research }\end{array}$

\section{1) Start-Up Phase}

First presentation of your project

Title: Cell Cycle Under Developmental Cues

- Writing or rewriting a project proposal

Title: Retinoblastoma-Related 1 protein regulatory network in root development

Writing a review or book chapter

Title: Tuning Division and Differentiation in Stomata: How to Silence a MUTE

Developmental Cell 45 (2018)3. - ISSN 1534-5807 - p. 282 - 283. DOI:10.1016/j.devcel.2018.04.019 MSc courses

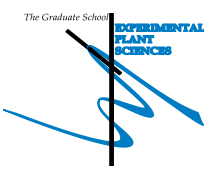

Subtotal Start-Up Phase

\begin{tabular}{c|c|}
\hline date & $\underline{c p}$ \\
05 Jun 2015 & 1,5 \\
Oct 2015 & 6,0 \\
07 May 2018 & 3,0 \\
\end{tabular}

2) Scientific Exposure

EPS PhD student days

EPS PhD student days 'Get2Gether', Soest, NL

EPS PhD student days 'Get2Gether', Soest, NL

EPS PhD student days 'Get2Gether', Soest, NL

EPS PhD student days 'Get2Gether', Soest, NL

- EPS theme symposia

EPS theme 1 'Developmental Biology of Plants', Wageningen, NL

EPS theme 1 'Developmental Biology of Plants', Wageningen, NL

EPS theme 1 'Developmental Biology of Plants', Leiden, NL

EPS theme 3 'Metabolism and Adaptation', Nijmegen, NL

- Lunteren Days and other national platforms

Annual Meeting 'Experimental Plant Sciences', Lunteren, NL
Annual Meeting 'Experimental Plant Sciences', Lunteren, NL

Annual

Annual Meeting 'Experimental Plant Sciences', Lunteren, NL

Annual Meeting Expenimental Plant

- Seminars (series), workshops and symposia

Symposium: Future Biochemistry, Wageningen, NL

Symposium: Lunch and Meet with Janet Sprent, Euan James \& Sofie Goormachtig, Wageningen, NL

Workshop: Plants and Patents, Wageningen, NL

Seminar: Dr. Mark Estelle, Auxin Signaling: Inputs and Outputs, Wageningen, NL

Seminar: Prof Alga Zuccaro, Plant-fungi symbiosis, Wageningen, NL

Seminar: Prof Ikram Blilou, Plant developmental biology, Wageningen, NL.

Seminar: Prof Jürgen Kleine-Vehn, Wageningen, NL

Seminar: Ritzema Bos Lecture - Prof. Malcolm Bennett, Wageningen, NL

Seminar plus

International symposia and congresses

8th European Plant Sciences Retreat, Barcelona, ES

10 th PhD school in Plant Development, Zellingen-Retzbach, DE

EMBO workshop - Plant Genome stability and change, Gatersleben, DE

12th Congress of the International Plant Molecular Biology, Montpellier, FR

11th European Plant Sciences Retreat, Nottingham, UK

- Presentations

Talk: EPS PhD student days 'Get2Gether', Soest, NL

Talk: Intemational Plant Molecular Biology, Montpellier, FR

Talk: EPS Theme 1 Symposium, Leiden, NL

Talk: 11 th European Plant Sciences Retreat, Nottingham, UK

Poster. 8th European Plant Sciences Retreat, Barcelona, ES

Poster: Annual Meeting 'Experimental Plant Sciences', Lunteren, NL

Poster: Annual Meeting 'Experimental Plant Sciences', Lunteren, NL

IAB interview

date

date

28-29 Jan 2016

09-10 Feb 2017

15-16 Feb 2018

$11-12$ Feb 2019

21 Jan 2016

30 Jan 2018

31 Jan 2019

21 Oct 2019

13-14 Apr 2015

11-12 Apr 2016

10-11 Apr 2017

08-11 Apr 2017

23 Sep 2017

26 Oct 2017

23 Jan 2018

21 Oct 2019

07 Apr 2016

10 Sep 2019

10 Sep 2019

28 Oct 2019

14 Oct 2019

20-23 Jun 2016

04-06 Oct 2017

03-06 Jun 2018

05-10 Aug 2018

08-10 Jul 2019

16 Feb 2018

08 Aug 2018

08 Aug 2018

31 Jan 2019

10 Jul 2019

21 Jun 2016

10 Apr 2017
08 Apr 2019

Subtotal Scientific Exposure

19,7

3) In-Depth Studies
Advanced scientific courses \& workshops
Environmental Signaling in Plants, Utrecht Summer School, Utrecht, NL
Transcription Factors \& Transcriptional Regulation, Wageningen, NL
EMBO practical course on Multi-level Modelling of Morphogenesis, Norwich, UK
Data Analysis and Visualization in R, Wageningen, NL
Microscopy and Spectroscopy in Food and Plant Science, Wageningen, NL
Journal club
Plant Developmental Biology Journal Club
Individual research training
Research stay Vielle-Calzada's lab, LANGEBIO, Irapuato, MX
EMBO short-term fellowship at Jones' lab, Warwick University, Coventry, UK

EMBO short-term fellowship at Jones' lab, Warwick University, Coventry, UK

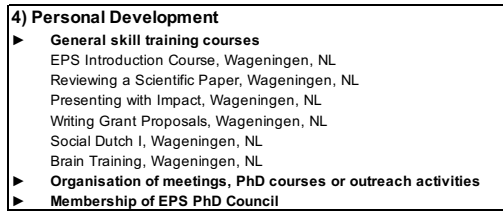

$\underline{\text { date }}$

24-26 Aug 2015 $12-14$ Dec 2016 16-28 Jul 2017 08-09 May 2018

Mar 2015 - Mar 2017 
The research described in this thesis was financially supported by Consejo Nacional de Ciencia y Tecnología (CONACyT, Mexico) Scholarship 383871.

Financial support from Wageningen University, Mexican Consejo Nacional de Ciencia y Tecnología, and ZEISS (Carl Zeiss BV) for printing this thesis is gratefully acknowledged.

Cover design by Jorge Zamora Zaragoza

Printed on FSC-certified paper 


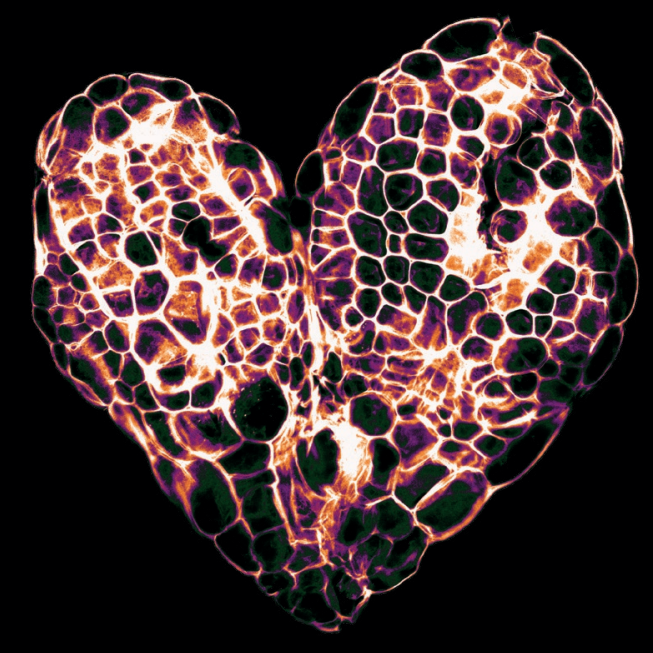

